AKIO HANASIRO

\title{
GERADORES PIEZELÉTRICOS DE ENERGIA COM MÚLTIPLOS GRAUS DE LIBERDADE: TEORIA E EXPERIMENTAÇÃO
}

Dissertação de Mestrado apresentada à Escola de Engenharia de São Carlos da Universidade de São Paulo como parte dos requisitos para obtenção do título de Mestre em Engenharia Mecânica

Área de Concentração: Dinâmica de Máquinas e Sistemas.

Orientador: Prof. Tit. Paulo S. Varoto

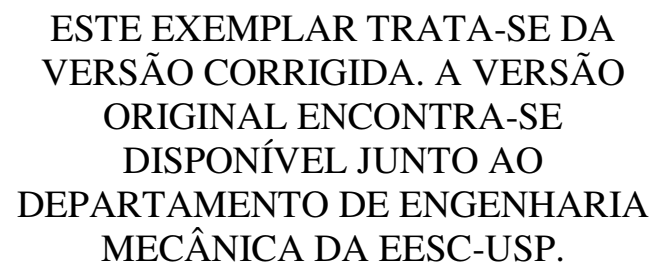

São Carlos 
AUTORIZO A REPRODUÇÃO TOTAL OU PARCIAL DESTE TRABALHO, POR QUALQUER MEIO CONVENCIONAL OU ELETRÔNICO, PARA FINS DE ESTUDO E PESQUISA, DESDE QUE CITADA A FONTE.

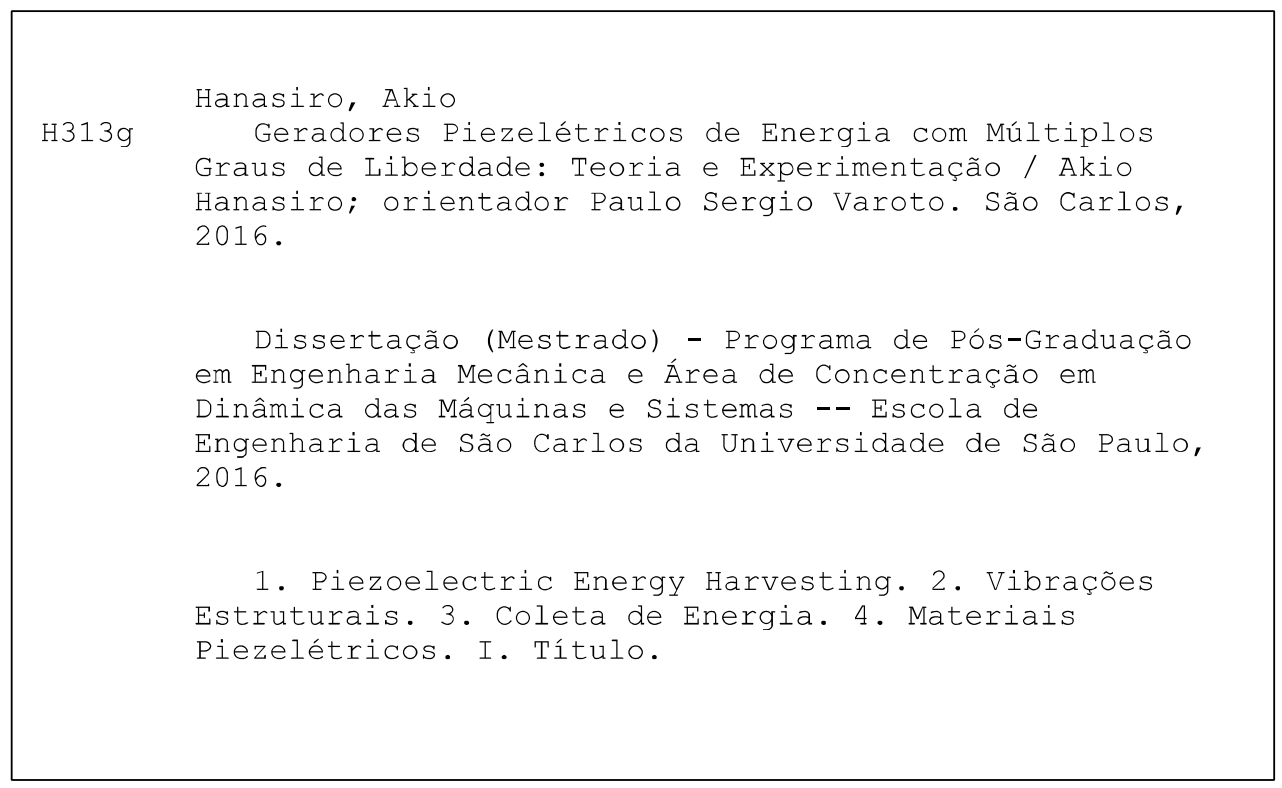




\section{FOLHA DE JULGAMENTO}

Candidato: Engenheiro AKIO HANASIRO.

Título da dissertaçāo: Geradores piezelétricos de energia com múltiplos graus de liberdade: teoria e experimentação".

Data da defesa: 22/02/2017.

Comissão Julgadora:

Resultado:

Prof. Titular Paulo Sergio Varoło

(Orientador)

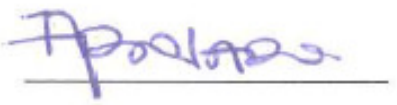

(Escola de Engenharia de São Carlos/EESC)

Prof. Dr. Domingos Alves Rade

(Instituto Tecnológico de Aeronáutica/ITA)

APAOVADO

Prof. Dr. Vitor Ramos Franco

(Universidade Federal de São Carlos/UFSCar)

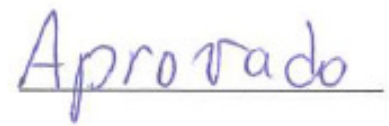

Coordenador do Programa de Pós-Graduação em Engenheira Mecânica: Prof. Associado Gherhardt Ribatski

Presidente da Comissão de Pós-Graduação:

Prof. Associado Luís Fernando Costa Alberło 


\section{Agradecimentos}

À minha esposa Nátaly, companheira em todos os momentos da minha vida, que com muito carinho e compreensão me deu todo o apoio necessário para a superação de mais este desafio.

Ao meu supervisor Marcelo Fogal, e à Maquinas Agrícolas Jacto, pelo incentivo e apoio dado a mais esta complementação de minha formação

Ao prof. Dr Paulo Sérgio Varoto, pela confiança, orientação, e todo o suporte necessário para o desenvolvimento deste trabalho. Ao Laboratório de Dinâmica da EESC e ao INCT-EIE pelo apoio laboratorial.

Aos meus pais e toda minha família, pelo apoio nos momentos difíceis, e pela paciência e compreensão naqueles em que fui ausente. 


\section{Resumo}

HANASIRO, A. (2016) Geradores piezelétricos de energia com múltiplos graus de liberdade: teoria e experimentação. São Carlos, 2016. Dissertação (Mestrado) - Escola de Engenharia de São Carlos, Universidade de São Paulo.

Motivado pela crescente demanda por fontes energéticas alternativas, este trabalho discute o uso do efeito piezelétrico para geração de energia a partir de vibrações estruturais, cujo caráter ubíquo as têm colocado em posição de destaque dentre outras fontes renováveis. O processo conhecido por piezoelectric energy harvesting ou scavenging é estudado utilizando-se de múltiplos graus de liberdade para maximização da energia gerada e aumento da faixa de frequência útil do gerador, permitindo melhores resultados em aplicações sujeitas a excitações aleatórias de larga banda de frequência. Diretamente relacionada ao custo do dispositivo, e por isso, à sua viabilidade comercial, a eficiência dos harvesters em função da quantidade de material piezelétrico utilizado também é amplamente discutida. Para o desenvolvimento do tema são realizadas simulações numéricas em MATLAB, primeiramente para modelos de parâmetros concentrados, com análises de sensibilidade da geração de energia em relação a características mecânicas, bem como disposição e propriedades dos elementos piezelétricos em soluções com dois e três graus de liberdade. Usando modelos de parâmetros distribuídos os estudos são replicados a uma solução construtiva do tipo viga "L", com validação do modelo matemático e das proposições levantadas através de ensaios em laboratório usando um protótipo do gerador. Ao final é feita uma análise crítica relativa ao piezoelectric energy harvesting através de geradores de múltiplos graus de liberdade, em que são confrontados e discutidos os resultados teóricos e experimentais obtidos. 


\section{Abstract}

HANASIRO, A. (2016) Multi-degree-of-freedom piezoelectric energy harvesters: theory and experimentation. São Carlos, 2016. Essay (Master) - Escola de Engenharia de São Carlos, Universidade de São Paulo.

Motivated by the increasing demand on alternative energy resources, this study discusses the usage of the piezoelectric effect for energy generation from structural vibrations, which stands out among other renewable energy resources by its ubiquitous essence. The process known as piezoelectric energy harvesting or scavenging is evaluated using multiple degrees-of-freedom to maximize the energy generated and broaden the useful frequency bandwidth of the harvester, enabling better outcomes in applications subjected to random broadband excitations. Due to its direct relation to costs, and therefore to market feasibility, the harvester efficiency based on the piezoelectric material quantity is widely discussed. Numeric simulation using MATLAB are performed for the subject development, firstly using lumped parameter models to conduct generation sensitivity analysis on the mechanical characteristics, piezoelectric properties and allocation of two and three degrees-of-freedom solutions. Using distributed parameter models the study is replicated to an L-shaped configuration, with validation of the theoretical model and the brought forward proposals through laboratory experiments using an energy harvester prototype. At the end, a critical analysis on piezoelectric energy harvesting through multiple degrees-of-freedom is conducted, comparing and discussing the theoretical and experimental results. 


\section{Lista de Símbolos}

\section{Romanas Maiúsculas}

$A_{B} \quad$ Amplitude da aceleração da base do gerador.

$C_{p c 1-n} \quad$ Capacitância do inserto piezelétrico " $n$-ésimo" oscilador, [N/V].

$\left(C_{p}\right)_{k} \quad$ Capacitância do inserto piezelétrico da " $k$-ésima" região da viga "L", [N/V].

$D_{3} \quad$ Deslocamento elétrico no inserto.

$E_{3} \quad$ Campo elétrico na direção $y,[\mathrm{~V} / \mathrm{m}]$.

$\operatorname{Er}(\omega) \quad$ Erro relativo entre os dados simulados e medidos.

$F_{\text {piezo 1-n }}$ Força aplicada pelo inserto piezelétrico associado ao " $n$-ésimo" oscilador quando submetido a um potencial elétrico $V_{n}$, [N].

$H_{r} \quad$ Amplitude da resposta mecânica modal do "r-ésimo" modo de vibrar.

$I_{k} \quad$ Momento de inércia a flexão do da " $k$-ésima" região da viga "L", [m].

$J_{1-2} \quad$ Momento de inércia de rotação das massas concentradas da viga " $L$ ".

$L \quad$ Comprimento da estrutura do gerador cantilever, [m].

$L_{0_{k}} \quad$ Distância do início do inserto piezelétrico à origem da " $k$-ésima" região da viga "L", [m].

$L_{p_{k}} \quad$ Comprimento do inserto piezelétrico da " $k$-ésima" região da viga "L", [m].

$M_{f} \quad$ Momento fletor, [Nm].

$M_{1-2} \quad$ Massas concentradas da viga " $\mathrm{L}$ ", $[\mathrm{kg}]$.

$M_{f}{ }^{p} \quad$ Momento fletor no elemento piezelétrico, [Nm].

$N_{r} \quad$ Função da excitação mecânica modal do "r"-ésimo modo de vibrar.

$P_{1-n} \quad$ Potência gerada pelo inserto do " $n$-ésimo" oscilador, [W].

$P_{\text {ave }} \quad$ Potência média gerada no resistor, $[\mathrm{W}]$.

$P_{l} \quad$ Potência gerada no resistor, [W].

$P_{m} \quad$ Potência gerada pelo " $m$-ésimo" inserto piezelétrico da viga " $L$ ", [W].

$Q \quad$ Corrente elétrica gerada no inserto piezelétrico, [A];

$Q_{l} \quad$ Corrente elétrica gerada no resistor, [A].

$R_{1-n} \quad$ Resistência associada ao circuito elétrico do " $n$-ésimo" oscilador, $[\Omega]$.

$R_{l} \quad$ Resistência associada ao circuito elétrico do gerador, $[\Omega]$.

$\Re_{k} \quad$ " $k$-ésima" região da viga "L".

$S_{1}^{p} \quad$ Deformação (strain) no inserto piezelétrico.

$T_{1}^{S} \quad$ Tensão na estrutura do gerador, $\left[\mathrm{N} / \mathrm{m}^{2}\right]$.

$T_{1}^{p} \quad$ Tensão no elemento piezelétrico do gerador, $\left[\mathrm{N} / \mathrm{m}^{2}\right]$.

$U_{0-n} \quad$ Transformada de Laplace do deslcamento para o modelo de parâmetros conentrados.

$V \quad$ Tensão no resistor, [V].

$V_{1-n} \quad$ Tensão nos eletrodos do inserto piezelétrico associado ao " $n$-ésimo" oscilador, [V]. 
$V_{a_{k}} \quad$ Amplitude da tensão entre os eletrodos do inserto piezelétrico da " $k$-ésima" região da viga "L", $\left[\mathrm{N} / \mathrm{m}^{2}\right]$

$V_{r m s} \quad$ Tensão RMS no resistor, [V];

V Transformada de Laplace da tensão no resistor para o modelo de parâmetros concentrados.

$Y \quad$ Módulo de elasticidade do compósito formado pela estrutura com inserto piezelétrico, [N/m2].

$Y_{p} \quad$ Modulo de elasticidade do inserto piezelétrico, [N/m2];

$\left(Y_{S}\right)_{k} \quad$ Módulo de elasticidade da estrutura da " $k$-ésima" região da viga "L", [N/m2];

$Z_{\text {sim,med }} \quad$ Amplitudes das FRFs simuladas ou medidas, usadas no cálculo do erro relativo.

\section{Romanas Minúsculas}

$a_{B} \quad$ aceleração de excitação do gerador, $\left[\mathrm{m} / \mathrm{s}^{2}\right]$

$b \quad$ Largura da seção da estrutura do gerador cantilever [m].

$b_{k} \quad$ Largura da seção da estrutura da " $k$-ésima" região da viga "L", [m].

$c_{1-n} \quad$ Coeficiente de amortecimento viscoso do amortecedor associado à " $n$-ésima" massa, [Ns/m].

$d_{31} \quad$ Constante piezelétrica.

$g \quad$ Aceleração da gravidade, $\left[\mathrm{m} / \mathrm{s}^{2}\right]$

$h_{a} \quad$ Distância entre a extremidade inferior da estrutura à linha neutra, [m].

$h_{b} \quad$ Distância entre a extremidade superior da estrutura e a linha neutra, [m].

$h_{c} \quad$ Distância entre a extremidade superior do elemento piezelétrico e a linha neutra, [m].

$h_{p} \quad$ Espessura do inserto piezelétrico, [m].

$\left(h_{p}\right)_{k} \quad$ Espessura do inserto da " $k$-ésima" região da viga "L", [m].

$\left(h_{s}\right)_{k} \quad$ Altura da secção da estrutura da " $k$-ésima" região da viga "L", [m].

$i_{k} \quad$ Corrente elétrica gerada pela inserto piezelétrico da " $k$-ésima" região da viga "L", [A].

$k_{1-n} \quad$ Rigidez do elemento elástico associado à " $n$-ésima” massa, [N/m].

$m_{1-n} \quad$ Massa do " $n$-ésimo" oscilador, [kg].

$\left(m_{l}\right)_{k} \quad$ Massa por unidade de comprimento da " $k$-ésima" região da viga "L", [kg/m].

$n_{k} \quad$ Razão entre os módulos de elasticidade da estrutura e do inserto piezelétrico da " $k$-ésima" região da viga "L".

$p \quad$ Número de insertos piezelétricos utilizados na viga " $L$ ".

$S_{11}^{E} \quad$ Elastic compliance sob campo elétrico constante $E$.

$u_{0} \quad$ Deslocamento da base do gerador de múltiplos graus de liberdade, [m].

$u_{1-n} \quad$ Deslocamento da " $n$-ésima" massa oscilante do gerador de múltiplos graus de liberdade, [m].

$\dot{u}_{1-n} \quad$ Velocidade da " $n$-ésima" massa oscilante do gerador de múltiplos graus de liberdade, [m/s].

$\ddot{u}_{1-n} \quad$ Aceleração da " $n$-ésima" massa oscilante do gerador de múltiplos graus de liberdade, $\left[\mathrm{m} / \mathrm{s}^{2}\right]$. 
$w_{k} \quad$ Deflexão transversão da estrutura do gerador em relação à origem da " $k$-ésima” região da viga "L", [m].

$w_{\text {rel }} \quad$ Deflexão transversão da estrutura do gerador cantilever em relação à sua base, [m].

$x_{k} \quad$ Coordenada na direção longitudinal à viga da " $k$-ésima" região da estrutura da viga "L",[m];

$y_{k} \quad$ Coordenada na direção transversal à viga da " $k$-ésima” região da estrutura da viga "L”,[m];

$v_{k}(t) \quad$ Tensão entre os eletrodos do inserto piezelétrico da " $k$-ésima" região da estrutura da viga "L",[V];

\section{Gregas Minúsculas}

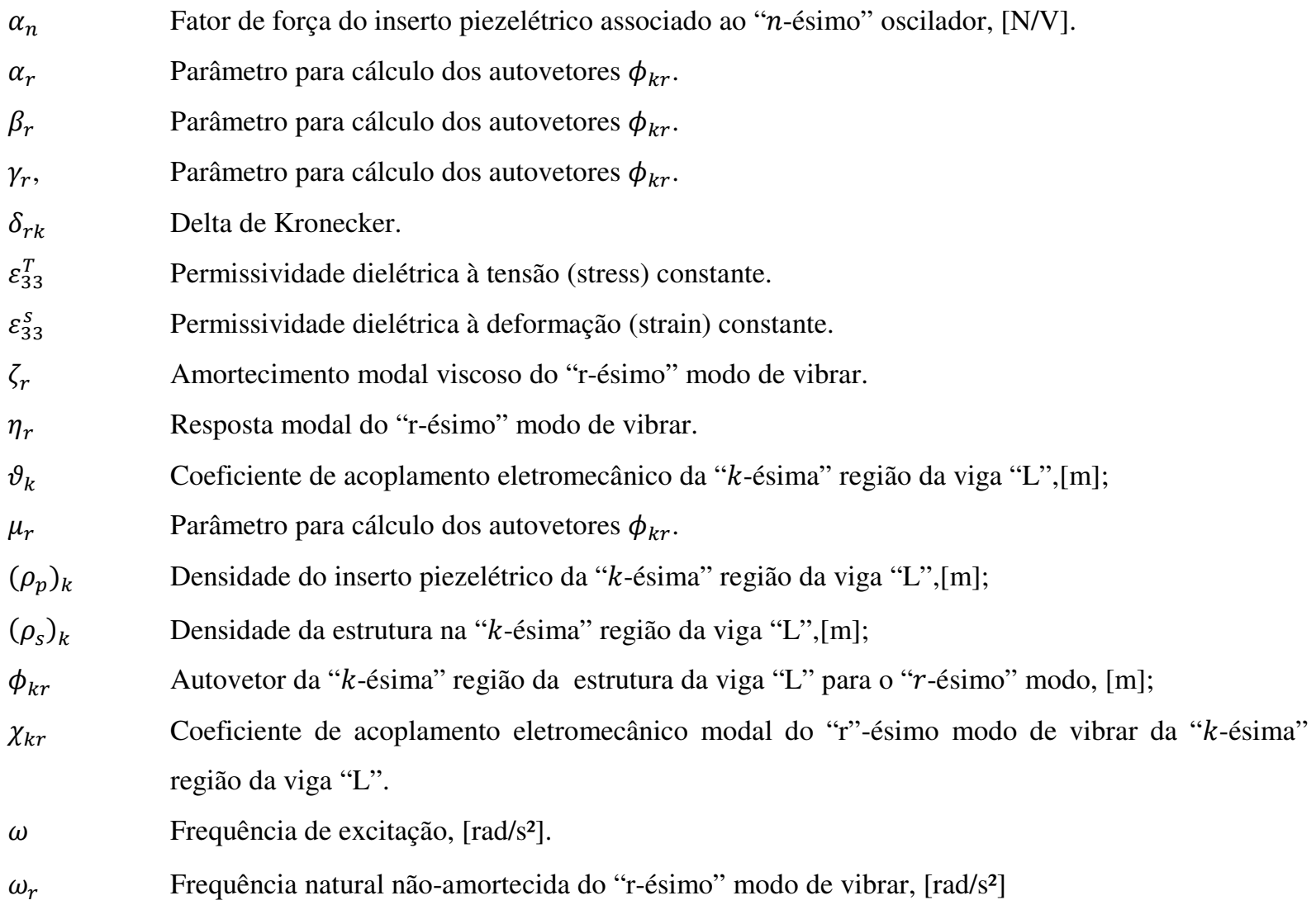

\section{Lista de Abreviações}

FRF

Função Resposta em Frequência

GDL Grau de Liberdade

nGDL Múltiplos Graus de Liberdade 


\section{Lista de Figuras}

Figura 1 - Evolução da quantidade de artigos relavantes na área de Energy harvesting, indicando o crescente interesse de pesquisas na área (Zuo, Tang, 2013).

Figura 2 - Evolução de tecnológica de componentes eletrônicos, na qual é possível notar o atraso na evolução da densidade energética de baterias em relação à outros elementos (Starner, Paradiso, 2004).

Figura 3 - Resposta em tensão do gerador de energia de dois graus de liberdade comparado com um dispositivo de um grau de liberdade de mesma massa (Kim et al. 2011).

Figura 4 - Montagem utilizada na validação experimental do modelo matemático desenvolvido por Wu et al.

(2013).

Figura 5 - Esquema dos modelos de nGDL (a) desenvolvido por Xiao et al. (2015) e (b) proposto neste estudo. 15

Figura 6 - Esquemático da viga cantilever usada por Erturk, Inman (2008a)...............................................16

Figura 7 - Esquema geral do gerador do tipo viga "L".

Figura 8 - Disposição dos sistemas de coordenadas e variáveis de posição para as três regiões do gerador do tipo

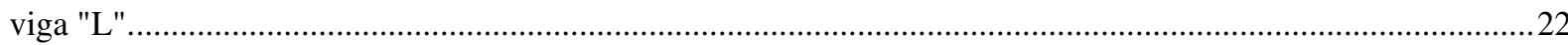

Figura 9 - Configurações de montagem estudadas para o gerador do tipo viga "L" ........................................23

Figura 10 - Circuito elétrico dos geradores com três insertos piezelétricos...................................................24

Figura 11 - Circuito elétrico do gerador com dois insertos piezelétricos..........................................................24

Figura 12- Esquema do modelo de dois graus de liberdade utilizados por (a) Tang e Yang (2012) e (b) Xiao et al. (2015).

Figura 13 - FRF da potência gerada para o exemplo avaliado por Tang (Tang, Yang, 2012) e Xiao (Xiao et al. 2015)

Figura 14 - FRF da potência gerada pelo primeiro e segundo elemento piezelétrico do exemplo de Xiao (Xiao et al. 2015).

Figura 15 - Máxima tensão gerada pelo inserto entre a primeira e a segunda massa oscilante do modelo de dois graus de liberdade em função do fator de força relativo e da resistência elétrica associada.

Figura 16 - Máxima potência gerada pelo inserto entre a primeira e a segunda massa oscilante do modelo de dois graus de liberdade em função do fator de força relativo e da resistência elétrica associada.

Figura 17 - FRF da tensão gerada pelo inserto entre a primeira e a segunda massa oscilante do modelo de dois graus de liberdade, com fator de força relativo igual a 2 para diferentes resistências elétricas, (a) na faixa de frequência contendo as duas ressonâncias, e (b) com destaque para a resposta na primeira frequência natural....40 Figura 18 - FRF da potência gerada pelo inserto entre a primeira e a segunda massa oscilante do modelo de dois graus de liberdade, com fator de força relativo igual a 2 para diferentes resistências elétricas, (a) na faixa de frequência contendo as duas ressonâncias, e (b) com destaque para a resposta na primeira frequência natural....41 Figura 19 - Esquema do gerador de três graus de liberdade.

Figura 20 - FRF de potência gerada para diferentes relações de massa Mr, com relação de rigidez $\mathrm{Kr}=3$, sendo: (a) primeiro inserto piezelétrico, (b) segundo inserto piezelétrico, (c) terceiro inserto piezelétrico.

Figura 21 - FRF de potência gerada pelo primeiro inserto piezelétrico para diferentes relações de rigidez $\mathrm{Kr}$ do primeiro elemento elástico, com (a) $\mathrm{Mr}=1$, (b) $\mathrm{Mr}=4$, (c) $\mathrm{Mr}=7$. 
Figura 22 - FRF de potência gerada pelo segundo inserto piezelétrico para diferentes relações de rigidez $\mathrm{Kr}$ do primeiro elemento elástico, com (a) $\mathrm{Mr}=1$, (b) $\mathrm{Mr}=4$, (c) $\mathrm{Mr}=7$.

Figura 23 - FRF de potência gerada pelo terceiro inserto piezelétrico para diferentes relações de rigidez $\mathrm{Kr}$ do primeiro elemento elástico, com (a) $\mathrm{Mr}=1$, (b) $\mathrm{Mr}=4$, (c) $\mathrm{Mr}=7$.

Figura 24 - FRF de potência gerada pelo primeiro inserto piezelétrico para diferentes relações de rigidez $\mathrm{Kr}$ do segundo elemento elástico, com (a) $\mathrm{Mr}=1$, (b) $\mathrm{Mr}=4$, (c) $\mathrm{Mr}=7$.

Figura 25 - FRF de potência gerada pelo segundo inserto piezelétrico para diferentes relações de rigidez $\mathrm{Kr}$ do segundo elemento elástico, com (a) $\mathrm{Mr}=1$, (b) $\mathrm{Mr}=4$, (c) $\mathrm{Mr}=7$.

Figura 26 - FRF de potência gerada pelo terceiro inserto piezelétrico para diferentes relações de rigidez $\mathrm{Kr}$ do segundo elemento elástico, com (a) $\mathrm{Mr}=1$, (b) $\mathrm{Mr}=4$, (c) $\mathrm{Mr}=7$.

Figura 27 - FRF de potência gerada pelo primeiro inserto piezelétrico para diferentes relações de rigidez $\mathrm{Kr}$ do terceiro elemento elástico, com (a) $\mathrm{Mr}=1$, (b) $\mathrm{Mr}=4$, (c) $\mathrm{Mr}=7$.

Figura 28 - FRF de potência gerada pelo segundo inserto piezelétrico para diferentes relações de rigidez $\mathrm{Kr}$ do terceiro elemento elástico, com (a) $\mathrm{Mr}=1$, (b) $\mathrm{Mr}=4$, (c) $\mathrm{Mr}=7$.

Figura 29 - FRF de potência gerada pelo terceiro inserto piezelétrico para diferentes relações de rigidez $\mathrm{Kr}$ do terceiro elemento elástico, com (a) $\mathrm{Mr}=1$, (b) $\mathrm{Mr}=4$, (c) $\mathrm{Mr}=7$.

Figura 30 - FRF de potência gerada para diferentes relações de massa Mr do segundo estudo de sensibilidade, com relação de rigidez $\mathrm{Kr}=3$, sendo: (a) primeiro inserto piezelétrico, (b) segundo inserto piezelétrico, (c) terceiro inserto piezelétrico.

Figura 31 - FRF de potência gerada para diferentes relações de rigidez Kr do primeiro elemento elástico para as relações de massa $\mathrm{Mr}=1$ e $\mathrm{Mr}=7$ do segundo estudo de sensibilidade, sendo: (a) primeiro inserto com $\mathrm{Mr}=1$, (b) primeiro inserto com $\mathrm{Mr}=7$, (c) segundo inserto com $\mathrm{Mr}=1$, (d) segundo inserto com $\mathrm{Mr}=7$, (e) terceiro inserto com $\mathrm{Mr}=1$, (e) terceiro inserto com $\mathrm{Mr}=7$

Figura 32 - FRF de potência gerada para diferentes relações de rigidez $\mathrm{Kr}$ do segundo elemento elástico para as relações de massa $\mathrm{Mr}=1$ e $\mathrm{Mr}=7$ do segundo estudo de sensibilidade, sendo: (a) primeiro inserto com $\mathrm{Mr}=1$, (b) primeiro inserto com $\mathrm{Mr}=7$, (c) segundo inserto com $\mathrm{Mr}=1$, (d) segundo inserto com $\mathrm{Mr}=7$, (e) terceiro inserto com $\mathrm{Mr}=1$, (e) terceiro inserto com $\mathrm{Mr}=7$.

Figura 33 - FRF de potência gerada para diferentes relações de rigidez $\mathrm{Kr}$ do terceiro elemento elástico para as relações de massa $\mathrm{Mr}=1$ e $\mathrm{Mr}=7$ do segundo estudo de sensibilidade, sendo: (a) primeiro inserto com $\mathrm{Mr}=1$, (b) primeiro inserto com $\mathrm{Mr}=7$, (c) segundo inserto com $\mathrm{Mr}=1$, (d) segundo inserto com $\mathrm{Mr}=7$, (e) terceiro inserto com $\mathrm{Mr}=1$, (e) terceiro inserto com $\mathrm{Mr}=7$

Figura 34 - FRF de potência gerada para diferentes relações de massa Mr do terceiro estudo de sensibilidade, com relação de rigidez $\mathrm{Kr}=3$, sendo: (a) primeiro inserto piezelétrico, (b) segundo inserto piezelétrico, (c) terceiro inserto piezelétrico.

Figura 35 - FRF de potência gerada para diferentes relações de rigidez $\mathrm{Kr}$ do primeiro elemento elástico para as relações de massa $\mathrm{Mr}=1$ e $\mathrm{Mr}=7$ do terceiro estudo de sensibilidade, sendo: (a) primeiro inserto com $\mathrm{Mr}=1$, (b) primeiro inserto com $\mathrm{Mr}=7$, (c) segundo inserto com $\mathrm{Mr}=1$, (d) segundo inserto com $\mathrm{Mr}=7$, (e) terceiro inserto com $\mathrm{Mr}=1$, (e) terceiro inserto com $\mathrm{Mr}=7$.

Figura 36 - FRF de potência gerada para diferentes relações de rigidez $\mathrm{Kr}$ do segundo elemento elástico para as relações de massa $\mathrm{Mr}=1$ e $\mathrm{Mr}=7$ do terceiro estudo de sensibilidade, sendo: (a) primeiro inserto com $\mathrm{Mr}=1$, (b) 
primeiro inserto com $\mathrm{Mr}=7$, (c) segundo inserto com $\mathrm{Mr}=1$, (d) segundo inserto com $\mathrm{Mr}=7$, (e) terceiro inserto com $\mathrm{Mr}=1$, (e) terceiro inserto com $\mathrm{Mr}=7$.

Figura 37 - FRF de potência gerada para diferentes relações de rigidez $\mathrm{Kr}$ do terceiro elemento elástico para as relações de massa $\mathrm{Mr}=1$ e $\mathrm{Mr}=7$ do terceiro estudo de sensibilidade, sendo: (a) primeiro inserto com $\mathrm{Mr}=1$, (b) primeiro inserto com $\mathrm{Mr}=7$, (c) segundo inserto com $\mathrm{Mr}=1$, (d) segundo inserto com $\mathrm{Mr}=7$, (e) terceiro inserto com $\mathrm{Mr}=1$, (e) terceiro inserto com $\mathrm{Mr}=7$.

Figura 38 - FRF de potência gerada para diferentes relações de massa Mr do quarto estudo de sensibilidade, com relação de rigidez $\mathrm{Kr}=3$, sendo: (a) primeiro inserto piezelétrico, (b) segundo inserto piezelétrico, (c) terceiro inserto piezelétrico.

Figura 39 - FRF de potência gerada para diferentes relações de rigidez $\mathrm{Kr}$ do primeiro elemento elástico para as relações de massa $\mathrm{Mr}=1$ e $\mathrm{Mr}=7$ do quarto estudo de sensibilidade, sendo: (a) primeiro inserto com $\mathrm{Mr}=1$, (b) primeiro inserto com $\mathrm{Mr}=7$, (c) segundo inserto com $\mathrm{Mr}=1$, (d) segundo inserto com $\mathrm{Mr}=7$, (e) terceiro inserto com $\mathrm{Mr}=1$, (e) terceiro inserto com $\mathrm{Mr}=7$.

Figura 40 - FRF de potência gerada para diferentes relações de rigidez $\mathrm{Kr}$ do segundo elemento elástico para as relações de massa $\mathrm{Mr}=1$ e $\mathrm{Mr}=7$ do quarto estudo de sensibilidade, sendo: (a) primeiro inserto com $\mathrm{Mr}=1$, (b) primeiro inserto com $\mathrm{Mr}=7$, (c) segundo inserto com $\mathrm{Mr}=1$, (d) segundo inserto com $\mathrm{Mr}=7$, (e) terceiro inserto com $\mathrm{Mr}=1$, (e) terceiro inserto com $\mathrm{Mr}=7$.

Figura 41 - FRF de potência gerada para diferentes relações de rigidez $\mathrm{Kr}$ do terceiro elemento elástico para as relações de massa $\mathrm{Mr}=1$ e $\mathrm{Mr}=7$ do quarto estudo de sensibilidade, sendo: (a) primeiro inserto com $\mathrm{Mr}=1$, (b) primeiro inserto com $\mathrm{Mr}=7$, (c) segundo inserto com $\mathrm{Mr}=1$, (d) segundo inserto com $\mathrm{Mr}=7$, (e) terceiro inserto com $\mathrm{Mr}=1$, (e) terceiro inserto com $\mathrm{Mr}=7$.

Figura 42- FRF de potência gerada em cada um dos três insertos do Caso 1 de otimização do modelo de 3GDL, e potência total gerada pelos modelos de 1GDL e pelo exemplo de 2GDL estudado por Xiao et al. (2015)...........76 Figura 43 - FRF de potência gerada em cada um dos três insertos do Caso 2 de otimização do modelo de 3GDL, e potência total gerada pelos modelos de 1GDL e pelo exemplo de 2GDL estudado por Xiao et al. (2015) ........76 Figura 44 - Máxima tensão gerada pelo inserto piezelétrico do terceiro oscilador do modelo de 3GDL do Caso 1, para diferentes resistências e fatores de força relativos.

Figura 45 - Máxima potência gerada pelo inserto piezelétrico do terceiro oscilador do modelo de 3GDL do Caso 1, para diferentes resistências e fatores de força relativos.

Figura 46 - FRFs de potência gerada pelo inseto do terceiro oscilador no modelo de 3GDL do Caso 1, para fatores de força relativos de 1, 2 e 3 nas resistência que maximizam o resultado, e FRFs do modelo de 1GDL equivalente, e 2GDL do exemplo de Xiao et al. (2015)......

Figura 47 - Máxima tensão gerada pelo inserto piezelétrico do terceiro oscilador do modelo de 3GDL do Caso 2, para diferentes resistências e fatores de força relativos.

Figura 48 - Máxima potência gerada pelo inserto piezelétrico do terceiro oscilador do modelo de 3GDL do Caso 2, para diferentes resistências e fatores de força relativos.

Figura 49 - FRFs de potência gerada pelo inseto do terceiro oscilador no modelo de 3GDL do Caso 2, para fatores de força relativos de 1, 2 e 3 nas resistência que maximizam o resultado, e FRFs do modelo de 1GDL equivalente, e 2GDL do exemplo de Xiao et al. (2015)...... 
Figura 50 - Máxima potência gerada pelo inserto piezelétrico do terceiro oscilador do modelo de 3GDL do Caso 3, para diferentes resistências e fatores de força relativos.

Figura 51 - FRFs de potência gerada pelo inseto do terceiro oscilador no modelo de 3GDL do Caso 3, para fatores de força relativos de 1, 2 e 3 nas resistência que maximizam o resultado, e FRFs do modelo de 1GDL equivalente, e 2 GDL do exemplo de Xiao et al. (2015).

Figura 52 - Tensão gerada na resistência elétrica de $50 \mathrm{k} \Omega$ do circuito associado ao gerador, com cancelamento no segundo modo de vibrar para diferentes posições de $\mathrm{M}_{2}$.

Figura 53 - Tensão gerada na resistência elétrica de $50 \mathrm{k} \Omega$ do circuito associado ao gerador, com cancelamento no primeiro modo de vibrar para diferentes posições de $\mathrm{M}_{2}$.

Figura 54 - Potência gerada na resistência elétrica de $50 \mathrm{k} \Omega$ do circuito associado ao gerador, com cancelamento no segundo modo de vibrar para diferentes posições de $\mathrm{M}_{2}$.

Figura 55 - Potência gerada na resistência elétrica de $50 \mathrm{k} \Omega$ do circuito associado ao gerador, com cancelamento no primeiro modo de vibrar para diferentes posições de $\mathrm{M}_{2}$.

Figura 56 - Potência gerada no inserto piezelétrico de $\mathfrak{R}_{1}$ usando uma resistência de $50 \mathrm{k} \Omega$ para diferentes posições de $\mathrm{M}_{2}$.

Figura 57 - Potência gerada no inserto piezelétrico de $\mathfrak{R}_{2}$ usando uma resistência de $50 \mathrm{k} \Omega$ para diferentes posições de $\mathrm{M}_{2}$

Figura 58 - Potência gerada no inserto piezelétrico de $\mathfrak{R}_{3}$ usando uma resistência de $50 \mathrm{k} \Omega$ para diferentes posições de $\mathrm{M}_{2}$

Figura 59 - Máxima potência gerada na resistência para o primeiro modo de vibrar, para diferentes resistências e posições de $\mathrm{M}_{2}$, com cancelamento no segundo modo.

Figura 60 - Máxima potência gerada na resistência para o segundo modo de vibrar, para diferentes resistências e posições de M2, com cancelamento no primeiro modo.

Figura 61 - Potência gerada na resistência de $50 \mathrm{k} \Omega$ para diferentes comprimentos do inserto de $\mathfrak{R}_{1}, \operatorname{com}_{2}$ posicionada em $L_{2}=107,8 \mathrm{~mm}$, e cancelamento no segundo modo.

Figura 62 - Potência gerada na resistência de $50 \mathrm{k} \Omega$ para diferentes comprimentos do inserto de $\mathfrak{R} 2$, com $\mathrm{M}_{2}$ posicionada em $L_{2}=107,8 \mathrm{~mm}$, e cancelamento no segundo modo.

Figura 63 - Potência gerada na resistência de $50 \mathrm{k} \Omega$ para diferentes comprimentos do inserto de $\mathfrak{R}_{1} \operatorname{com} \mathrm{M}_{2}$ posicionada em $L_{2}=107,8 \mathrm{~mm}$, e cancelamento no primeiro modo.

Figura 64 - Potência gerada na resistência de $50 \mathrm{k} \Omega$ para diferentes comprimentos do inserto de $\mathfrak{R}_{2}$, com $\mathrm{M}_{2}$ posicionada em $L_{2}=107,8 \mathrm{~mm}$, e cancelamento no primeiro modo.

Figura 65 - Máxima potência gerada na resistência para o primeiro modo de vibrar, com $\mathrm{M}_{2} \mathrm{em} 108 \mathrm{~mm}$ e cancelamento no segundo modo, para diferentes resistências e comprimentos do inserto de $\mathfrak{R}_{1}$.

Figura 66 - Máxima potência gerada na resistência para o primeiro modo de vibrar, com $\mathrm{M}_{2}$ em 107,8 mm e cancelamento no segundo modo, para diferentes resistências e comprimentos do inserto de $\mathfrak{R}_{2}$.

Figura 67 - Máxima potência gerada na resistência para o segundo modo de vibrar, com $\mathrm{M}_{2}$ em 107,8mm e cancelamento no primeiro modo, para diferentes resistências e comprimentos do inserto de $\mathfrak{R}_{1}$

Figura 68 - Máxima potência gerada na resistência para o segundo modo de vibrar, com $\mathrm{M}_{2}$ em 107,8mm e cancelamento no primeiro modo, para diferentes resistências e comprimentos do inserto de $\mathfrak{R}_{2}$ 
Figura 69 - FRF de potência gerada na resistência, com $\mathrm{M}_{2}$ em 107,8mm e cancelamento no segundo modo, para diferentes comprimentos do inserto de $\mathfrak{R}_{1}$ às resistências que otimizam a resposta do gerador. Figura 70 - FRF de potência gerada na resistência, com $\mathrm{M}_{2}$ em 107,8mm e cancelamento no segundo modo, para diferentes comprimentos do inserto de $\mathfrak{R}_{2}$ às resistências que otimizam a resposta do gerador.

Figura 71 - FRF de potência gerada na resistência, com $\mathrm{M}_{2}$ em 107,8mm e cancelamento no primeiro modo, para diferentes comprimentos do inserto de $\mathfrak{R}_{1}$ às resistências que otimizam a resposta do gerador.

Figura 72 - FRF de potência gerada na resistência, com $\mathrm{M}_{2}$ em 107,8mm e cancelamento no primeiro modo, para diferentes comprimentos do inserto de $\mathfrak{R}_{2}$ às resistências que otimizam a resposta do gerador. Figura 73 - Máxima potência gerada no primeiro modo de vibrar, à resistência de maior eficiência e cancelamento no segundo modo, para diferentes posições de $\mathrm{M}_{2}$ e comprimentos do inserto de $\mathfrak{R}_{1}$ Figura 74 - Máxima potência gerada no primeiro modo de vibrar, à resistência de maior eficiência e cancelamento no segundo modo, para diferentes posições de $\mathrm{M}_{2}$ e comprimentos do inserto de $\mathfrak{R}_{2}$. Figura 75 - Máxima potência gerada no segundo modo de vibrar, à resistência de maior eficiência e cancelamento no primeiro modo, para diferentes posições de $\mathbf{M}_{2}$ e comprimentos do inserto de $\mathfrak{R}_{1}$ Figura 76 - Máxima potência gerada no segundo modo de vibrar, à resistência de maior eficiência e cancelamento no primeiro modo, para diferentes posições de $\mathrm{M}_{2}$ e comprimentos do inserto de $\mathfrak{R}_{2}$ Figura 77 - FRF de potência gerada na resistência elétrica, para diferentes posições do inserto de $\mathfrak{R}_{1}$, com $\mathrm{M}_{2}$ em $107,8 \mathrm{~mm}$, resistência de $50 \mathrm{k} \Omega$, e cancelamento no segundo modo.

Figura 78 - FRF de potência gerada na resistência elétrica, para diferentes posições do inserto de $\mathfrak{R}_{2}$, com $\mathrm{M}_{2}$ em $107,8 \mathrm{~mm}$, resistência de $50 \mathrm{k} \Omega$, e cancelamento no segundo modo.

Figura 79 - FRF de potência gerada na resistência elétrica, para diferentes posições do inserto de $\mathfrak{R}_{1}, \mathrm{com} \mathrm{M}_{2} \mathrm{em}$ $107,8 \mathrm{~mm}$, resistência de $50 \mathrm{k} \Omega$, e cancelamento no primeiro modo.

Figura 80 - FRF de potência gerada na resistência elétrica, para diferentes posições do inserto de $\mathfrak{R}_{2}$, com $\mathrm{M}_{2}$ em $107,8 \mathrm{~mm}$, resistência de $50 \mathrm{k} \Omega$, e cancelamento no primeiro modo.

Figura 81 - Máxima potência gerada no primeiro modo de vibrar, para diferentes resistências e posições do inserto de $\mathfrak{R}_{1}$, com cancelamento no segundo modo e $\mathrm{M}_{2}$ em 107,8mm.

Figura 82 - Máxima potência gerada no primeiro modo de vibrar, para diferentes resistências e posições do inserto de $\mathfrak{R}_{2}$, com cancelamento no segundo modo e $\mathrm{M}_{2}$ em $107,8 \mathrm{~mm}$.

Figura 83 - Máxima potência gerada no segundo modo de vibrar, para diferentes resistências e posições do inserto de $\mathfrak{R}_{1}$, com cancelamento no primeiro modo e $\mathbf{M}_{2}$ em 107,8mm.

Figura 84 - Máxima potência gerada no segundo modo de vibrar, para diferentes resistências e posições do inserto de $\mathfrak{R}_{2}$, com cancelamento no primeiro modo e $\mathrm{M}_{2}$ em $107,8 \mathrm{~mm}$.

Figura 85 - Máxima potência gerada no primeiro modo de vibrar, para diferentes posições de $\mathrm{M}_{2}$ e do inserto de $\mathfrak{R}_{1}$ com $\mathrm{Lo}_{1}$ na forma porcentagem de $\mathrm{L}_{1}$, com cancelamento no segundo modo à resistência de maior resposta.

Figura 86 - Máxima potência gerada no primeiro modo de vibrar, para diferentes posições de $\mathrm{M}_{2}$ e do inserto de $\mathfrak{R}_{2}$, com $\mathrm{Lo}_{2}$ na forma porcentagem de $\mathrm{L}_{2}$, com cancelamento no segundo modo à resistência de maior resposta. 
Figura 87 - Máxima potência gerada no segundo modo de vibrar, para diferentes posições de $\mathrm{M}_{2}$ e do inserto de $\mathfrak{R}_{1}$, com $\mathrm{Lo}_{1}$ na forma porcentagem de $\mathrm{L}_{1}$, com cancelamento no primeiro modo à resistência de maior resposta.

Figura 88 - Máxima potência gerada no segundo modo de vibrar, para diferentes posições de $\mathrm{M}_{2}$ e do inserto de $\mathfrak{R}_{2}$, com $\mathrm{LO}_{2}$ na forma porcentagem de $\mathrm{L}_{2}$, com cancelamento no primeiro modo à resistência de maior resposta.

Figura 89 - FRF de potência gerada nos insertos das três regiões do gerador, com $\mathrm{M}_{2}$ em $\mathrm{L}_{2}=41,8 \mathrm{~mm}, \mathrm{Lo}_{\mathrm{k}}=0$, e resistência de $110 \mathrm{k} \Omega$.

Figura 90 - FRF de potência gerada nos insertos das três regiões do gerador, com $\mathrm{M}_{2}$ em $\mathrm{L}_{2}=107,8 \mathrm{~mm}, \mathrm{Lo}_{\mathrm{k}}=0$, e resistência de $110 \mathrm{k} \Omega$.

Figura 91 - FRF de potência gerada nos insertos das três regiões do gerador, com $\mathrm{M}_{2}$ em $\mathrm{L}_{2}=173,8 \mathrm{~mm}, \mathrm{Lo}_{\mathrm{k}}=0$, e resistência de $130 \mathrm{k} \Omega$. 107

Figura 92 - Tensão gerada na resistência para a Configuração 2, com cancelamento no segundo modo de vibrar para diferentes posições de $\mathrm{M}_{2}$, usando uma resistência de $50 \mathrm{k} \Omega$. 110 Figura 93 - Tensão gerada na resistência para a Configuração 2, com cancelamento no primeiro modo de vibrar para diferentes posições de $\mathrm{M}_{2}$, usando uma resistência de $50 \mathrm{k} \Omega$. 110 Figura 94 - Potência gerada na resistência para a Configuração 2, com cancelamento no segundo modo de vibrar para diferentes posições de $\mathrm{M}_{2}$, usando uma resistência de $50 \mathrm{k} \Omega$. Figura 95 - Potência gerada na resistência para a Configuração 2, com cancelamento no primeiro modo de vibrar para diferentes posições de $\mathrm{M}_{2}$, usando uma resistência de $50 \mathrm{k} \Omega$.

Figura 96 - Potência gerada no inserto de $\mathfrak{R}_{1}$ para a Configuração 2, em diferentes posições de $\mathrm{M}_{2}$, usando uma resistência de $50 \mathrm{k} \Omega$.

Figura 97 - Potência gerada no primeiro inserto de $\mathfrak{R}_{2}$ para a Configuração 2, em diferentes posições de $\mathrm{M}_{2}$, usando uma resistência de $50 \mathrm{k} \Omega$.

Figura 98 - Potência gerada no segundo inserto de $\mathfrak{R}_{2}$ para a Configuração 2, em diferentes posições de $\mathrm{M}_{2}$, usando uma resistência de $50 \mathrm{k} \Omega$.

Figura 99 - Máxima potência gerada na resistência para o primeiro modo de vibrar da Configuração 2, para diferentes resistências e posições de $\mathrm{M}_{2}$, com cancelamento no segundo modo.

Figura 100 - Máxima potência gerada na resistência para o segundo modo de vibrar da Configuração 2, para diferentes resistências e posições de $\mathrm{M}_{2}$, com cancelamento no primeiro modo.

Figura 101 - FRF de potência gerada na resistência para a configuração 2, com $\mathrm{M}_{2}$ em 107,8mm e cancelamento no segundo modo, para diferentes comprimentos do insertos de $\mathfrak{R}_{2}$ e resistência de $50 \mathrm{k} \Omega$.

Figura 102 - FRF de potência gerada na resistência para a configuração 2, com $\mathrm{M}_{2}$ em 107,8mm e cancelamento no primeiro modo, para diferentes comprimentos do insertos de $\mathfrak{R}_{2}$ e resistência de $50 \mathrm{k} \Omega$. 115 Figura 103 - Máxima potência gerada na resistência para a configuração 2 no primeiro modo de vibrar, com $\mathbf{M}_{2}$ em 107,8mm e cancelamento no segundo modo, para diferentes resistências e comprimentos do inserto de $\mathfrak{R}_{2} 116$ Figura 104 - Máxima potência gerada na resistência para a configuração 2 no segundo modo de vibrar, com $\mathbf{M}_{2}$ em 107,8mm e cancelamento no primeiro modo, para diferentes resistências e comprimentos do inserto de $\mathfrak{R}_{2}$. 
Figura 105 - FRF de potência gerada na resistência para a configuração 2, com $\mathrm{M}_{2}$ em 107,8mm e cancelamento no segundo modo, para diferentes comprimentos do insertos de $\mathfrak{R}_{2}$ às resistências que otimizam a resposta do gerador.

Figura 106 - FRF de potência gerada na resistência para a configuração 2, com $\mathrm{M}_{2}$ em 107,8mm e cancelamento no primeiro modo, para diferentes comprimentos do insertos de $\mathfrak{R}_{2}$ às resistências que otimizam a resposta do gerador.

Figura 107 - Máxima potência gerada para a configuração 2 no primeiro modo de vibrar, à resistência de maior eficiência e cancelamento no segundo modo, para diferentes posições de $\mathrm{M}_{2}$ e comprimentos dos insertos de $\mathfrak{R}_{2}$.

Figura 108 - Máxima potência gerada para a configuração 2 no segundo modo de vibrar, à resistência de maior eficiência e cancelamento no primeiro modo, para diferentes posições de $\mathrm{M}_{2}$ e comprimentos dos insertos de $\mathfrak{R}_{2}$.

Figura 109 - FRF de potência gerada na resistência elétrica para a configuração 2, para diferentes posições dos insertos de $\mathfrak{R}_{2}$, com $\mathrm{M}_{2}$ em $107,8 \mathrm{~mm}$, resistência de $50 \mathrm{k} \Omega$, e cancelamento no segundo modo. 120

Figura 110 - FRF de potência gerada na resistência elétrica para a configuração 2, para diferentes posições dos insertos de $\mathfrak{R}_{2}$, com $\mathrm{M}_{2}$ em $107,8 \mathrm{~mm}$, resistência de $50 \mathrm{k} \Omega$, e cancelamento no primeiro modo. Figura 111 - Máxima potência gerada no primeiro modo de vibrar da configuração 2 para diferentes resistências e posições dos insertos de $\mathfrak{R}_{2}$, com cancelamento no segundo modo e $\mathrm{M}_{2}$ em 107,8mm. 121 Figura 112 - Máxima potência gerada no segundo modo de vibrar da configuração 2 para diferentes resistências e posições dos insertos de $\mathfrak{R}_{2}$, com cancelamento no primeiro modo e $\mathrm{M}_{2}$ em 107,8mm.

Figura 113 - Máxima potência gerada no primeiro modo de vibrar da configuração 2 para diferentes posições de $\mathrm{M}_{2}$ e dos insertos de $\mathfrak{R}_{2}$, com cancelamento no segundo modo à resistência de máxima resposta. Figura 114 - Máxima potência gerada no segundo modo de vibrar da configuração 2 para diferentes posições de $\mathrm{M}_{2}$ e dos insertos de $\mathfrak{R}_{2}$, com cancelamento no primeiro modo à resistência de máxima resposta.

Figura 115 - FRF de potência gerada nos insertos da configuração 2, sendo o primeiro em $\mathfrak{R}_{1}$ e os demais em $\mathfrak{R}_{2}$, com $\mathrm{M}_{2}$ em $\mathrm{L}_{2}=41,8 \mathrm{~mm}, \mathrm{Lo}_{\mathrm{k}}=0$, e resistência de $50 \mathrm{k} \Omega$.

Figura 116 - FRF de potência gerada nos insertos da configuração 2, sendo o primeiro em $\mathfrak{R}_{1}$ e os demais em $\mathfrak{R}_{2}$, com $\mathrm{M}_{2}$ em $\mathrm{L}_{2}=107,8 \mathrm{~mm}, \mathrm{Lo}_{\mathrm{k}}=0$, e resistência de $70 \mathrm{k} \Omega$.

Figura 117 - FRF de potência gerada nos insertos da configuração 2, sendo o primeiro em $\mathfrak{R}_{1}$ e os demais em $\mathfrak{R}_{2}$, com $\mathrm{M}_{2}$ em $\mathrm{L}_{2}=173,8 \mathrm{~mm}, \mathrm{Lo}_{\mathrm{k}}=0$, e resistência de $70 \mathrm{k} \Omega$.

Figura 118 - FRF de tensão gerada na resistência para a Configuração 3, em diferentes posições de $\mathrm{M}_{2}$, usando uma resistência de $50 \mathrm{k} \Omega$.

Figura 119 - FRF de potência gerada na resistência para a Configuração 3, em diferentes posições de $\mathrm{M}_{2}$, usando uma resistência de $50 \mathrm{k} \Omega$.

Figura 120 - Máxima potência gerada na resistência para o primeiro modo da configuração 3, para diferentes valores de resistência e posições de $\mathrm{M}_{2}$.

Figura 121 - Máxima potência gerada na resistência para o segundo modo da configuração 3, para diferentes valores de resistência e posições de $\mathrm{M}_{2}$

Figura 122 - FRF de potência gerada na resistência para a configuração 3, com $\mathrm{M}_{2}$ em 107,8mm, diferentes comprimentos dos insertos de $\mathfrak{R}_{2}$ e resistência de $50 \mathrm{k} \Omega$...... 
Figura 123 - Máxima potência gerada na resistência para a configuração 3 no primeiro modo de vibrar, com $\mathrm{M}_{2}$ em 107,8mm, para diferentes resistências e comprimentos dos insertos de $\mathfrak{R}_{2}$

Figura 124 - Máxima potência gerada na resistência para a configuração 3 no segundo modo de vibrar, com $\mathrm{M}_{2}$ em 107,8mm, para diferentes resistências e comprimentos dos insertos de $\mathfrak{R}_{2}$ 130 Figura 125 - FRF de potência gerada na resistência para a configuração 3, com $\mathrm{M}_{2} \mathrm{em}$ 107,8mm, para diferentes comprimentos dos insertos de $\mathfrak{R}_{2}$ à resistência que maximiza a resposta no primeiro modo de vibrar. Figura 126 - FRF de potência gerada na resistência para a configuração 3, com $\mathrm{M}_{2}$ em 107,8mm, para diferentes comprimentos dos insertos de $\mathfrak{R}_{2}$ à resistência que maximiza a resposta no segundo modo de vibrar...... Figura 127 - Máxima potência gerada para a configuração3 no primeiro modo de vibrar, à resistência de maior eficiência, para diferentes posições de $\mathrm{M}_{2}$ e comprimentos dos insertos de $\mathfrak{R}_{2}$. 132 Figura 128 - Máxima potência gerada para a configuração3 no segundo modo de vibrar, à resistência de maior eficiência, para diferentes posições de $\mathrm{M}_{2}$ e comprimentos dos insertos de $\mathfrak{R}_{2}$. 132 Figura 129 - FRF de tensão gerada na resistência para a configuração 3, em diferentes posições dos insertos de $\Re_{2}$, para $\mathrm{L}_{2}=107,8 \mathrm{~mm}$ e usando uma resistência de $50 \mathrm{k} \Omega$.

Figura 130 - Máxima potência gerada no primeiro modo de vibrar da configuração 3 para diferentes resistências e posições dos insertos de $\mathfrak{R}_{2}$, com $\mathrm{M}_{2}$ em $107,8 \mathrm{~mm}$

Figura 131 - Máxima potência gerada no segundo modo de vibrar da configuração 3 para diferentes resistências e posições dos insertos de $\mathfrak{R}_{2}$, com $\mathrm{M}_{2}$ em $107,8 \mathrm{~mm}$.

Figura 132 - Máxima potência gerada no primeiro modo de vibrar da configuração 3 para diferentes posições de $\mathrm{M}_{2}$ e dos insertos de $\mathfrak{R}_{2}$, à resistência de máxima resposta.

Figura 133 - Máxima potência gerada no segundo modo de vibrar da configuração 3 para diferentes posições de $\mathrm{M}_{2}$ e dos insertos de $\mathfrak{R}_{2}$, à resistência de máxima resposta.

Figura 134 - Modos de vibrar do gerador viga "L", sendo: a) primeiro modo de vibrar, com $\mathrm{L}_{2}=41,8 \mathrm{~mm}$; b) segundo modo de vibrar, com $\mathrm{L}_{2}=41,8 \mathrm{~mm}$; c) primeiro modo de vibrar com $\mathrm{L}_{2}=173,8 \mathrm{~mm}$; d) segundo modo de vibrar com $\mathrm{L}_{2}=173,8 \mathrm{~mm}$.

Figura 135 - Derivada dos autovetores do gerador viga "L" normalizados para $x_{k}=0$, sendo: a) primeiro modo, com $\mathrm{L}_{2}=41,8 \mathrm{~mm}$; b) segundo modo, com $\mathrm{L}_{2}=41,8 \mathrm{~mm}$; c) primeiro modo, com $\mathrm{L}_{2}=173,8 \mathrm{~mm}$; d) segundo modo, $\operatorname{com} \mathrm{L}_{2}=173,8 \mathrm{~mm}$.

Figura 136 - Derivada segunda dos autovetores do gerador viga "L", sendo: a) primeiro modo, com $\mathrm{L}_{2}=41,8 \mathrm{~mm}$; b) segundo modo, com $\mathrm{L}_{2}=41,8 \mathrm{~mm}$; c) primeiro modo, com $\mathrm{L}_{2}=173,8 \mathrm{~mm}$; d) segundo modo, com $\mathrm{L}_{2}=173,8 \mathrm{~mm}$.

Figura 137 - Potência gerada na resistência elétrica para as configurações 1 com insertos de 38,1mm (azul) e com recobrimento total (preto), ambos com cancelamento no segundo modo, e configurações 3 com insertos de $38,1 \mathrm{~mm}$ (vermelho) e recobrimento de $80 \%$ de $\mathfrak{R}_{2}$ (magenta) otimizados para o primeiro modo. 143 Figura 138 - Potência gerada na resistência elétrica para as configurações 1 com insertos de 38,1mm (azul) e com recobrimento total (preto), ambos com cancelamento no primeiro modo, e configurações 3 com insertos de $38,1 \mathrm{~mm}$ (vermelho) e recobrimento de $80 \%$ de $\mathfrak{R}_{2}$ (magenta) otimizados para o segundo modo. 144

Figura 139 - Esquemático do arranjo utilizado para os ensaios experimentais.

Figura 140 - Montagem do protótipo do gerador piezelétrico para realização dos ensaios experimentais. 147 
Figura 141 -FRFs de tensão e potência geradas medidas para o gerador na configuração 1 usando diferentes resistências, sendo (a) e (b) as tensões geradas, (c) e (d) as potências geradas, e (e) e (f) o pico de potência gerada no primeiro modo, com cancelamentos no primeiro e segundo modo respectivamente.

Figura 142 -FRFs de potência gerada medidas para as configurações 1, 2 e 3 do gerador tipo viga L, com resistência de $500 \mathrm{k} \Omega$ e cancelamentos (a) no primeiro e (b) segundo modo.

Figura 143 - Resultados simulados e medidos em M1 e M2, sendo (a) a transmissibilidade na direção transversal para M1 e M2, e (b) o erro relativo entre os resultados simulados e medidos.

Figura 144 - FRF de tensão na resistência para a Configuração 1, sendo: (a) e (b) as respostas simuladas para insertos com propriedades iguais, (c) e (d) as respostas simuladas para insertos com propriedades ajustadas, (e) e (f) resultados medidos, com cancelamentos no primeiro e segundo modo respectivamente.

Figura 145 - FRF de tensão na resistência para a Configuração 2, sendo: (a) e (b) as respostas simuladas para insertos com propriedades iguais, (c) e (d) as respostas simuladas para insertos com propriedades ajustadas, (e) e (f) resultados medidos, com cancelamentos no primeiro e segundo modo respectivamente

Figura 146 - Resultados simulados e medidos para a configuração 1, sendo (a) e (b) as FRFs de tensão na resistência, e (c) e (d) os erros relativos entre os resultados simulados e medidos, com cancelamento no primeiro e segundo modo respectivamente.

Figura 147 - Resultados simulados e medidos para a configuração 2, sendo (a) e (b) as FRFs de tensão na resistência, e (c) e (d) os erros relativos entre os resultados simulados e medidos, com cancelamento no primeiro e segundo modo respectivamente.

Figura 148 -FRF de tensão na resistência para a Configuração 3, sendo: (a) as respostas simuladas para insertos com propriedades iguais, (b) as respostas simuladas para insertos com propriedades ajustadas, (c) os resultados medidos, (d) os resultados medidos e simulados confrontados, e (e) o erro relativo entre os resultados simulados e medidos. 


\section{Lista de Tabelas}

Tabela 1 - Parâmetros do modelo com dois graus de liberdade estudados por Tang e Yang (2012) e Xiao et al.

Tabela 2 - Resultados de potência máxima gerada para os exemplos apresentados nos trabalhos de Xiao (Xiao et al. 2015) e Tang (Tang, Yang, 2012), nos quais a linha " $1^{\circ}$ piezo" indica a energia gerada pelo elemento piezelétrico entre a base e a primeira massa, e a linha " $2^{\circ}$ piezo" indica o inserto entre a primeira e a segunda massa.

Tabela 3 - Massa dos osciladores em cada configuração do primeiro estudo de sensibilidade do gerador de três graus de liberdade

Tabela 4 - Relação de distribuição de massa entre os osciladores em cada configuração do primeiro estudo de sensibilidade do gerador de três graus de liberdade.

Tabela 5 - Parâmetros de massa e rigidez em cada configuração do primeiro estudo de sensibilidade do gerador de três graus de liberdade.

Tabela 6 - Massa dos osciladores em cada configuração do segundo estudo de sensibilidade do gerador de três graus de liberdade

Tabela 7 - Relação de distribuição de massa entre os osciladores em cada configuração do segundo estudo de sensibilidade do gerador de três graus de liberdade

Tabela 8 - Massa dos osciladores em cada configuração do terceiro estudo de sensibilidade do gerador de três graus de liberdade

Tabela 9 - Relação de distribuição de massa entre os osciladores em cada configuração do terceiro estudo de sensibilidade do gerador de três graus de liberdade.

Tabela 10 - Massa dos osciladores em cada configuração do quarto estudo de sensibilidade do gerador de três graus de liberdade.

Tabela 11 - Relação de distribuição de massa entre os osciladores em cada configuração do quarto estudo de sensibilidade do gerador de três graus de liberdade.

Tabela 12- Parâmetros do modelo de 3 graus de liberdade para dois casos com resultados otimizados encontrados nos estudos de sensibilidade.

Tabela 13 - Máxima potência gerada para o modelo de 3GDL dos Casos 1 e 2 na configuração de referência, contendo um inserto piezelétrico para cada massa oscilante

Tabela 14 - Parâmetros do modelo de 3 graus de liberdade para um terceiro caso de otimização, com relações entre as massas de mesma ordem de grandeza do exemplo de 2 GDL estudado por outros autores.

Tabela 15 - Máxima potência gerada para o modelo de 3GDL do Casos 3 na configuração de referência, contendo um inserto piezelétrico para cada massa oscilante

Tabela 16 - Resumo dos resultados dos modelos de 2 e 3 GDL estudados, nas configurações de referência e otimizada

Tabela 17 - Parâmetros do modelo da viga "L" estudado ao longo do capítulo.

Tabela 18 - Resultados de potência máxima no $1^{\circ}$ modo para o gerador na configuração 1 com cancelamento no $2^{\circ}$ modo 
Tabela 19 - Resultados de potência máxima no $2^{\circ}$ modo para o gerador na configuração 1 com cancelamento no $1^{\circ}$ modo. 108

Tabela 20 - Resultados de potência máxima no $1^{\circ}$ modo para o gerador na configuração 2 com cancelamento no $2^{\mathrm{o}}$ modo.

Tabela 21 - Resultados de potência máxima no $2^{\circ}$ modo para o gerador na configuração 2 com cancelamento no $1^{\mathrm{o}}$ modo. 125

Tabela 22 - Resultados de potência máxima no $1^{\circ}$ modo de vibrar para o gerador na configuração 3. 136

Tabela 23 - Resultados de potência máxima no $2^{\circ}$ modo de vibrar para o gerador na configuração 3. 136

Tabela 24 - Parâmetros do protótipo da viga-L e do modelo ajustado pela FRF de transmissibilidade medida em $\mathrm{M}_{1}$ e $\mathrm{M}_{2}$

Tabela 25 - Propriedades dos insertos piezelétricos utilizadas nos modelos com parâmetros uniformes, e ajustados de acordo com os dados medidos, em que $\mathfrak{R}_{2 \mathrm{a}}$ e $\mathfrak{R}_{2 \mathrm{~b}}$ correspondem aos insertos que configuram a montagem bimorph de $\mathfrak{R}_{2}$, sendo $\mathfrak{R}_{2 \mathrm{a}} \mathrm{o}$ inserto utilizado também na configuração 1 .

Tabela 26 - Capacitâncias medidas nos insertos e valores de permissividade dielétrica utilizados no modelo ajustado. 


\section{Sumário}

1. INTRODUÇÃ

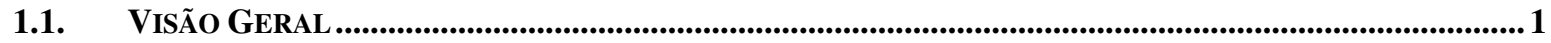

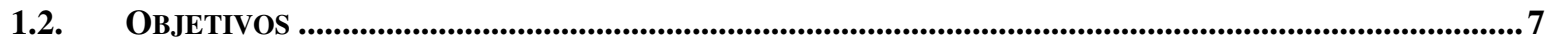

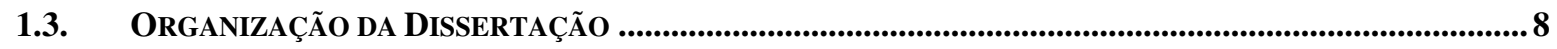

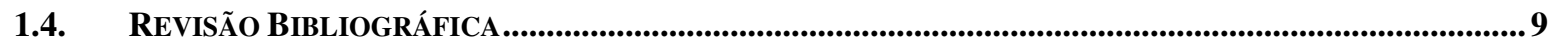

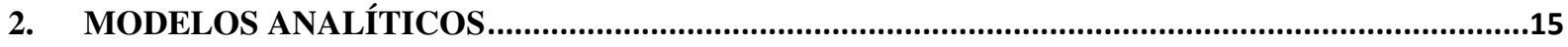

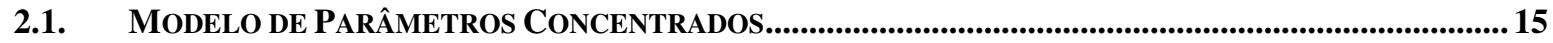

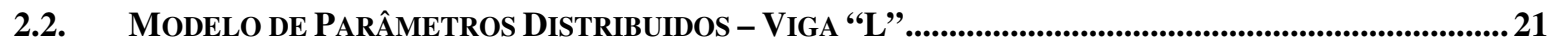

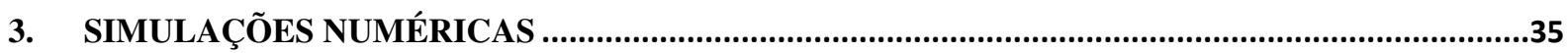

3.1. Simulações Numéricas - Modelo de Parâmetros ConCentrados .........................................35

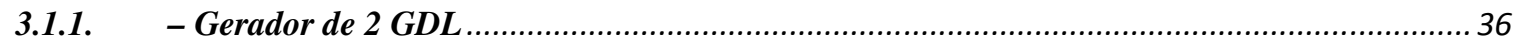

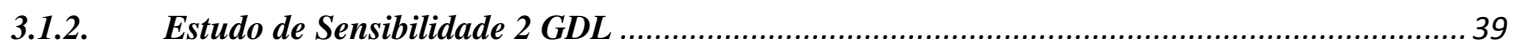

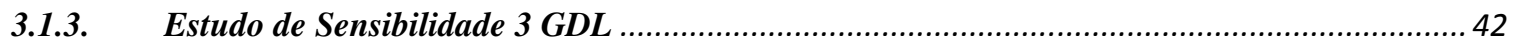

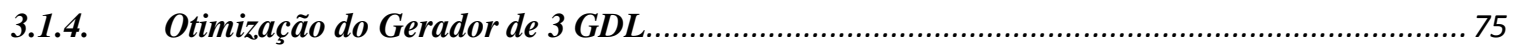

3.2. Simulações Numéricas - Modelo de PARÂMetros Distribuídos - Viga “L” .......................85

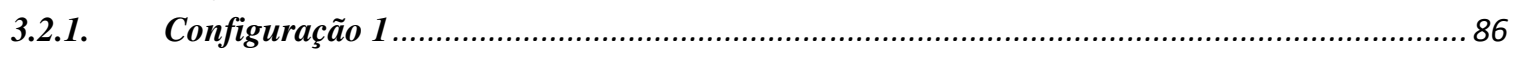

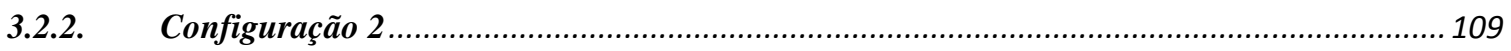

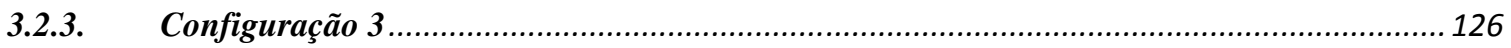

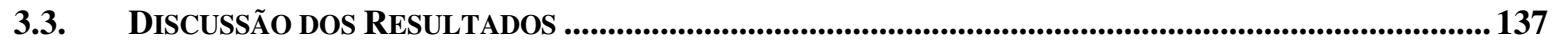

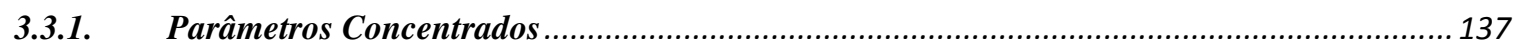

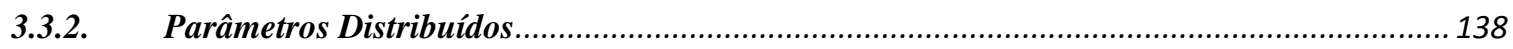

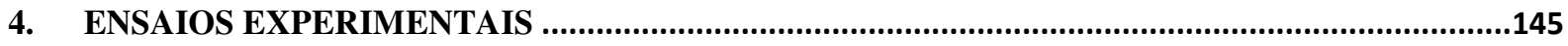

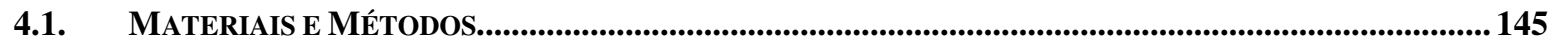

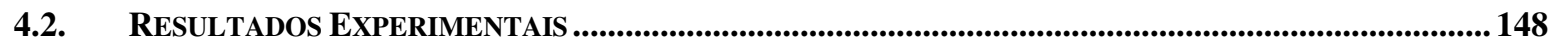

4.3. VALIDAÇÃ̃ DO MODELO MATEMÁTICO ........................................................................................... 150

4.4. DISCUSSÃO

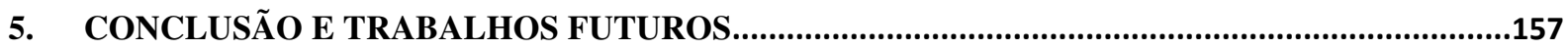

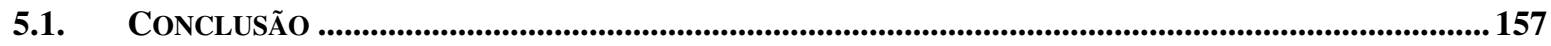

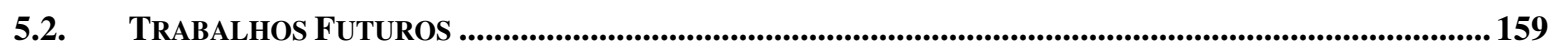

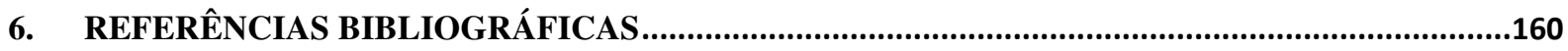





\section{Introdução}

\subsection{Visão Geral}

Intrínseco ao crescente desenvolvimento de tecnologias microeletrônicas e dispositivos com interfaces sem fio está o desenvolvimento de novas tecnologias energéticas que estejam aptas a alimentar esses dispositivos, mesmo frente às restrições técnicas e funcionais de seus sistemas. A inexistência de ligações físicas entre tais dispositivos e potenciais fontes de energia, seja por uma restrição da operação, ou por conveniência para seus usuários, faz com que toda a energia necessária para a operação esteja disponível no próprio equipamento.

Tradicionalmente essa reserva energética é suprida por pilhas ou baterias eletroquímicas, que para uma considerável parcela de aplicações atendem aos requisitos sem grandes comprometimentos. Mas é evidente que esse tipo de solução apresenta limitações quanto à autonomia do dispositivo, e requer, inevitavelmente, sua substituição ou conexão a uma fonte externa para reabastecimento de seu potencial energético.

No entanto, há aplicações em que esse compromisso com a recarga ou substituição das baterias prejudica significativamente o uso destes dispositivos. Como exemplo pode-se citar o emprego de sensoriamento em pneus de veículos terrestres, em que a vida útil do item monitorado normalmente é superior ao de uma bateria de características compatíveis com a aplicação, e o acesso para recarga exige manutenções dispendiosas. Outro exemplo está na área médica, cujos dispositivos microeletrônicos implantados estão sujeitos aos mesmos transtornos.

Tendo em vista aplicações que compartilham desse tipo de restrição, seja esta imposta pelo custo, manutenabilidade, ou simplesmente pela conveniência para o usuário, as pesquisas por novas fontes energéticas, especialmente renováveis e que possam ser embarcadas em dispositivos microeletrônicos, tem recebido bastante atenção da indústria e das comunidades científicas. Dentre essas potenciais fontes renováveis de energia, as mais tradicionalmente estudadas são a solar, eólica e hídrica, mas é fácil perceber que nem todas as aplicações permitem adotar esse tipo de solução, como nos exemplos dados anteriormente.

É dentro deste contexto que o uso de vibrações para geração de energia, processo conhecido como Energy Harvesting, vem ganhando posição de destaque dentre os tópicos estudados atualmente (\#Figura 1). A característica ubíqua das vibrações favorece uma gama 
muito grande de aplicações, cuja simples existência de solicitações mecânicas caracteriza potencial energético aproveitável. Em suas publicações, Roundy et al. (2003) e Zuo, Tang (2013) revisam tal potencial para geração de energia, abordando desde vibrações de baixa magnitude, associadas ao corpo humano ou típicos de ambientes domésticos e escritórios, até vibrações de grandes potenciais, como em veículos e até mesmo edificações.

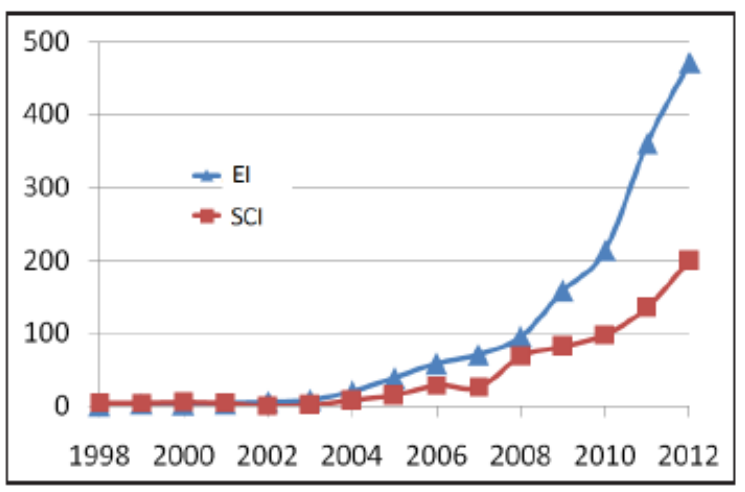

Figura 1 - Evolução da quantidade de artigos relavantes na área de Energy harvesting, indicando o crescente interesse de pesquisas na área (Zuo, Tang, 2013).

Starner (Starner, Paradiso, 2004) destaca que a evolução na densidade energética de baterias têm se mostrado muito aquém do desenvolvimento tecnológico em outras áreas, como capacidade de armazenamento, processamento e transmissão de dados (\#Figura 2). Partindo dessa premissa, os autores apresentam fontes energéticas alternativas para alimentação de microeletrônicos, com foco no potencial energético do corpo humano, analisando-se desde atividades metabólicas, como pressão sanguínea e respiração, até atividades físicas, como correr e pedalar. Mostrou-se que há potenciais aproveitáveis variando desde décimos de Watts provenientes do próprio metabolismo, chegando a dezenas de Watts para atividades mais intensas como correr.

Já para aplicações em veículos terrestres o potencial energético disponível é bem mais elevado, na qual as irregularidades do pavimento, além de vibrações provenientes do próprio powertrain, constituem abundantes fontes de vibrações. Em seu review, Zuo (Zuo, Tang, 2013) cita potenciais que podem ir de $100 \mathrm{~W}$ para um veículo médio (aproximadamente $1500 \mathrm{~kg}$ ) a 60 milhas $/ \mathrm{h}$ em pavimentos bons, a até $1600 \mathrm{~W}$ para o mesmo caso, mas em pavimentos ruins. Já em aplicações off-road, são relatados potenciais de 1 a $10 \mathrm{~kW}$. 


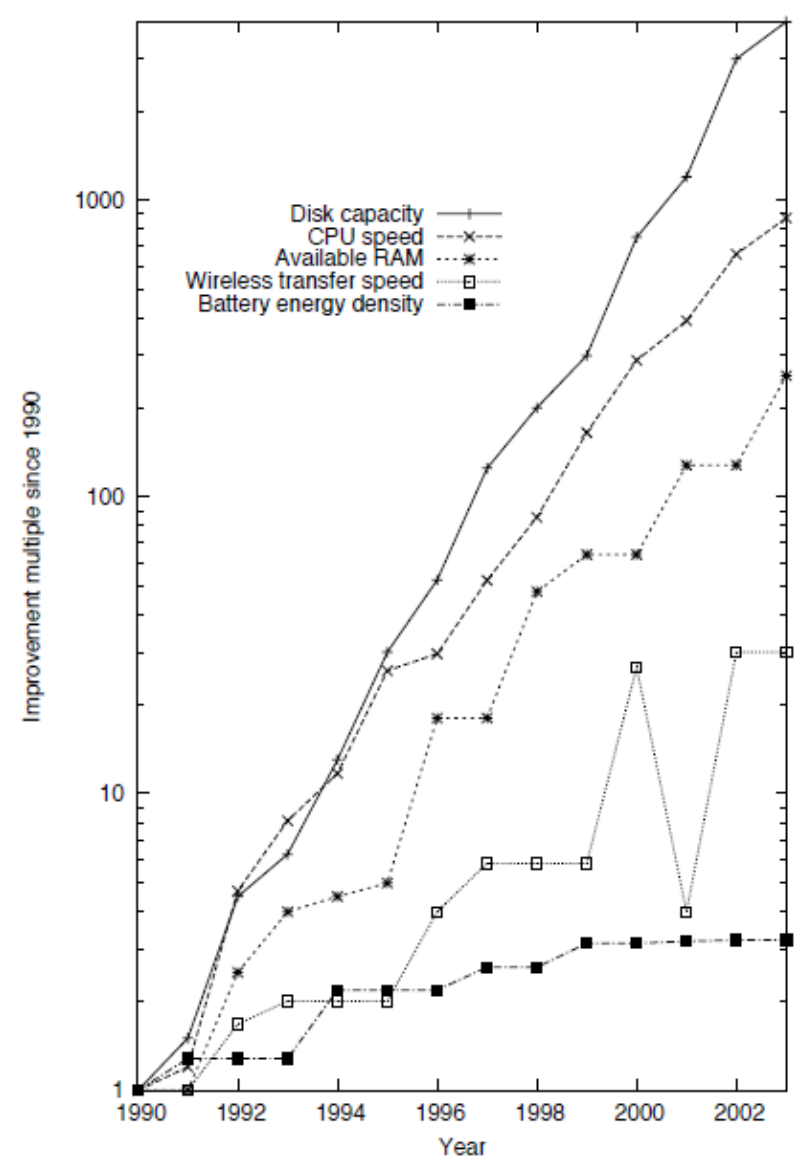

Figura 2 - Evolução de tecnológica de componentes eletrônicos, na qual é possível notar o atraso na evolução da densidade energética de baterias em relação à outros elementos (Starner, Paradiso, 2004).

Para a conversão da energia cinética disponível em aplicações como as discutidas, diferentes mecanismos de transdução vem sendo extensivamente estudados, conforme retratado por Beepy (2006), em que são descritas e comentadas pesquisas em energy harvesting para microeletrônicos wireless, com destaque para os mecanismos de transdução piezelétrico, eletromagnético e eletrostático. Em sua publicação ficam evidenciados os aspectos positivos e negativos inerentes a cada solução, na qual o mecanismo piezelétrico chama atenção pela simplicidade construtiva e de funcionamento do gerador, sem comprometimento do potencial de geração de energia. Nas pesquisas citadas, comparado aos outros transdutores, os piezelétricos apresentaram uma relação entre quantidade de energia gerada e a massa do dispositivo sensivelmente inferior, mas quando avaliada em função do volume do gerador, nota-se resultados superiores aos dos demais. 
De maneira análoga à geração de energia a partir de vibrações, denominada Energy Harvesting, os geradores de energia que executam essa função são genericamente chamados de Energy Harvesters.

\section{Energy Harvesters Piezelétricos}

A piezeletricidade, propriedade descoberta por Jacques e Pierre Curie em 1880, consiste na geração de potencial elétrico quando o material é submetido a uma solicitação mecânica. Tal propriedade é encontrada em materiais que apresentam dipolos elétricos alinhados, natural ou artificialmente, cujo potencial elétrico gerado é consequência da movimentação desses dipolos, causada pela deformação do material quando solicitado.

O principio básico de funcionamento de um gerador piezelétrico consiste na aplicação de esforços mecânicos a materiais com propriedades piezelétricas para consequente geração de tensão, em que estes estão associados a um circuito elétrico conveniente para o aproveitamento de tal potencial. Normalmente esses circuitos contêm (mas não se restringem a) uma resistência, um retificador de tensão e um elemento para armazenamento da energia gerada (bateria ou capacitor).

Os energy harvesters também apresentam características bastante específicas dependendo da forma como o material piezelétrico é solicitado, até porque esses materiais normalmente não são isotrópicos, apresentando diferentes comportamentos para cada direção. Há dois modos de operação normalmente utilizados, cuja classificação relaciona a direção em que o material é solicitado com a posição em que os eletrodos do circuito elétrico são associados.

Para o modo denominado d33, a solicitação é aplicada normal aos planos que contêm os eletrodos, no qual o material piezelétrico é usualmente submetido a esforços compressivos. Montagens que contemplam esse modo de operação apresentam maiores coeficientes de acoplamento eletromecânico devido às próprias propriedades do material piezelétrico, além de resistir a carregamentos de maior intensidade no caso dos stacks, montagem mais comum para o modo d33. No entanto, esse tipo de montagem apresenta rigidez muito elevada, e por isso suas características dinâmicas dificilmente podem ser usadas para favorecer o gerador, dificultando soluções de natureza inercial. Como exemplos de aplicação com montagens d33 pode-se destacar a inserção de stacks em calçados para geração de energia a partir do impacto 
dos passos do usuário, ou sob trilhos de trens, onde a variação de carga devido à passagem dos vagões permite a alimentação de sensores da linha.

Já no modo de operação denominado $\mathrm{d} 31$, a solicitação encontra-se num plano paralelo ao dos eletrodos. A montagem mais comum desse modo de operação consiste na associação de filmes de material piezelétrico à superfície de estruturas submetidas a flexão. Essas estruturas normalmente são projetadas de modo que a secção transversal favoreça uma direção de trabalho, devido ao menor momento de inércia, e nesses casos são genericamente denominados cantilevers.

Uma característica muito importante dos harvesters do tipo cantilever é que sua rigidez reduzida favorece modos de operação de natureza inercial, na qual a solicitação mecânica decorre do movimento relativo entre sua fixação e um elemento inercial de referência, normalmente uma massa localizada na extremidade do cantilever. A presença de frequências naturais mais baixas facilitam o uso das características de resposta dinâmica do sistema em benefício da otimização da quantidade de energia gerada, a qual é obtida através do alinhamento da frequência de ressonância do dispositivo com a frequência de excitação à qual este é submetido. Há ainda publicações em que são trabalhadas a forma e disposição dos eletrodos para permitir a utilização do modo d33 nas vigas cantilever (duToit et al., 2005; Jeon et al., 2005), permitindo maior acoplamento eletromecânico para esse tipo de solução.

\section{Requisitos para Aplicação Comercial de Geradores Piezelétricos}

Dentro do contexto discutido anteriormente, o desenvolvimento de geradores piezelétricos de energia para aplicações comerciais deve levar em conta uma série de fatores que nem sempre são requisitos ou restrições mandatórias para pesquisas científicas, mas que certamente orientam as mesmas. Dentre esses fatores, o custo, peso, a manufaturabilidade confrontados com a eficiência do dispositivo são sem dúvida requisitos fundamentais para viabilização comercial do gerador.

Muitas das aplicações de dispositivos microeletrônicos ocorrem em ambientes sujeitos a solicitações de natureza aleatória, onde muitas vezes esta não se restringe a uma estreita banda de frequência. Aplicações em veículos terrestres são um bom exemplo desse fato, na qual o regime de trabalho contempla frequentes variações de velocidade, características de pavimento, rotação do motor, e a composição de todas essas fontes de vibração pode tornar o espectro da excitação bastante abrangente e diversificado. Dentro de 
cenários como este, geradores constituídos por cantilevers de apenas um grau de liberdade (GDL) se mostram pouco adequados, uma vez que o advento do tunning de frequências, essencial para maximizar a quantidade de energia gerada, não é mais trivial, já que não há uma frequência dominante ou conhecida para a excitação.

Para contornar esse problema, uma abordagem que vem sendo estudada recentemente consiste do uso de múltiplos graus de liberdade como forma de se aumentar a faixa de frequência em que é possível maximizar a quantidade de energia gerada através das características da resposta dinâmica do sistema. Em trabalhos que utilizam essa abordagem, como os de Kim I. et al. (2011), Tang et al. (2012) ou Xiao et al. (2015), ficam evidentes a presença de mais de uma frequência de ressonância em que, trabalhando-se as características da estrutura, é possível aproximá-las ou afastá-las de modo a ampliar a faixa de trabalho nos arredores das ressonâncias. Deve-se levar em conta, como nota-se no trabalho de Tang et al. (2012), que a presença de múltiplos graus de liberdade pode gerar regiões de anti-ressonância, e ao mesmo tempo em que favorece algumas faixas de frequências, pode prejudicar outras significativamente.

Outra abordagem, com resultados bastante promissores, mas que não será estudada neste trabalho, faz uso de não linearidades para ampliar a faixa de frequência de trabalho dos geradores. Várias das soluções propostas neste sentido usam sistemas bi ou tri-estáveis, obtidos ou pela inserção de elementos magnéticos (Lin, Alphenaar, 2010; Mann, Owens, 2010; Stanton et al., 2009, 2010) ou através de instabilidades estruturais (Cottone et al., 2012) e batentes mecânicos (Kluger et al., 2015).

Já em relação ao custo do gerador, outro aspecto relevante do uso comercial de energy harvesters piezelétricos, nota-se que em soluções do tipo cantilever o elemento piezelétrico é potencialmente o item com impacto mais significativo. Isso porque quando se compara os processos necessários tanto para a obtenção da matéria prima, como para seu processamento e montagem à estrutura do cantilever, ao dos materiais e processos utilizados para a confecção da própria estrutura, fica evidente o maior nível de complexidade e consequente custo associado.

Incorporando mais este aspecto ao cenário proposto, pode-se dizer que a otimização da quantidade de energia gerada, não apenas em função da massa do gerador, que também é um importante requisito, usado como referência na maioria dos trabalhos - como Xiao et al. (2015) e Kim et al. (2011) - mas também em função da quantidade de material piezelétrico utilizado no gerador é de grande importância para sua viabilização comercial. Em muitos dos 
trabalhos citados anteriormente, como o de Xiao (2015), o aumento na quantidade de energia gerada através dos múltiplos graus de liberdade também está associado ao aumento da quantidade de material piezelétrico inerente ao modelo proposto. Nestes casos, se as eficiências fossem calculadas não somente em função da relação entre energia gerada por energia mecânica disponível, ou por massa do gerador, mas sim pela quantidade de material piezelétrico utilizado, notar-se-ia uma queda significativa nos ganhos obtidos.

\subsection{Objetivos}

O objetivo fundamental deste trabalho é contribuir com o desenvolvimento de geradores de energia piezelétricos para aplicações de baixo consumo de potência através da complementação dos estudos do uso de múltiplos graus de liberdade para maximização da faixa de operação dos geradores, bem como de sua eficiência. Usando como direcionamento requisitos e características correlatas a viabilização comercial de energy harvesters do tipo cantilever com múltiplos graus de liberdade, este trabalho, em adição aos demais estudos consultados, busca fornecer dados relevantes quanto à eficiência de tal abordagem em função da quantidade de material piezelétrico utilizado na solução, sem desprezar a massa total do gerador, bem como características de rigidez e amortecimento condizentes com soluções manufaturáveis para tal propósito.

Para alcançar tais objetivos, foram utilizadas simulações numéricas em MATLAB com modelos de parâmetros concentrados contendo 2 e 3 graus de liberdade, nas quais a partir da solução proposta e estudada na publicação de Xiao et al. (2015) buscou-se a maximização da quantidade de energia gerada em função da quantidade de material piezelétrico no dispositivo, através da eliminação parcial ou completa dos elementos de menor contribuição para a energia total gerada, bem como com o aumento da quantidade de material onde houve maximização da razão avaliada.

Além disso, buscou-se neste trabalho estudar a utilização de cantilivers do tipo viga "L" como solução construtiva para energy harvesters de múltiplos graus de liberdade, na qual o estudo do potencial de geração de energia em função das características da estrutura, bem como da disposição e quantidade de material piezelétrico devem fornecer subsídios quanto ao potencial de utilização de tal solução nas mais variadas aplicações, bem como referências para otimização de geradores de natureza similar. O estudo da viga "L" foi realizado através de um modelo de parâmetros distribuídos, baseado na viga de Euler-Bernoulli, através de simulações 
em MATLAB. Para validação do modelo utilizado foram realizados ensaios em laboratório usando um Shaker unidirecional para se excitar um protótipo do gerador do tipo viga "L" e assim confrontar as respostas medidas com as do modelo teórico.

\subsection{Organização da Dissertação}

O trabalho desenvolvido foi dividido em cinco capítulos, com conteúdos conforme descrito abaixo:

Capítulo 1 - Introdução ao tema desenvolvido, com apresentação das considerações preliminares, a qual contempla breve contextualização, com motivadores e síntese do estado da técnica, descrição dos objetivos, revisão bibliográfica, além da organização do conteúdo da dissertação.

Capítulo 2 - Descrição dos modelos analíticos desenvolvidos no trabalho, iniciandose pelo modelo de parâmetros concentrados, com equacionamento generalizado para nGDL, seguido do modelo de parâmetros distribuídos relativo à viga "L".

Capítulo 3 - Apresentação dos resultados simulados, primeiramente para o modelo de parâmetros concentrados usando geradores de 2 e 3 GDL como base para os estudos de sensibilidade e discussão dos resultados. Em seguida, são apresentados os resultados relativos ao modelo de parâmetros distribuídos da viga "L", contendo também estudos de sensibilidade quanto às características construtivas e posicionamento dos elementos piezelétricos. Ao final do capítulo os resultados obtidos em ambos os modelos são sumarizados e discutidos.

Capitulo 4 - Ensaios experimentais realizados em laboratório, com descrição detalhada do equipamento, dos corpos de prova procedimentos e resultados obtidos, além do confronto desses resultados com os previstos através dos modelos analíticos.

Capítulo 5 - Conclusões e disposições relevantes para trabalhos futuros. 


\subsection{Revisão Bibliográfica}

Os trabalhos de Umeda (Umeda et al., 1996) e Williams (Williams, Yates, 1996) foram pioneiros no uso de vibrações estruturais para geração de energia, em que o trabalho de Umeda se destaca pelo pioneirismo também no uso do efeito piezelétrico para conversão da energia de vibração em energia elétrica. Em seu estudo, Umeda faz uso de uma esfera metálica em queda livre para geração de energia a partir de seu impacto contra a estrutura que contém o material piezelétrico. Outros trabalhos pioneiros foram revisados por Sodano (Sodano et al., 2003), nos quais grande parte das aplicações fazem uso de stacks, pilhas de material piezelétrico solicitados no modo $d_{33}$. Nota-se nesses estudos a pequena atenção dada às características dinâmicas dos geradores, condição essa que impacta negativamente nos resultados obtidos. Em seu trabalho, Sodano (2003) testa algumas condições de excitação para dois materiais piezelétricos diferentes, apresentando as quantidades de energia geradas na forma de tempos para a recarga de baterias de referência.

Usando a viga cantilever, Baker et al. (2005) apresentam um estudo em que a geometria da viga é otimizada para uma melhor distribuição de deformações, o qual também foi desenvolvido de maneira similar por Goldschmidtboeing (2008). Os resultados obtidos evidenciam que à medida que se estreita a extremidade da viga a distribuição de deformações fica mais uniforme, nos quais uma estrutura praticamente triangular apresenta melhores resultados. Através de ensaios experimentais o Baker obtém $30 \%$ mais potência para uma viga trapezoidal em relação à retangular, resultados condizentes com os obtidos por Goldschmidtboeing. Ainda no trabalho de Baker é discutido o uso de uma condição biestável, através da compressão da viga entre dois apoios, como forma de se aumentar a faixa de frequência útil do gerador, além de uma breve discussão a respeito do modo de solicitação, já que o modo d31, apesar de ser mais utilizado em soluções de viga cantilever, apresenta menor coeficiente de acoplamento do que o modo d33.

duToit et al. (2005) apresentaram um extenso trabalho sobre o projeto de geradores piezelétricos usando vigas cantilever. $\mathrm{O}$ autor desenvolve e compara modelos simplificados de parâmetros concentrados com apenas um grau de liberdade a modelos mais completos usando parâmetros distribuídos, comentando e discutindo efeitos de cancelamento ocorrido em alguns modos de vibrar. $\mathrm{O}$ autor discute também soluções para utilizar tanto o modo d31 como o d33 para geração de energia usando a viga cantilever.

Jeon et al. (2005) também estudam a viga cantilever, mas com maior foco em resultados experimentais. $O$ autor faz uso de uma viga com massa concentrada na 
extremidade, cuja montagem dos eletrodos faz uso do modo d33 para geração de energia. $\mathrm{O}$ autor faz uma breve explicação justificando o uso do modo d33 em relação ao modo d31 por apresentar vantagens quanto à fabricação além de um potencial 20 vezes maior para geração de energia.

Anton et al. (2007) apresentaram uma revisão com amplo conteúdo na área de piezoelectric energy harvesting. Mesmo tendo sido publicada há vários anos, algumas das questões abordadas ainda são temas de discussão em estudos mais recentes, apresentados por Kim H. et al. (2011) e Li et al. (2014). Um desses temas refere-se à sintonia da frequência natural do gerador com as frequências da excitação, problema crítico no projeto de geradores inerciais, uma vez que sua eficiência operacional está diretamente relacionada à proximidade dessas frequências. Relativos a essa questão, são abordados estudos que visam aumentar a faixa de utilização do gerador, conferindo a ele alguma forma de adaptabilidade para casos em que a frequência da fonte de excitação sofre variações com o tempo (Roundy et al., 2004; Ibrahim et al., 2012).

Erturk realizou um estudo evidenciando erros cometidos em publicações de piezoelectric energy harvesting, bem como quantificando o erro associado aos resultados de algumas das aproximações mais comuns. Dentre os artigos citados está o de Lu et al. (2004), no qual os autores estudam o uso da viga cantilever para geração de energia para microeletrônicos. No entanto, o modelo desenvolvido na publicação para o cálculo da potência negligência os efeitos de ressonância do gerador, exibindo resultados bastante equivocados. Usando da viga de Euler-Bernoulli, Erturk também apresentou modelos de maior representatividade, com respectiva validação experimental, nesse e em outros trabalhos (Erturk et al., 2009; Erturk, Inman, 2008a, 2008b, 2008c, 2009) .

Ao longo das publicações em piezoelectric energy harvesting alguns padrões foram criados e amplamente estudados, como a viga cantilever com e sem massa concentrada na extremidade, bem como o padrão de associação do material piezelétrico à estrutura, comumente chamada de substrato ou subestrutura, em que o recobrimento de apenas uma superfície recebe o nome de unimorph, e o de ambas bimorph.

Em todos esses estudos, consideradas as devidas aproximações, ficou evidente a interdependência entre o alinhamento das frequências de excitação e natural do sistema, e a eficiência de geração de energia. Consequentemente, também ficou clara a limitação do gerador de apenas um GDL, já que este pode ser otimizado apenas para uma estreita faixa de operação. 
Buscando o aumento da faixa de frequência útil dos energy harvesters, diferentes abordagens passaram a ser adotadas. Dentre elas é possível destacar a introdução de efeitos restauradores não-lineares com o auxílio de elementos magnéticos (Stanton et al., 2009, 2010; Lin, Alphenaar, 2010; Mann, Owens, 2010), ou com o uso de instabilidades estruturais (Baker et al., 2005; Cottone et al., 2012), além do uso de batentes mecânicos para gerar padrões nãolineares de solicitação (Kluger et al., 2015), sempre com resultados bastante promissores em relação ao gerador de um GDL.

Outra abordagem utilizada para aumentar a faixa de trabalho do gerador foi a incorporação de múltiplos graus de liberdade ao dispositivo. Como estratégia de otimização algumas publicações evidenciaram a presença de mais de uma frequência de ressonância na qual a geração de energia poderia ser maximizada (Tang, Yang, 2012), enquanto outras buscaram aproximar duas frequências naturais distintas como forma de aumentar a máxima energia gerada, bem como as amplitudes de uma maior faixa de frequência nos arredores das ressonâncias (Kim et al., 2011).

Em seu trabalho, Kim I. et al. (2011) propõem a utilização de dois graus de liberdade com um dispositivo formado por um corpo de prova com massa, inércia e rigidez elevadas, caracterizando um corpo rígido, ligado a um cantilever distinto em cada extremidade, atribuindo ao sistema um grau de liberdade de translação e um de rotação. Através de modelos teóricos e validação experimental, os autores demonstram o aumento da faixa de frequência de trabalho, a qual pode ser observada na figura 3.

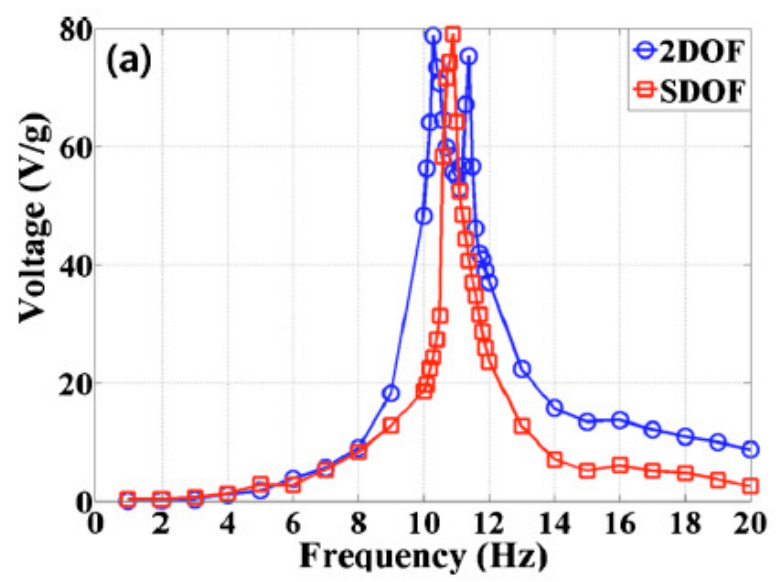

Figura 3 - Resposta em tensão do gerador de energia de dois graus de liberdade comparado com um dispositivo de um grau de liberdade de mesma massa (Kim et al. 2011).

No estudo de Tang e Yang (2012), um gerador de 1 GDL é comparado a um gerador com 2 GDL com duas configurações distintas de posicionamento do elemento piezelétrico 
através de modelos de parâmetros concentrados. No trabalho é feita uma análise de sensibilidade à relação de massas e frequências naturais para diferentes coeficientes de acoplamento eletromecânicos, em que é avaliado também o efeito do amortecimento na quantidade de energia gerada. Os resultados obtidos indicam aumento da energia gerada com pouco aumento de massa para a nomeada "Configuração A" do gerador de 2 GDL em relação ao gerador de $1 \mathrm{GDL}$, na qual o elemento piezelétrico é disposto entre a base e a primeira massa. Curiosamente, o autor não avalia um exemplo da dita "Configuração B" utilizando os mesmos dados, com o elemento piezelétrico disposto entre a primeira e a segunda massa. Mais adiante o autor relata que para a "Configuração B" é necessário aumentar consideravelmente a massa do gerador para que este apresente resultados razoáveis, comprometendo a relação de energia gerada por massa do gerador, mesmo em relação aos modelos de 1GDL.

Ainda neste estudo, a solução da "Configuração A" é generalizada para múltiplos GDL através da vinculação de sistemas massa mola parasitas ligados à massa principal, continuando com apenas um elemento piezelétrico disposto entre a base e a primeira massa.

Explorando outras soluções para a viga cantilever, Wu (Wu et al., 2013) propuseram uma abordagem de dois graus de liberdade com packaging bastante otimizado em relação a outras soluções. Fazendo basicamente a montagem de dois cantilevers em série, ambos com material piezelétrico e em uma disposição que favorece o aproveitamento de espaço, os autores apresentam resultados promissores para diversas combinações de massa e frequências através do modelo teórico desenvolvido, o qual é validado experimentalmente com um estudo de caso (\#Figura 4). No ano seguinte, os autores publicaram um estudo da associação de imãs permanentes à solução, atribuindo ao dispositivo de dois graus de liberdade uma condição de não linearidade biestável a partir do efeito magnético. Através dessa associação é verificado um aumento ainda mais acentuado da largura da faixa de frequência de trabalho em relação àquela obtida anteriormente (Wu et al., 2014). 


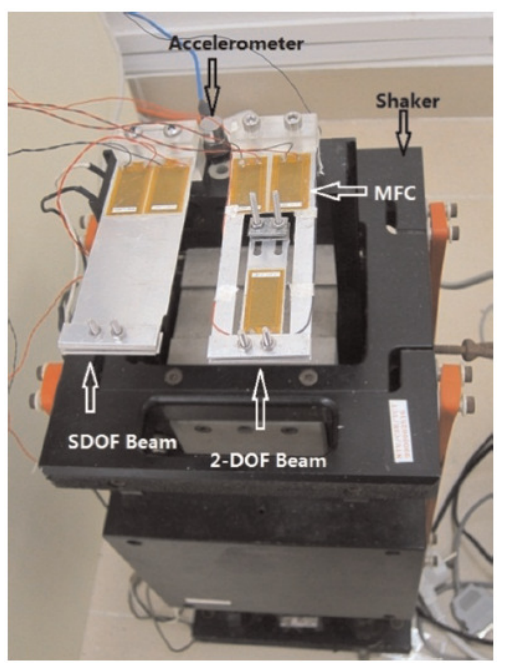

Figura 4 - Montagem utilizada na validação experimental do modelo matemático desenvolvido por Wu et al. (2013).

Estudos com outros conceitos de harvesters com múltiplos graus de liberdade foram apresentadas nos trabalhos de Sadeqi (Sadeqi et al., 2014) e Wang (Wang et al., 2014). No primeiro caso, os autores propõem uma solução com dois graus de liberdade para aplicação em rodas de veículos terrestres, na qual dois sistemas massa mola são interligados por uma viga cantilever contendo o material piezelétrico. $\mathrm{O}$ estudo utiliza como entrada apenas o movimento de rotação constante da roda, hipótese simplificadora discutida brevemente no trabalho, e os resultados apresentados vão ao encontro da proposta de aumento da faixa de frequência de trabalho. No caso do trabalho desenvolvido por Wang et al. (2014), são estudados conceitos híbridos com dois graus de liberdade, nos quais é associado a cada grau de liberdade um tipo de acoplamento eletromecânico diferente, sendo estes o efeito piezelétrico e o eletromagnético. Os autores promovem o aumento da faixa de frequência com sucesso, e demonstram que o aumento dos coeficientes de acoplamento eletromecânico de cada transdutor têm efeitos concorrentes, em que o aumento da eficiência de um, impacta na redução da energia gerada pelo outro, devido aos efeitos do amortecimento elétrico associado ao sistema.

Ainda fazendo o uso dos múltiplos graus de liberdade, Xiao et al. (2015) publicaram um estudo utilizando modelos de parâmetros concentrados no qual é proposta uma configuração com as massas ligadas em série contendo sempre um elemento piezelétrico entre elas. O estudo é primeiramente desenvolvido e validado experimentalmente para 2GDL, em que são feitos estudos de sensibilidade em relação às relações de massa, frequências naturais, fatores de amortecimento, fatores de força e resistências do circuito elétrico. Os autores usam um exemplo partindo dos mesmos dados utilizados por Tang e Yang (2012), e destacam um 
aumento de quase 10 vezes no pico de potência gerada para a nova configuração. Como os autores avaliam a energia total gerada em função da massa do gerador, e calculam a eficiência do gerador usando como referência a potência elétrica gerada em relação à potência mecânica disponível, os resultados obtidos se mostram bastante superiores aos da publicação citada. Nota-se que o para o elemento piezelétrico adicional foram adotadas as mesmas propriedades do original, caracterizando o dobro de material piezelétrico, mas indicando que o resultado obtido não decorre da otimização do elemento piezelétrico e seu circuito associado, mas sim da configuração do gerador. Ao se avaliar os resultados exibidos, pode-se notar que a maior contribuição da potência total é dada pelo segundo elemento piezelétrico, configuração essa que chegou a ser comentada pejorativamente no artigo de Tang e Yang (2012) e sequer chegou a ser simulada para as mesmas entradas. Ao final, faz um estudo de sensibilidade aumentando-se o número GDL e mantendo-se a massa constante, concluindo-se que tal configuração de gerador aumenta significativamente a quantidade de energia gerada por massa do gerador à medida que se aumenta o número de graus de liberdade. Além disso, o uso de múltiplos GDL se mostra como solução para se diminuir a primeira frequência natural do sistema sem o aumento da massa do gerador. 


\section{Modelos Analíticos}

\subsection{Modelo de Parâmetros Concentrados}

O modelo de parâmetros concentrados do gerador piezelétrico de múltiplos graus de liberdade (nGDL) pode ser idealizado conforme os esquemas da figura 5, no qual há um conjunto de massas, entre as quais define-se uma rigidez, um amortecimento, e eventualmente um elemento piezelétrico ligado a um circuito elétrico independente. Ao contrário das publicações de Tang e Yang (2012), em que havia apenas um elemento piezelétrico entre a primeira massa e a base, ou de Xiao et. Al. (2015), no qual entre cada massa foi disposto um elemento piezelétrico, no modelo proposto o posicionamento dos elementos piezelétricos pode ser feito entre cada massa, ou apenas nos graus de liberdade mais convenientes.

a)

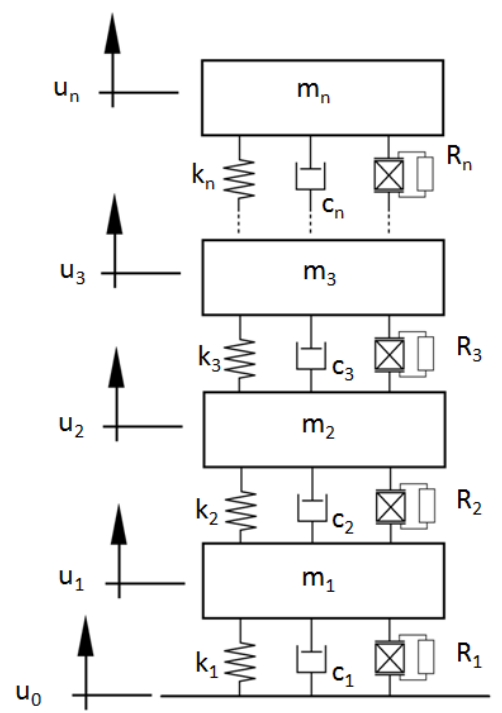

b)

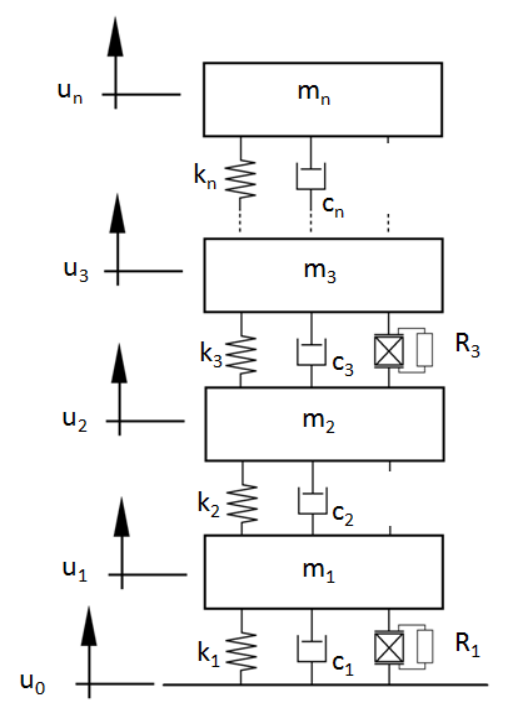

Figura 5 - Esquema dos modelos de nGDL (a) desenvolvido por Xiao et al. (2015) e (b) proposto neste estudo.

\section{Representação do Efeito Piezelétrico}

Seguindo o mesmo padrão de várias publicações em piezoelectric energy harvesting, a representação do elemento piezelétrico no modelo de parâmetros concentrados foi realizada através de um fator de força $\alpha$ e uma capacitância $C_{p}$, de modo a simplificar os estudos de sensibilidade, conforme as equações (1) e (2). 


$$
\begin{gathered}
F_{\text {piezo } n}=-\alpha_{n} \cdot V_{n} \\
\frac{V_{n}}{R_{n}}=\alpha_{n} \cdot\left(\dot{u}_{n}-\dot{u}_{n-1}\right)-C_{p c n} \cdot \dot{V}_{n}
\end{gathered}
$$

Em que $F_{\text {piezo }}$ é a força aplicada pelo elemento piezelétrico aos vínculos, $R$ a resistência do circuito elétrico, $V$ a tensão (voltage) no circuito, $u$ o deslocamento das massas, e o índice $n$ indica o n-ésimo elemento piezelétrico do sistema e seu circuito associado.

Como o foco do trabalho está em geradores do tipo viga cantilever, o cálculo de tais propriedades pode ser demonstrado usando o modelo apresentado por Erturk, Inman (2008a), supondo um energy harvester dessa natureza conforme a figura 6 , no qual se pode calcular o momento $M_{f}(x, t)$ do conjunto através da equação (3).

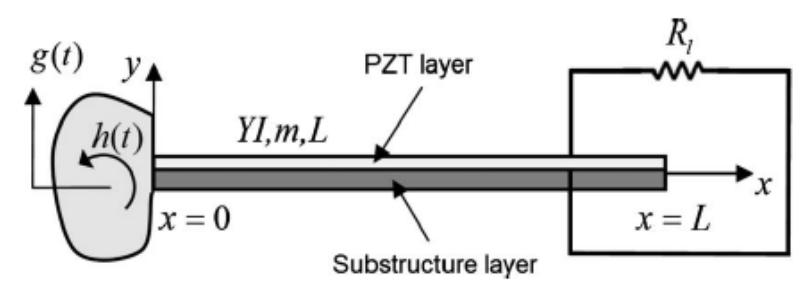

Figura 6 - Esquemático da viga cantilever usada por Erturk, Inman (2008a).

$$
M_{f}(x, t)=-\int_{h_{a}}^{h_{b}} T_{1}^{s} b y d y-\int_{h_{a}}^{h_{b}} T_{1}^{p} b y d y
$$

Em que $b$ é a largura da estrutura, $T$ é a tensão (stress) no componente, cujos índices p e s indicam o elemento piezelétrico e a estrutura respectivamente, $h_{a}, h_{b}$ e $h_{c}$ são as distâncias em relação à linha neutra da extremidade inferior da estrutura, da extremidade superior da estrutura (inferior do elemento piezelétrico), e da extremidade superior do elemento piezelétrico, respectivamente.

Fazendo o desenvolvimento do termo relativo ao elemento piezelétrico obtém-se:

$$
M_{f}^{p}(x, t)=-\int_{h_{a}}^{h_{b}} V(t) Y_{p} b \frac{d_{31}}{h_{p}} y d y
$$


A partir de suas propriedades constitutivas dadas por:

$$
S_{1}=s_{11}^{E} T_{1}+d_{31} E_{3}
$$

As quais podem ser rearranjadas como:

$$
T_{1}^{p}=Y_{p}\left(S_{1}^{p}+d_{31} E_{3}\right)
$$

Com

$$
E_{3}(t)=-\frac{V(t)}{h_{p}}
$$

$\mathrm{Na}$ qual $S_{1}$ indica a deformação (strain) na direção x, $s_{11}^{E}$ é o elastic compliance sob um campo elétrico constante $E$ e $Y_{p}$ o seu recíproco, $E_{3}$ é o campo elétrico na direção y, $d_{31}$ é a constante piezelétrica, $V(t)$ é a tensão (voltage) nos eletrodos e $h_{p}$ é a espessura do elemento piezelétrico.

Desenvolvendo a equação (3) para o caso em que o elemento piezelétrico recobre toda a viga obtém-se:

$$
M_{f}^{p}(x, t)=\left(-\frac{Y_{p} b d_{31}}{2 h_{p}}\left(h_{c}^{2}-h_{b}^{2}\right)\right) V(t)
$$

No caso em que a viga é parcialmente recoberta basta multiplicar o resultado acima por uma função ponderadora, conforme desenvolvido no artigo de referência.

De maneira análoga à equação (1), a equação (8) indica o esforço mecânico realizado pelo elemento piezelétrico quando submetido a uma tensão elétrica (voltage). Analisando-se o termo da equação que multiplica $V(t)$, o qual é representado pelo fator de força no modelo de parâmetros concentrados, pode-se notar sua dependência das propriedades do elemento piezelétrico $\left(Y_{p}\right.$ e $\left.d_{31}\right)$ e de sua geometria construtiva $\left(b, h_{p}, h_{b}\right.$ e $\left.h_{c}\right)$.

Da mesma maneira, Erturk (Erturk, Inman, 2008 ${ }^{a}$ ) desenvolve a equação do circuito elétrico com acoplamento mecânico a partir da propriedade constitutiva dada pela equação (9), chegando à equação (10), convenientemente rearranjada de modo a facilitar sua comparação à equação (2). 


$$
\begin{gathered}
D_{3}=\varepsilon_{33}^{T} E_{3}+d_{31} T_{1} \\
\frac{v(t)}{R_{l}}=-\left[\int_{x=0}^{L} d_{31} Y_{p} h_{p c} b \frac{\partial^{3} w_{r e l}(x, t)}{\partial x^{2} \partial t} d x+\frac{\varepsilon_{33}^{S} b L}{h_{p}} \frac{d V(t)}{d t}\right]
\end{gathered}
$$

Em que $\varepsilon_{33}^{T}$ é a permissividade dielétrica à tensão (stress) constante, $\varepsilon_{33}^{S}$ é permissividade dielétrica à deformação (strain) constante, $D_{3}$ é o deslocamento elétrico, $w_{r e l}$ é a deflexão transversal da viga em relação à base e $R_{l}$ a resistência associada ao circuito elétrico.

Comparando-se a equação (10) á equação (2), nota-se que para o modelo da viga cantilever analisado, a capacitância $C_{p c}$ do elemento piezelétrico é dada pelo termo $\left(\varepsilon_{33}^{s} b L\right)$ / $h_{p}$, no qual $\varepsilon_{33}^{S}$ é propriedade do material utilizado, e os demais termos relativos a solução construtiva (geometria).

\section{Equacionamento do Sistema de nGDL}

As equações que definem o equilíbrio de forças para o sistema do energy harvester de nGDL da figura 5, são:

$$
\left\{\begin{array}{c}
m_{1} \cdot \ddot{u}_{1}=-k_{1} \cdot\left(u_{1}-u_{0}\right)-c_{1} \cdot\left(\dot{u}_{1}-\dot{u}_{0}\right)-\alpha_{1} \cdot V_{1} \\
+k_{2} \cdot\left(u_{2}-u_{1}\right)+c_{2} \cdot\left(\dot{u}_{2}-\dot{u}_{1}\right)+\alpha_{2} \cdot V_{2} \\
m_{2} \cdot \ddot{u}_{2}=-k_{2} \cdot\left(u_{2}-u_{1}\right)-c_{2} \cdot\left(\dot{u}_{2}-\dot{u}_{1}\right)-\alpha_{2} \cdot V_{2} \\
+k_{3} \cdot\left(u_{3}-u_{2}\right)+c_{3} \cdot\left(\dot{u}_{3}-\dot{u}_{2}\right)+\alpha_{3} \cdot V_{3} \\
\vdots \\
m_{n-1} \cdot \ddot{u}_{n-1}=-k_{n-1} \cdot\left(u_{n-1}-u_{n-2}\right)-c_{n-1} \cdot\left(\dot{u}_{n-1}-\dot{u}_{n-2}\right)-\alpha_{n-1} \cdot V_{n-1} \\
+k_{n} \cdot\left(u_{n}-u_{n-1}\right)-c_{n} \cdot\left(\dot{u}_{n}-\dot{u}_{n-1}\right)+\alpha_{n} \cdot V_{n} \\
m_{n} \cdot \ddot{u}_{n}=-k_{n} \cdot\left(u_{n}-u_{n-1}\right)-c_{n} \cdot\left(\dot{u}_{n}-\dot{u}_{n-1}\right)-\alpha_{n} \cdot V_{n}
\end{array}\right.
$$

Já as equações que definem o circuito elétrico com acoplamento mecânico são definidas por: 


$$
\left\{\begin{array}{c}
\frac{V_{1}}{R_{1}}=\alpha_{1} \cdot\left(\dot{u}_{1}-\dot{u}_{0}\right)-C_{p c 1} \cdot \dot{V}_{1} \\
\frac{V_{2}}{R_{2}}=\alpha_{2} \cdot\left(\dot{u}_{2}-\dot{u}_{1}\right)-C_{p c 2} \cdot \dot{V}_{2} \\
\vdots \\
\frac{V_{n}}{R_{n}}=\alpha_{n} \cdot\left(\dot{u}_{n}-\dot{u}_{n-1}\right)-C_{p c n} \cdot \dot{V}_{n}
\end{array}\right.
$$

Aplicando-se a transformada de Laplace, obtém-se:

$$
\left\{\begin{array}{c}
m_{1} \cdot s^{2} U_{1}=-k_{1} \cdot\left(U_{1}-U_{0}\right)-c_{1} \cdot\left(s \cdot U_{1}-s \cdot U_{0}\right)-\alpha_{1} \cdot \mathbb{V}_{1} \\
+k_{2} \cdot\left(U_{2}-U_{1}\right)+c_{2} \cdot\left(s \cdot U_{2}-s \cdot U_{1}\right)+\alpha_{2} \cdot V_{2} \\
m_{2} \cdot s^{2} u_{2}=-k_{2} \cdot\left(U_{2}-U_{1}\right)-c_{2} \cdot\left(s \cdot U_{2}-s \cdot U_{1}\right)-\alpha_{2} \cdot \mathbb{V}_{2} \\
+k_{3} \cdot\left(U_{3}-U_{2}\right)+c_{3} \cdot\left(s \cdot U_{3}-s \cdot U_{2}\right)+\alpha_{2} \cdot V_{2} \\
\vdots \\
\\
m_{n-1} \cdot s^{2} U_{n-1}=-k_{n-1} \cdot\left(U_{n-1}-U_{n-2}\right)-c_{n-1} \cdot\left(s \cdot U_{n-1}-s \cdot U_{n-2}\right)-\alpha_{n-1} \cdot \mathbb{V}_{n-1} \\
+k_{n \cdot}\left(U_{n}-U_{n-1}\right)+c_{n} \cdot\left(s \cdot U_{n}-s \cdot U_{n-1}\right)+\alpha_{n} \cdot \mathbb{V}_{n} \\
m_{n} \cdot s^{2} U_{n}=-k_{n} \cdot\left(U_{n}-U_{n-1}\right)-c_{n} \cdot\left(s \cdot U_{n}-s \cdot U_{n-1}\right)-\alpha_{n} \cdot \mathbb{V}_{n}
\end{array}\right.
$$

$$
\left\{\begin{array}{c}
\frac{V_{1}}{R_{1}}=\alpha_{1} \cdot\left(s . U_{1}-s . U_{0}\right)-C_{p c 1} . s . \mathbb{V}_{1} \\
\frac{V_{2}}{R_{2}}=\alpha_{2} \cdot\left(s . U_{2}-s . U_{1}\right)-C_{p c 2} . s . \mathbb{V}_{2} \\
\quad \vdots \\
\frac{V_{n}}{R_{n}}=\alpha_{n} .\left(s . U_{n}-s . U_{n-1}\right)-C_{p c n} . s . \mathbb{V}_{n}
\end{array}\right.
$$

Rearranjando as equações:

$$
\left\{\begin{array}{c}
\left(m_{1} \cdot s^{2}+k_{1}+c_{1} \cdot s+k_{2}+c_{2} \cdot s\right) \cdot U_{1}-\left(k_{2}+c_{2} \cdot s\right) \cdot U_{2} \\
+\alpha_{1} \cdot V_{1}-\alpha_{2} \cdot \mathbb{V}_{2}=\left(k_{1}+c_{1} \cdot s\right) \cdot U_{0} \\
-\left(k_{2}+c_{2} \cdot s\right) \cdot U_{1}+\left(m_{2} \cdot s^{2}+k_{2}+c_{2} \cdot s+k_{3}+c_{3} \cdot s\right) \cdot U_{2}-\left(k_{3}+c_{3} \cdot s\right) \cdot U_{3} \\
+\alpha_{2} \cdot \mathbb{V}_{2}-\alpha_{3} \cdot \mathbb{V}_{3}=0 \\
\vdots \\
-\left(k_{n-1}+c_{n-1} \cdot s\right) \cdot U_{n-2}+\left(m_{n-1} \cdot s^{2}+k_{n-1}+c_{n-1} \cdot s+k_{n}+c_{n} \cdot s\right) \cdot U_{n-1} \\
-\left(k_{n}+c_{n} \cdot s\right) \cdot U_{n}+\alpha_{n-1} \cdot \mathbb{V}_{n-1}-\alpha_{n} \cdot \mathbb{V}_{n}=0 \\
-\left(k_{n}+c_{n} \cdot s\right) \cdot U_{n-1}+\left(m_{n} \cdot s^{2}+k_{n}+c_{n} \cdot s\right) \cdot U_{n}+\alpha_{n} \cdot \mathbb{V}_{n}=0
\end{array}\right.
$$




$$
\left\{\begin{array}{c}
\alpha_{1} . s . U_{1}-\left(C_{p c 1} . s .+\frac{1}{R_{1}}\right) \mathbb{V}_{1}=\alpha_{1} \cdot s . U_{0} \\
-\alpha_{2} . s . U_{1}+\alpha_{2} . s . U_{2}-\left(C_{p c 2} . s .+\frac{1}{R_{2}}\right) \mathbb{V}_{2}=0 \\
\vdots \\
-\alpha_{n} . s . U_{n-1}+\alpha_{n} . s . U_{n}-\left(C_{p c n} . s .+\frac{1}{R_{n}}\right) \mathbb{V}_{n}=0
\end{array}\right.
$$

Fazendo $s=i \omega$ :

$$
\left\{\begin{array}{c}
\left(-m_{1} \cdot \omega^{2}+\left(c_{1}+c_{2}\right) \cdot \omega \cdot i+k_{1}+k_{2}\right) \cdot U_{1}-\left(k_{2}+c_{2} \cdot \omega \cdot i\right) \cdot U_{2} \\
+\alpha_{1} \cdot \mathbb{V}_{1}-\alpha_{2} \cdot \mathbb{V}_{2}=\left(k_{1}+c_{1} \cdot \omega \cdot i\right) \cdot U_{0} \\
-\left(k_{2}+c_{2} \cdot \omega \cdot i\right) \cdot U_{1}+\left(-m_{2} \cdot \omega^{2}+\left(c_{2}+c_{3}\right) \cdot \omega \cdot i+k_{2}+k_{3}\right) \cdot U_{2} \\
-\left(k_{3}+c_{3} \cdot \omega \cdot i\right) \cdot U_{3}+\alpha_{2} \cdot \mathbb{V}_{2}-\alpha_{3} \cdot \mathbb{V}_{3}=0 \\
\vdots \\
-\left(k_{n-1}+c_{n-1} \cdot \omega \cdot i\right) \cdot U_{n-2}+\left(-m_{n-1} \cdot \omega^{2}+\left(c_{n-1}+c_{n}\right) \cdot \omega \cdot i+k_{n-1}+k_{n}\right) \cdot U_{n-1} \\
-\left(k_{n}+c_{n} \cdot \omega \cdot i\right) \cdot U_{n}+\alpha_{n-1} \cdot \mathbb{V}_{n-1}-\alpha_{n} \cdot \mathbb{V}_{n}=0 \\
-\left(k_{n}+c_{n} \cdot \omega \cdot i\right) \cdot U_{n-1}+\left(-m_{n} \cdot \omega^{2}+k_{n}+c_{n} \cdot \omega \cdot i\right) \cdot U_{n}+\alpha_{n} \cdot \mathbb{V}_{n}=0
\end{array}\right.
$$

$$
\left\{\begin{array}{c}
\alpha_{1} \cdot \omega \cdot i \cdot U_{1}-\left(C_{p c 1} \cdot \omega \cdot i+\frac{1}{R_{1}}\right) \mathbb{V}_{1}=\alpha_{1} \cdot \omega \cdot i \cdot U_{0} \\
-\alpha_{2} \cdot \omega \cdot i \cdot U_{1}+\alpha_{2} \cdot \omega \cdot i \cdot U_{2}-\left(C_{p c 2} \cdot \omega \cdot i+\frac{1}{R_{2}}\right) \mathbb{V}_{2}=0 \\
\vdots \\
-\alpha_{n} \cdot \omega \cdot i \cdot U_{n-1}+\alpha_{n} \cdot \omega \cdot i \cdot U_{n}-\left(C_{p c n} \cdot \omega \cdot i+\frac{1}{R_{n}}\right) \mathbb{V}_{n}=0
\end{array}\right.
$$

O sistema de equações composto por (32) a (38) define o gerador de nGDL, cuja solução permite encontrar os deslocamentos e a tensão no circuito de cada oscilador em função da frequência e deslocamento de excitação. Para a obtenção das respostas de tensão em função da aceleração de excitação basta fazer:

$$
V_{n}(\ddot{u})=-\frac{V_{n}(u)}{\omega^{2}}
$$

E para o cálculo da potência gerada $\left|P_{n}(\ddot{u})\right|$ :

$$
\left|P_{n}(\ddot{u})\right|=\frac{\left|V_{n}(\ddot{u})\right|^{2}}{R_{n}}
$$




\subsection{Modelo de Parâmetros Distribuidos - Viga "L"}

O modelo de parâmetros distribuídos utilizado foi desenvolvido por Erturk et al. (2009), baseado no modelo proposto e validado por Erturk e Inman (2008a, 2009), no qual o gerador é representado por duas vigas de Euler-Bernoulli compostas e duas massas concentradas, sendo uma na extremidade da primeira viga, e outra com posição ajustável ao longo da segunda viga, excitada em sua base através de uma aceleração vertical, conforme esquemas das figuras 7 e 8 .

a)

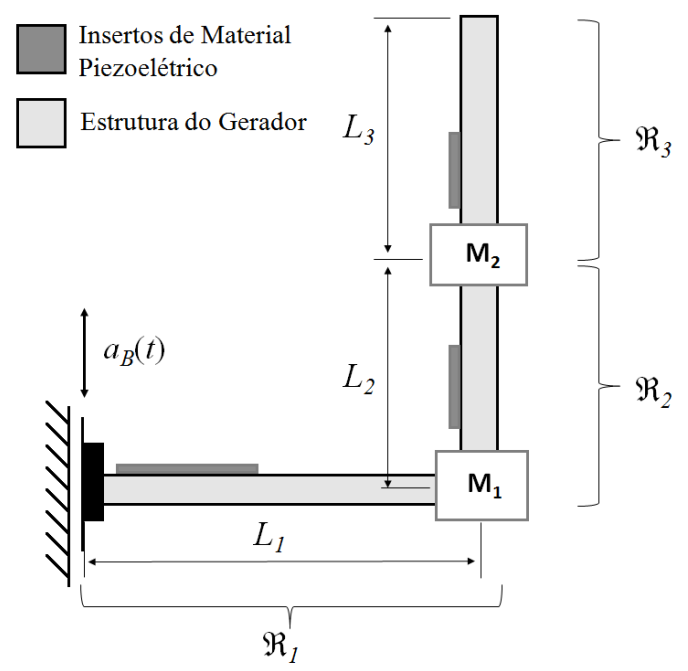

b)

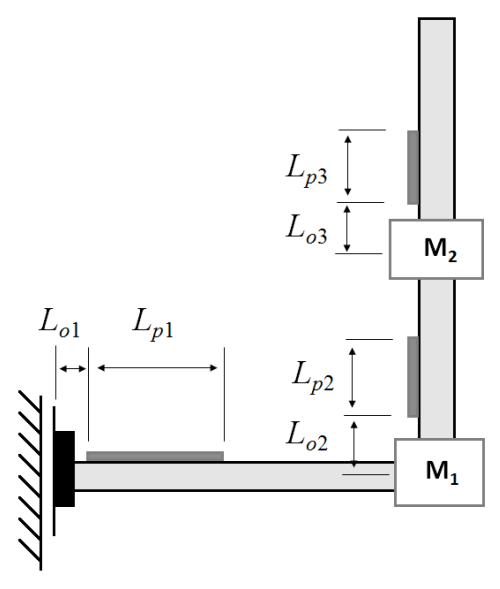

Figura 7 - Esquema geral do gerador do tipo viga "L".

Assim como na publicação de Erturk et al. (2009), a resposta do gerador foi avaliada em três regiões diferentes, $\mathfrak{R}_{1}, \mathfrak{R}_{2}$ e $\mathfrak{R}_{3}$, cada qual com seu sistema de coordenadas $\left(x_{k}, y_{k}\right)$ de modo que:

$$
\mathfrak{R}_{k}=\left\{x_{k} \mid 0 \leq x_{k} \leq L_{k}\right\} \quad k=1,2,3 .
$$

No entanto, ao invés da viga inteiramente recoberta por material piezelétrico, foram utilizados insertos com comprimentos reduzidos, em que $L_{0_{k}}$ corresponde à posição $x_{k}$ onde se inicia o recobrimento e $L_{p_{k}}$ indica o comprimento do inserto piezelétrico utilizado.

Foram utilizadas também outras montagens contemplando dois e três insertos, distribuídos conforme os esquemas da figura 9, em que na primeira configuração são dispostos um inserto por segmento, enquanto na segunda utiliza-se 1 para a região $\mathfrak{R}_{1}$ e dois para $\mathfrak{R}_{2}$, usando nesta última uma montagem bimorph. Na terceira configuração avalia-se 
uma montagem com apenas dois elementos piezelétricos, configurando uma montagem bimorph para a região $\mathfrak{R}_{2}$.

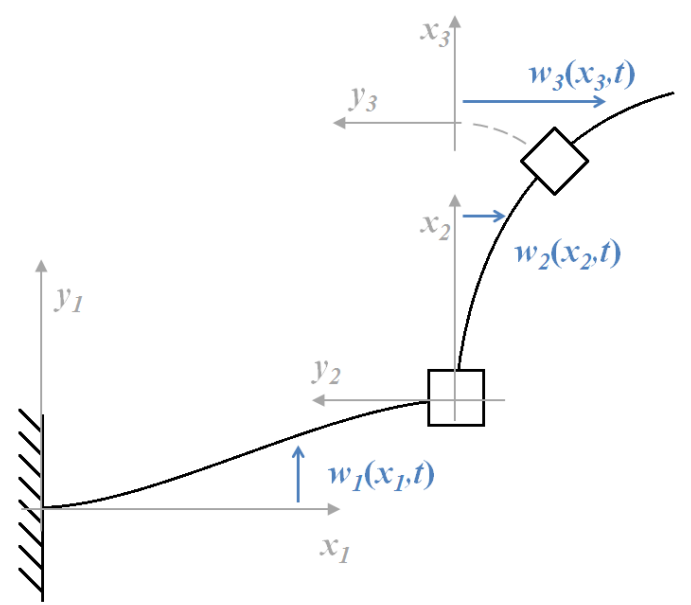

Figura 8 - Disposição dos sistemas de coordenadas e variáveis de posição para as três regiões do gerador do tipo viga " $L "$.

As camadas de material piezelétrico são polarizadas na direção da espessura, recobertas por pares de eletrodos condutores separados, e estão sujeitas a solicitações na direção longitudinal, devido às deformações advindas da flexão da viga. Esses eletrodos estão ligados em série a um circuito elétrico contendo uma única resistência $R_{l}$, conforme os esquemas das figuras 10 e 11, correspondentes a cada montagem.

Assumiu-se ainda que o substrato e o inserto são geometricamente uniformes ao longo da direção longitudinal, utilizando-se o produto $Y I_{k}$ relativo à secção da viga com o inserto piezelétrico para todo o comprimento de cada região. Tal aproximação é admissível nos casos em que a ordem de grandeza dos módulos de elasticidade e momentos de inércia da viga são muito superiores aos dos insertos piezelétricos, como é o caso do estudo desenvolvido. Para levar em conta a descontinuidade de propriedades geométricas pode-se dividir o gerador em mais regiões, em que estas sejam constantes, com a inclusão das condições de contorno adequadas no equacionamento do sistema. 
a)

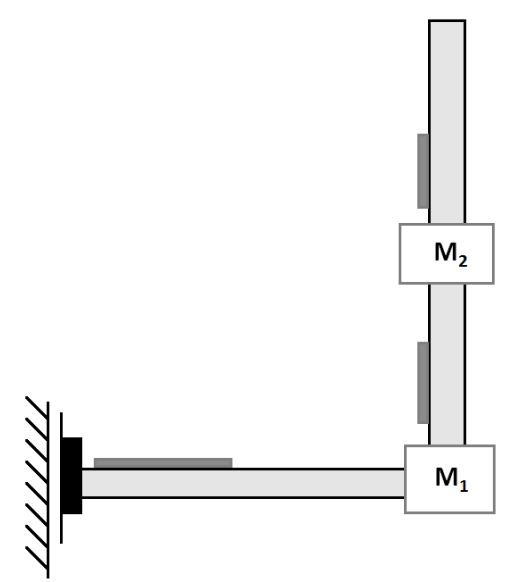

c)

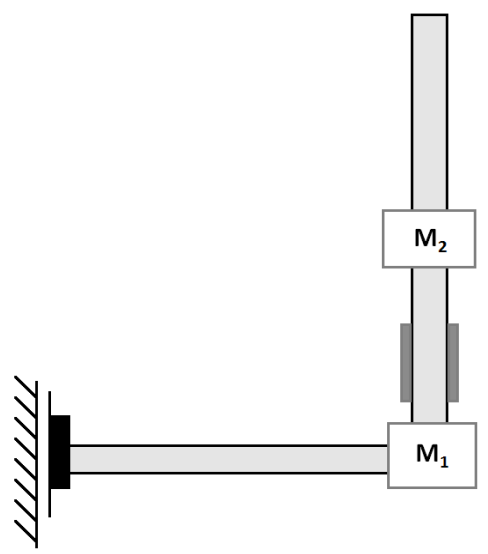

b)

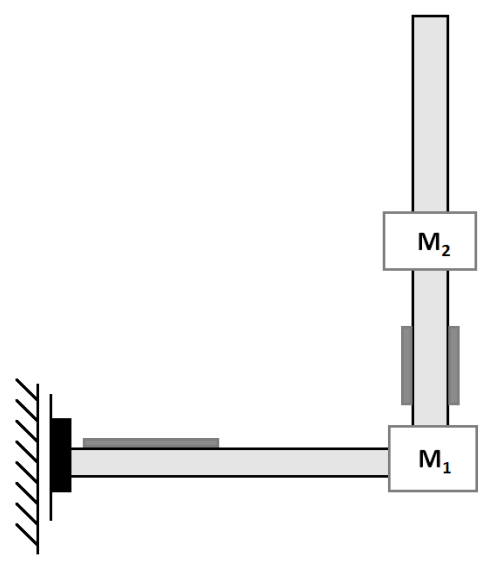

Insertos de Material

Piezoelétrico

Estrutura do Gerador

Figura 9 - Configurações de montagem estudadas para o gerador do tipo viga " $L$ ".

Para o desenvolvimento do modelo também foram assumidas: (i) hipóteses da viga de Euler-Bernoulli; (ii) O substrato e o inserto piezelétrico são perfeitamente colados um ao outro; (iii) Viga axialmente rígida, desprezando-se as vibrações longitudinais; (iv) Pequenos deslocamentos; (v) Material isotrópico, linear elástico e homogêneo para a viga e a piezocerâmica, exceto no caso das propriedades piezelétricas, caracterizadas de maneira ortotrópica; 


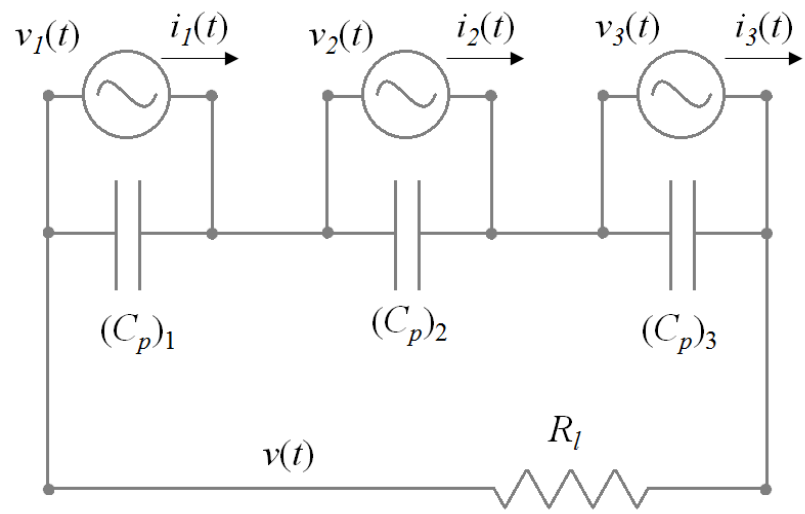

Figura 10 - Circuito elétrico dos geradores com três insertos piezelétricos.

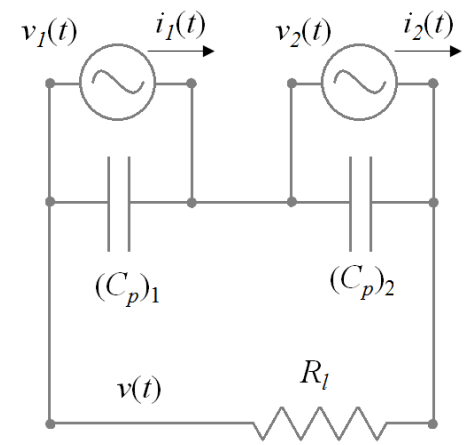

Figura 11 - Circuito elétrico do gerador com dois insertos piezelétricos.

Para a estrutura, as equações que definem as vibrações transversais livres não amortecidas podem ser escritas como:

$$
\begin{gathered}
\frac{\partial^{2}\left(M_{f}\right)_{k}\left(x_{k}, t\right)}{\partial x_{k}^{2}}+\left(m_{l}\right)_{k} \frac{\partial^{2} w_{k}\left(x_{k}, t\right)}{\partial t^{2}}+\delta_{2 k} M_{2} g \frac{\partial^{2} w_{k}\left(x_{k}, t\right)}{\partial x_{k}^{2}}=0, x_{k} \in \Re_{k} \\
\left(m_{l}\right)_{k}=b_{k}\left[\left(\rho_{s}\right)_{k}\left(h_{s}\right)_{k}+\left(\rho_{p}\right)_{k}\left(h_{p}\right)_{k}\right]
\end{gathered}
$$

Na qual:

$\left(m_{l}\right)_{k}=$ Massa por unidade de comprimento;

$b_{k}=$ largura do segmento $\Re_{k}$;

$\left(\rho_{s}\right)_{k}=$ densidade da estrutura do segmento $\mathfrak{R}_{k}$;

$\left(h_{s}\right)_{k}=$ espessura da estrutura do segmento $\mathfrak{R}_{k}$;

$\left(\rho_{p}\right)_{k}=$ densidade do inserto piezelétrico do segmento $\mathfrak{R}_{k}$;

$\left(h_{p}\right)_{k}=$ espessura do inserto piezelétrico do segmento $\mathfrak{R}_{k}$; 
$\left(M_{f}\right)_{k}\left(x_{k}, t\right)=$ Momento fletor;

$w_{k}\left(x_{k}, t\right)=$ Deslocamento transversal do segmento $\mathfrak{R}_{k} ;$

$M_{2}=$ Segunda massa concentrada;

$g=$ Aceleração da gravidade;

$\delta_{r k}=$ Delta de Kronecker (1 para r=s e 0 para $\left.\mathrm{r} \neq \mathrm{s}\right)$;

As condições de contorno para a extremidade engastada $\left(x_{1}=0\right)$ são dadas por:

$$
\begin{gathered}
w_{1}(0, t)=0 \\
\left.\frac{\partial w_{1}\left(x_{1}, t\right)}{\partial x_{1}}\right|_{x_{1}=0}=0
\end{gathered}
$$

As relações de deslocamento linear e angular e as equações que definem o equilíbrio de forças e momentos nas interfaces dos segmentos $\mathfrak{R}_{1}, \mathfrak{R}_{2}$ e $\mathfrak{R}_{3}$ podem ser escritas como:

$$
\begin{gathered}
w_{2}(0, t)=0 \\
\left.\frac{\partial w_{1}\left(x_{1}, t\right)}{\partial x_{1}}\right|_{x_{1}=L_{1}}=\left.\frac{\partial w_{2}\left(x_{2}, t\right)}{\partial x_{2}}\right|_{x_{2}=0} \\
\left.Y I_{1} \frac{\partial^{3} w_{1}\left(x_{1}, t\right)}{\partial x_{1}^{3}}\right|_{x_{1}=L_{1}}=\left.\left(M_{1}+M_{2}+\left(m_{l}\right)_{2} L_{2}+\left(m_{l}\right)_{3} L_{3}\right) \frac{\partial^{2} w_{1}\left(x_{1}, t\right)}{\partial t^{2}}\right|_{x_{1}=L_{1}} \\
\left.Y I_{1} \frac{\partial^{2} w_{1}\left(x_{1}, t\right)}{\partial x_{1}^{2}}\right|_{x_{1}=L_{1}}+\left.J_{1} \frac{\partial^{3} w_{1}\left(x_{1}, t\right)}{\partial t^{2} \partial x_{1}}\right|_{x_{1}=L_{1}}=\left.Y I_{2} \frac{\partial^{2} w_{2}\left(x_{1}, t\right)}{\partial x_{2}^{2}}\right|_{x_{2}=0} \\
\left.\frac{w_{2}\left(L_{2}, t\right)=w_{3}(0, t)}{\partial x_{2}\left(x_{2}, t\right)}\right|_{x_{2}=L_{2}}=\left.\frac{\partial w_{3}\left(x_{3}, t\right)}{\partial x_{3}}\right|_{x_{3}=0}
\end{gathered}
$$




$$
\begin{gathered}
\left.M_{2} g \frac{\partial w_{2}\left(x_{2}, t\right)}{\partial x_{2}}\right|_{x_{2}=L_{2}}+\left.Y I_{2} \frac{\partial^{3} w_{2}\left(x_{1}, t\right)}{\partial x_{2}^{3}}\right|_{x_{2}=L_{2}} \\
=\left.Y I_{3} \frac{\partial^{3} w_{3}\left(x_{3}, t\right)}{\partial x_{3}^{3}}\right|_{x_{3}=0}+\left.M_{2} \frac{\partial^{2} w_{2}\left(x_{2}, t\right)}{\partial t^{2}}\right|_{x_{2}=L_{2}} \\
\left.Y I_{2} \frac{\partial^{2} w_{2}\left(x_{1}, t\right)}{\partial x_{2}^{2}}\right|_{x_{2}=L_{2}}+\left.J_{2} \frac{\partial^{3} w_{2}\left(x_{2}, t\right)}{\partial t^{2} \partial x_{2}}\right|_{x_{2}=L_{2}}=\left.Y I_{3} \frac{\partial^{2} w_{3}\left(x_{3}, t\right)}{\partial x_{3}^{2}}\right|_{x_{3}=0}
\end{gathered}
$$

E as condições de contorno da extremidade livre (segmento $\Re_{3}$ ), dadas por:

$$
\begin{aligned}
& \left.Y I_{3} \frac{\partial^{3} w_{3}\left(x_{3}, t\right)}{\partial x_{3}^{3}}\right|_{x_{3}=L_{3}}=0 \\
& \left.Y I_{3} \frac{\partial^{2} w_{3}\left(x_{3}, t\right)}{\partial x_{3}^{2}}\right|_{x_{3}=L_{3}}=0
\end{aligned}
$$

Com:

$J_{1}=$ Momento de inércia de rotação da massa $M_{1}$;

$J_{2}=$ Momento de inércia de rotação da massa $M_{2}$;

$Y=$ Módulo de elasticidade do segmento $\mathfrak{R}_{k}$;

$I_{k}=$ Momento de inércia a flexão do segmento $\Re_{k}$

Cujo produto $Y I_{k}$ para a configuração unimorph é dado por:

$$
Y I_{k}=\frac{b_{k}}{3}\left[\left(Y_{s}\right)_{k}\left(\left(h_{b}\right)_{k}^{3}-\left(h_{a}\right)_{k}^{3}\right)+\left(Y_{p}\right)_{k}\left(\left(h_{c}\right)_{k}^{3}-\left(h_{b}\right)_{k}^{3}\right)\right]
$$

E para uma bimorph:

$$
Y I_{k}=\frac{b_{k}}{3}\left[\left(Y_{s}\right)_{k}\left(\left(h_{b}\right)_{k}^{3}-\left(h_{a}\right)_{k}^{3}\right)+2\left(Y_{p}\right)_{k}\left(\left(h_{c}\right)_{k}^{3}-\left(h_{b}\right)_{k}^{3}\right)\right]
$$


Com:

$\left(Y_{p}\right)_{k}=$ Módulo de Young do elemento piezelétrico do segmento $\mathfrak{R}_{k}$ $\left(Y_{s}\right)_{k}=$ Módulo de Young da estrutura do segmento $\mathfrak{R}_{k}$ $\left(h_{a}\right)_{k}=$ distância da superfície inferior da estrutura até a linha neutra; $\left(h_{b}\right)_{k}=$ distância da superfície superior da estrutura até a linha neutra;

$\left(h_{c}\right)_{k}=$ distância da superfície superior do inserto piezelétrico até a linha neutra;

Em que para a construção unimorph, têm-se:

$$
\begin{gathered}
\left(h_{a}\right)_{k}=-\frac{\left(h_{p}\right)_{k}^{2}+2\left(h_{p}\right)_{k}\left(h_{s}\right)_{k}+n_{k}\left(h_{s}\right)_{k}^{2}}{2\left[\left(h_{p}\right)_{k}+n_{k}\left(h_{s}\right)_{k}\right]} \\
\left(h_{b}\right)_{k}=\frac{n_{k}\left(h_{s}\right)_{k}^{2}-\left(h_{p}\right)_{k}^{2}}{2\left[\left(h_{p}\right)_{k}+n_{k}\left(h_{s}\right)_{k}\right]} \\
\left(h_{c}\right)_{k}=-\frac{\left(h_{p}\right)_{k}^{2}+2 n_{k}\left(h_{p}\right)_{k}\left(h_{s}\right)_{k}+n_{k}\left(h_{s}\right)_{k}^{2}}{2\left[\left(h_{p}\right)_{k}+n_{k}\left(h_{s}\right)_{k}\right]} \\
n_{k}=\frac{\left(Y_{s}\right)_{k}}{\left(Y_{p}\right)_{k}}
\end{gathered}
$$

E para a bimorph:

$$
\begin{gathered}
\left(h_{a}\right)_{k}=-\frac{\left(h_{s}\right)_{k}}{2} \\
\left(h_{b}\right)_{k}=\frac{\left(h_{s}\right)_{k}}{2} \\
\left(h_{c}\right)_{k}=\frac{\left(h_{s}\right)_{k}}{2}+\left(h_{p}\right)_{k}
\end{gathered}
$$

O movimento do segmento $\mathfrak{R}_{k}$ escrito na forma de uma série uniformemente convergente de autovetores é dado por:

$$
w_{k}\left(x_{k}, t\right)=\sum_{r=1}^{\infty} \phi_{k r}\left(x_{k}\right) \eta_{r}(t), \quad x_{k} \in \Re_{k}
$$


Com autovetores definidos por partes:

$$
\begin{gathered}
\phi_{1 r}\left(x_{1}\right)=A_{1 r} \operatorname{sen}\left(\alpha_{r} x_{1}\right)+B_{1 r} \cos \left(\alpha_{r} x_{1}\right)+C_{1 r} \operatorname{senh}\left(\alpha_{r} x_{1}\right) \\
+D_{1 r} \cosh \left(\alpha_{r} x_{1}\right) \\
\phi_{2 r}\left(x_{2}\right)=A_{2 r} \operatorname{sen}\left(\beta_{r} x_{2}\right)+B_{2 r} \cos \left(\beta_{r} x_{2}\right)+C_{2 r} \operatorname{senh}\left(\gamma_{r} x_{2}\right) \\
+D_{2 r} \cosh \left(\gamma_{r} x_{2}\right) \\
\phi_{3 r}\left(x_{3}\right)=A_{3 r} \\
\operatorname{sen}\left(\mu_{r} x_{1}\right)+B_{3 r} \cos \left(\mu_{r} x_{1}\right)+C_{3 r} \operatorname{senh}\left(\mu_{r} x_{1}\right) \\
+D_{3 r} \cosh \left(\mu_{r} x_{1}\right)
\end{gathered}
$$

$\eta_{r}(t)=$ Resposta modal do "r-ésimo" modo de vibrar.

Cujos parâmetros $\alpha_{r}, \beta_{r}, \gamma_{r}$, e $\mu_{r}$ são calculados para movimentos harmônicos em função das características e frequências naturais de cada segmento, conforme descrito por Rao (2007):

$$
\begin{gathered}
\alpha_{r}^{4}=\omega_{r}^{2} \frac{\left(m_{l}\right)_{1}}{Y I_{1}} \\
\beta_{r}^{2}=\frac{\kappa}{2}+\sqrt{\frac{\kappa^{2}}{4}+\omega_{r}^{2} \frac{\left(m_{l}\right)_{2}}{Y I_{2}}} \\
\gamma_{r}^{2}=-\frac{\kappa}{2}+\sqrt{\frac{\kappa^{2}}{4}+\omega_{r}^{2} \frac{\left(m_{l}\right)_{2}}{Y I_{2}}} \\
\mu_{r}^{4}=\omega_{r}^{2} \frac{\left(m_{l}\right)_{3}}{Y I_{3}} \\
\kappa=\frac{M_{2} g}{Y I_{2}}
\end{gathered}
$$

Nas quais:

$\omega_{r}=$ frequência natural não amortecida do "r"-ésimo modo de vibrar;

A substituição das equações (65) a (68) em (44) a (55) resulta em um problema de autovetores cuja solução fornece as frequências naturais da estrutura. 
Para que fiquem consistentes com a formulação proposta por Erturk e Inman (2008a), as funções devem ser normalizadas pela massa conforme a condição de ortogonalidade dada por:

$$
\begin{gathered}
\sum_{k=1}^{3} \int_{0}^{L_{k}}\left(m_{l}\right) \phi_{k r}\left(x_{k}\right) \phi_{k s}\left(x_{k}\right) d x_{k} \\
+\left(M_{1}+M_{2}+\left(m_{l}\right)_{2} L_{2}+\left(m_{l}\right)_{3} L_{3}\right) \phi_{1 r}\left(L_{1}\right) \times \phi_{1 s}\left(L_{1}\right)+M_{2} \phi_{2 r}\left(L_{2}\right) \phi_{2 s}\left(L_{2}\right) \\
+\left.\left.J_{1} \frac{d \phi_{1 r}\left(x_{1}\right)}{d x_{1}}\right|_{x_{1}=L_{1}} \frac{d \phi_{1 s}\left(x_{1}\right)}{d x_{1}}\right|_{x_{1}=L_{1}} \\
+\left.\left.J_{2} \frac{d \phi_{2 r}\left(x_{2}\right)}{d x_{2}}\right|_{x_{2}=L_{2}} \frac{d \phi_{2 s}\left(x_{2}\right)}{d x_{2}}\right|_{x_{2}=L_{2}}=\delta_{r s}
\end{gathered}
$$

A equação do movimento forçado pode ser escrita em coordenadas modais conforme a equação (75), partindo da substituição de (65) em (42), com a aplicação das condições de ortogonalidade:

$$
\begin{aligned}
& \frac{d^{2} \eta_{r}(t)}{d t^{2}}+2 \zeta_{r} \omega_{r} \frac{d \eta_{r}(t)}{d t} \omega_{r}^{2} \eta_{r}(t)+\sum_{k=1}^{3} \chi_{k r} v_{k}(t)=N_{r}(t) \\
& \chi_{k r}=\left.\vartheta_{k} \frac{d \phi_{k r}\left(x_{k}\right)}{d x_{k}}\right|_{L_{o_{k}}} ^{L_{0_{k}}+L_{p_{k}}} \\
& N_{r}(t)=-\left[m_{1} \int_{0}^{L_{1}} \phi_{1 r}\left(x_{1}\right) d x_{1}\right. \\
& \left.+\left(M_{1}+M_{2}+\left(m_{l}\right)_{2} L_{2}+\left(m_{l}\right)_{3} L_{3}\right) \phi_{1 r}\left(L_{1}\right)\right] a_{B}(t) \\
& \vartheta_{k}=\frac{\left(Y_{p}\right)_{k}\left(d_{31}\right)_{k} b_{k}}{2\left(h_{p}\right)_{k}}\left[\left(h_{b}\right)_{k}^{2}-\left(h_{c}\right)_{k}^{2}\right]
\end{aligned}
$$

Sendo:

$a_{B}(t)=$ aceleração de excitação.

$\zeta_{r}=$ amortecimento modal viscoso do "r"-ésimo modo de vibrar; 
$\vartheta_{k}=$ coeficiente de acoplamento eletromecânico do segmento $\mathfrak{R}_{k}$

$v_{k}(t)=$ Tensão entre os eletrodos do segmento $\mathfrak{R}_{k}$

$\chi_{k r}=$ Coeficiente de acoplamento eletromecânico modal do "r"-ésimo modo de vibrar para o segmento $\mathfrak{R}_{k}$;

$N_{r}(t)=$ Função da excitação mecânica modal do "r"-ésimo modo de vibrar

$\left(d_{31}\right)_{k}=$ Constante piezelétrica do inserto do segmento $\mathfrak{R}_{k}$

Cabe destacar que função de excitação modal é composta por dois termos, cujo primeiro corresponde à inércia da massa distribuída ao longo de $x_{1}$, e o segundo, às massas concentradas em $x_{1}=L_{1}$. Efeitos externos de amortecimento são desprezados neste modelo.

A corrente elétrica gerada pelo inserto de cada segmento $\mathfrak{R}_{k}$ pode ser definida como:

$$
\begin{gathered}
i_{k}(t)=\sum_{r=1}^{\infty} \psi_{k r} \frac{d \eta_{r}(t)}{d t} \\
\psi_{k r}=-\left.\left(d_{31}\right)_{k}\left(Y_{p}\right)_{k}\left(h_{p c}\right)_{k} b_{k} \frac{d \phi_{k r}\left(x_{k}\right)}{d x_{k}}\right|_{L_{0_{k}}} ^{L_{0_{k}}+L_{p_{k}}}
\end{gathered}
$$

Sendo para a viga unimorph:

$$
\left(h_{p c}\right)_{k}=\frac{n_{k}\left(h_{s}\right)_{k}\left[\left(h_{p}\right)_{k}+\left(h_{s}\right)_{k}\right]}{2\left[\left(h_{p}\right)_{k}+n_{k}\left(h_{s}\right)_{k}\right]}
$$

E para uma bimorph:

$$
\left(h_{p c}\right)_{k}=\frac{\left(h_{s}\right)_{k}}{2}+\frac{\left(h_{p}\right)_{k}}{2}
$$

A capacitância interna de cada elemento piezelétrico é dada por:

$$
\left(C_{p}\right)_{k}=\frac{\left(\varepsilon_{33}^{S}\right)_{k} b_{k} L_{p_{k}}}{\left(h_{p}\right)_{k}}
$$

Em que:

$\left(\varepsilon_{33}^{S}\right)_{k}=$ permissividade a deformação constante do inserto piezelétrico do segmento $\Re_{k}$ 
Aplicando-se a Lei de Kirchhoff para o circuito do gerador com 2 elementos piezelétricos obtém-se:

$$
\begin{aligned}
& \frac{1}{R_{l}} v_{1}(t)+\left(C_{p}\right)_{1} \frac{d v_{1}(t)}{d t}+\frac{1}{R_{l}} v_{2}(t)=i_{1}(t) \\
& \frac{1}{R_{l}} v_{1}(t)+\frac{1}{R_{l}} v_{2}(t)+\left(C_{p}\right)_{2} \frac{d v_{2}(t)}{d t}=i_{2}(t)
\end{aligned}
$$

No caso de um circuito com 3 elementos piezelétricos obtém-se:

$$
\begin{aligned}
& \frac{1}{R_{l}} v_{1}(t)+\left(C_{p}\right)_{1} \frac{d v_{1}(t)}{d t}+\frac{1}{R_{l}} v_{2}(t)+\frac{1}{R_{l}} v_{3}(t)=i_{1}(t) \\
& \frac{1}{R_{l}} v_{1}(t)+\frac{1}{R_{l}} v_{2}(t)+\left(C_{p}\right)_{2} \frac{d v_{2}(t)}{d t}+\frac{1}{R_{l}} v_{3}(t)=i_{2}(t) \\
& \frac{1}{R_{l}} v_{1}(t)+\frac{1}{R_{l}} v_{2}(t)+\frac{1}{R_{l}} v_{3}(t)+\left(C_{p}\right)_{3} \frac{d v_{3}(t)}{d t}=i_{3}(t)
\end{aligned}
$$

Substituindo a equação (79) em (84) e (85):

$$
\begin{aligned}
& \frac{1}{R_{l}} v_{1}(t)+\left(C_{p}\right)_{1} \frac{d v_{1}(t)}{d t}+\frac{1}{R_{l}} v_{2}(t)=\sum_{r=1}^{\infty} \psi_{1 r} \frac{d \eta_{r}(t)}{d t} \\
& \frac{1}{R_{l}} v_{1}(t)+\frac{1}{R_{l}} v_{2}(t)+\left(C_{p}\right)_{2} \frac{d v_{2}(t)}{d t}=\sum_{r=1}^{\infty} \psi_{2 r} \frac{d \eta_{r}(t)}{d t}
\end{aligned}
$$


Ou a equação (79) em (86) a (88):

$$
\begin{aligned}
& \frac{1}{R_{l}} v_{1}(t)+\left(C_{p}\right)_{1} \frac{d v_{1}(t)}{d t}+\frac{1}{R_{l}} v_{2}(t)+\frac{1}{R_{l}} v_{3}(t)=\sum_{r=1}^{\infty} \psi_{1 r} \frac{d \eta_{r}(t)}{d t} \\
& \frac{1}{R_{l}} v_{1}(t)+\frac{1}{R_{l}} v_{2}(t)+\left(C_{p}\right)_{2} \frac{d v_{2}(t)}{d t}+\frac{1}{R_{l}} v_{3}(t)=\sum_{r=1}^{\infty} \psi_{2 r} \frac{d \eta_{r}(t)}{d t} \\
& \frac{1}{R_{l}} v_{1}(t)+\frac{1}{R_{l}} v_{2}(t)+\frac{1}{R_{l}} v_{3}(t)+\left(C_{p}\right)_{3} \frac{d v_{3}(t)}{d t}=\sum_{r=1}^{\infty} \psi_{3 r} \frac{d \eta_{r}(t)}{d t}
\end{aligned}
$$

Resolvendo o sistema de equações formado por (89) e (90) ou (91) a (93) e (75) para as variáveis $v_{1}(t), v_{2}(t), v_{3}(t)$ e $\eta_{r}(t)$ se obtém as funções que definem a resposta do gerador.

A tensão na resistência elétrica é dada por:

$$
v(t)=\sum_{k=1}^{p} v_{k}(t)
$$

Com

$p$ = número de insertos piezelétricos utilizados;

E a resposta mecânica pode ser calculada substituindo-se $\eta_{r}(t)$ em (75) juntamente com as funções dadas por (66) a (68) normalizadas por (74).

Para uma excitação harmônica, na qual a aceleração é da forma:

$$
a_{B}(t)=A_{B} e^{j \omega t}
$$

Com:

$A_{B}=$ Amplitude da aceleração da base;

$\omega=$ frequência de excitação;

Pode-se escrever a resposta do gerador na forma: 


$$
\begin{gathered}
\eta_{r}(t)=H_{r} e^{j \omega t} \\
v_{k}(t)=V_{a_{k}} e^{j \omega t}
\end{gathered}
$$

Com:

$H_{r}=$ Amplitude da resposta mecânica modal do "r"-ésimo modo de vibrar;

$V_{a_{k}}=$ Amplitude da tensão elétrica entre os eletrodos do inserto piezelétrico do segmento $\mathfrak{R}_{k}$;

E substituindo-se (95) a (97) em (75) pode-se escrever a relação:

$$
\begin{gathered}
H_{r}=\frac{\lambda_{r} A_{B}-\sum_{k=1}^{p} \chi_{k r} V_{a_{k}}}{\omega_{r}^{2}-\omega^{2}+j 2 \zeta_{r} \omega_{r} \omega} \\
\lambda_{r}=-\left[m_{1} \int_{0}^{L_{1}} \phi_{1 r}\left(x_{1}\right) d x_{1}+\left(M_{1}+M_{2}+\left(m_{l}\right)_{2} L_{2}+\left(m_{l}\right)_{3} L_{3}\right) \phi_{1 r}\left(L_{1}\right)\right]
\end{gathered}
$$

Em que a eliminação dos termos da resposta modal mecânica permite escrever:

$$
\begin{gathered}
\sum_{k=1}^{p} Q_{m k} V_{a_{k}}=P_{m} \quad m=1,2, \ldots, p . \\
Q_{m k}=\frac{1}{R_{l}}+j \omega\left(C_{p}\right)_{m} \delta_{m k}+\sum_{r=1}^{\infty} \frac{j \omega \psi_{m r} \chi_{k r}}{\omega_{r}^{2}-\omega^{2}+j 2 \zeta_{r} \omega_{r} \omega} \\
P_{m}=\sum_{r=1}^{\infty} \frac{j \omega \psi_{m r} \lambda_{r} A_{B}}{\omega_{r}^{2}-\omega^{2}+j 2 \zeta_{r} \omega_{r} \omega}
\end{gathered}
$$

Sendo a tensão na resistência elétrica igual dada por:

$$
V=\sum_{k=1}^{p} V_{a_{k}}
$$


Com a corrente elétrica, $Q_{l}$, e a potência gerada, $P_{l}$, dados por:

$$
\begin{gathered}
Q_{l}=\frac{V}{R_{l}} \\
P_{l}=\frac{|V|^{2}}{R_{l}}
\end{gathered}
$$

Por fim, pode-se definir também a tensão RMS, $V_{r m s}$, e a potência média, $P_{\text {ave }}$, como:

$$
\begin{gathered}
V_{r m s}=\frac{V}{\sqrt{2}} \\
P_{\text {ave }}=\frac{P_{l}}{2}
\end{gathered}
$$




\section{Simulações Numéricas}

\subsection{Simulações Numéricas - Modelo de Parâmetros Concentrados}

Usando o modelo de parâmetros concentrados desenvolvido no capítulo 2, foram feitos estudos de sensibilidade visando diretivas para a otimização de energy harvesters em relação à quantidade de material piezelétrico utilizado, os quais foram divididos em duas etapas.

Na primeira, avaliou-se os geradores de 2 graus de liberdade cujos resultados foram apresentados nos trabalhos de Xiao (Xiao et al. 2015) e Tang (Tang, Yang, 2012), Em que a partir dos mesmos dados de entrada utilizados nos exemplos desenvolvidos nestas publicações avaliou-se os impactos na potência total gerada decorrentes da manipulação da disposição e quantidade de material piezelétrico.

Tabela 1 - Parâmetros do modelo com dois graus de liberdade estudados por Tang e Yang (2012) e Xiao et al. (2015).

\begin{tabular}{ccc}
\hline \multicolumn{3}{c}{ Parâmetros - Gerador de 2 GDL } \\
\hline Parâmetro & Valor & Unidade \\
\hline$m_{l}$ & $4 \times 10^{-2}$ & $\mathrm{~kg}$ \\
$m_{2}$ & $8 \times 10^{-3}$ & $\mathrm{~kg}$ \\
$k_{1}$ & 100 & $\mathrm{~N} / \mathrm{m}$ \\
$k_{2}$ & 14,45 & $\mathrm{~N} / \mathrm{m}$ \\
$c_{1}$ & $8 \times 10^{-2}$ & $\mathrm{~N} /(\mathrm{m} / \mathrm{s})$ \\
$c_{2}$ & $2,72 \times 10^{-3}$ & $\mathrm{~N} /(\mathrm{m} / \mathrm{s})$ \\
$\alpha_{1}$ & $3,16 \times 10^{-5}$ & $\mathrm{~N} / \mathrm{V}$ \\
$\alpha_{2}$ & $3,16 \times 10^{-5}$ & $\mathrm{~N} / \mathrm{V}$ \\
$C p_{1}$ & $2,5 \times 10^{-8}$ & $\mathrm{~F}$ \\
$C p_{2}$ & $2,5 \times 10^{-8}$ & $\mathrm{~F}$ \\
$R_{l}$ & $1,0 \times 10^{6}$ & $\Omega$ \\
$R_{2}$ & $1,0 \times 10^{6}$ & $\Omega$ \\
\hline
\end{tabular}

Na segunda etapa foi adicionado um grau de liberdade ao modelo da primeira etapa, cuja potencia de geração foi estudada em função da variação dos parâmetros de massa, rigidez e quantidade de material piezelétrico com coeficiente de amortecimento proporcional à rigidez para o conjunto.. 


\subsection{1. - Gerador de 2 GDL}

Analisando-se os exemplos das publicações de Xiao (Xiao et al. 2015) e Tang (Tang, Yang, 2012) nota-se primeiramente que a diferença básica entre elas está na inserção de um elemento piezelétrico adicional entre a primeira e segunda massa do sistema, conforme a figura 12. Os resultados obtidos para cada caso estão dispostos na tabela 2 e no gráfico da figura 13.

Tabela 2 - Resultados de potência máxima gerada para os exemplos apresentados nos trabalhos de Xiao (Xiao et al. 2015) e Tang (Tang, Yang, 2012), nos quais a linha " $1^{\circ}$ piezo" indica a energia gerada pelo elemento piezelétrico entre a base e a primeira massa, e a linha " $2^{\circ}$ piezo" indica 0 inserto entre a primeira e a segunda massa.

\begin{tabular}{ccc}
\hline \multicolumn{3}{c}{ Resultados - 2 Graus de Liberdade } \\
\hline Publicação & Inserto & Máxima Potência Gerada \\
Tang e Yang (2012) & Total & $250,4 \mu \mathrm{W}$ \\
& Total & $2,44 \mathrm{~mW}$ \\
Xiao et al. (2015) & $1^{\circ}$ piezo & $227,1 \mu \mathrm{W}$ \\
& $2^{\circ}$ piezo & $2,217 \mathrm{~mW}$ \\
\hline
\end{tabular}

a)

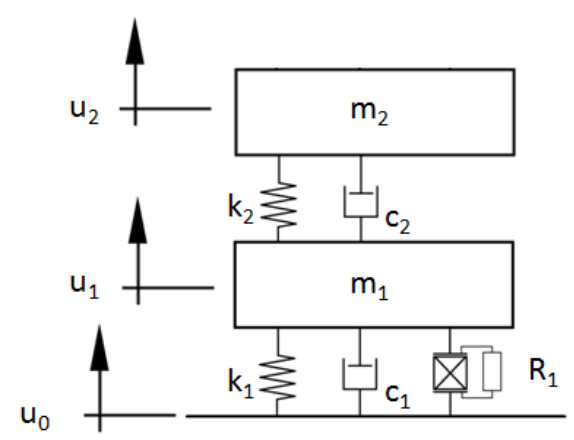

b)

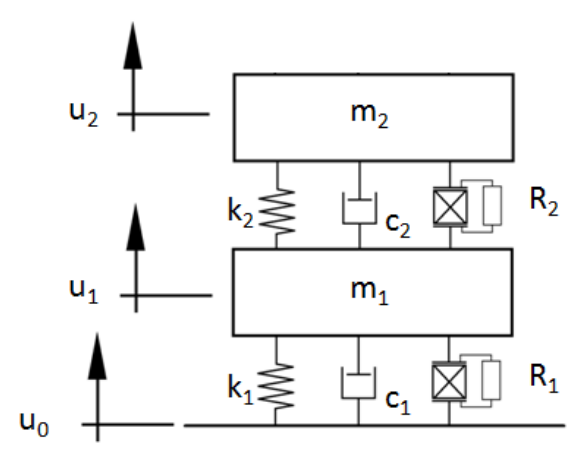

Figura 12- Esquema do modelo de dois graus de liberdade utilizados por (a) Tang e Yang (2012) e (b) Xiao et al. (2015).

Ao se comparar a máxima potência gerada pelos dois exemplos, observa-se que o modelo com dois elementos piezelétrico apresenta um resultado quase 10 vezes maior que aquele contendo apenas um entre a primeira massa e a base, resultado este que é ressaltado 
por Xiao em seu trabalho como sendo o grande mérito da estrutura construtiva proposta em relação à avaliada por Tang.

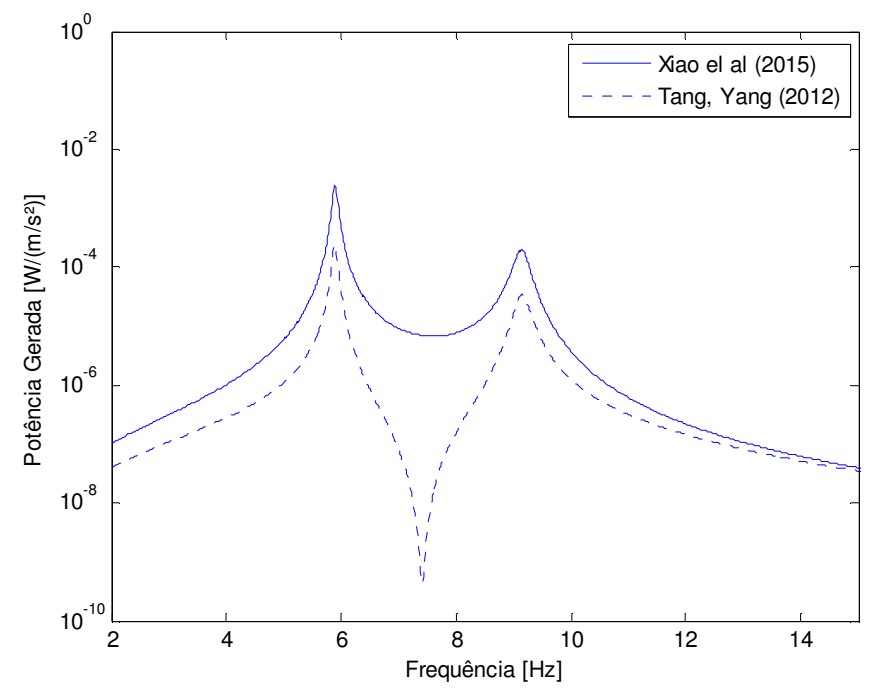

Figura 13 - FRF da potência gerada para o exemplo avaliado por Tang (Tang, Yang, 2012) e Xiao (Xiao et al. 2015).

No entanto, ao se analisar individualmente a potência gerada por cada elemento piezelétrico(\#Figura 14), fica evidente que o segundo inserto é o responsável pelo ganho obtido, sendo sua potência máxima igual a 2,217 mW, enquanto a do primeiro fica em 227,1 $\mu \mathrm{W}$, muito próxima àquela obtida por Tang.

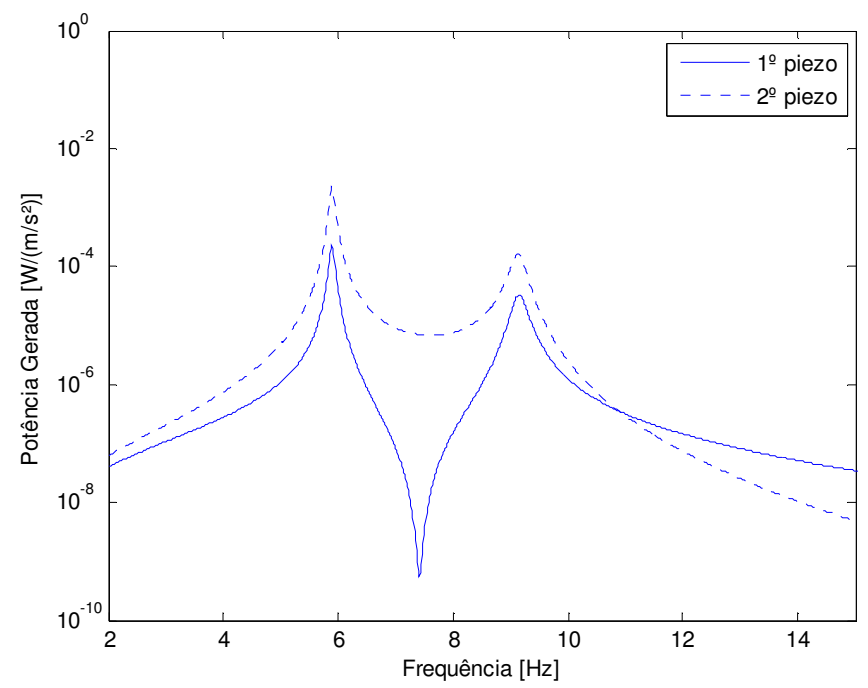

Figura 14 - FRF da potência gerada pelo primeiro e segundo elemento piezelétrico do exemplo de Xiao (Xiao et al. 2015). 
Fazendo-se então a análise do mesmo gerador, mas apenas com o elemento piezelétrico entre a primeira e a segunda massa, estrutura esta já proposta no trabalho de Tang, mas sem exemplo desenvolvido, nota-se que os resultados são bastante próximos aos obtidos por Xiao, cuja máxima potência fica em 2,238 mW, com densidade energética de $46,63 \mathrm{~mW} / \mathrm{kg}$ contra 51,03 $\mathrm{mW} / \mathrm{kg}$ de Xiao.

Apesar de a densidade energética da solução proposta quando calculada em função massa do gerador se mostrar ligeiramente inferior à obtida por Xiao, nota-se que ao se fazer tal análise em função da massa de material piezelétrico $m_{p} \mathrm{o}$ cenário se inverte, com resultados iguais a $250 \mu \mathrm{W} / \mathrm{m}_{\mathrm{p}}$ para o exemplo de Tang, $1,22 \mathrm{~mW} / \mathrm{m}_{\mathrm{p}}$ no caso de Xiao, e 2,24 $\mathrm{mW} / \mathrm{m}_{\mathrm{p}}$ para a configuração proposta, na qual conforme discutido no capítulo 2, pode-se dizer que a quantidade de material piezelétrico (ou massa, assumindo-se que todos os geradores apresentam mesma solução construtiva) é diretamente proporcional ao fator de força utilizado para cada inserto. 


\subsubsection{Estudo de Sensibilidade 2 GDL}

Tendo em vista a maior eficiência de geração do elemento alocado entre a primeira e a segunda massa, o gerador proposto foi avaliado para diferentes valores de fator de força, capacitância e resistência do circuito elétrico associados a este elemento (\#Figura 15 e 16).

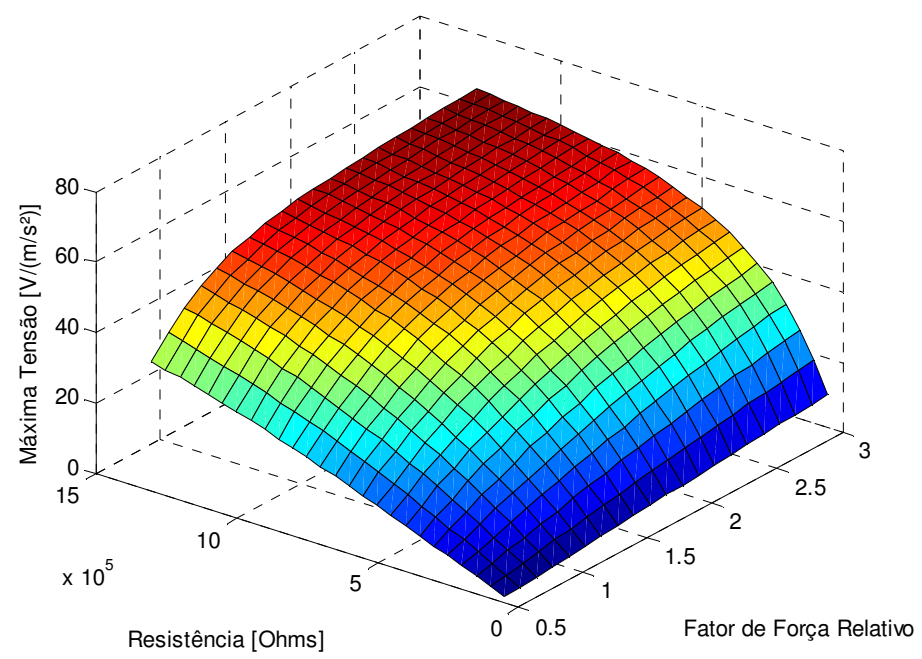

Figura 15 - Máxima tensão gerada pelo inserto entre a primeira e a segunda massa oscilante do modelo de dois graus de liberdade em função do fator de força relativo e da resistência elétrica associada.

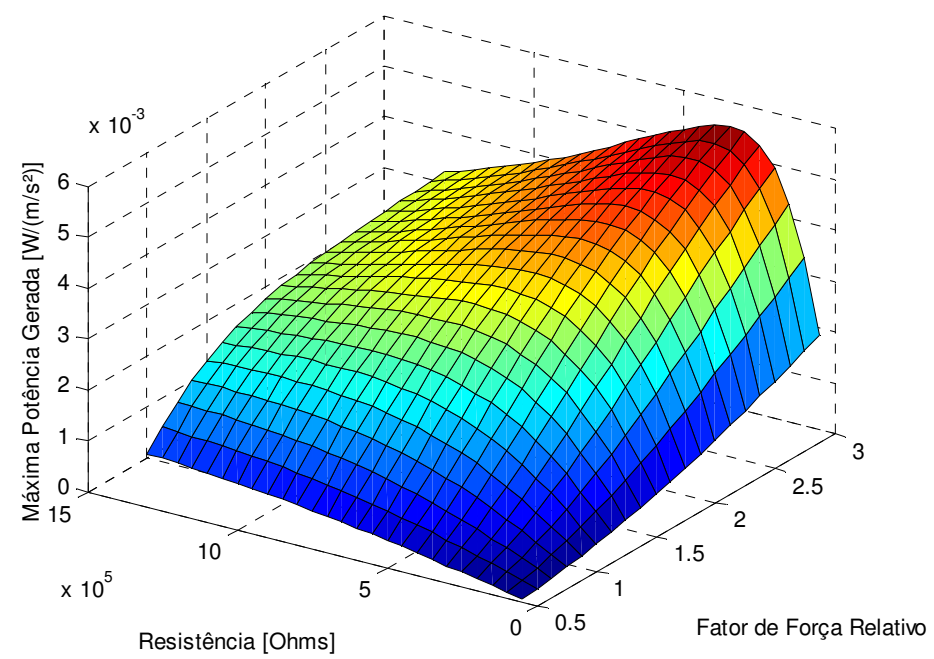

Figura 16 - Máxima potência gerada pelo inserto entre a primeira e a segunda massa oscilante do modelo de dois graus de liberdade em função do fator de força relativo e da resistência elétrica associada.

Partindo da premissa que o modelo em parâmetros concentrados avaliado deve fazer analogia a uma viga cantilever, o fator de força e a capacitância do inserto foram variados 
seguindo-se sempre a mesma proporção linear, o que corresponde a aumentar ou diminuir a superfície recoberta por material piezelétrico em uma viga cantilever, conforme as equações (8) e (10) desenvolvidas no capítulo 2. Em particular, foram destacados os resultados para um fator de força e capacitância duas vezes maiores, análogos ao uso de uma solução bimorph em relação a uma unimorph (\#Figuras 17 e 18).

a)

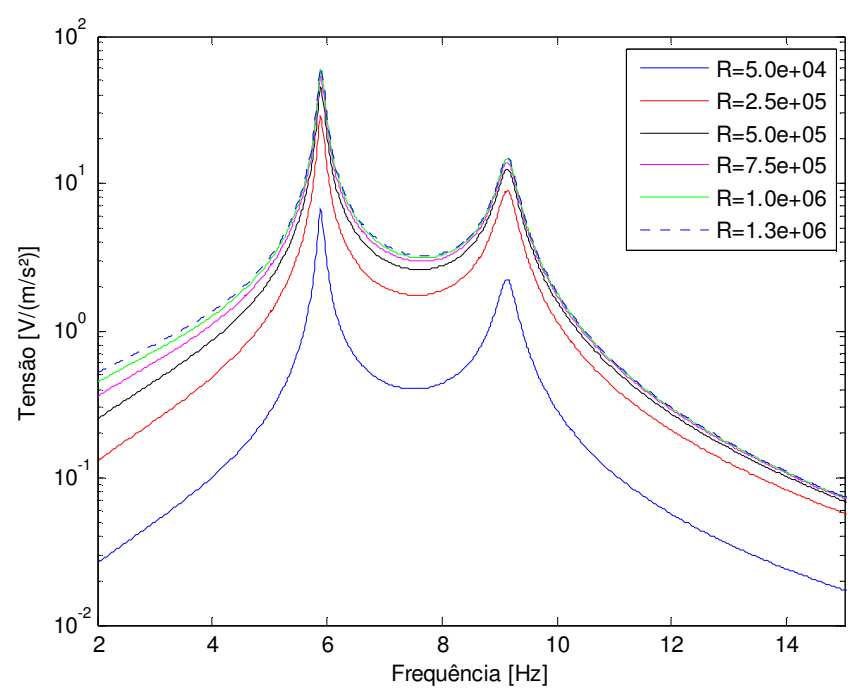

b)

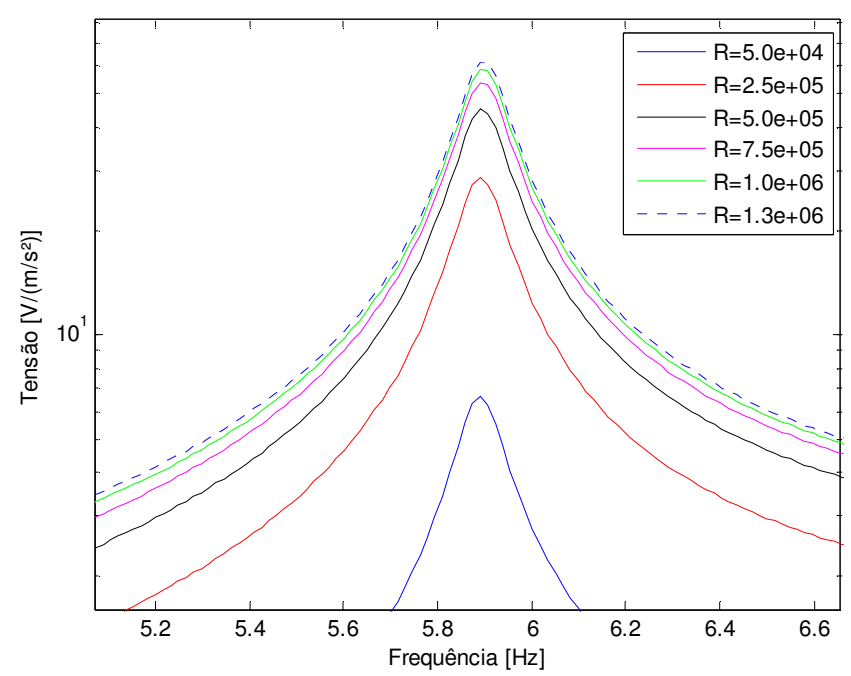

Figura 17 - FRF da tensão gerada pelo inserto entre a primeira e a segunda massa oscilante do modelo de dois graus de liberdade, com fator de força relativo igual a 2 para diferentes resistências elétricas, (a) na faixa de frequência contendo as duas ressonâncias, e (b) com destaque para a resposta na primeira frequência natural.

Ao se analisar os resultados obtidos, nota-se que a tensão gerada é maximizada à medida que se aumenta a resistência utilizada, mas com incrementos decrescentes, exibindo um perfil assintótico para resistência maiores. No entanto, ao se verificar a potência gerada no 
resistor, nota-se que esta é maximizada para um valor determinado de resistência elétrica, em que tanto seu aumento quanto sua diminuição impactam na redução da potência gerada.

Pode-se destacar ainda que a resistência elétrica que maximiza a potência gerada não é a mesma para cada fator de força, sendo necessário utilizar resistências menores para fatores maiores.

a)

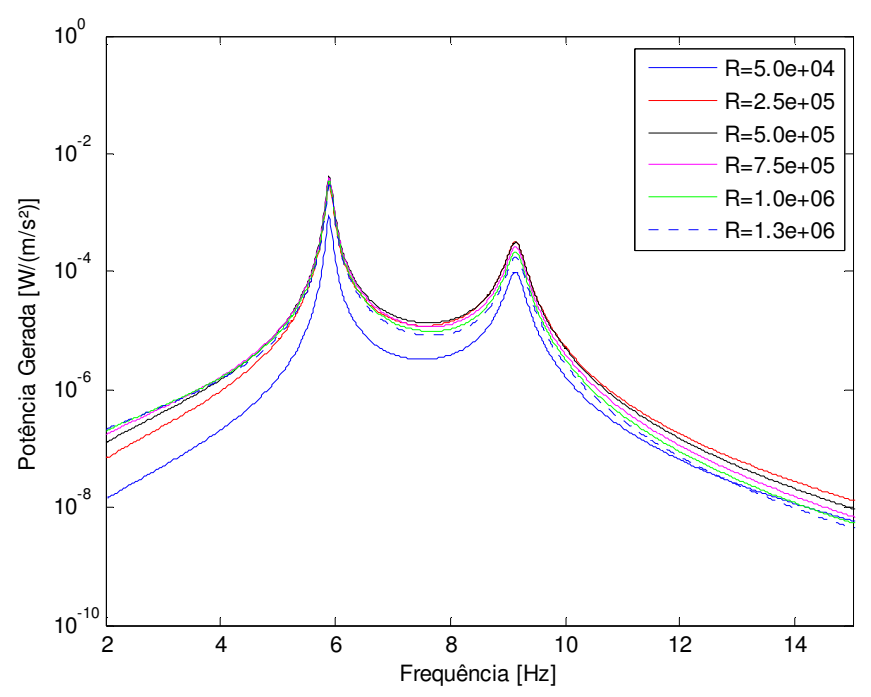

b)

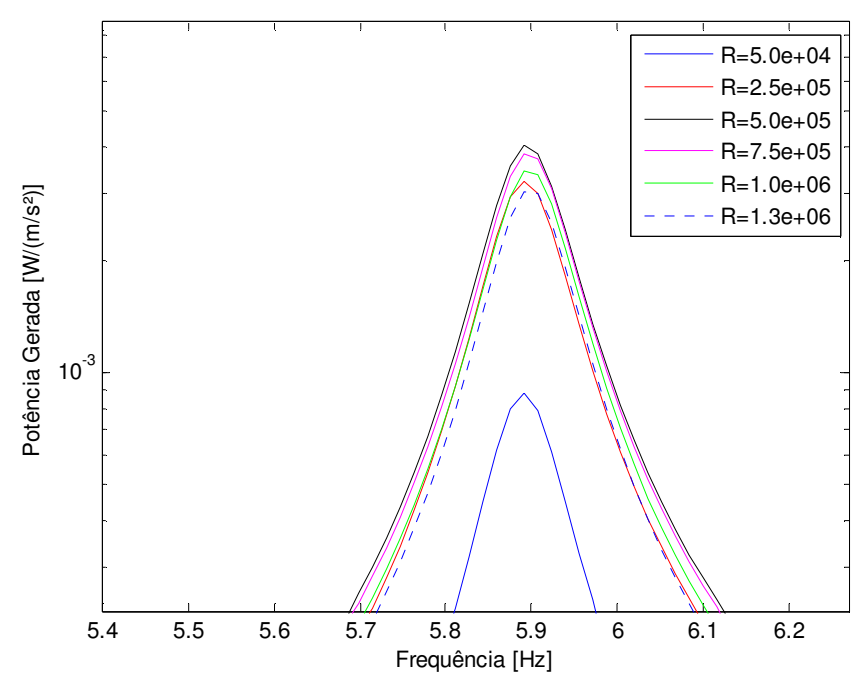

Figura 18 - FRF da potência gerada pelo inserto entre a primeira e a segunda massa oscilante do modelo de dois graus de liberdade, com fator de força relativo igual a 2 para diferentes resistências elétricas, (a) na faixa de frequência contendo as duas ressonâncias, e (b) com destaque para a resposta na primeira frequência natural.

No caso com o dobro de material piezelétrico a máxima potência gerada foi de $4,057 \mathrm{~mW}$, obtida para uma resistência de $550 \mathrm{k} \Omega$, sendo 1,66 vezes maior que aquela obtida por Xiao. Neste caso, a densidade energética calculada em função da massa de material piezelétrico não se altera significativamente em relação ao gerador proposto com fator de 
força original, sendo 2,029 $\mathrm{mW} / \mathrm{m}_{\mathrm{p}}$ ante a 2,238 $\mathrm{mW} / \mathrm{m}_{\mathrm{p}}$ respectivamente, mas a densidade energética em relação à massa do gerador cresce expressivamente, sendo 84,52 mW/kg com o maior fator de força contra 46,63 $\mathrm{mW} / \mathrm{kg}$ do gerador proposto inicialmente, e 51,03 $\mathrm{mW} / \mathrm{kg}$ do exemplo estudado por Xiao.

\subsubsection{Estudo de Sensibilidade 3 GDL}

Para um sistema de 3 graus de liberdade, conforme o esquema apresentado na figura 19, entende-se que é possível fazer o mesmo estudo realizado anteriormente para o sistema de 2 GDL, e ao invés de se utilizar três elementos piezelétricos no gerador, como na solução proposta por Xiao et al. (2015), usar apenas um ou dois insertos, maximizando sua eficiência em relação à quantidade de material piezelétrico sem comprometimento da eficiência energética em função da massa do gerador.

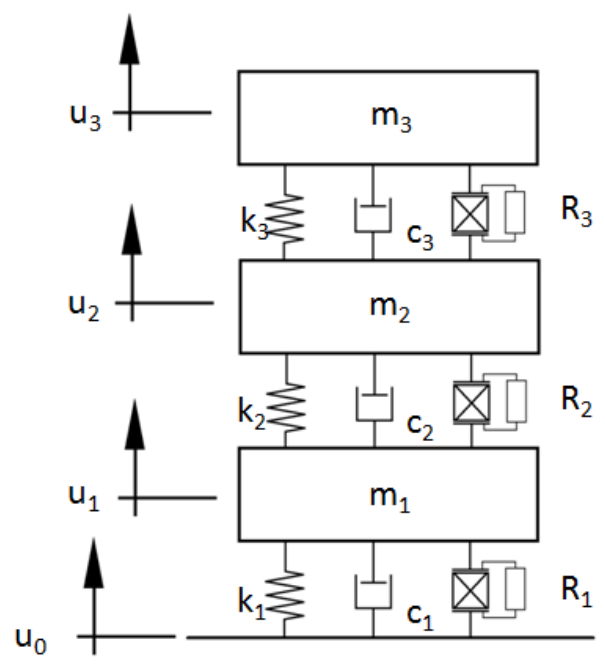

Figura 19 - Esquema do gerador de três graus de liberdade.

Inicialmente, como é necessário conhecer a contribuição dos elementos piezelétricos para cada posição de montagem para realização da otimização, foi avaliada a configuração contendo três elementos piezolétricos, a qual corresponde exatamente à solução proposta por Xiao et al. (2015). Essa configuração também foi utilizada como referência para comparação dos resultados obtidos para as demais configurações.

Em todos os experimentos manteve-se a massa total do gerador sempre igual à do exemplo de 2 GDL avaliado, variando-se apenas a proporção entre elas, além da rigidez e o 
amortecimento de cada elemento. No caso do amortecimento, assumiu-se a hipótese de amortecimento proporcional à rigidez, uma vez que para as soluções construtivas de referência, as vigas cantilever, a maior parcela do amortecimento do conjunto advém da própria estrutura metálica que o constitui (substrato), o qual pode ser razoavelmente representado por tal aproximação.

Em cada caso assumiu-se diferentes distribuições de massa entre os três osciladores, em que a rigidez adotada para cada um seguiu sempre a mesma relação de proporcionalidade entre rigidez e massa do primeiro oscilador do modelo de 2 GDL. Em termos das variáveis utilizadas por Xiao et al. (2015), seria o equivalente a afirmar que o ponto de partida dos estudos foi a adoção sempre do mesmo $\omega_{n}$ para todos os osciladores, definido na publicação em questão conforme a Equação 108. Apesar disso, tal notação não será adotada ao longo do trabalho para que não se tenha uma impressão equivocada de que a equação representa as frequências naturais do sistema.

$$
\omega_{n}=\sqrt{\frac{k_{n}}{m_{n}}}
$$

A partir da configuração base foi variada a rigidez de cada elemento de modo permitir que a verificação da influência dessa relação entre massa e rigidez nos resultados do gerador.

Para todos os elementos piezelétricos e resistências elétricas associadas foram mantidos sempre os mesmos valores utilizados no exemplo de 2 GDL.

É importante destacar que se buscou, tanto nas relações entre as diferentes massas do gerador, como na variação da rigidez de cada uma, utilizar ordens de grandeza compatíveis com uma aplicação real, já que soluções que não apresentem sentido físico não são objetivos do trabalho. Ressalta-se ainda que assumiu-se como adequadas as relações adotadas para o exemplo utilizado nas publicações de Xiao et al. (2005) e Tang (Tang, Yang, 2012) até para que seja possível a comparação dos resultados.

Ainda para efeito de comparação foram acrescentados aos gráficos os resultados obtidos para um modelo de 1GDL e mesma relação de massa e rigidez, além do resultado da potência total gerada para o exemplo de 2 GDL de Xiao et al. (2015).

Os valores de massa e rigidez testados estão dispostos nas tabelas 3 a 5 . 


\subsubsection{Estudo de Sensibilidade 1}

A primeira análise de sensibilidade verificou os efeitos da distribuição de massa de forma crescente e decrescente entre os graus de liberdade do gerador. Nos gráficos da figura 20 estão dispostos os resultados de potência gerada para cada elemento piezelétrico do harvester de acordo com a relação de massa utilizada ( $\mathrm{Mr}$ de 1 a 7) para a rigidez de referência $(\mathrm{Kr}=3)$.

Tabela 3 - Massa dos osciladores em cada configuração do primeiro estudo de sensibilidade do gerador de três graus de liberdade.

\section{Estudo de Sensibilidade 1}

\begin{tabular}{cccc}
\hline $\begin{array}{c}\text { ID da Relação de Massa } \\
\text { Mr }\end{array}$ & $\begin{array}{c}\text { Massa 1 } \\
{[\mathbf{k g}]}\end{array}$ & $\begin{array}{c}\text { Massa 2 } \\
{[\mathbf{k g}]}\end{array}$ & $\begin{array}{c}\text { Massa 3 } \\
{[\mathbf{k g}]}\end{array}$ \\
\hline 1 & 0,0032 & 0,0160 & 0,0288 \\
2 & 0,0064 & 0,0160 & 0,0256 \\
3 & 0,0096 & 0,0160 & 0,0224 \\
4 & 0,0160 & 0,0160 & 0,0160 \\
5 & 0,0224 & 0,0160 & 0,0096 \\
6 & 0,0256 & 0,0160 & 0,0064 \\
7 & 0,0288 & 0,0160 & 0,0032 \\
\hline
\end{tabular}

Tabela 4 - Relação de distribuição de massa entre os osciladores em cada configuração do primeiro estudo de sensibilidade do gerador de três graus de liberdade.

Estudo de Sensibilidade 1

\begin{tabular}{cccc}
\hline $\begin{array}{c}\text { ID da Relação de Massa } \\
\text { Mr }\end{array}$ & $\begin{array}{c}\text { Massa 1 } \\
{[\%]}\end{array}$ & $\begin{array}{c}\text { Massa 2 } \\
{[\%]}\end{array}$ & $\begin{array}{c}\text { Massa 3 } \\
{[\%]}\end{array}$ \\
\hline 1 & $7 \%$ & $33 \%$ & $60 \%$ \\
2 & $13 \%$ & $33 \%$ & $53 \%$ \\
3 & $20 \%$ & $33 \%$ & $47 \%$ \\
4 & $33 \%$ & $33 \%$ & $33 \%$ \\
5 & $47 \%$ & $33 \%$ & $20 \%$ \\
6 & $53 \%$ & $33 \%$ & $13 \%$ \\
7 & $60 \%$ & $33 \%$ & $7 \%$ \\
\hline
\end{tabular}


Tabela 5 - Parâmetros de massa e rigidez em cada configuração do primeiro estudo de sensibilidade do gerador de três graus de liberdade.

Estudo de Sensibilidade de Rigidez

\begin{tabular}{|c|c|c|c|}
\hline $\begin{array}{c}\text { ID da Relação de } \\
\text { Rigidez } \\
\mathbf{K r}\end{array}$ & $\frac{k}{m}$ & $\frac{\omega_{n}}{\omega_{n \text { referência }}}$ & $\frac{k}{k_{\text {referência }}}$ \\
\hline 1 & 1250 & 0,707 & 0,50 \\
\hline 2 & 1875 & 0,866 & 0,75 \\
\hline 3 & 2500 & 1,000 & 1,00 \\
\hline 4 & 3125 & 1,118 & 1,25 \\
\hline 5 & 3750 & 1,225 & 1,50 \\
\hline
\end{tabular}

Nos resultados (\#Figuras 20 a 29) verifica-se que para Mr=1, cuja maior massa está no terceiro oscilador, ocorre um distanciamento entre as frequências de ressonância, além da minimização da primeira frequência do sistema. É possível dizer ainda que para essa condição ocorre a maximização da máxima energia gerada pelo primeiro elemento piezelétrico em detrimento da energia gerada pelo último elemento. Nessa configuração nota-se que ao contrário do que se deseja há um claro estreitamento da banda de frequência útil apesar das grandes amplitudes de potência para a primeira frequência natural do sistema quando comparado aos sistemas com um e dois GDL.

À medida que atribui maior massa ao oscilador da base, reduzindo-se a do oscilador da extremidade, verifica-se o significativo aumento das amplitudes de potência gerada para a segunda e terceira frequência natural em todos os elementos piezelétricos. Para o primeiro e segundo inserto essa mudança impacta também numa redução da máxima potência gerada na primeira frequência de ressonância, mais acentuada no caso do primeiro. Ao contrário dos demais, para o terceiro elemento piezelétrico nota-se a maximização da potência gerada para todas as frequências de ressonância.

Os resultados evidenciam ainda as características de resposta de cada inserto no gerador de 3GDL. Para o primeiro, notas-se que entre as três frequências de ressonância há duas de anti-ressonância, enquanto para o segundo encontram-se apenas uma, entre o segundo e o terceiro modo de vibrar, e para o terceiro elemento não se verificam anti-ressonâncias entre as frequências naturais 
a)

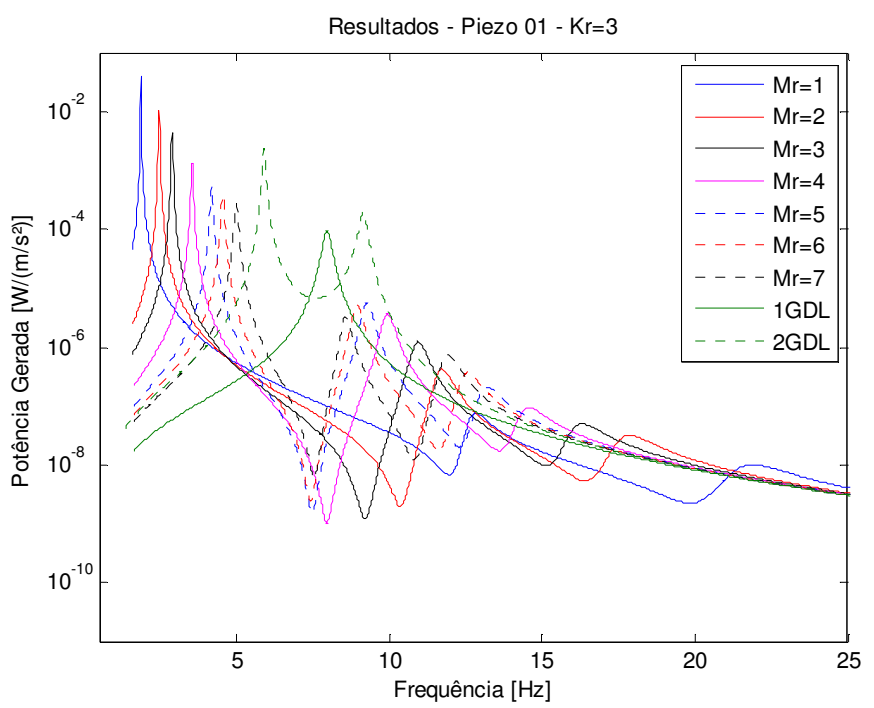

b)

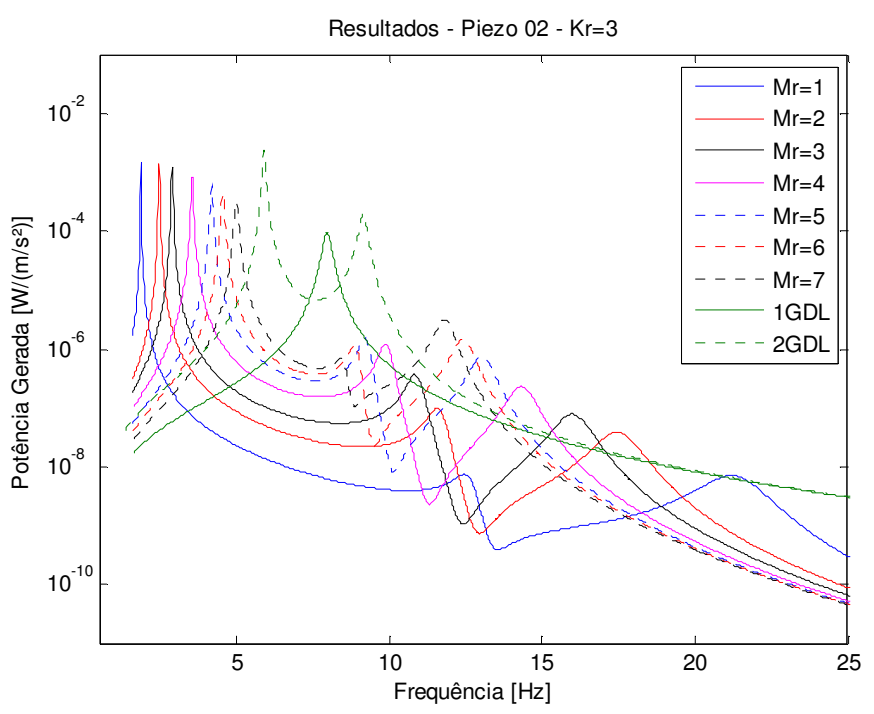

c)

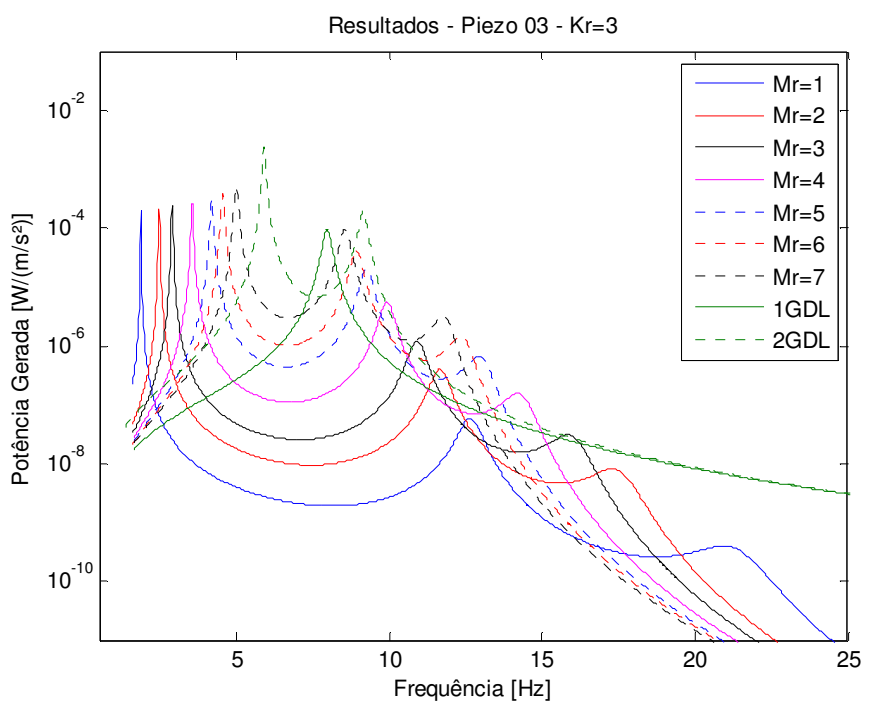

Figura 20 - FRF de potência gerada para diferentes relações de massa $\mathrm{Mr}$, com relação de rigidez $\mathrm{Kr}=3$, sendo: (a) primeiro inserto piezelétrico, (b) segundo inserto piezelétrico, (c) terceiro inserto piezelétrico. 
Ao se fixar a relação de massas e variar a rigidez do primeiro elemento elástico(\#Figura 21 a 23), primeiramente para a $\mathrm{Mr}=1$, em que a maior massa está no terceiro oscilador, nota-se que há pouca influência na potência gerada para os três elementos piezelétricos para a faixa testada, de mais ou menos $50 \%$ da rigidez de referência. No caso do primeiro inserto há um pequeno aumento da potência gerada na primeira frequência natural para rigidezes menores, enquanto nos outros dois insertos esse aumento ocorre para rigidezes mais elevadas.

À medida que se inverte a relação de massas, passando a maior massa a ser a do primeiro oscilador, nota-se que a influência da rigidez do primeiro elemento elástico passa a ser maior, principalmente nas frequências das ressonâncias do que em suas respostas.

Ao se fazer a mesma análise, mas variando-se a rigidez do segundo elemento elástico (\#Figuras 24 a 26), observa-se uma grande influência na terceira ressonância dos três insertos piezelétricos. No caso do primeiro, nota-se ainda grande influência na anti-ressonância entre a primeira e a segunda frequência natural, enquanto para o segundo, verifica-se grandes variações da resposta na segunda frequência natural.

Já em relação à rigidez do terceiro elemento elástico (\#Figuras 27 a 29) observa-se grande influência nas frequências e amplitudes do segundo modo, chegando a provocar alterações também no terceiro modo para relações de massa com maior massa na base. No caso do primeiro modo praticamente não há influência para os dois primeiros insertos, observando-se variações em sua amplitude de resposta apenas para o terceiro elemento piezelétrico. 
a)

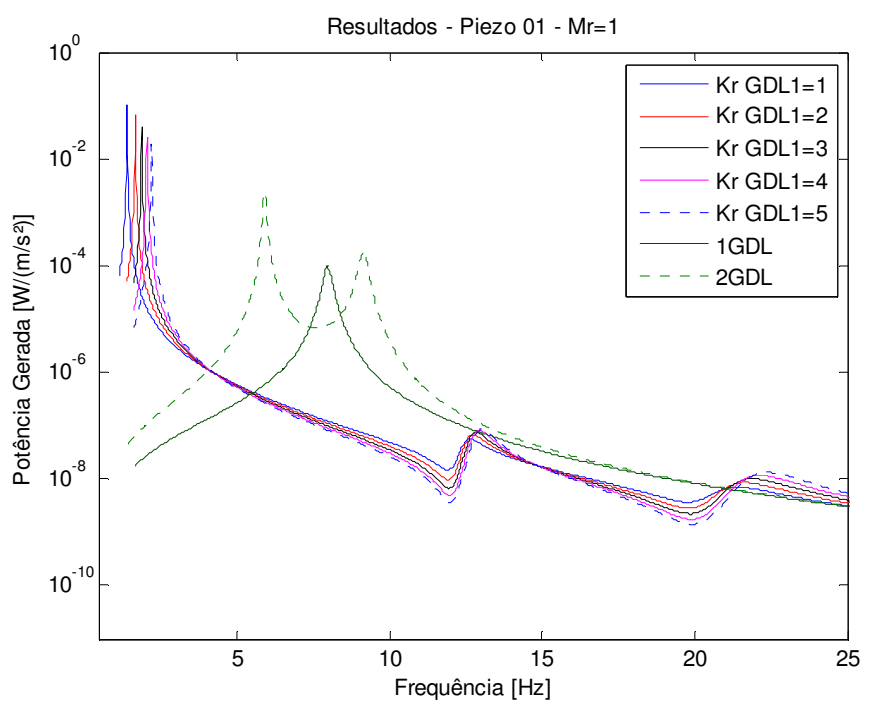

b)

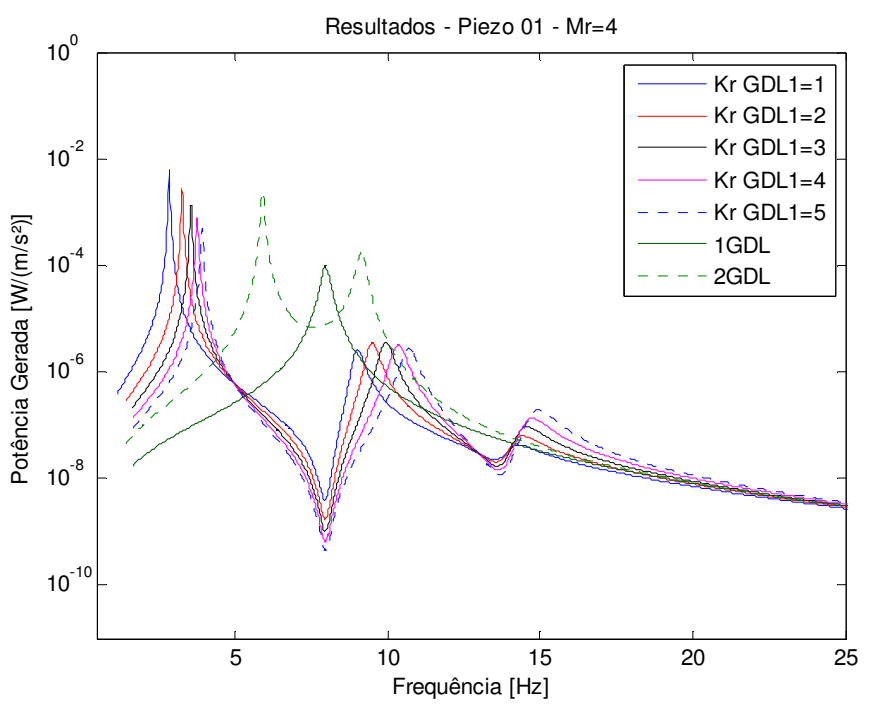

c)

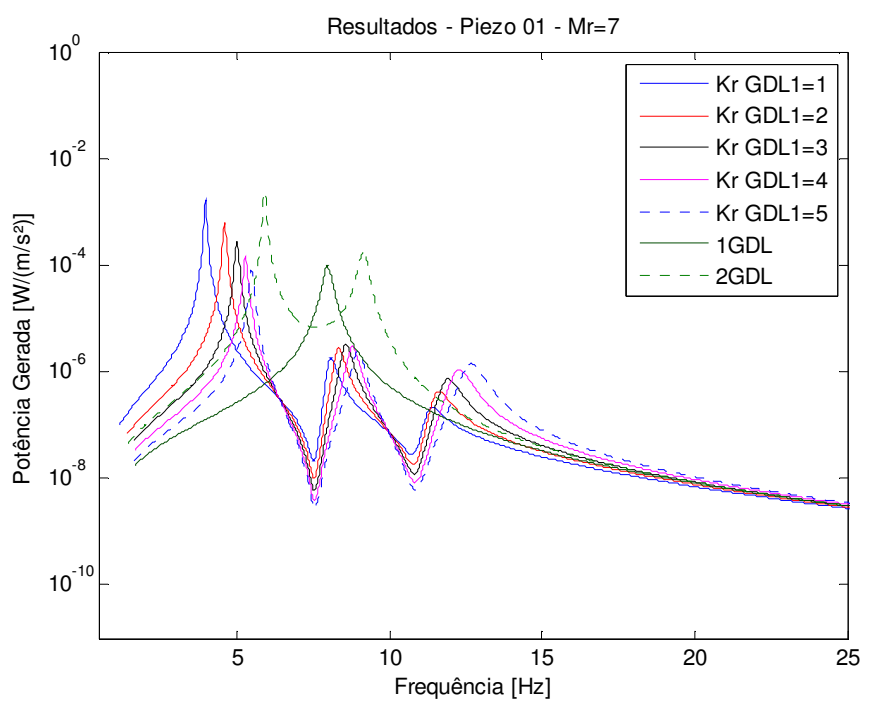

Figura 21 - FRF de potência gerada pelo primeiro inserto piezelétrico para diferentes relações de rigidez Kr do primeiro elemento elástico, com (a) $M r=1$, (b) $M r=4$, (c) $M r=7$. 
a)

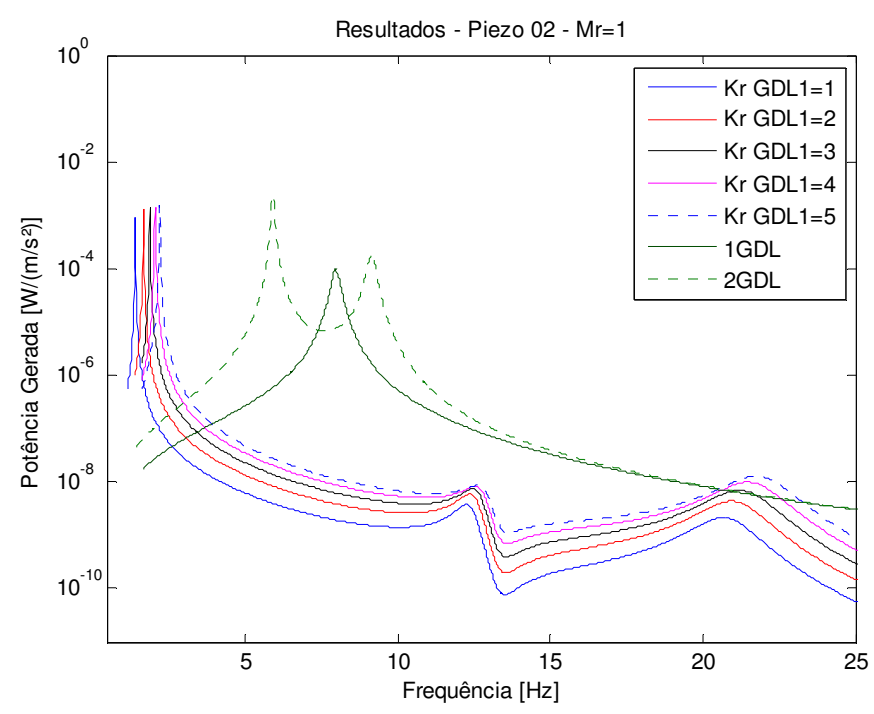

b)

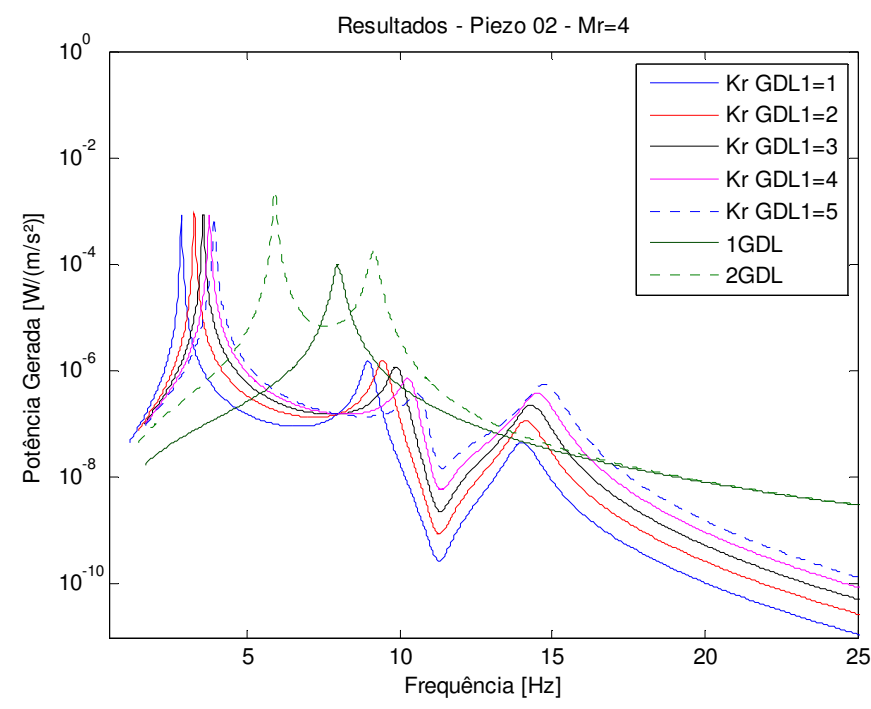

c)

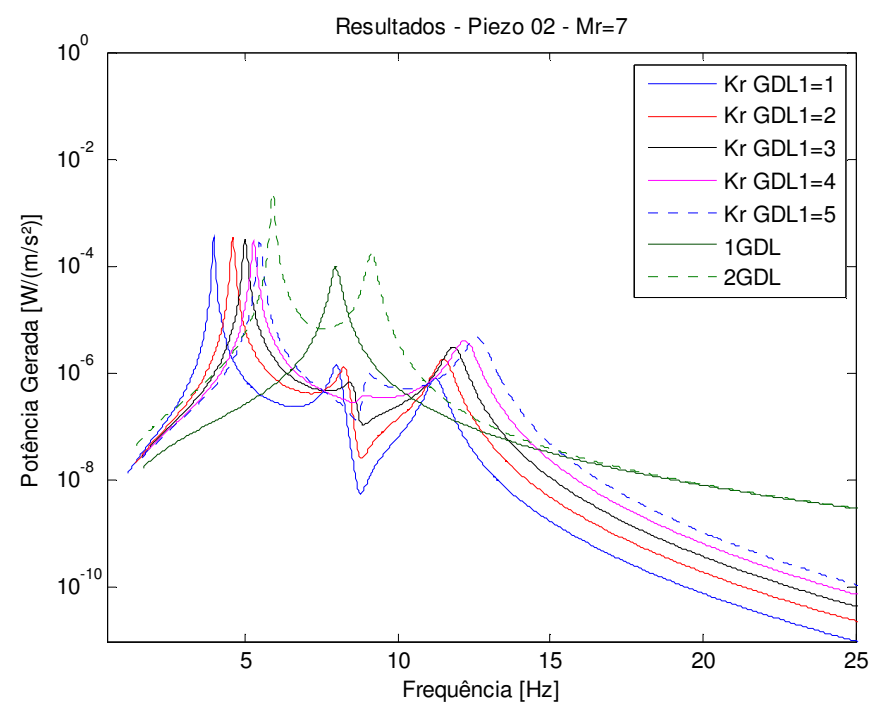

Figura 22 - FRF de potência gerada pelo segundo inserto piezelétrico para diferentes relações de rigidez Kr do primeiro elemento elástico, com (a) $\mathrm{Mr}=1$, (b) $\mathrm{Mr}=4$, (c) $\mathrm{Mr}=7$. 
a)

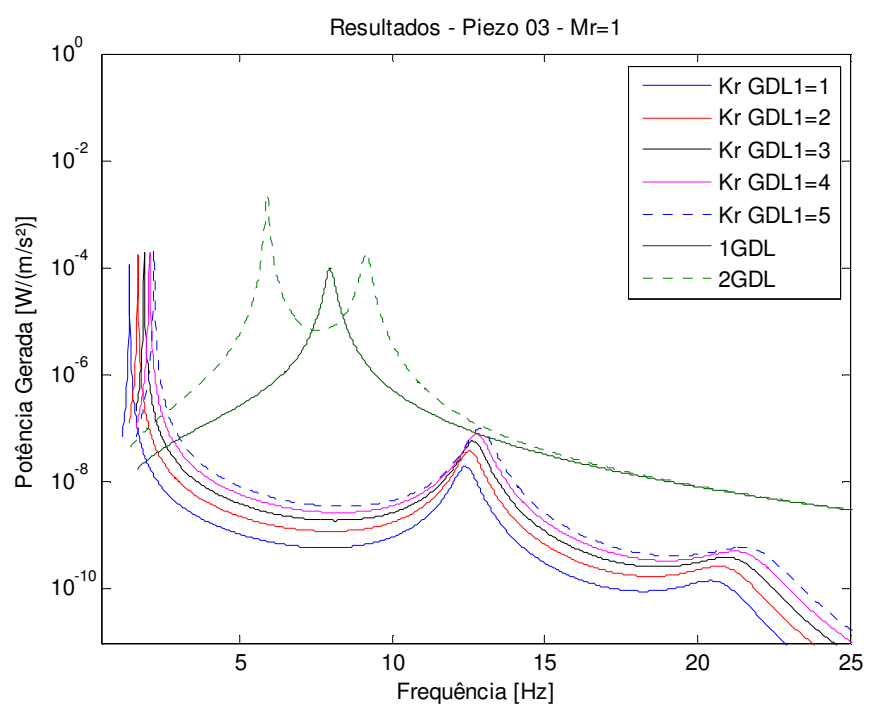

b)

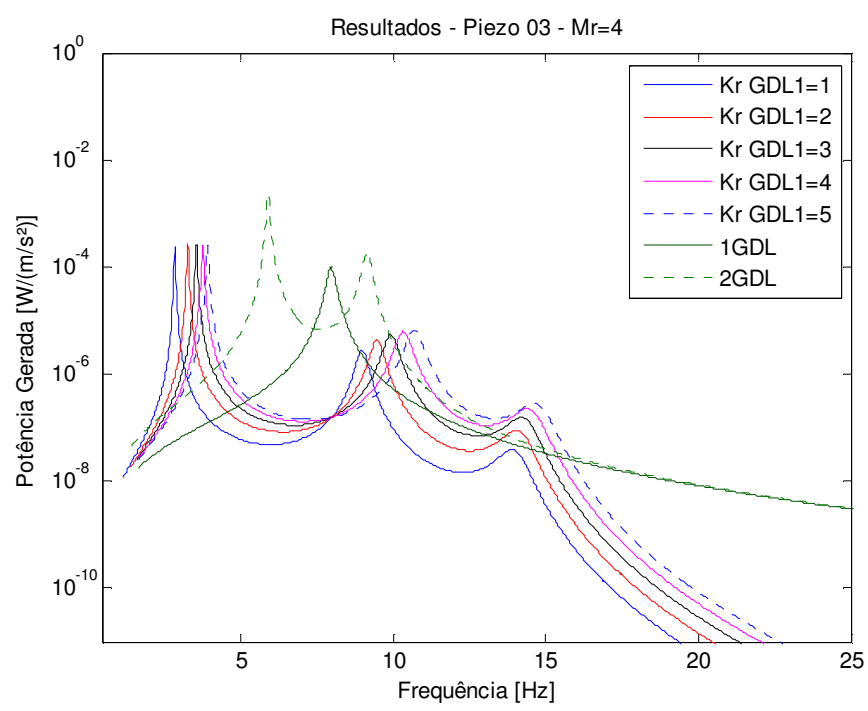

c)

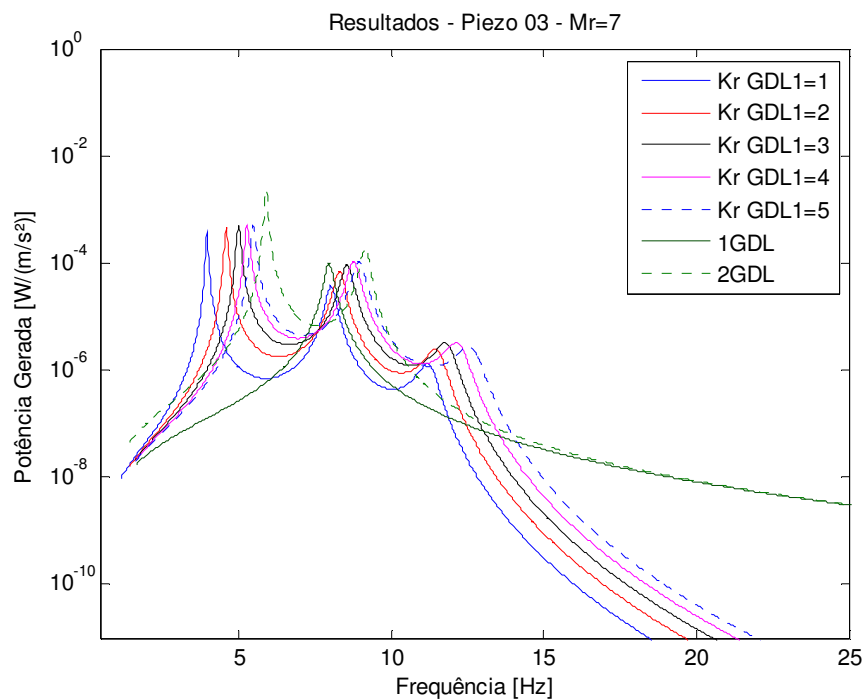

Figura 23 - FRF de potência gerada pelo terceiro inserto piezelétrico para diferentes relações de rigidez Kr do primeiro elemento elástico, com (a) $\mathrm{Mr}=1$, (b) $\mathrm{Mr}=4$, (c) $\mathrm{Mr}=7$. 
a)

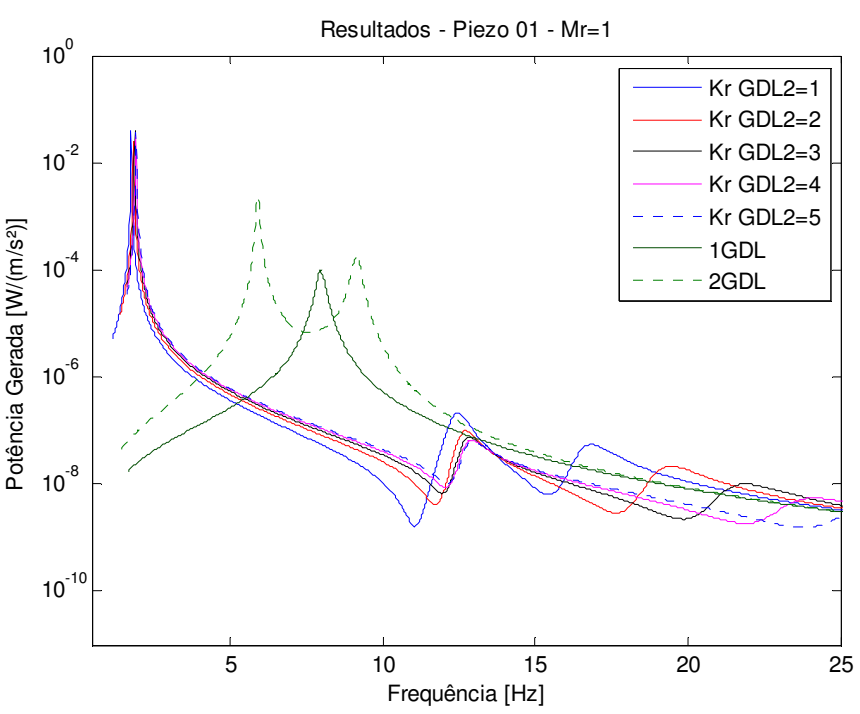

b)

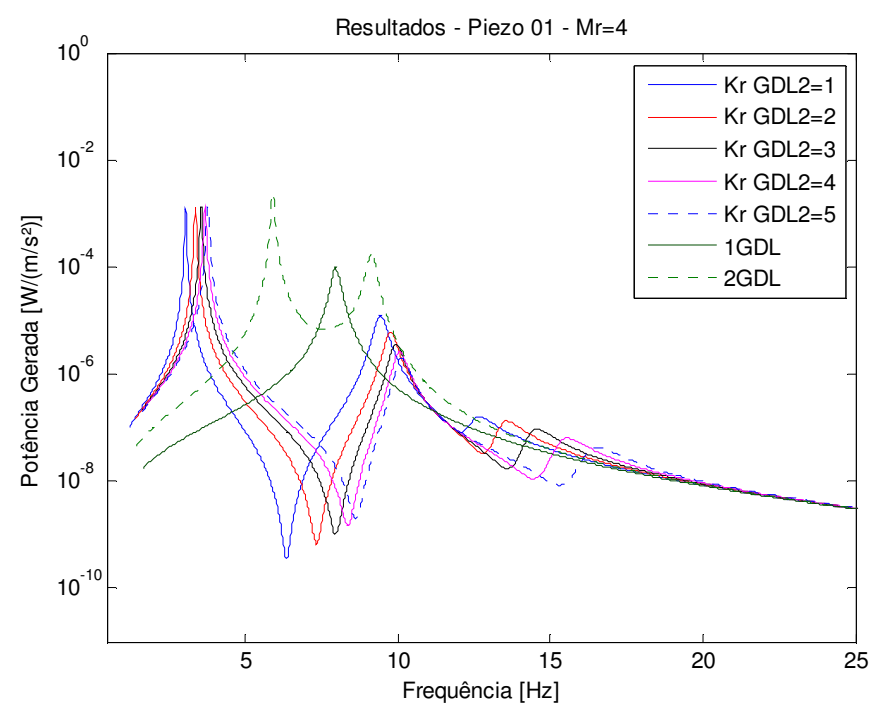

c)

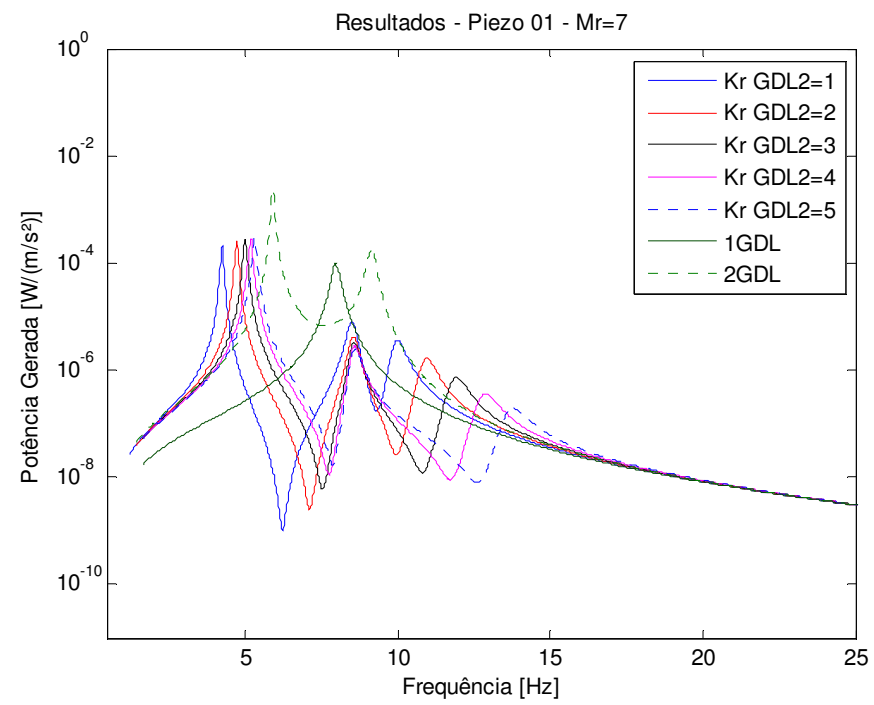

Figura 24 - FRF de potência gerada pelo primeiro inserto piezelétrico para diferentes relações de rigidez Kr do segundo elemento elástico, com (a) $\mathrm{Mr}=1$, (b) $\mathrm{Mr}=4$, (c) $\mathrm{Mr}=7$. 
a)

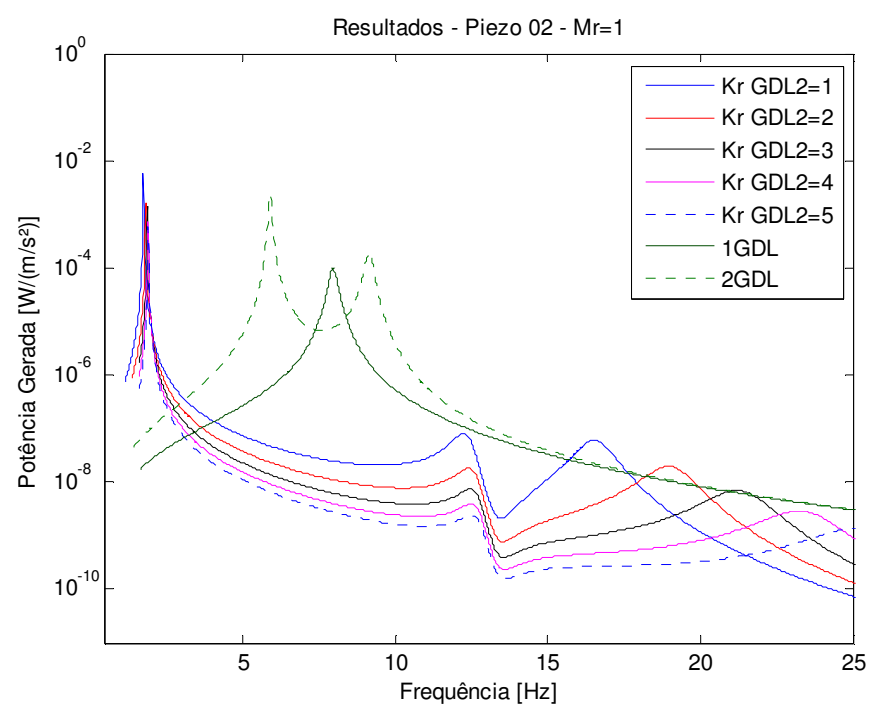

b)

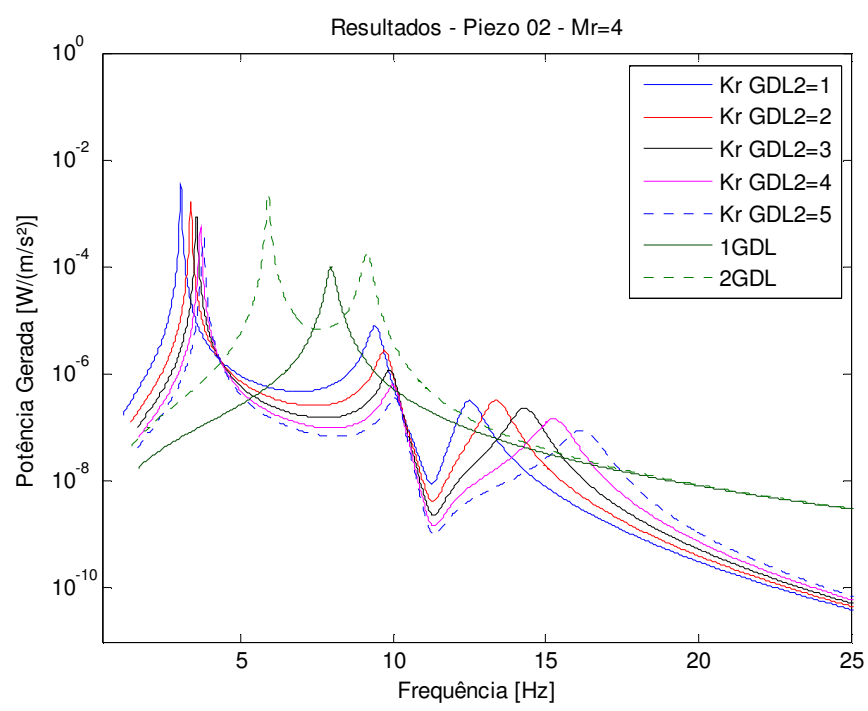

c)

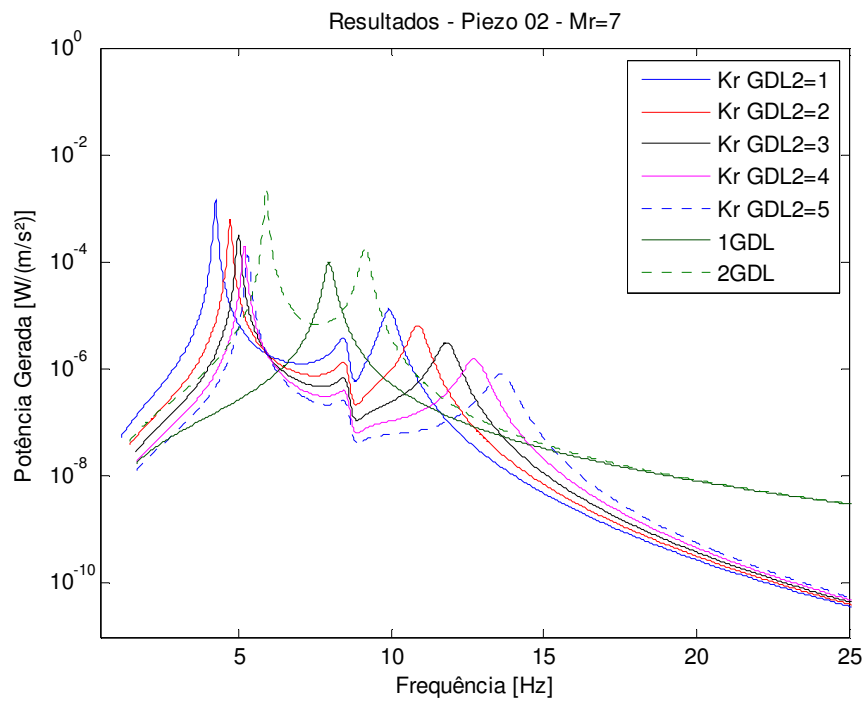

Figura 25 - FRF de potência gerada pelo segundo inserto piezelétrico para diferentes relações de rigidez Kr do segundo elemento elástico, com (a) $\mathrm{Mr}=1$, (b) $\mathrm{Mr}=4$, (c) $\mathrm{Mr}=7$. 
a)

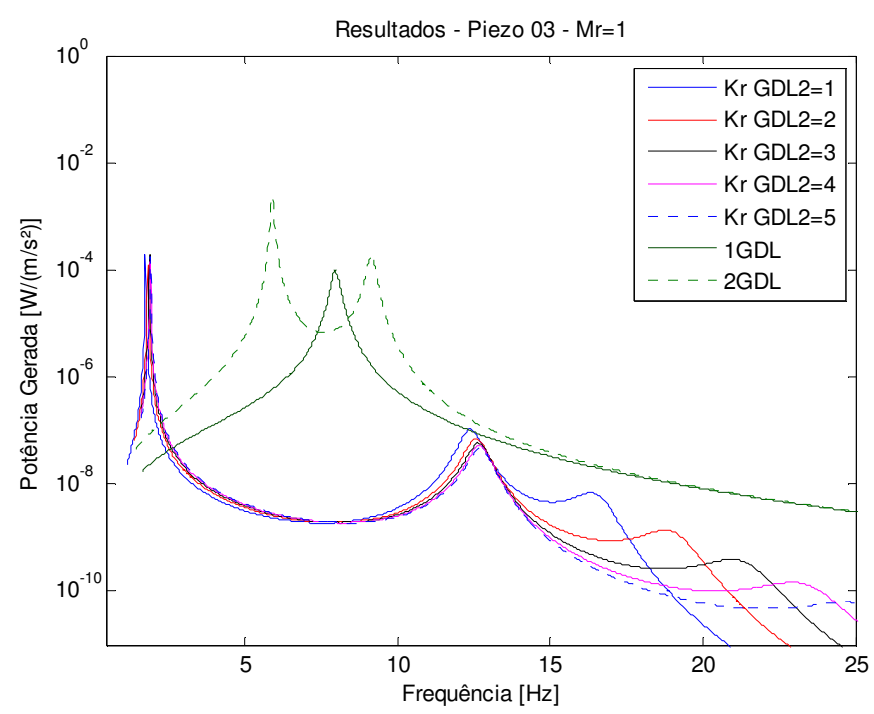

b)

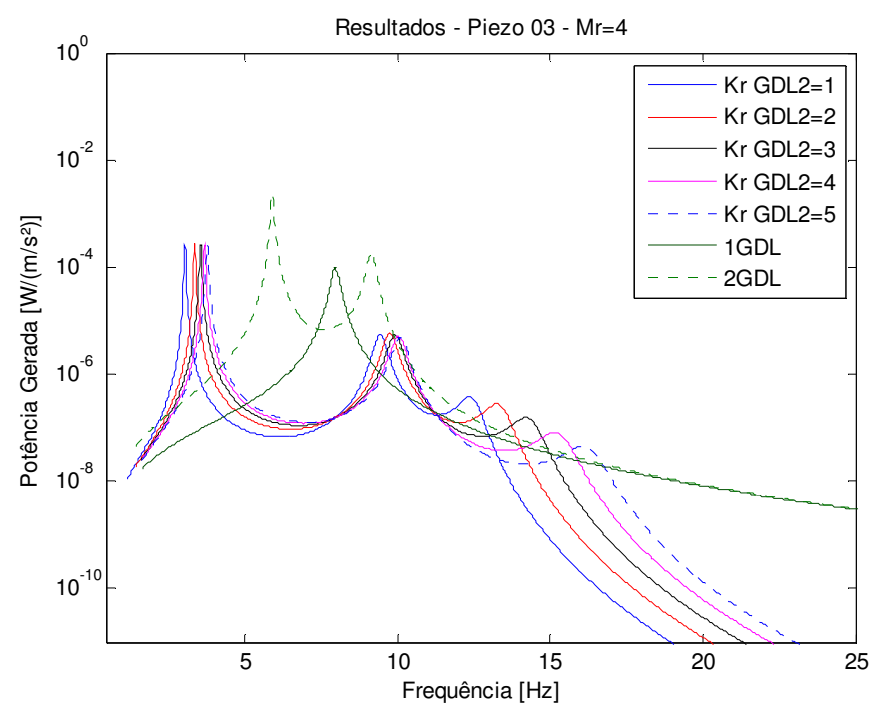

c)

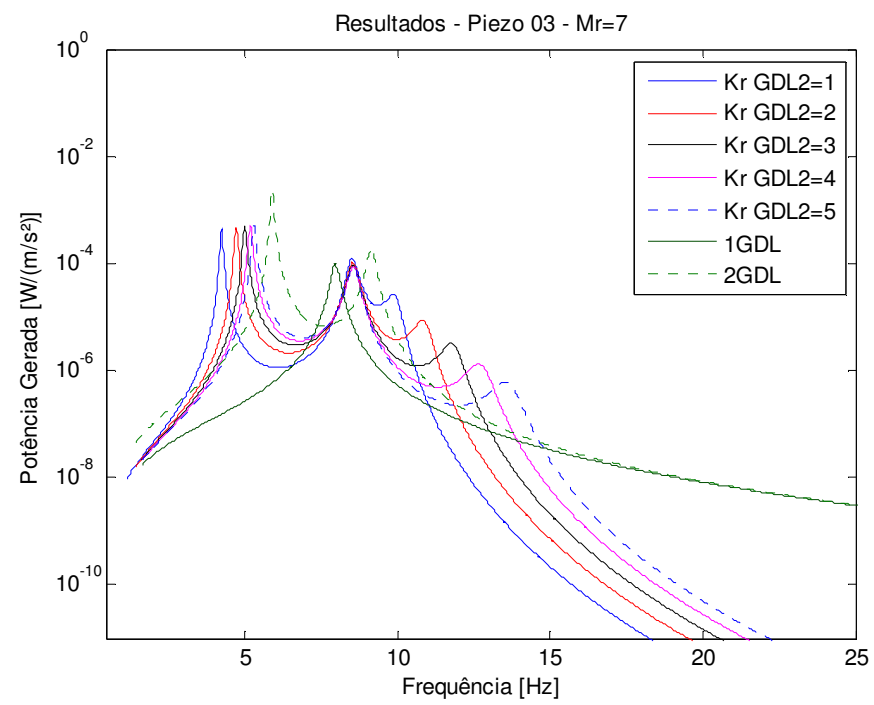

Figura 26 - FRF de potência gerada pelo terceiro inserto piezelétrico para diferentes relações de rigidez Kr do segundo elemento elástico, com (a) $\mathrm{Mr}=1$, (b) $\mathrm{Mr}=4$, (c) $\mathrm{Mr}=7$. 
a)

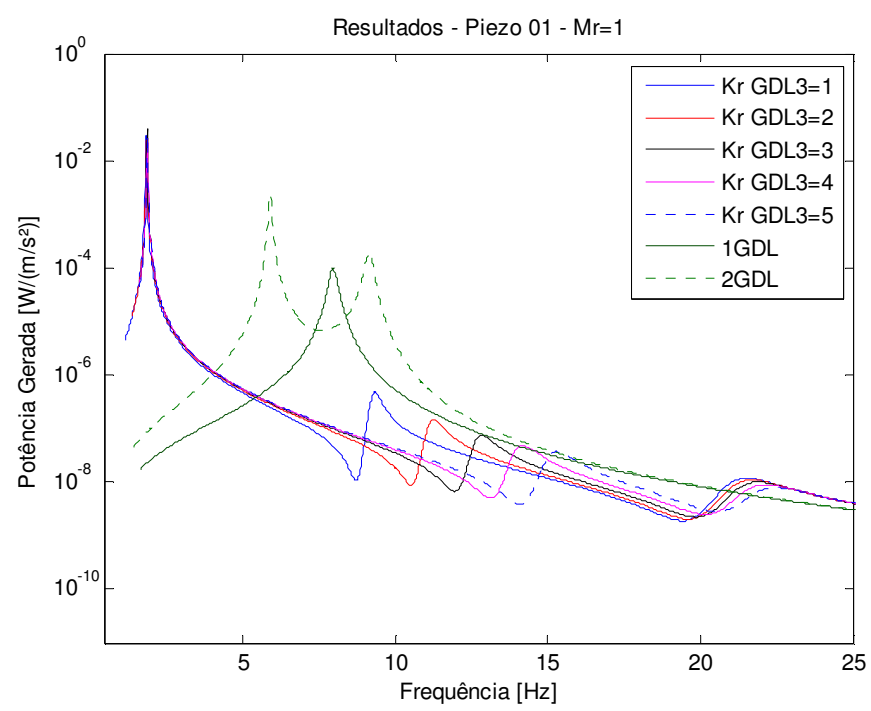

b)

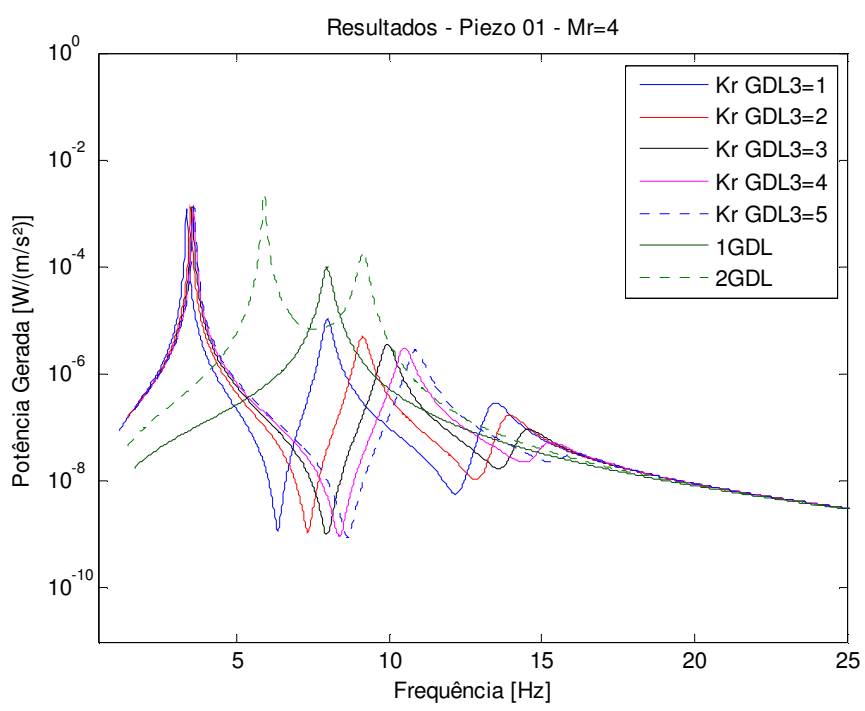

c)

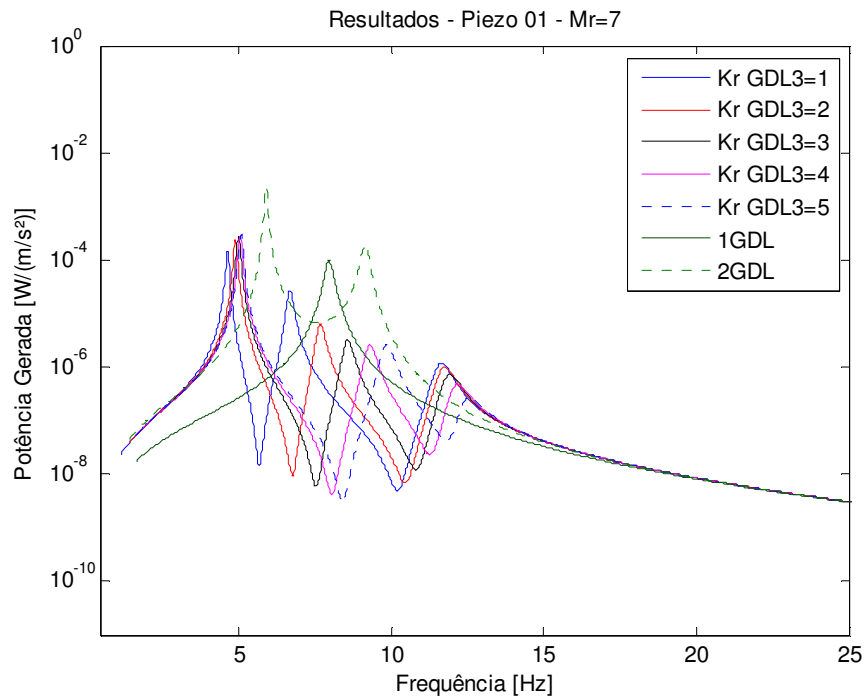

Figura 27 - FRF de potência gerada pelo primeiro inserto piezelétrico para diferentes relações de rigidez Kr do terceiro elemento elástico, com (a) $\mathrm{Mr}=1$, (b) $\mathrm{Mr}=4$, , (c) $\mathrm{Mr}=7$. 
a)

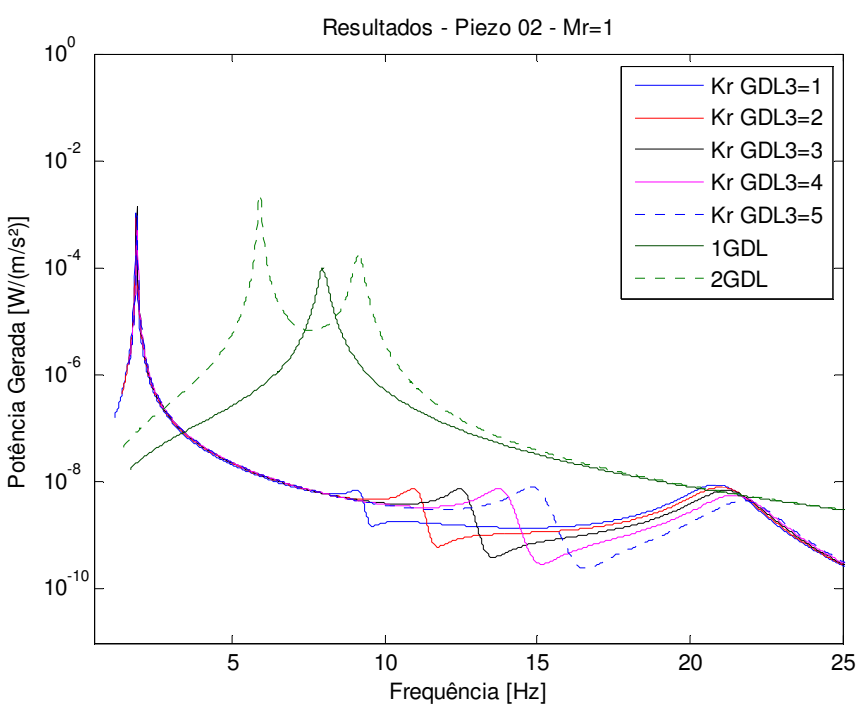

b)

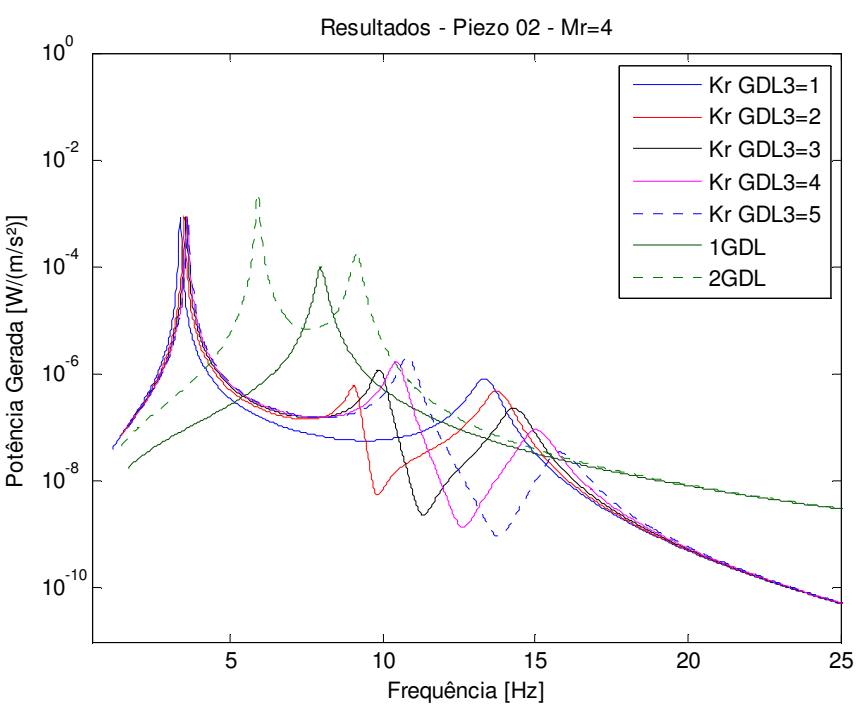

c)

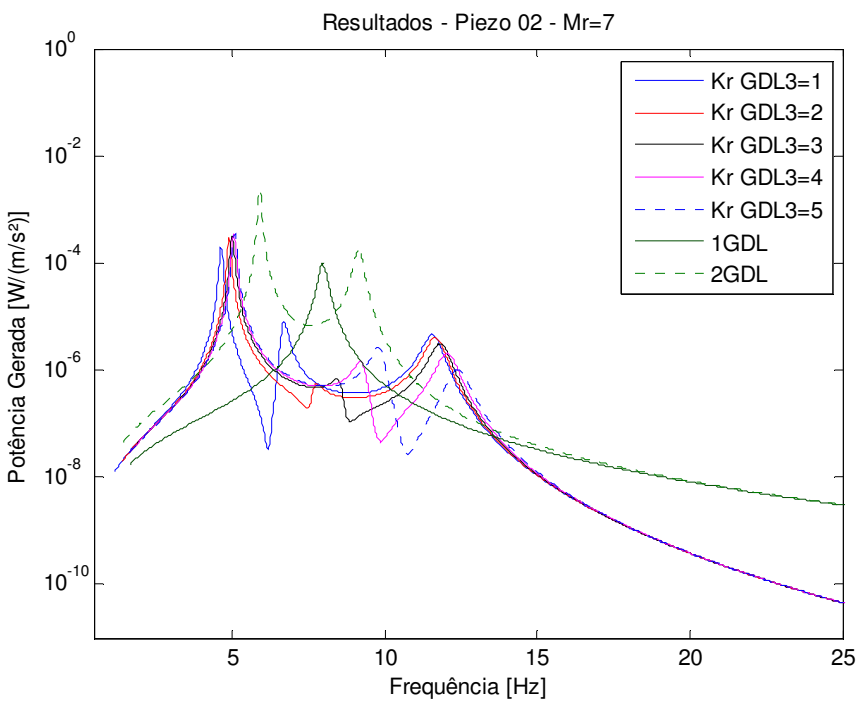

Figura 28 - FRF de potência gerada pelo segundo inserto piezelétrico para diferentes relações de rigidez Kr do terceiro elemento elástico, com (a) $\mathrm{Mr}=1$, (b) $\mathrm{Mr}=4$, (c) $\mathrm{Mr}=7$. 
a)

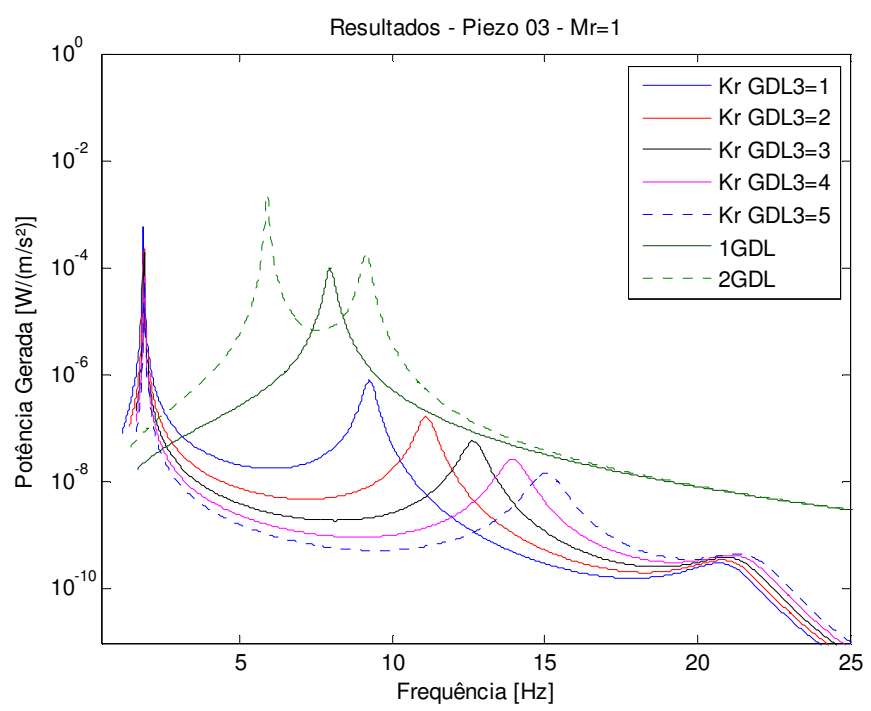

b)

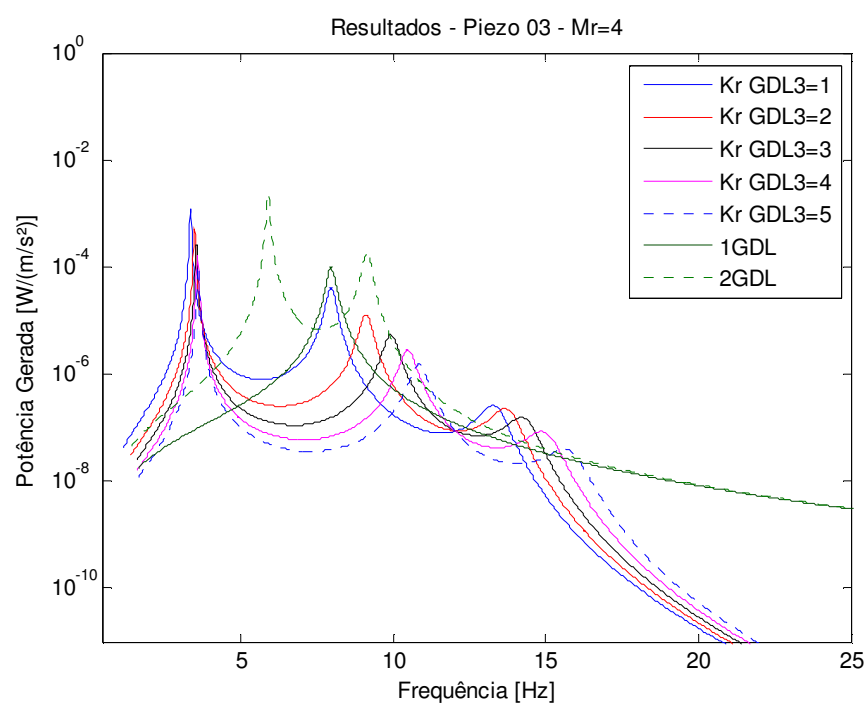

c)

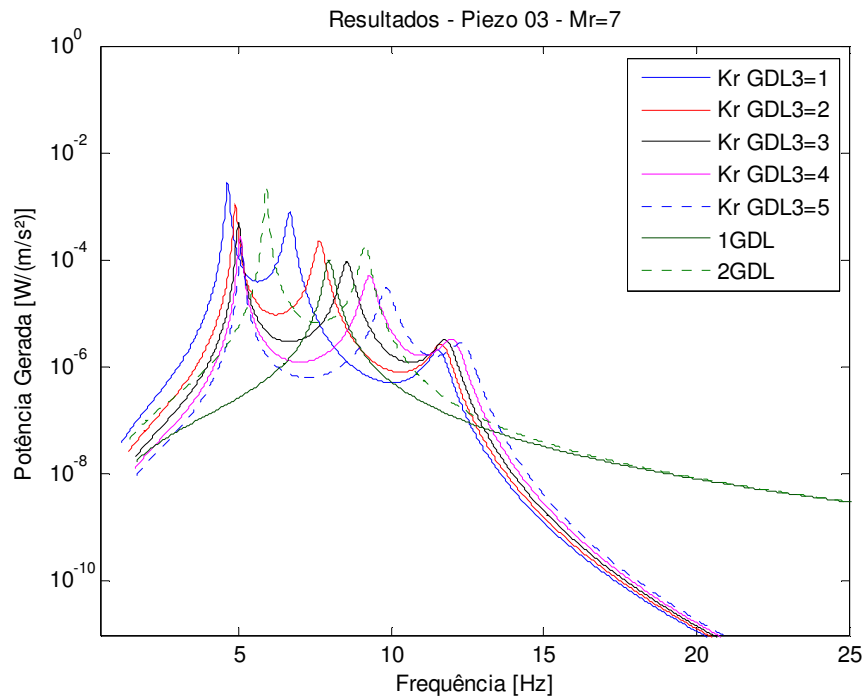

Figura 29 - FRF de potência gerada pelo terceiro inserto piezelétrico para diferentes relações de rigidez Kr do terceiro elemento elástico, com (a) $M r=1$, (b) $M r=4$, , c) $M r=7$. 


\subsubsection{Estudo de Sensibilidade 2}

No segundo estudo variou-se a proporção entre as massas mantendo-se sempre o primeiro e o terceiro oscilador com massas idênticas, cobrindo desde proporções com $82 \%$ da massa no oscilador central, até apenas 5\% para o mesmo (\#Tabelas 6 e 7). Assim como no primeiro experimento, estudou-se também os efeitos da variação da rigidez de cada termo em relação à rigidez de referência.

Tabela 6 - Massa dos osciladores em cada configuração do segundo estudo de sensibilidade do gerador de três graus de liberdade

\section{Estudo de Sensibilidade 2}

\begin{tabular}{cccc}
\hline $\begin{array}{c}\text { ID da Relação de Massa } \\
\text { Mr }\end{array}$ & $\begin{array}{c}\text { Massa 1 } \\
{[\mathbf{k g}]}\end{array}$ & $\begin{array}{c}\text { Massa 2 } \\
{[\mathbf{k g}]}\end{array}$ & $\begin{array}{c}\text { Massa 3 } \\
{[\mathbf{k g}]}\end{array}$ \\
\hline 1 & 0,0044 & 0,0393 & 0,0044 \\
2 & 0,0080 & 0,0320 & 0,0080 \\
3 & 0,0111 & 0,0258 & 0,0111 \\
4 & 0,0160 & 0,0160 & 0,0160 \\
5 & 0,0198 & 0,0085 & 0,0198 \\
6 & 0,0213 & 0,0053 & 0,0213 \\
7 & 0,0227 & 0,0025 & 0,0227 \\
\hline
\end{tabular}

Tabela 7 - Relação de distribuição de massa entre os osciladores em cada configuração do segundo estudo de sensibilidade do gerador de três graus de liberdade

\section{Estudo de Sensibilidade 2}

\begin{tabular}{cccc}
\hline $\begin{array}{c}\text { ID da Relação de Massa } \\
\text { Mr }\end{array}$ & $\begin{array}{c}\text { Massa 1 } \\
{[\%]}\end{array}$ & $\begin{array}{c}\text { Massa 2 } \\
{[\%]}\end{array}$ & $\begin{array}{c}\text { Massa 3 } \\
{[\%]}\end{array}$ \\
\hline 1 & $9 \%$ & $82 \%$ & $9 \%$ \\
2 & $17 \%$ & $67 \%$ & $17 \%$ \\
3 & $23 \%$ & $54 \%$ & $23 \%$ \\
4 & $33 \%$ & $33 \%$ & $33 \%$ \\
5 & $41 \%$ & $18 \%$ & $41 \%$ \\
6 & $44 \%$ & $11 \%$ & $44 \%$ \\
7 & $47 \%$ & $5 \%$ & $47 \%$ \\
\hline
\end{tabular}


Comparando-se as diferentes relações de massa (\#Figura 30) nota-se um comportamento curioso, em que as frequências da primeira e da segunda ressonância do sistema permanecem as mesmas para distribuições de massa opostas. No entanto nota-se para o primeiro e segundo inserto uma sensível variação na amplitude das respostas, sendo que para o primeiro a diminuição da massa central impactou na redução das amplitudes para a primeira ressonância e aumento das mesmas para a segunda, enquanto para o segundo inserto houve a maximização de ambas as amplitudes com a redução da massa central.

Para as variações de rigidez, nota-se novamente que variações no primeiro elemento elástico (\#Figura 31) tem pouca influência nas amplitudes da primeira frequência natural, resultando apenas em pequenas variações em sua frequência para as relações com maior massa central. Já nas relações com menor massa central há uma significativa influência tanto na amplitude quanto na frequência da segunda ressonância para todos os elementos piezelétricos. No caso do terceiro inserto ocorrem mudanças de amplitude para as duas primeiras as frequências naturais para as relações de menor massa.

Para as variações de rigidez no segundo elemento elástico (\#Figura 32) nota-se uma influência muito pequena para frequências menores, impactando principalmente no terceiro modo de vibrar, em faixas de frequência muito distantes dos primeiros modos.

O mesmo ocorre para as variações de rigidez no terceiro elemento elástico (\#Figura 33), nas quais apenas o terceiro inserto piezelétrico exibe variações na resposta dentro das faixas úteis para o energy harvester, sendo estas variações na segunda frequência natural para as configurações com maior massa central, e nas duas primeiras frequências naturais para os geradores com menor massa central. 
a)

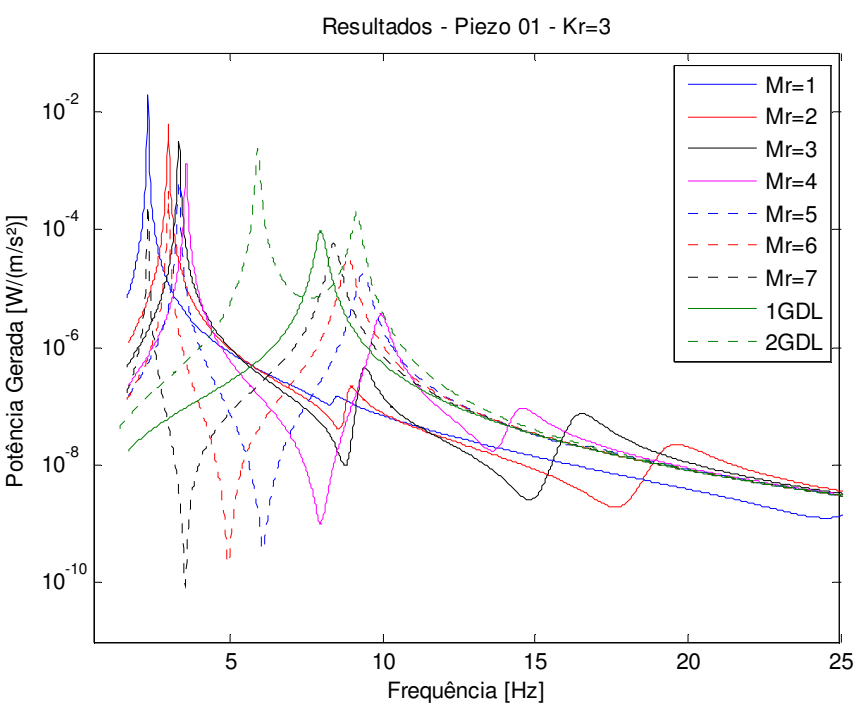

b)

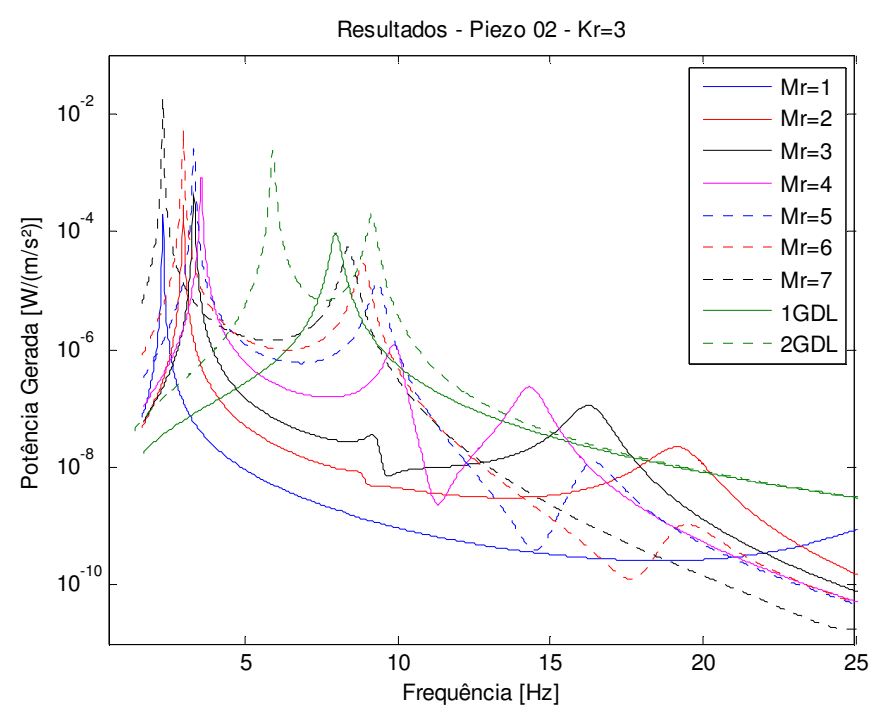

c)

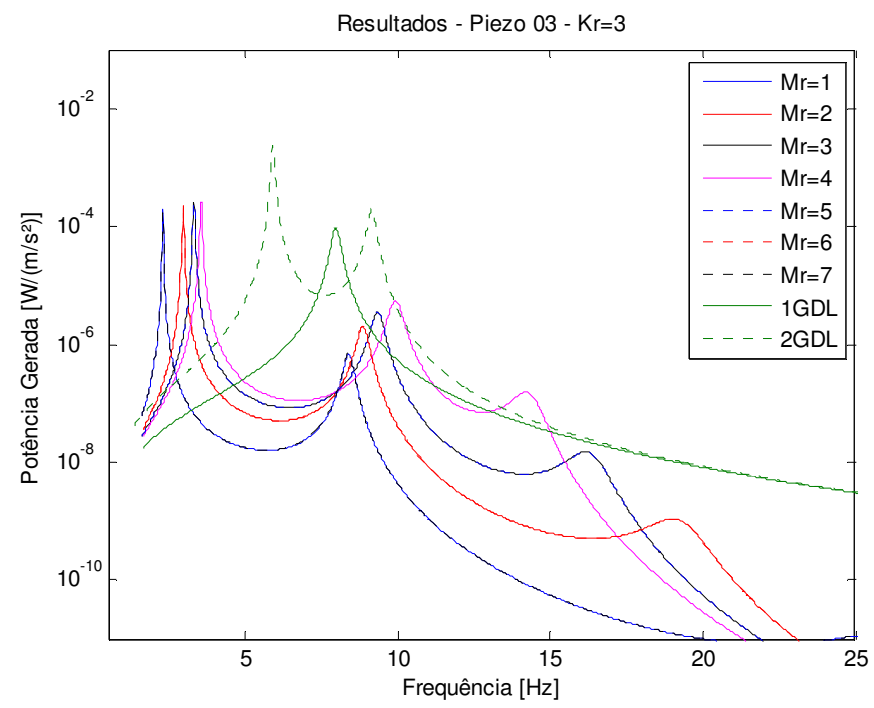

Figura 30 - FRF de potência gerada para diferentes relações de massa Mr do segundo estudo de sensibilidade, com relação de rigidez $\mathrm{Kr}=3$, sendo: (a) primeiro inserto piezelétrico, (b) segundo inserto piezelétrico, (c) terceiro inserto piezelétrico. 
a)

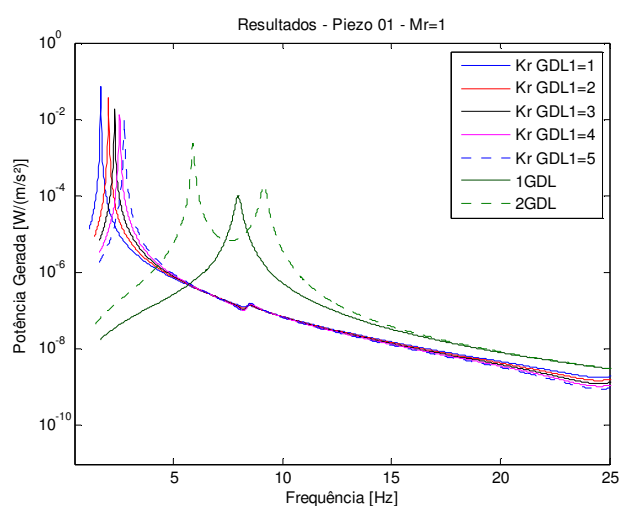

c)

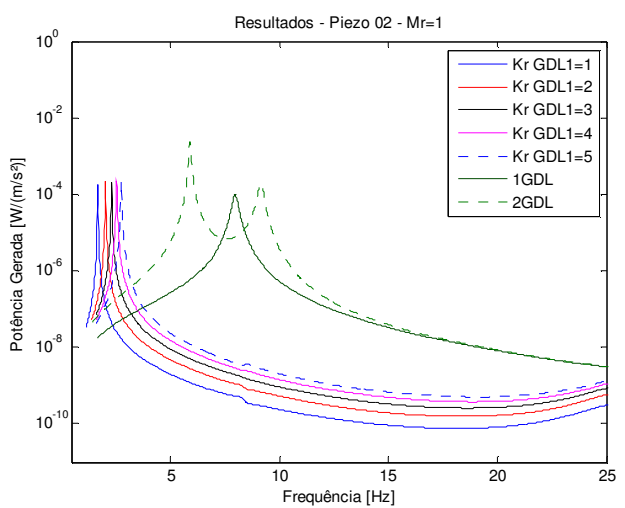

e)

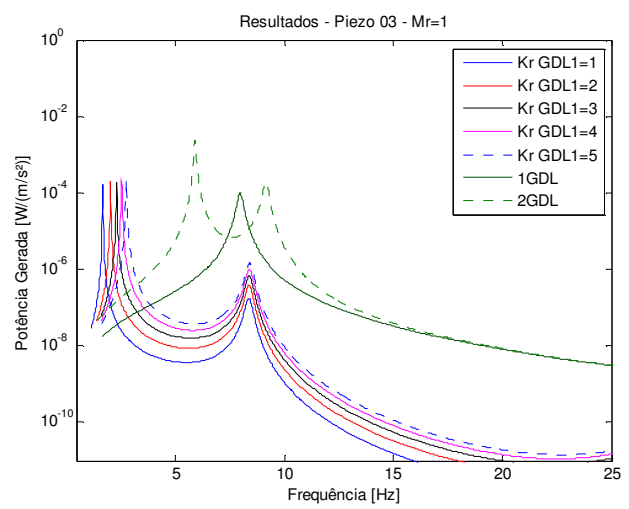

b)

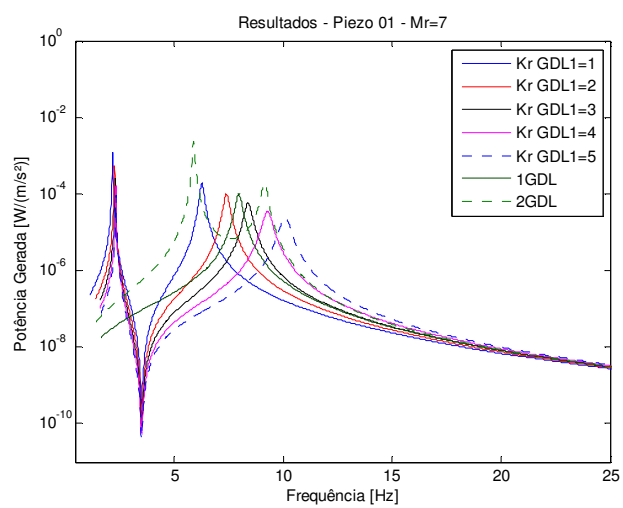

d)

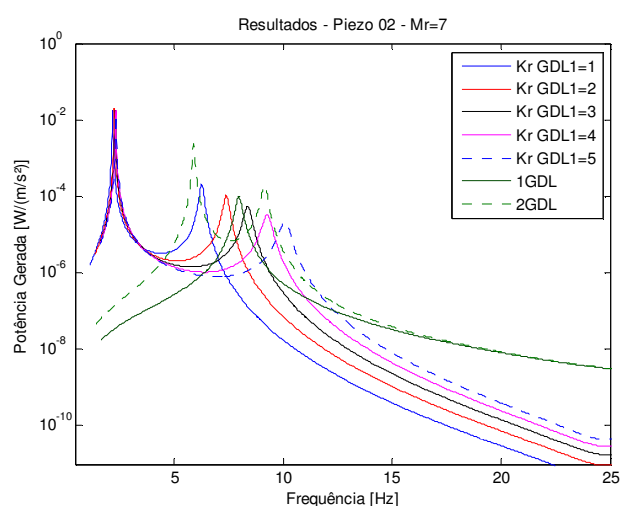

f)

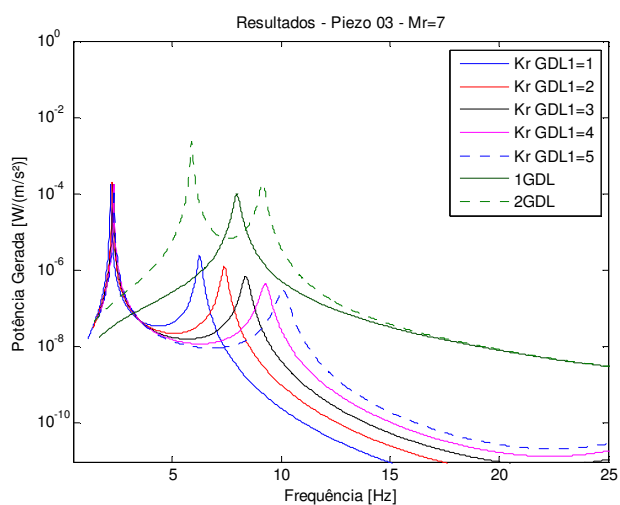

Figura 31 - FRF de potência gerada para diferentes relações de rigidez $\mathrm{Kr}$ do primeiro elemento elástico para as relações de massa $\mathrm{Mr}=1$ e $\mathrm{Mr}=7$ do segundo estudo de sensibilidade, sendo: (a) primeiro inserto com $\mathrm{Mr}=1$, (b) primeiro inserto com $\mathrm{Mr}=7$, (c) segundo inserto com $\mathrm{Mr}=1$, (d) segundo inserto com $\mathrm{Mr}=7$, (e) terceiro inserto com $\mathrm{Mr}=1$, (e) terceiro inserto com $\mathrm{Mr}=7$. 
a)

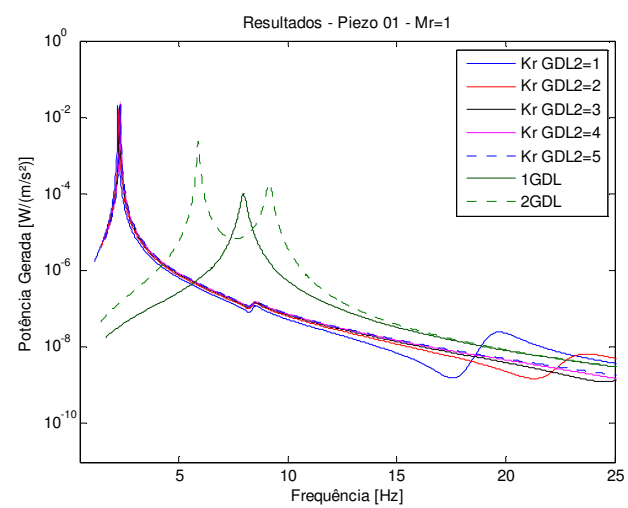

c)

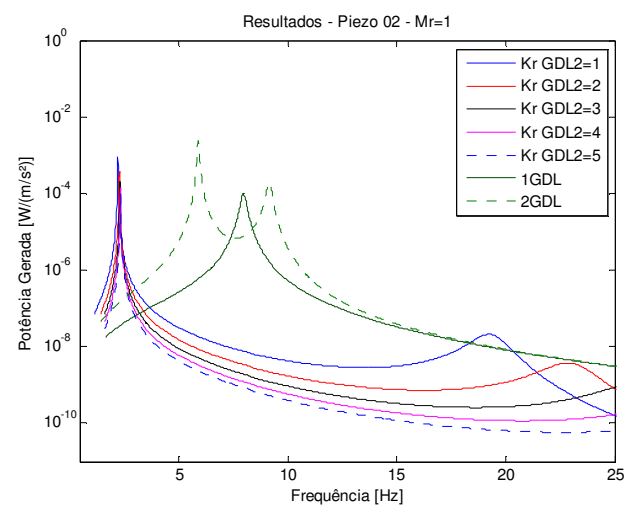

e)

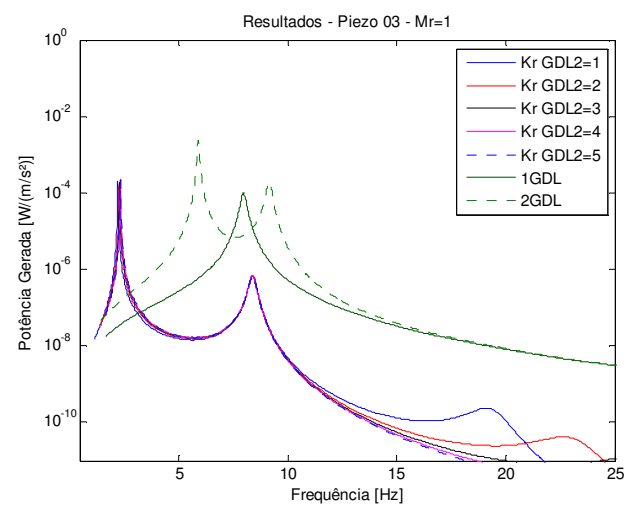

b)

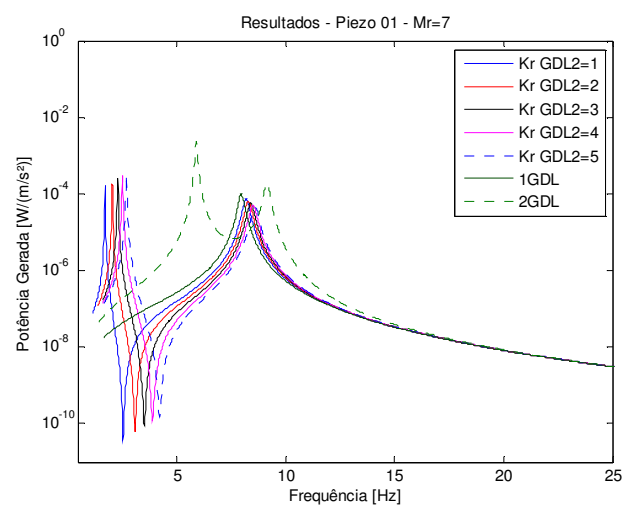

d)

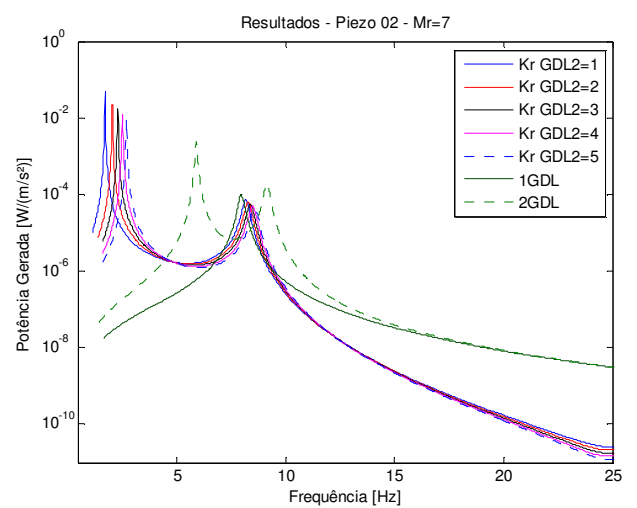

f)

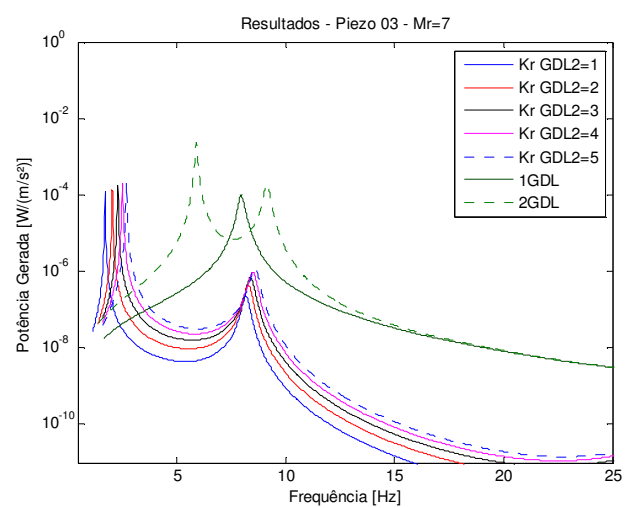

Figura 32 - FRF de potência gerada para diferentes relações de rigidez $\mathrm{Kr}$ do segundo elemento elástico para as relações de massa $\mathrm{Mr}=1$ e $\mathrm{Mr}=7$ do segundo estudo de sensibilidade, sendo: (a) primeiro inserto com $\mathrm{Mr}=1$, (b) primeiro inserto com $\mathrm{Mr}=7$, (c) segundo inserto com $\mathrm{Mr}=1$, (d) segundo inserto com $\mathrm{Mr}=7$, (e) terceiro inserto com $\mathrm{Mr}=1$, (e) terceiro inserto com $\mathrm{Mr}=7$. 
a)

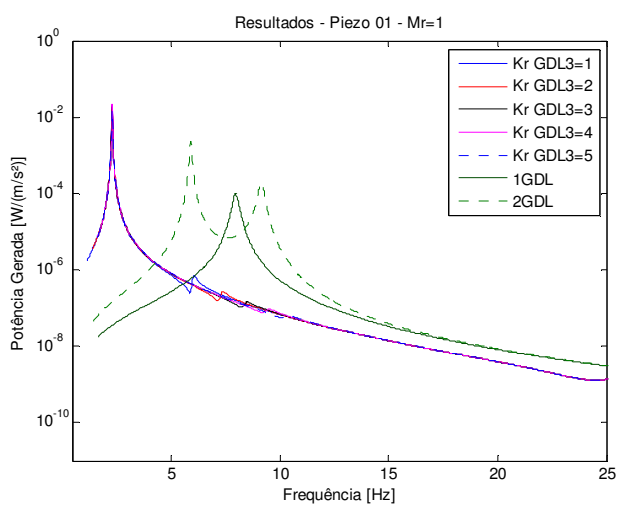

c)

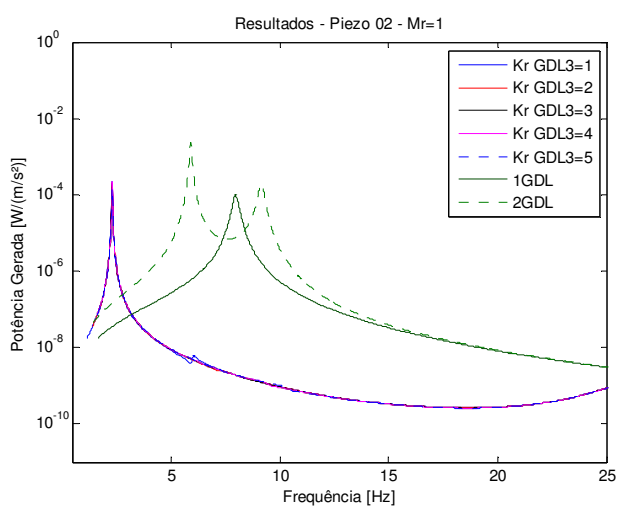

e)

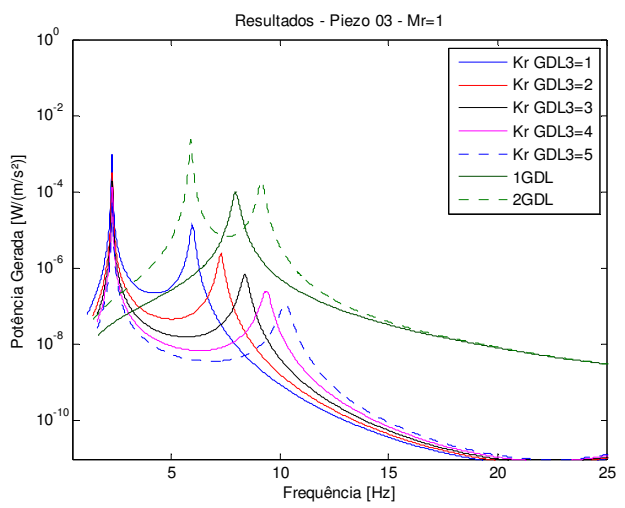

b)

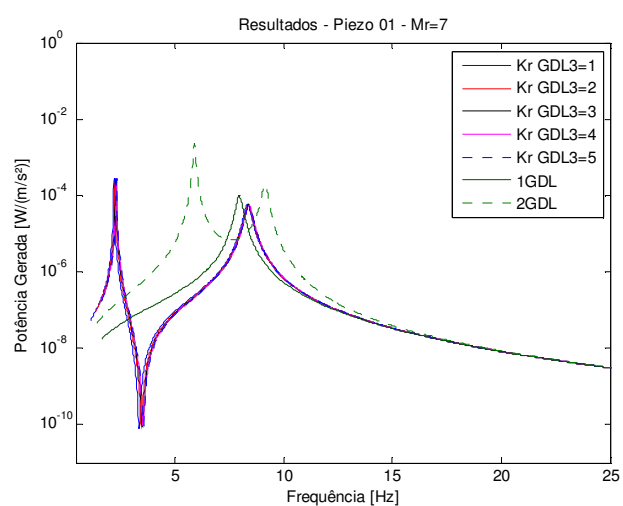

d)

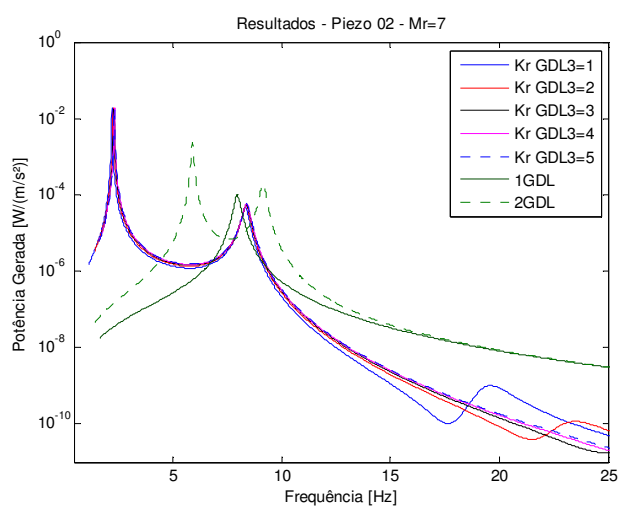

f)

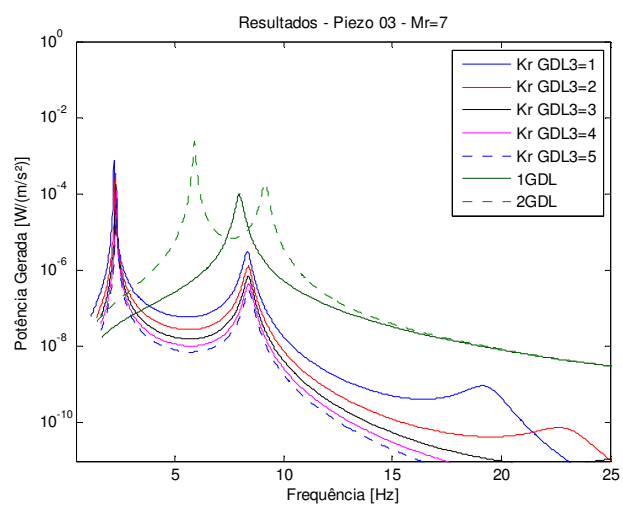

Figura 33 - FRF de potência gerada para diferentes relações de rigidez $\mathrm{Kr}$ do terceiro elemento elástico para as relações de massa $\mathrm{Mr}=1$ e $\mathrm{Mr}=7$ do segundo estudo de sensibilidade, sendo: (a) primeiro inserto com $M r=1$, (b) primeiro inserto com $M r=7$, (c) segundo inserto com $M r=1$, (d) segundo inserto com $M r=7$, (e) terceiro inserto com $\mathrm{Mr}=1$, (e) terceiro inserto com $\mathrm{Mr}=7$. 


\subsubsection{Estudo de Sensibilidade 3}

No terceiro estudo foram mantidas as duas primeiras massas idênticas variando-se a relação destas com a do terceiro oscilador, conforme valores dispostos nas tabelas 8 e 9.

Tabela 8 - Massa dos osciladores em cada configuração do terceiro estudo de sensibilidade do gerador de três graus de liberdade.

\begin{tabular}{cccc}
\hline \multicolumn{4}{c}{ Estudo de Sensibilidade 3 } \\
\hline ID da Relação de Massa & Massa 1 & Massa 2 & Massa 3 \\
Mr & {$[\mathbf{k g}]$} & {$[\mathbf{k g}]$} & {$[\mathbf{k g}]$} \\
\hline 1 & 0,0044 & 0,0044 & 0,0393 \\
2 & 0,0080 & 0,0080 & 0,0320 \\
3 & 0,0111 & 0,0111 & 0,0258 \\
4 & 0,0160 & 0,0160 & 0,0160 \\
5 & 0,0198 & 0,0198 & 0,0085 \\
6 & 0,0213 & 0,0213 & 0,0053 \\
7 & 0,0227 & 0,0227 & 0,0025 \\
\hline
\end{tabular}

Tabela 9 - Relação de distribuição de massa entre os osciladores em cada configuração do terceiro estudo de sensibilidade do gerador de três graus de liberdade.

\begin{tabular}{cccc}
\hline \multicolumn{4}{c}{ Estudo de Sensibilidade 3 } \\
\hline ID da Relação de Massa & Massa 1 & Massa 2 & Massa 3 \\
Mr & {$[\%]$} & {$[\%]$} & {$[\%]$} \\
\hline 1 & $9 \%$ & $9 \%$ & $82 \%$ \\
2 & $17 \%$ & $17 \%$ & $67 \%$ \\
3 & $23 \%$ & $23 \%$ & $54 \%$ \\
4 & $33 \%$ & $33 \%$ & $33 \%$ \\
5 & $41 \%$ & $41 \%$ & $18 \%$ \\
6 & $44 \%$ & $44 \%$ & $11 \%$ \\
7 & $47 \%$ & $47 \%$ & $5 \%$ \\
\hline
\end{tabular}

Avaliando-se os resultados para a rigidez de referência $(\mathrm{Kr}=3)$ nota-se que à medida que se diminui a massa da extremidade ocorre a aproximação das frequências de ressonância (\#Figura 34), com redução das amplitudes nas duas primeiras frequências naturais e aumento da amplitude na terceira para os insertos 1 e 2. Para o terceiro elemento piezelétrico, a redução de massa impacta no aumento da potencia total gerada em toda a faixa entre as três frequências naturais. 
Já para as variações de rigidez, nota-se que nas configurações com maior massa na extremidade as variações dos dois primeiros elementos elásticos têm maior influência na segunda ressonância (\#Figuras 35 e 36), enquanto a rigidez do terceiro elemento elástico impacta apenas na potência gerada pelo terceiro inserto piezelétrico para a faixa útil de trabalho (\#Figuras 37). Já para as configurações com menor massa na extremidade é possível verificar que a rigidez da primeira e segunda mola tem influência principalmente nas frequências do primeiro e terceiro modo, enquanto a rigidez da terceira mola reflete no valor das frequências do segundo. 
a)

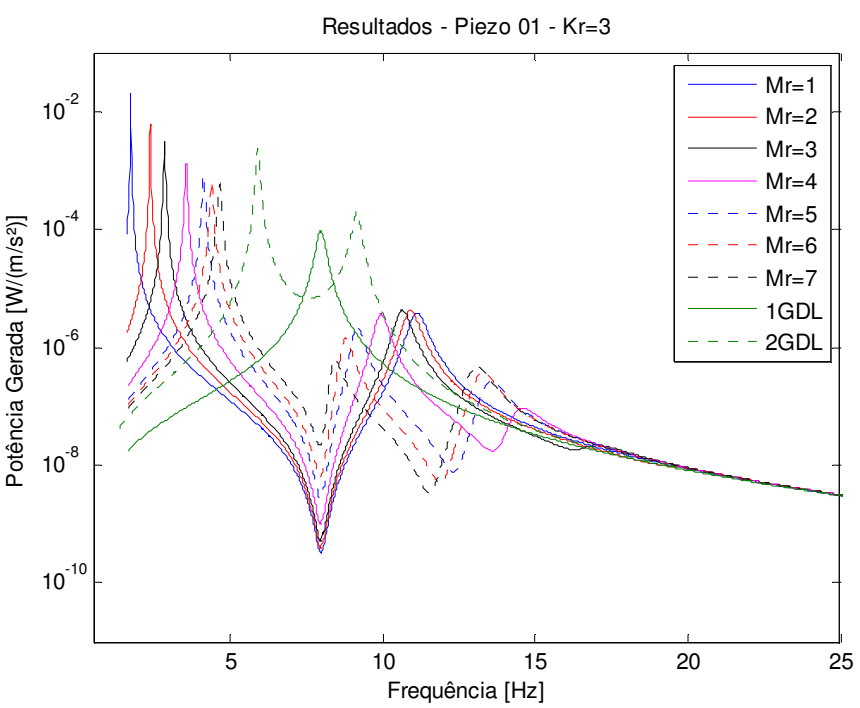

b)

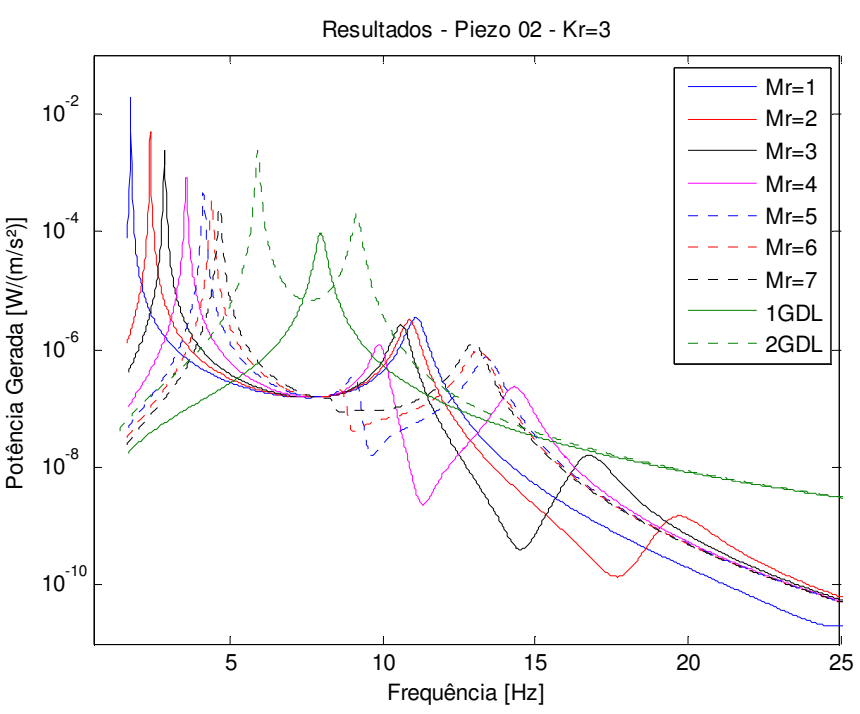

c)

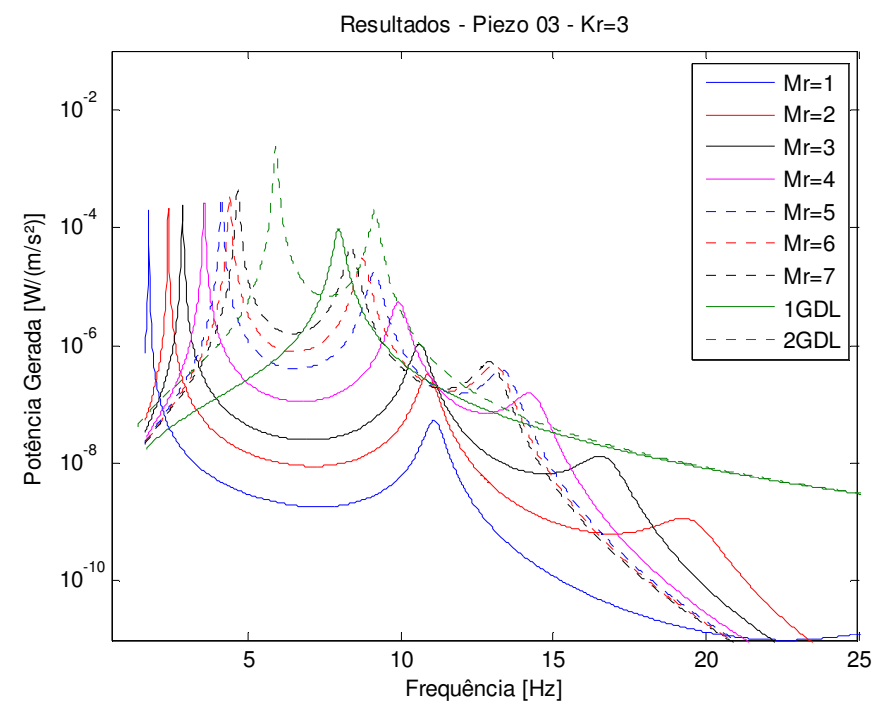

Figura 34 - FRF de potência gerada para diferentes relações de massa Mr do terceiro estudo de sensibilidade, com relação de rigidez $\mathrm{Kr}=3$, sendo: (a) primeiro inserto piezelétrico, (b) segundo inserto piezelétrico, (c) terceiro inserto piezelétrico. 
a)

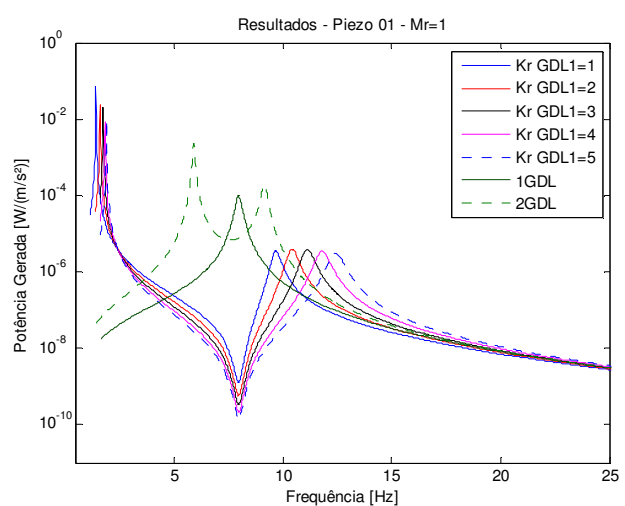

c)

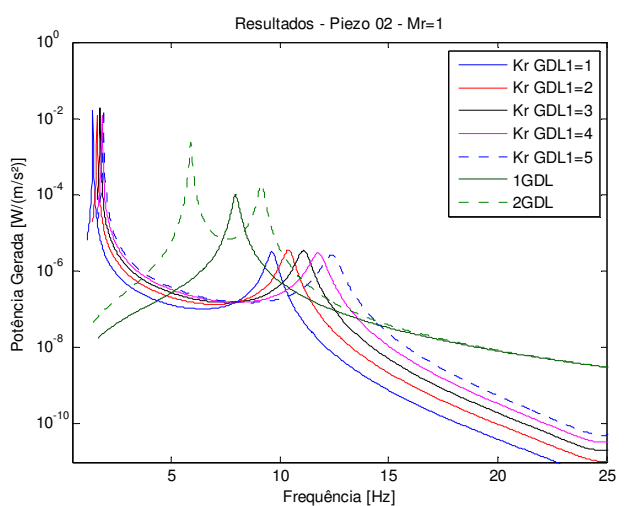

e)

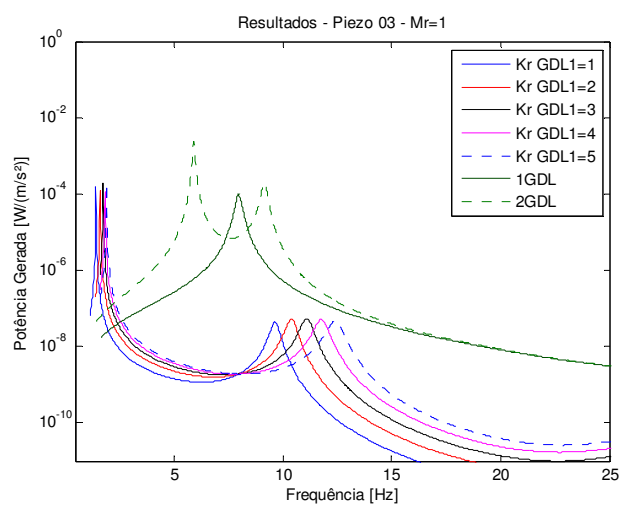

b)

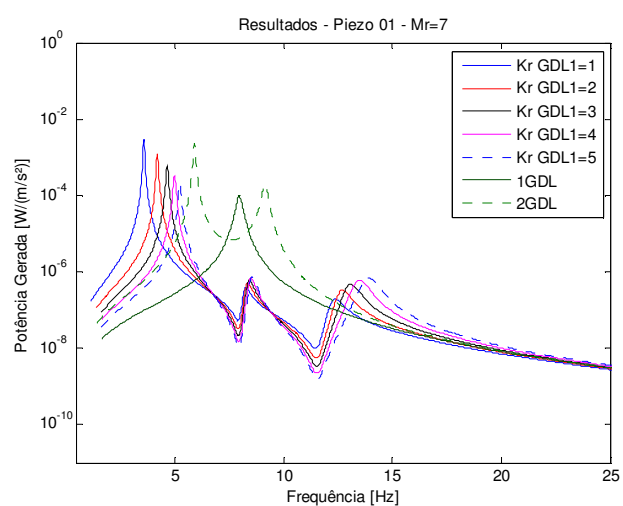

d)

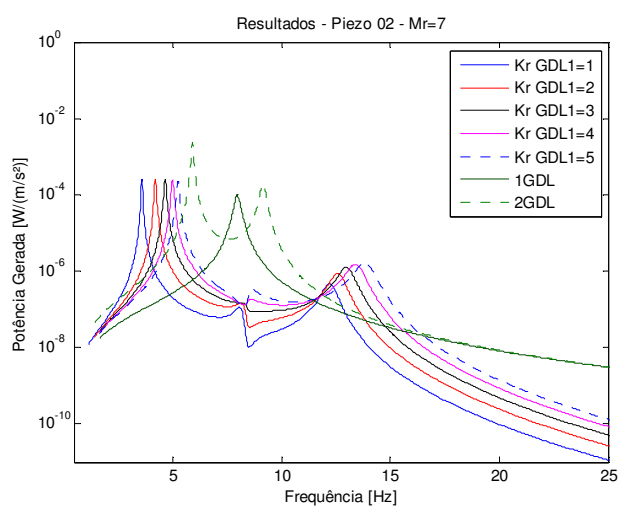

f)

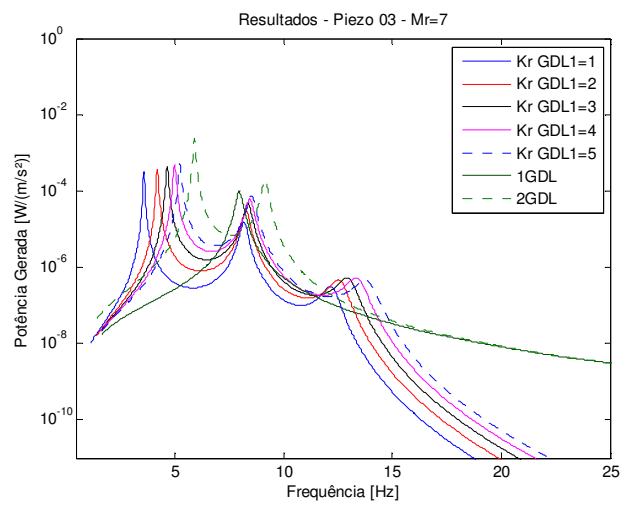

Figura 35 - FRF de potência gerada para diferentes relações de rigidez $\mathrm{Kr}$ do primeiro elemento elástico para as relações de massa $\mathrm{Mr}=1$ e $\mathrm{Mr}=7$ do terceiro estudo de sensibilidade, sendo: (a) primeiro inserto com $M r=1$, (b) primeiro inserto com $M r=7$, (c) segundo inserto com $M r=1$, (d) segundo inserto com $M r=7$, (e) terceiro inserto com $\mathrm{Mr}=1$, (e) terceiro inserto com $\mathrm{Mr}=7$. 
a)

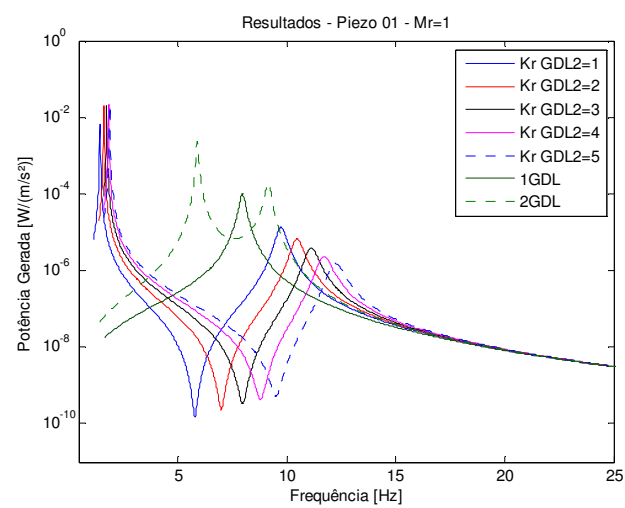

c)

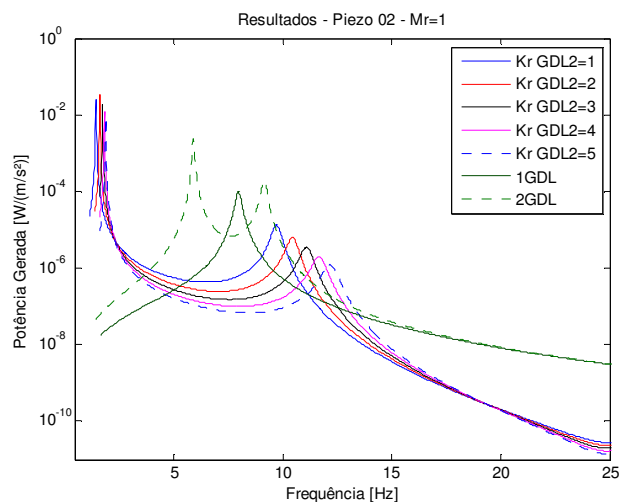

e)

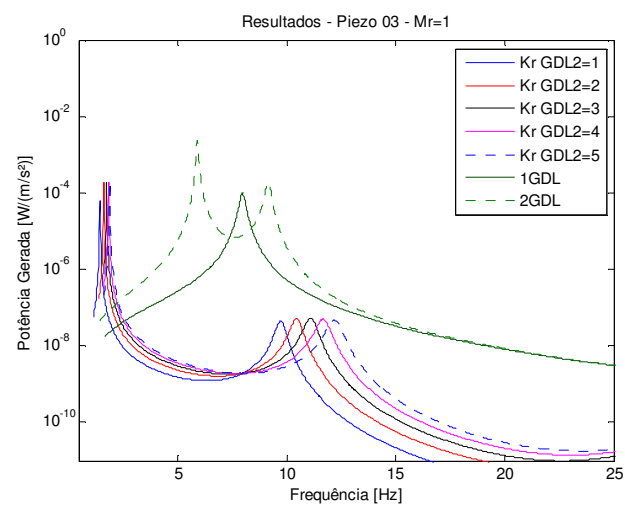

b)

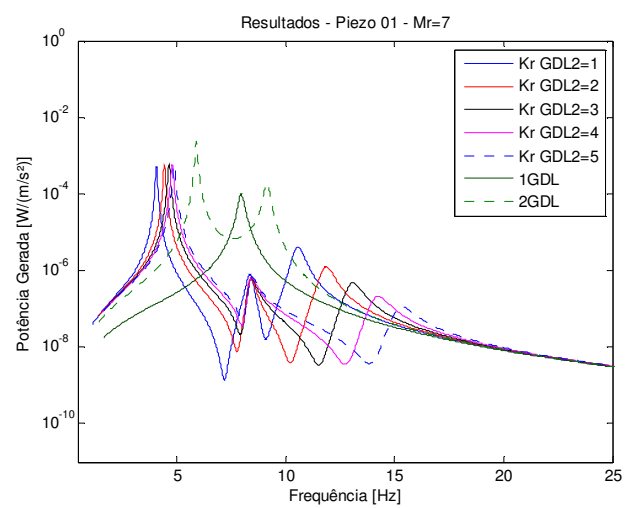

d)

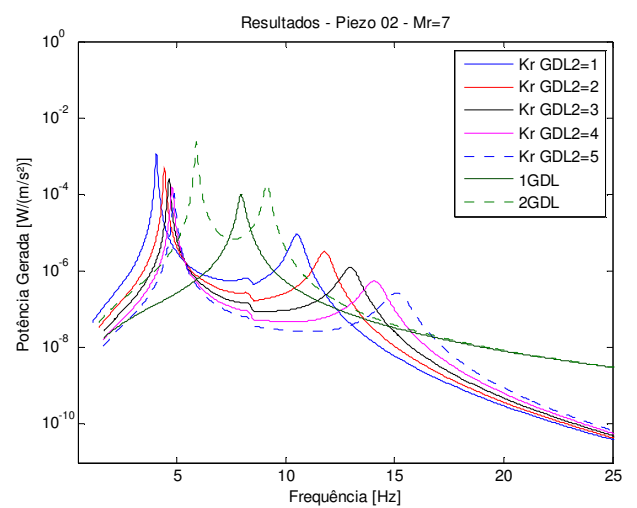

f)

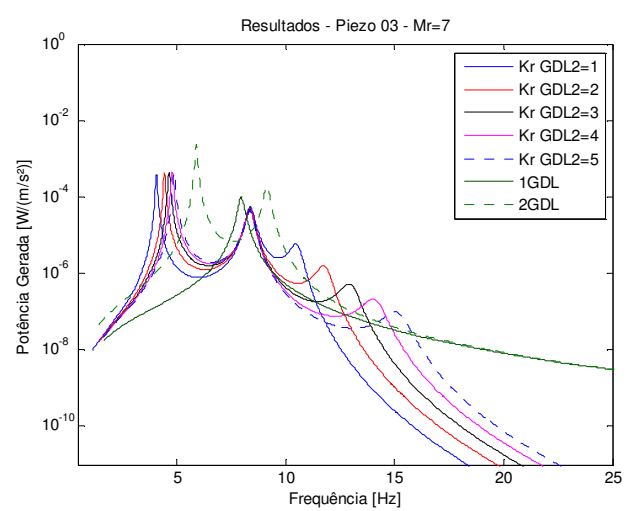

Figura 36 - FRF de potência gerada para diferentes relações de rigidez $\mathrm{Kr}$ do segundo elemento elástico para as relações de massa $\mathrm{Mr}=1$ e $\mathrm{Mr}=7$ do terceiro estudo de sensibilidade, sendo: (a) primeiro inserto com $M r=1$, (b) primeiro inserto com $M r=7$, (c) segundo inserto com $M r=1$, (d) segundo inserto com $M r=7$, (e) terceiro inserto com $\mathrm{Mr}=1$, (e) terceiro inserto com $\mathrm{Mr}=7$. 
a)

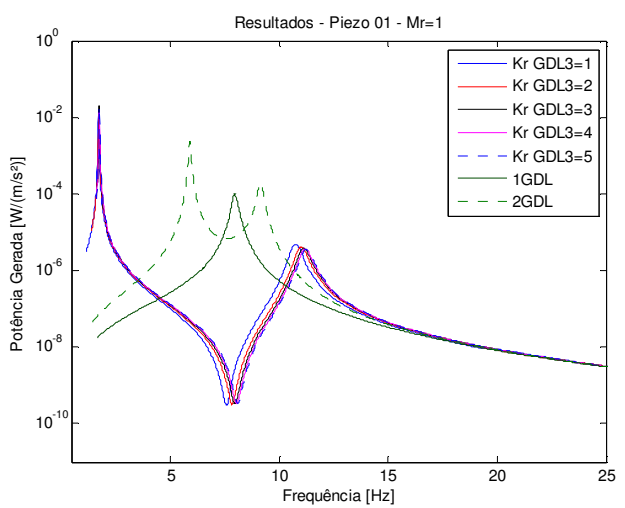

c)

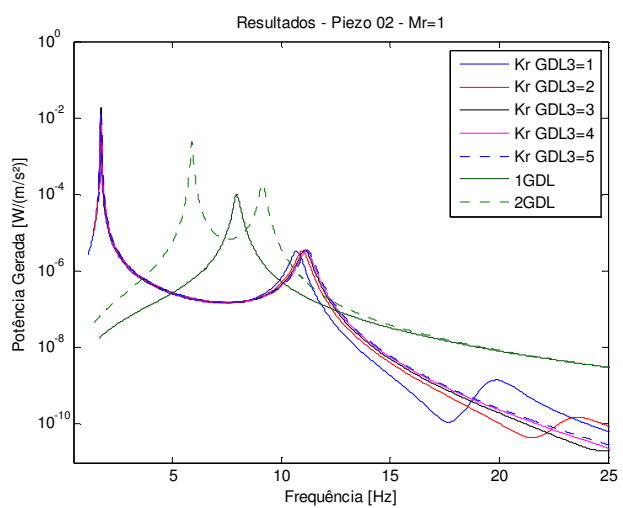

e)

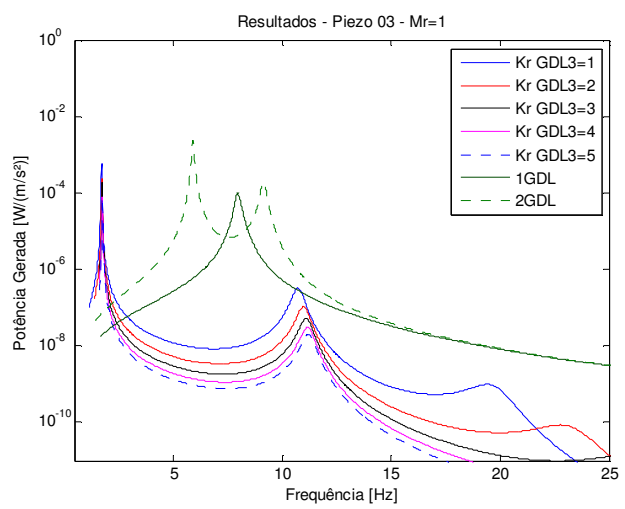

b)

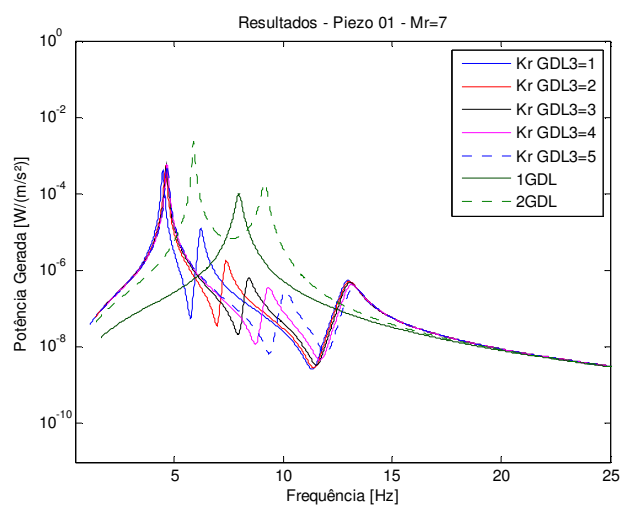

d)

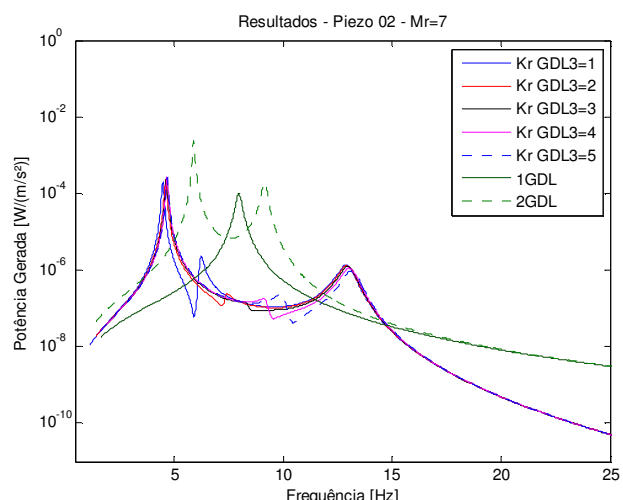

f)

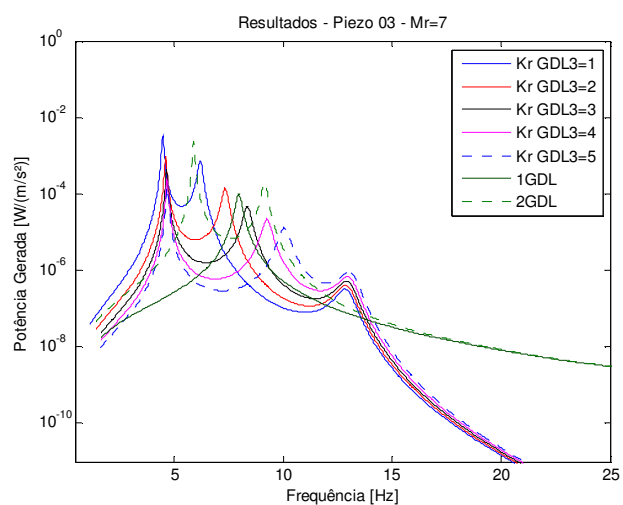

Figura 37 - FRF de potência gerada para diferentes relações de rigidez $\mathrm{Kr}$ do terceiro elemento elástico para as relações de massa $\mathrm{Mr}=1$ e $\mathrm{Mr}=7$ do terceiro estudo de sensibilidade, sendo: (a) primeiro inserto com $M r=1$, (b) primeiro inserto com $M r=7$, (c) segundo inserto com $M r=1$, (d) segundo inserto com $M r=7$, (e) terceiro inserto com $\mathrm{Mr}=1$, (e) terceiro inserto com $\mathrm{Mr}=7$. 


\subsubsection{Estudo de Sensibilidade 4}

No quarto estudo, assim como no segundo e terceiro, a duas massas foram atribuídos valores sempre iguais, com variação da proporção em relação à massa remanescente (\#Tabelas 10 e 11). Neste caso as massas idênticas foram as dos osciladores 2 e 3.

Tabela 10 - Massa dos osciladores em cada configuração do quarto estudo de sensibilidade do gerador de três graus de liberdade.

\begin{tabular}{cccc}
\hline \multicolumn{4}{c}{ Estudo de Sensibilidade 4 } \\
\hline $\begin{array}{c}\text { ID da Relação de Massa } \\
\text { Mr }\end{array}$ & Massa 1 & Massa 2 & Massa 3 \\
{$[\mathbf{k g}]$} & {$[\mathbf{k g}]$} & {$[\mathbf{k g}]$} \\
\hline 1 & 0,0393 & 0,0044 & 0,0044 \\
2 & 0,0320 & 0,0080 & 0,0080 \\
3 & 0,0258 & 0,0111 & 0,0111 \\
4 & 0,0160 & 0,0160 & 0,0160 \\
5 & 0,0085 & 0,0198 & 0,0198 \\
6 & 0,0053 & 0,0213 & 0,0213 \\
7 & 0,0025 & 0,0227 & 0,0227 \\
\hline
\end{tabular}

Tabela 11 - Relação de distribuição de massa entre os osciladores em cada configuração do quarto estudo de sensibilidade do gerador de três graus de liberdade.

\begin{tabular}{cccc}
\hline \multicolumn{4}{c}{ Estudo de Sensibilidade 4 } \\
\hline ID da Relação de Massa & Massa 1 & Massa 2 & Massa 3 \\
Mr & {$[\%]$} & {$[\%]$} & {$[\%]$} \\
\hline 1 & $82 \%$ & $9 \%$ & $9 \%$ \\
2 & $67 \%$ & $17 \%$ & $17 \%$ \\
3 & $54 \%$ & $23 \%$ & $23 \%$ \\
4 & $33 \%$ & $33 \%$ & $33 \%$ \\
5 & $18 \%$ & $41 \%$ & $41 \%$ \\
6 & $11 \%$ & $44 \%$ & $44 \%$ \\
7 & $5 \%$ & $47 \%$ & $47 \%$ \\
\hline
\end{tabular}

Nos resultados obtidos para o quarto estudo (\#Figuras 38 a 41) nota-se que o uso de uma massa menor associada a uma rigidez mais baixa para o primeiro oscilador, pela forma como se configuraram os estudos, causa uma significativa minimização da frequência do primeiro modo, com aumento da frequência dos demais. Em relação à amplitude, observa-se para o primeiro inserto uma maximização da resposta na primeira frequência natural para as 
configurações de menor massa no primeiro oscilador, mas com severa redução na amplitude das demais faixas. À medida que se aumenta a massa do primeiro oscilados, ocorre a diminuição da resposta do primeiro inserto na primeira frequência natural, mas com sensível aumento no restante das faixas.

No caso dos demais insertos o comportamento é muito semelhante em relação às frequências e amplitudes de resposta, mas nestes, o aumento da massa do primeiro oscilador sempre maximiza a energia gerada, mesmo para a primeira frequência natural.

Já as variações de rigidez na primeira mola (\#Figura 39), para as configurações com maior massa no primeiro oscilador, afetam principalmente a segunda frequência natural, mas há também variações de amplitude tanto na primeira frequência, para o primeiro inserto, como na terceira frequência natural, para os demais insertos. Já a configuração com menor massa no primeiro oscilador apresenta alguma sensibilidade da resposta na primeira frequência de ressonância para o primeiro elemento piezelétrico, enquanto para os demais insertos nota-se variação da amplitude em toda a banda de frequência após a primeira frequência natural, mas que muito pequena nos arredores da primeira ressonância.

No caso das variações de rigidez da segunda mola (\#Figura 40), observam-se grandes variações nas frequências da primeira e terceira ressonâncias, mas com pouca variação na amplitude da resposta para a configuração com maior massa no primeiro oscilador, enquanto para a configuração com menor massa, percebe-se mudanças apenas no terceiro modo para o primeiro e terceiro inserto, e no segundo e terceiro modo para o segundo inserto.

Por fim, as variações de rigidez da terceira mola (\#Figura 41) causam pouco efeito nas respostas do primeiro inserto, enquanto para os demais insertos nota-se variações mais acentuadas na terceira frequência natural na configuração com maior massa no primeiro oscilador, e variações na segunda frequência natural, principalmente para o terceiro inserto, na configuração com menor massa. 
a)

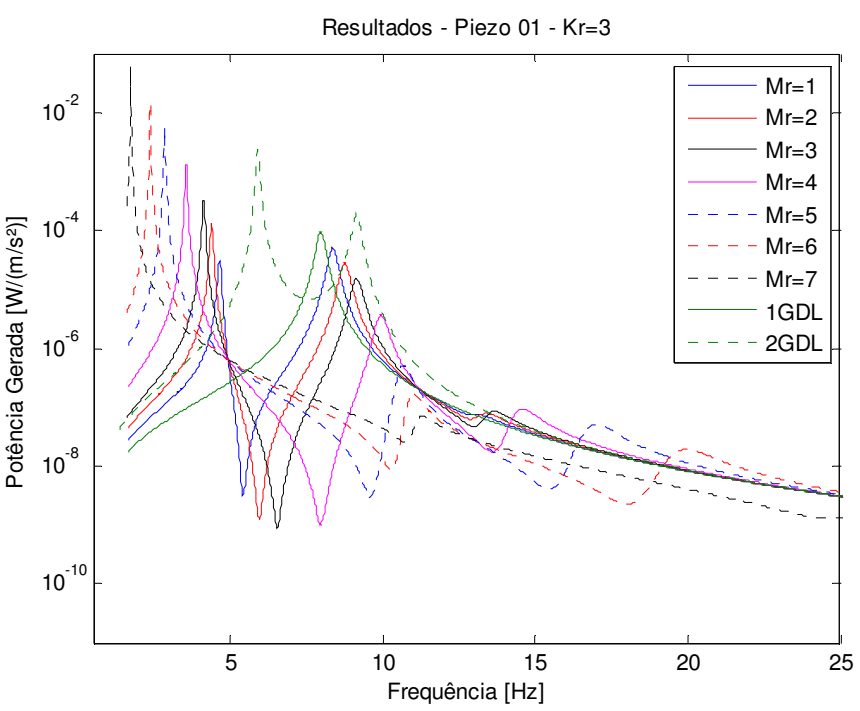

b)

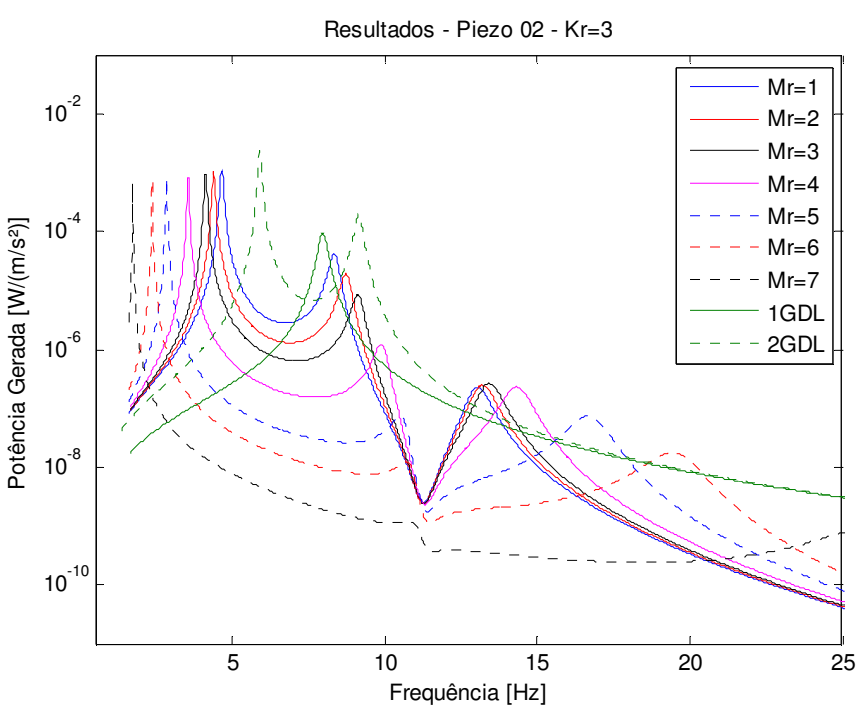

c)

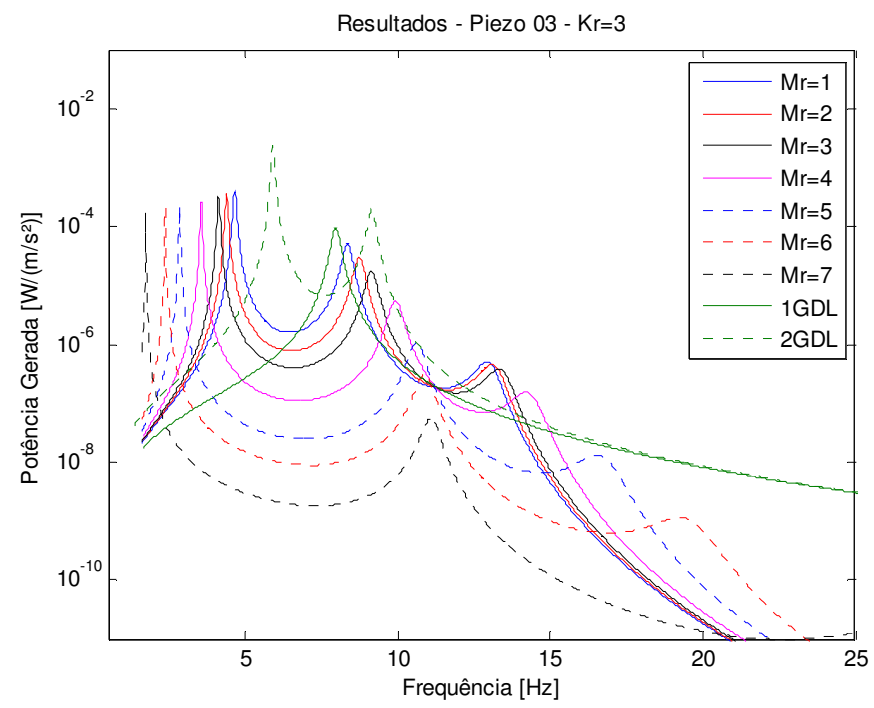

Figura 38 - FRF de potência gerada para diferentes relações de massa Mr do quarto estudo de sensibilidade, com relação de rigidez $\mathrm{Kr}=3$, sendo: (a) primeiro inserto piezelétrico, (b) segundo inserto piezelétrico, (c) terceiro inserto piezelétrico. 
a)

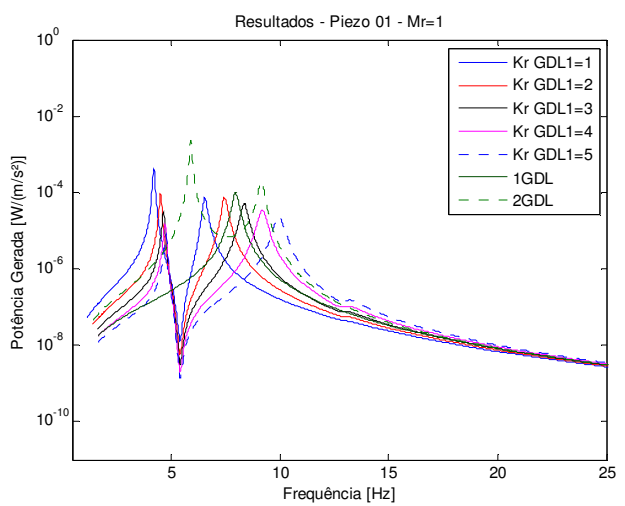

c)

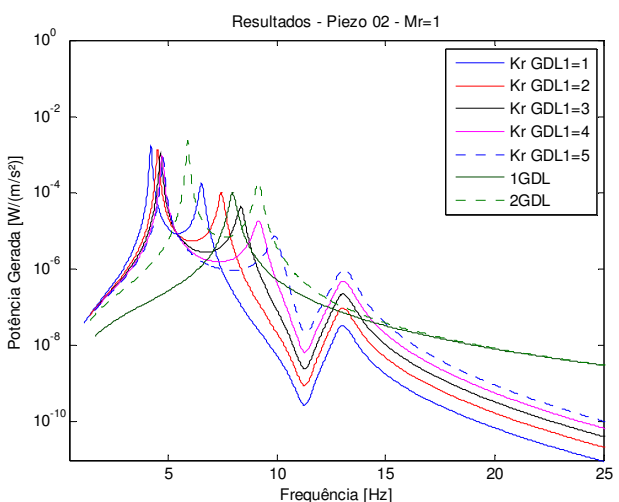

e)

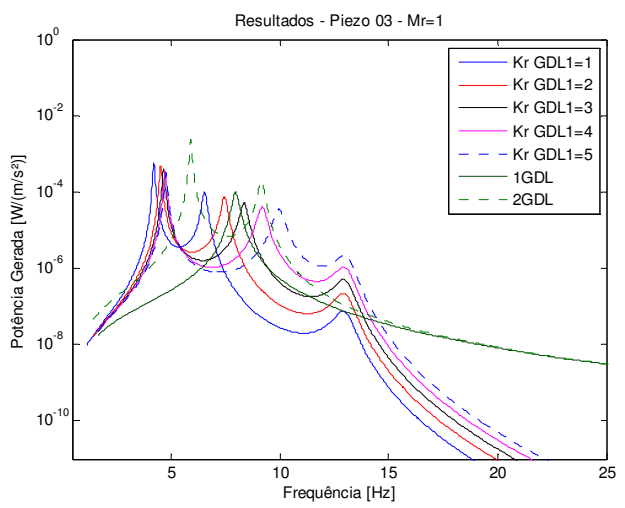

b)

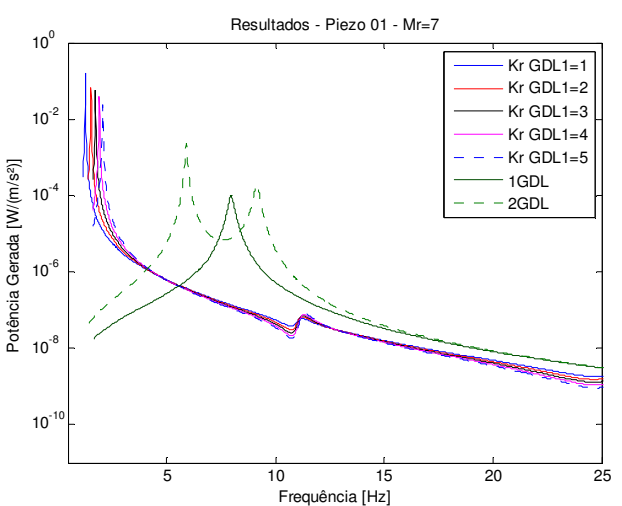

d)

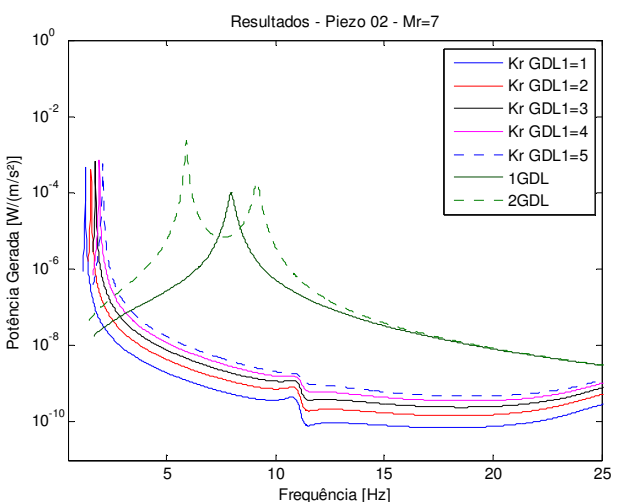

f)

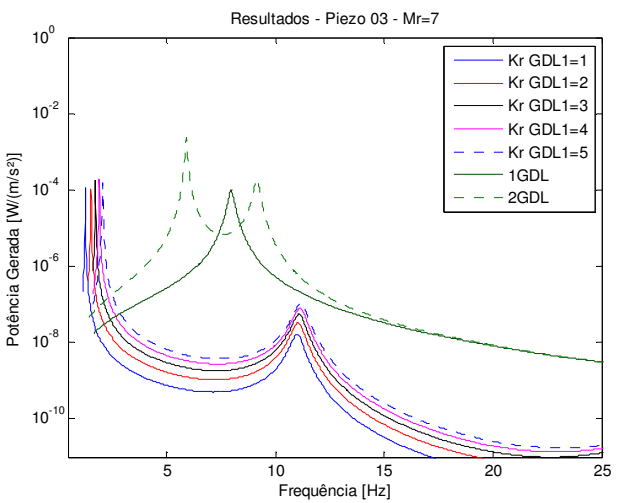

Figura 39 - FRF de potência gerada para diferentes relações de rigidez $\mathrm{Kr}$ do primeiro elemento elástico para as relações de massa $\mathrm{Mr}=1$ e $\mathrm{Mr}=7$ do quarto estudo de sensibilidade, sendo: (a) primeiro inserto com $\mathrm{Mr}=1$, (b) primeiro inserto com $\mathrm{Mr}=7$, (c) segundo inserto com $\mathrm{Mr}=1$, (d) segundo inserto com $\mathrm{Mr}=7$, (e) terceiro inserto com $\mathrm{Mr}=1$, (e) terceiro inserto com $\mathrm{Mr}=7$. 
a)

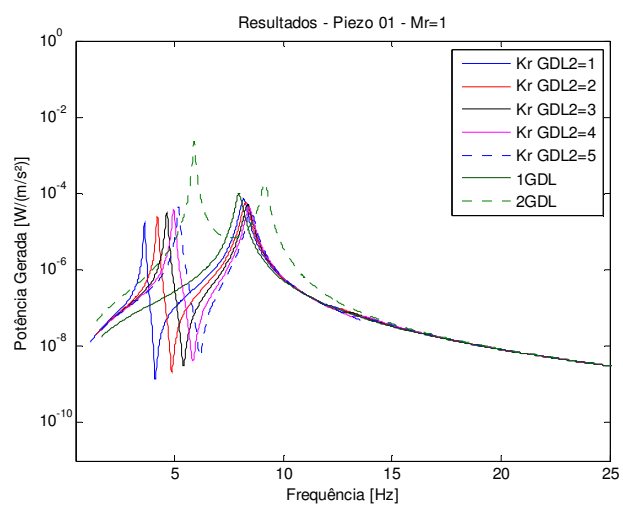

c)

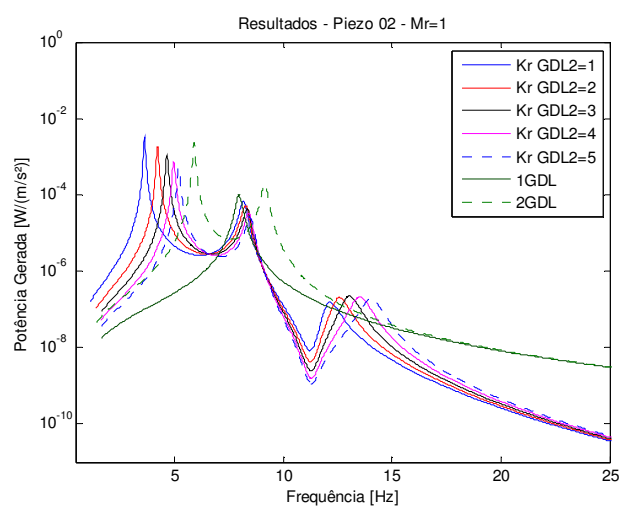

e)

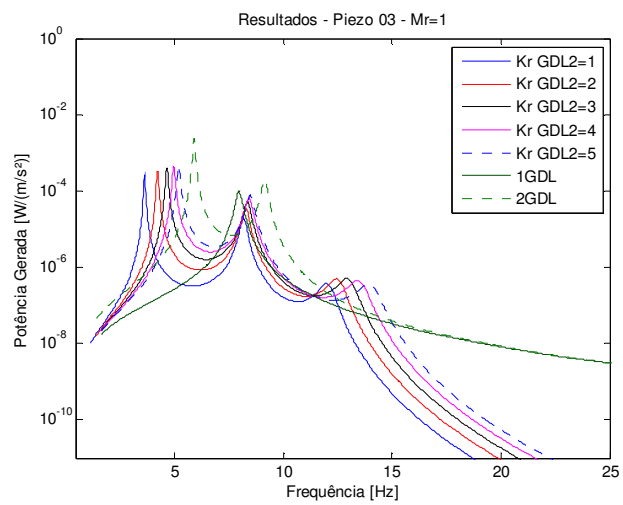

b)

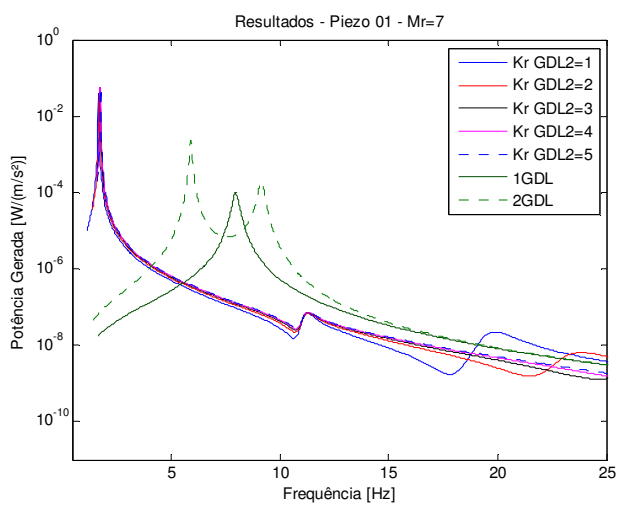

d)

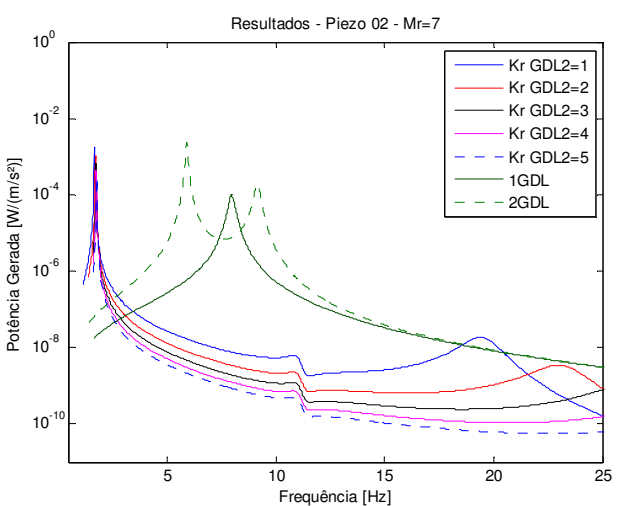

f)

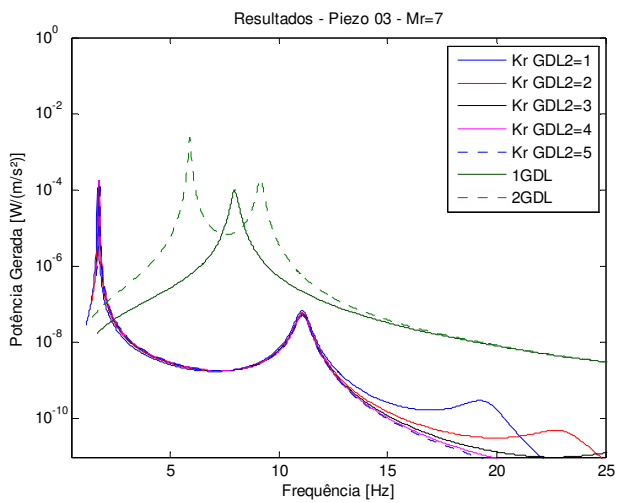

Figura 40 - FRF de potência gerada para diferentes relações de rigidez $\mathrm{Kr}$ do segundo elemento elástico para as relações de massa $\mathrm{Mr}=1$ e $\mathrm{Mr}=7$ do quarto estudo de sensibilidade, sendo: (a) primeiro inserto com $M r=1$, (b) primeiro inserto com $M r=7$, (c) segundo inserto com $M r=1$, (d) segundo inserto com $M r=7$, (e) terceiro inserto com $\mathrm{Mr}=1$, (e) terceiro inserto com $\mathrm{Mr}=7$. 
a)

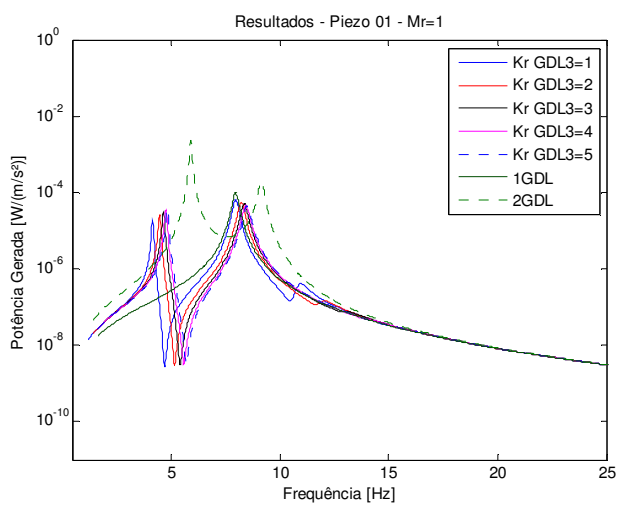

c)

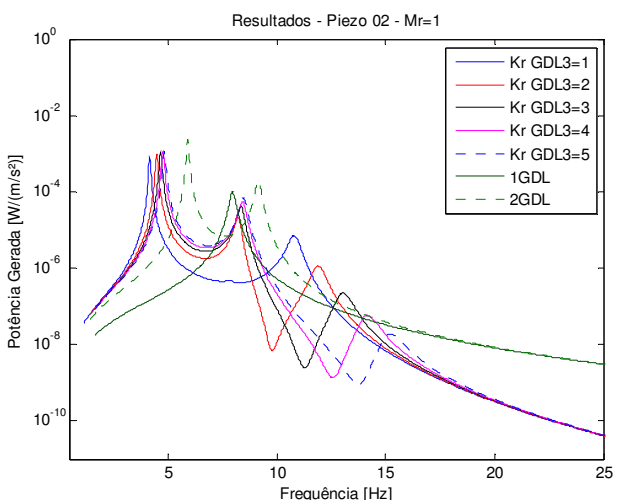

e)

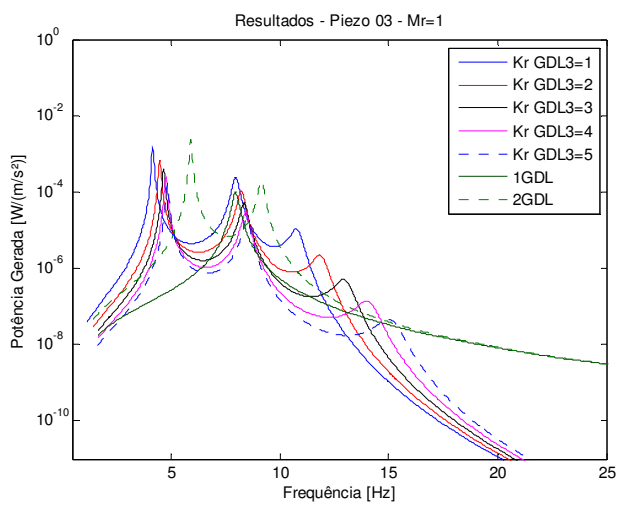

b)

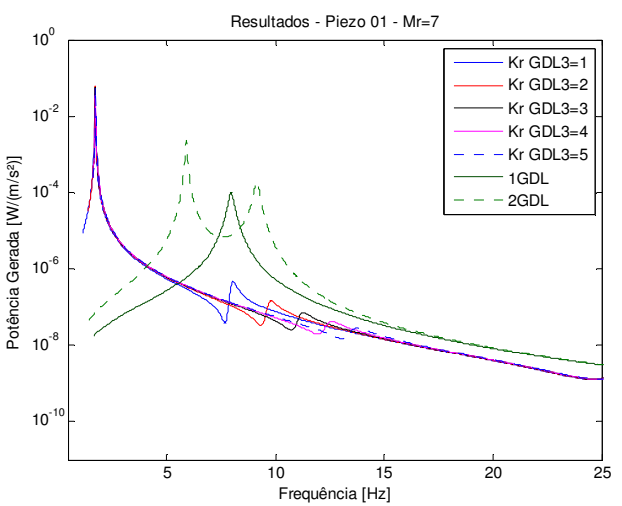

d)

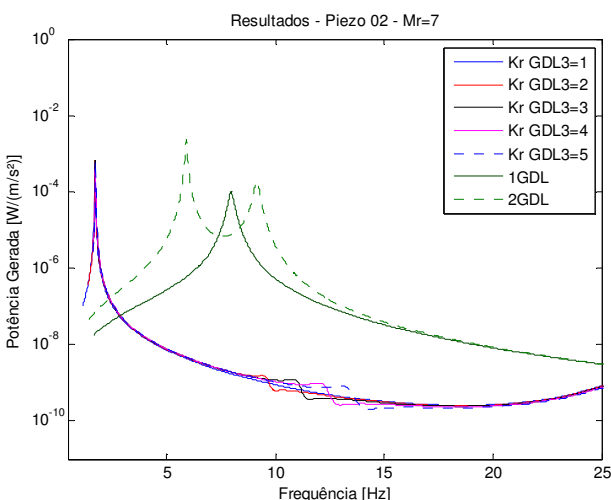

f)

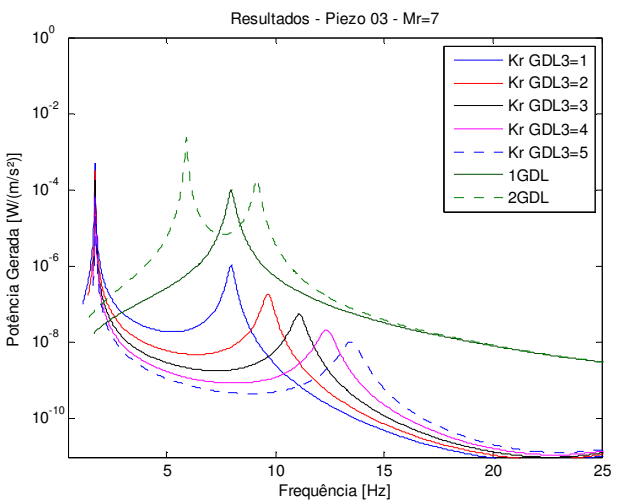

Figura 41 - FRF de potência gerada para diferentes relações de rigidez $\mathrm{Kr}$ do terceiro elemento elástico para as relações de massa $\mathrm{Mr}=1$ e $\mathrm{Mr}=7$ do quarto estudo de sensibilidade, sendo: (a) primeiro inserto com $M r=1$, (b) primeiro inserto com $M r=7$, (c) segundo inserto com $M r=1$, (d) segundo inserto com $M r=7$, (e) terceiro inserto com $\mathrm{Mr}=1$, (e) terceiro inserto com $\mathrm{Mr}=7$. 


\subsubsection{Otimização do Gerador de 3 GDL}

Dentre as diversas configurações avaliadas nos testes de sensibilidade foram escolhidas duas para se otimizar os parâmetros dos insertos piezelétricos, buscando a maximização da eficiência do gerador em termos de massa total do gerador e massa de material piezelétrico. As propriedades das configurações escolhidas estão dispostas na tabela 12, e as funções de resposta em frequência nas figuras 42 e 43.

Tabela 12- Parâmetros do modelo de 3 graus de liberdade para dois casos com resultados otimizados encontrados nos estudos de sensibilidade.

\begin{tabular}{cccc}
\hline \multicolumn{4}{c}{ Parâmetros - Gerador de 3 GDL } \\
\hline \multirow{2}{*}{ Parâmetro } & \multicolumn{3}{c}{ Valor } \\
\hline$m_{1}$ & $2,88 \times 10^{-2}$ & $2,88 \times 10^{-2}$ & Unidade \\
$m_{2}$ & $1,60 \times 10^{-2}$ & $1,60 \times 10^{-2}$ & $\mathrm{~kg}$ \\
$m_{3}$ & $3,2 \times 10^{-3}$ & $3,2 \times 10^{-3}$ & $\mathrm{~kg}$ \\
$k_{1}$ & $\mathbf{7 2}$ & $\mathbf{9 0}$ & $\mathrm{N} / \mathrm{m}$ \\
$k_{2}$ & $\mathbf{5 0}$ & $\mathbf{3 0}$ & $\mathrm{N} / \mathrm{m}$ \\
$k_{3}$ & $\mathbf{4}$ & $\mathbf{6}$ & $\mathrm{N} / \mathrm{m}$ \\
$c_{1}$ & $\mathbf{5 , 7 6 \times 1 0 ^ { - 2 }}$ & $\mathbf{7 , 2 0 \times 1 0 ^ { - 2 }}$ & $\mathrm{N} /(\mathrm{m} / \mathrm{s})$ \\
$c_{2}$ & $\mathbf{4 , 0 0 \times 1 0 ^ { - 2 }}$ & $\mathbf{2 , 4 0 \times 1 0 ^ { - 2 }}$ & $\mathrm{N} /(\mathrm{m} / \mathrm{s})$ \\
$c_{3}$ & $\mathbf{3 , 2 0 \times 1 0 ^ { - 3 }}$ & $\mathbf{4 , 8 0 \times 1 0 ^ { - 3 }}$ & $\mathrm{N} /(\mathrm{m} / \mathrm{s})$ \\
$\alpha_{1}$ & $3,16 \times 10^{-5}$ & $3,16 \times 10^{-5}$ & $\mathrm{~N} / \mathrm{V}$ \\
$\alpha_{2}$ & $3,16 \times 10^{-5}$ & $3,16 \times 10^{-5}$ & $\mathrm{~N} / \mathrm{V}$ \\
$\alpha_{3}$ & $3,16 \times 10^{-5}$ & $3,16 \times 10^{-5}$ & $\mathrm{~N} / \mathrm{V}$ \\
$C p_{1}$ & $2,5 \times 10^{-8}$ & $2,5 \times 10^{-8}$ & $\mathrm{~F}$ \\
$C p_{2}$ & $2,5 \times 10^{-8}$ & $2,5 \times 10^{-8}$ & $\mathrm{~F}$ \\
$C p_{3}$ & $2,5 \times 10^{-8}$ & $2,5 \times 10^{-8}$ & $\mathrm{~F}$ \\
$R_{1}$ & $1,00 \times 10^{6}$ & $1,00 \times 10^{6}$ & $\Omega$ \\
$R_{2}$ & $1,00 \times 10^{6}$ & $1,00 \times 10^{6}$ & $\Omega$ \\
$R_{3}$ & $1,00 \times 10^{6}$ & $1,00 \times 10^{6}$ & $\Omega$ \\
\hline & & & \\
\hline
\end{tabular}

A primeira cofiguração escolhida ilustra uma solução na qual há a maximização da energia gerada nas primeiras frequências naturais em detrimento da largura da banda de frequência útil para o gerador (quando comparada ao de dois GDL). Já a segunda, apresenta amplitudes menores nas ressonâncias, mas com maximização da energia gerada em seus arredores abrangendo faixas de frequência mais extensas. Convenientemente foram escolhidas soluções em que, assim como no exemplo de dois GDL, existe um elemento piezelétrico que apresenta uma resposta muito superior à dos demais (\#Tabela 13). 


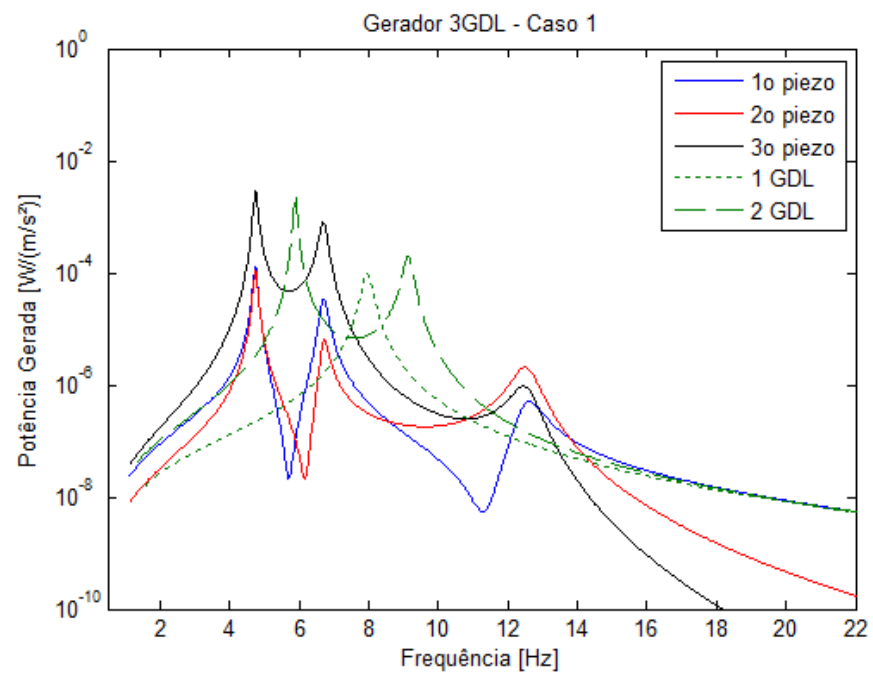

Figura 42- FRF de potência gerada em cada um dos três insertos do Caso 1 de otimização do modelo de 3GDL, e potência total gerada pelos modelos de 1GDL e pelo exemplo de 2GDL estudado por Xiao et al. (2015)

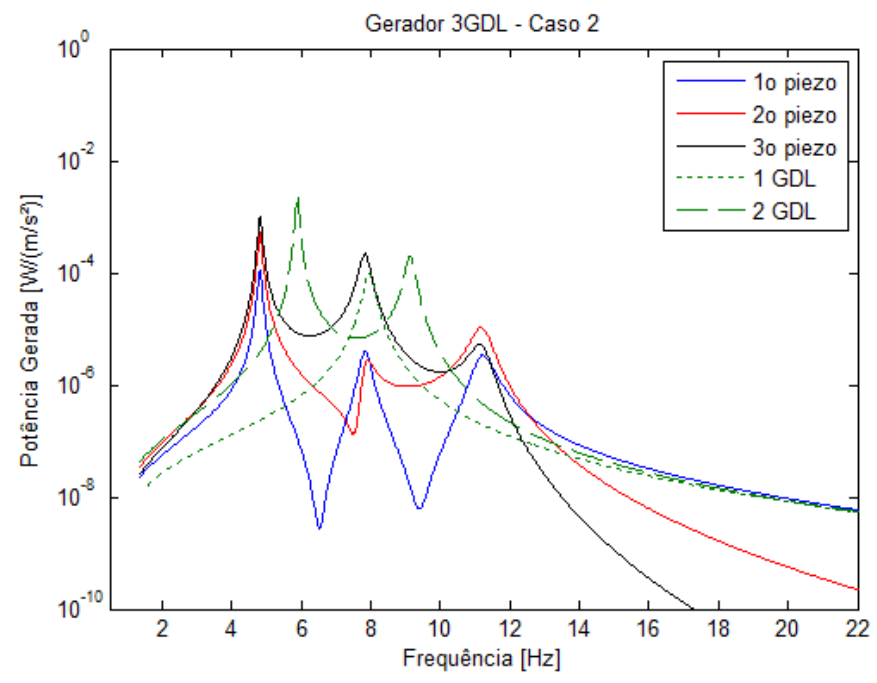

Figura 43 - FRF de potência gerada em cada um dos três insertos do Caso 2 de otimização do modelo de 3GDL, e potência total gerada pelos modelos de 1GDL e pelo exemplo de 2GDL estudado por Xiao et al. (2015)

Destaca-se que não foram escolhidas configurações em que a faixa de frequência útil fosse inferior à solução de 1 GDL, uma vez que o foco do trabalho está no uso de múltiplos graus de liberdade para maximização dessas faixas, e não apenas da resposta.

Para maximização da eficiência do gerador foram removidos os dois elementos piezelétricos com piores resultados de potência gerada, no caso o primeiro e segundo inserto, deixando apenas o mais eficiente deles. A partir dessa configuração, variaram-se as características de fator de força e capacitância, diretamente associadas à massa de material 
piezelétrico, para se entender seus impactos na potência total gerada, desta vez para o sistema de três graus de liberdade

Tabela 13 - Máxima potência gerada para o modelo de 3GDL dos Casos 1 e 2 na configuração de referência, contendo um inserto piezelétrico para cada massa oscilante

\begin{tabular}{ccc}
\hline \multicolumn{3}{c}{$\begin{array}{c}\text { Máxima Potência Gerada } \\
\text { 3 GDL } \\
\text { Configuraçoses de Referência } \\
\text { [mW] }\end{array}$} \\
\hline \multirow{3}{*}{ Caso 1 } & 1o piezo & 0,132 \\
& 2o piezo & 0,113 \\
& 3o piezo & 2,920 \\
& Total & 3,166 \\
\hline \multirow{2}{*}{ Caso 2 } & 1o piezo & 0,115 \\
& 2o piezo & 0,513 \\
& 3o piezo & 1,003 \\
& Total & 1,630 \\
\hline
\end{tabular}

\section{Otimização do Gerador de 3 GDL - Caso 1}

Observando-se os resultados de tensão gerada em função dos fatores de força e resistências nota-se novamente que esta é maximizada à medida que se aumenta a resistência do circuito associado, mas com uma tendência assintótica, conforme evidenciado na figura 44. Como comentado para o modelo de dois GDL, essa característica faz com que a potência gerada apresente um valor ótimo, Em que qualquer variação da resistência, para mais ou para menos, resulte em sua diminuição (\#Figura 45).

Para a configuração do Caso 1 as máximas potências geradas para fator de força relativo de 1, 2 e 3 foram 3,058 $\mathrm{mW}, 5,136 \mathrm{~mW}$ e $6,690 \mathrm{~mW}$, para resistências de 1,35x $10^{6}$, $6,5 \times 10^{5}$ e $4,5 \times 10^{5} \Omega$ respectivamente (\#Figura 46). Fazendo-se o cálculo da densidade energética do gerador em função de sua massa total se obtém 63,71, 107,00 e 139,38 mW/kg para cada fator de força citado. No caso da eficiência em termos de massa de material piezelétrico os resultados são 3,06, 2,57 e 2,23 mW/mp. Comparando-se esses resultados com os do modelo com um inseto entre cada oscilador proposto por Xiao et al. (2015), fica evidente que para a configuração estudada é possível maximizar a energia total gerada mesmo que utilizando a mesma quantidade, ou até menos material piezelétrico, resultando em densidades energéticas bastante superiores para o gerador. 


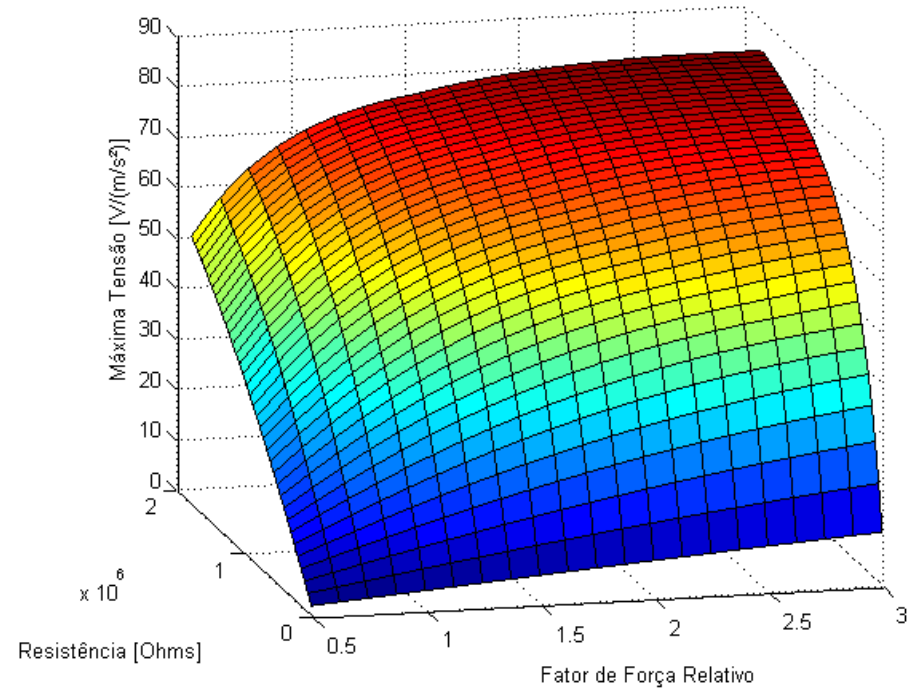

Figura 44 - Máxima tensão gerada pelo inserto piezelétrico do terceiro oscilador do modelo de 3GDL do Caso 1, para diferentes resistências e fatores de força relativos.

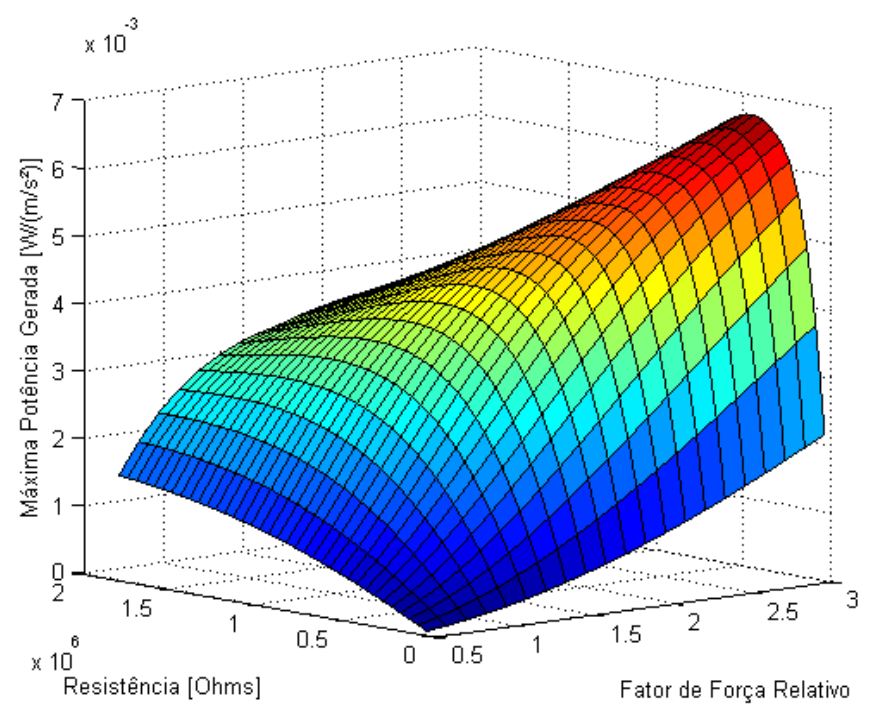

Figura 45 - Máxima potência gerada pelo inserto piezelétrico do terceiro oscilador do modelo de 3GDL do Caso 1, para diferentes resistências e fatores de força relativos.

Outro aspecto relevante é que para a configuração do Caso 1, apesar de a largura total da banda de frequência ser sensivelmente menor que a do gerador de dois GDL, dependendo da magnitude de referência adotada, a região entre as duas ressonâncias apresenta amplitudes significativamente maiores, com potência mínima de 91,74 $\mu \mathrm{W}$ (fator de força relativo igual a 2) contra $6,78 \mu \mathrm{W}$ do exemplo de 2 GDL. 


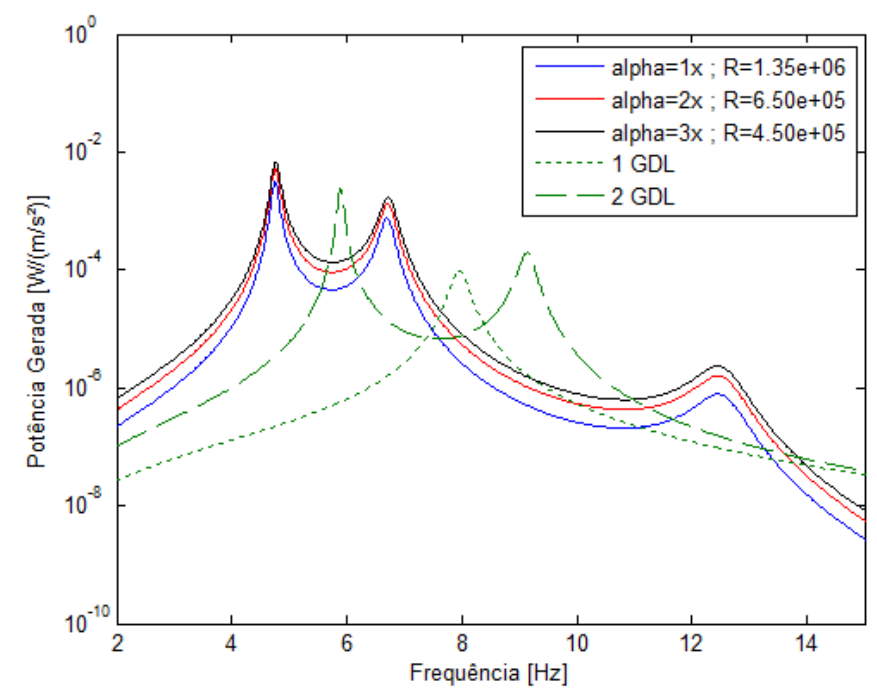

Figura 46 - FRFs de potência gerada pelo inseto do terceiro oscilador no modelo de 3GDL do Caso 1, para fatores de força relativos de 1, 2 e 3 nas resistência que maximizam o resultado, e FRFs do modelo de 1GDL equivalente, e 2GDL do exemplo de Xiao et al. (2015).

No entanto, observa-se que para a configuração proposta a relação entre a menor e a maior massa do sistema é significativamente superior à do exemplo de dois GDL ( 9 e 5 vezes respectivamente), e que tal característica pode ter grande influência nos resultados obtidos.

\section{Otimização do Gerador de 3 GDL - Caso 2}

Para a segunda configuração as características das respostas de tensão máxima e potência máxima para os diferentes fatores de força e resistências são essencialmente as mesmas já verificadas no caso anterior (\#Figuras 47 e 48). As máximas potências geradas para os fatores de força relativos de 1,2 e 3, foram $1,07 \mathrm{~mW}, 2,014 \mathrm{~mW}$ e $2,842 \mathrm{~mW}$ para resistências $1,35 \times 10^{6}, 6,5 \times 10^{5} 4,0 \times 10^{5}$ respectivamente (\#Figura 49). As densidades energéticas, na mesma ordem, ficam em 22,29, 41,96 e 59,21 mW/kg em relação à massa total do gerador, e 1,07, 1,01 e 0,94 mW/m em relação à quantidade de material piezelétrico. Neste caso, apesar de os resultados serem superiores aos da configuração com um inserto entre cada oscilador, nota-se que a máxima potência gerada, a qual ocorre na primeira frequência natural, não se mostra superior ao exemplo de 2 GDL quando avaliados com a mesma quantidade de material piezelétrico. No entanto, observando-se as regiões entre as frequências naturais nota-se que a mínima potência gerada entre as duas primeiras ressonâncias para o modelo de três GDL com fator de força relativo de 2 é igual a $14,19 \mu \mathrm{W}$, 
significativamente superior à do exemplo de dois GDL, de $6,78 \mu \mathrm{W}$. Ao se analisar para ambos os harversters a largura da banda de frequência que contempla amplitudes superiores aos $14,19 \mu \mathrm{W}$ encontrados no gerador de $3 \mathrm{GDL}$, encontra-se uma faixa que vai de 4,22 a $8,63 \mathrm{~Hz}$ para o mesmo (faixa de 4,41 Hz), contra dois intervalos para o modelo com $2 \mathrm{GDL}$, um de 5,30 a 6,69 e outro de 8,49 a 9,60 Hz (faixa total de 2,5 Hz).

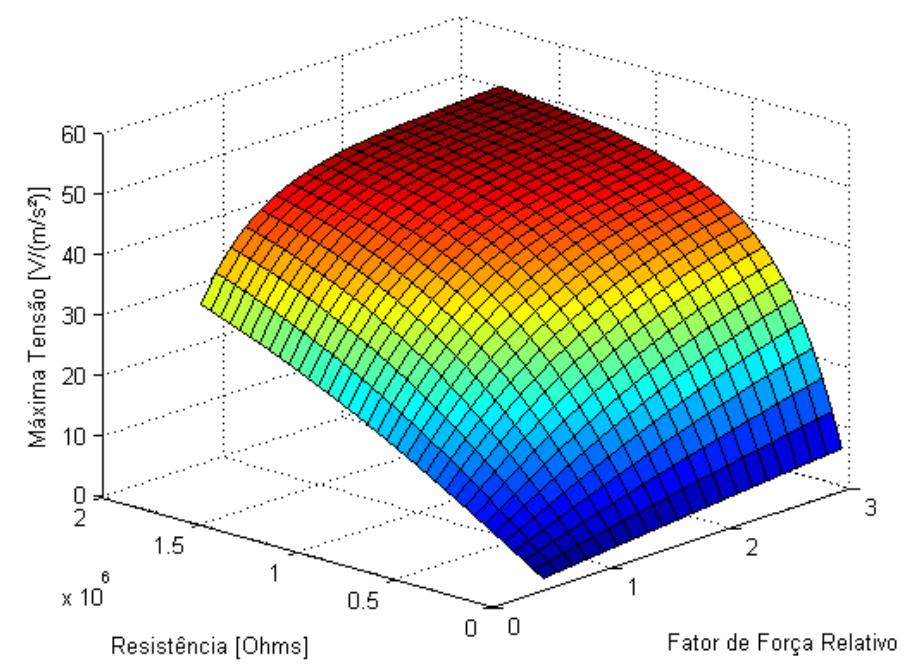

Figura 47 - Máxima tensão gerada pelo inserto piezelétrico do terceiro oscilador do modelo de 3GDL do Caso 2, para diferentes resistências e fatores de força relativos.

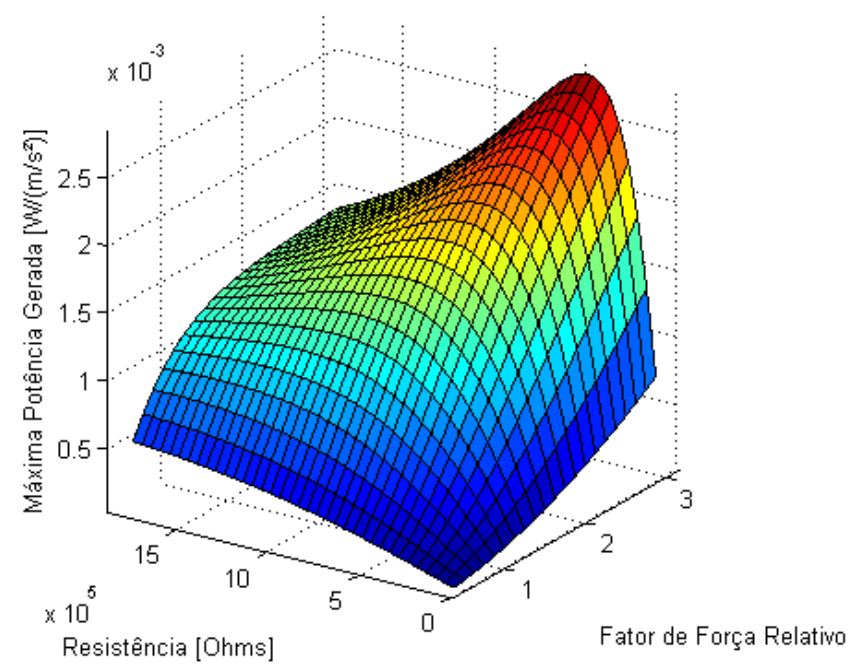

Figura 48 - Máxima potência gerada pelo inserto piezelétrico do terceiro oscilador do modelo de 3GDL do Caso 2, para diferentes resistências e fatores de força relativos. 
Fazendo-se a mesma análise para uma amplitude menor, de $2 \mu \mathrm{W}$, encontra-se para 2GDL uma faixa de frequência que vai de 4,48 a 10,27 Hz, enquanto para o gerador de 3 GDL com fator de força relativo igual a 2, essa faixa vai de 3,50 a 11,62 Hz, ou seja, uma faixa de $5,79 \mathrm{~Hz}$ contra $8,12 \mathrm{~Hz}$ respectivamente.

Novamente, já que as massas do Caso 1 e 2 são as mesmas, nota-se que a diferença nas relações de proporcionalidade entre as massas pode ter significativa influência nos resultados obtidos.

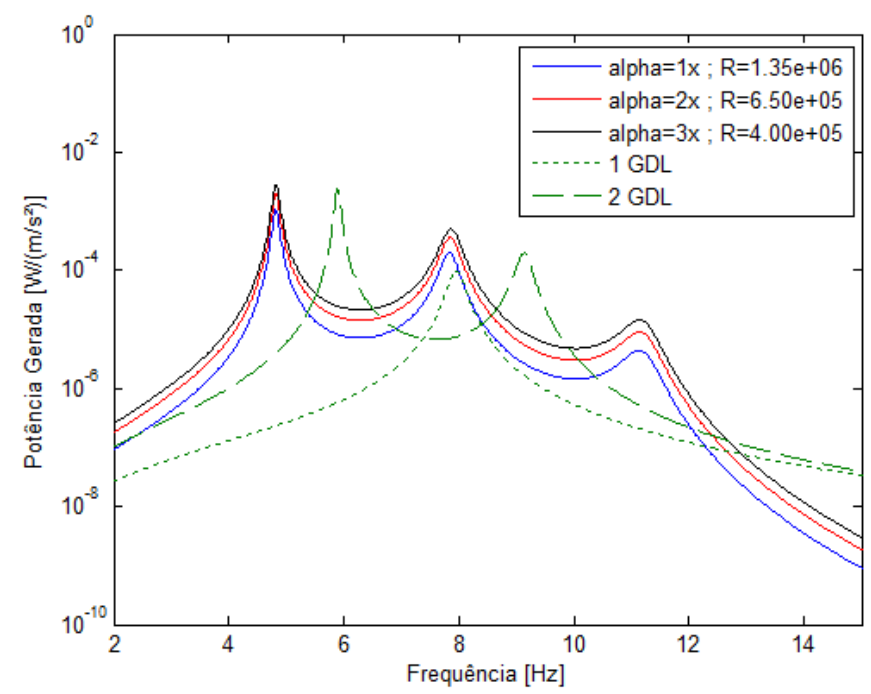

Figura 49 - FRFs de potência gerada pelo inseto do terceiro oscilador no modelo de 3GDL do Caso 2, para fatores de força relativos de 1, 2 e 3 nas resistência que maximizam o resultado, e FRFs do modelo de 1GDL equivalente, e 2GDL do exemplo de Xiao et al. (2015).

\section{Otimização do Gerador de 3 GDL - Caso 3}

Tendo em vista as divergências entre as relações de massa encontradas nos Casos $1 \mathrm{e}$ 2, realizou-se um terceiro caso de estudo, no qual se buscou uma configuração em que essa relação fosse mais próxima à do modelo de dois GDL, cujos parâmetros estão dispostos na tabela 14.

Nos resultados de tensão e potência máxima gerados para o Caso 3 (\#Figuras 50, 51 e Tabela 15) pode-se observar que os resultados obtidos ainda são promissores, com máximas potências geradas de $2,043 \mathrm{~mW}, 3,744 \mathrm{~mW}$ e $5,147 \mathrm{~mW}$ para fatores de forças relativo 1, 2 e 3 , e resistências de $1,45 \times 10^{6}, 7 \times 10^{5}$ e $4,5 \times 10^{5}$ respectivamente, apresentando as mesmas 
características de sensibilidade aos parâmetros do elemento piezelétrico, mas com magnitude sensivelmente reduzida em relação à configuração de três GDL avaliada para o Caso 1.

Apesar das máximas potências geradas menores, nota-se que o intervalo entre as duas ressonâncias ainda apresenta respostas superiores aos do modelo de dois GDL, com potência mínima de $16,8 \mu \mathrm{W}$ (fator de força relativo igual a 2 ) contra $6,782 \mu \mathrm{W}$..

Tabela 14 - Parâmetros do modelo de 3 graus de liberdade para um terceiro caso de otimização, com relações entre as massas de mesma ordem de grandeza do exemplo de 2 GDL estudado por outros autores.

\begin{tabular}{ccc}
\hline \multicolumn{3}{c}{ Parâmetros - Gerador de 3 GDL } \\
\hline \multicolumn{3}{c}{ Valor } \\
Parâmetro & Caso 3 & Unidade \\
\hline$m_{1}$ & $2,56 \times 10^{-2}$ & $\mathrm{~kg}$ \\
$m_{2}$ & $1,60 \times 10^{-2}$ & $\mathrm{~kg}$ \\
$m_{3}$ & $6,40 \times 10^{-3}$ & $\mathrm{~kg}$ \\
$k_{1}$ & $\mathbf{8 0}$ & $\mathrm{N} / \mathrm{m}$ \\
$k_{2}$ & $\mathbf{4 0}$ & $\mathrm{N} / \mathrm{m}$ \\
$k_{3}$ & $\mathbf{8}$ & $\mathrm{N} / \mathrm{m}$ \\
$c_{1}$ & $\mathbf{6 , 4 0 \times 1 0 ^ { - 2 }}$ & $\mathrm{N} /(\mathrm{m} / \mathrm{s})$ \\
$c_{2}$ & $\mathbf{3 , 2 0 \times 1 0 ^ { - 2 }}$ & $\mathrm{N} /(\mathrm{m} / \mathrm{s})$ \\
$c_{3}$ & $\mathbf{6 , 4 0 \times 1 0 ^ { - 3 }}$ & $\mathrm{N} /(\mathrm{m} / \mathrm{s})$ \\
$\alpha_{1}$ & $3,16 \times 10^{-5}$ & $\mathrm{~N} / \mathrm{V}$ \\
$\alpha_{2}$ & $3,16 \times 10^{-5}$ & $\mathrm{~N} / \mathrm{V}$ \\
$\alpha_{3}$ & $3,16 \times 10^{-5}$ & $\mathrm{~N} / \mathrm{V}$ \\
$C p_{1}$ & $2,5 \times 10^{-8}$ & $\mathrm{~F}$ \\
$C p_{2}$ & $2,5 \times 10^{-8}$ & $\mathrm{~F}$ \\
$C p_{3}$ & $2,5 \times 10^{-8}$ & $\mathrm{~F}$ \\
$R_{1}$ & $1,00 \times 10^{6}$ & $\Omega$ \\
$R_{2}$ & $1,00 \times 10^{6}$ & $\Omega$ \\
$R_{3}$ & $1,00 \times 10^{6}$ & $\Omega$ \\
\hline
\end{tabular}

Tabela 15 - Máxima potência gerada para o modelo de 3GDL do Casos 3 na configuração de referência, contendo um inserto piezelétrico para cada massa oscilante

\begin{tabular}{ccc}
\hline \multicolumn{3}{c}{ Máxima Potência Gerada } \\
3 GDL \\
Configurações de Referência \\
[mW] \\
1o piezo & \\
\multirow{3}{*}{ Caso 3 } & 2o piezo & 0,131 \\
& 3o piezo & 0,301 \\
& Total & 1,884 \\
& & 2,316 \\
\hline
\end{tabular}




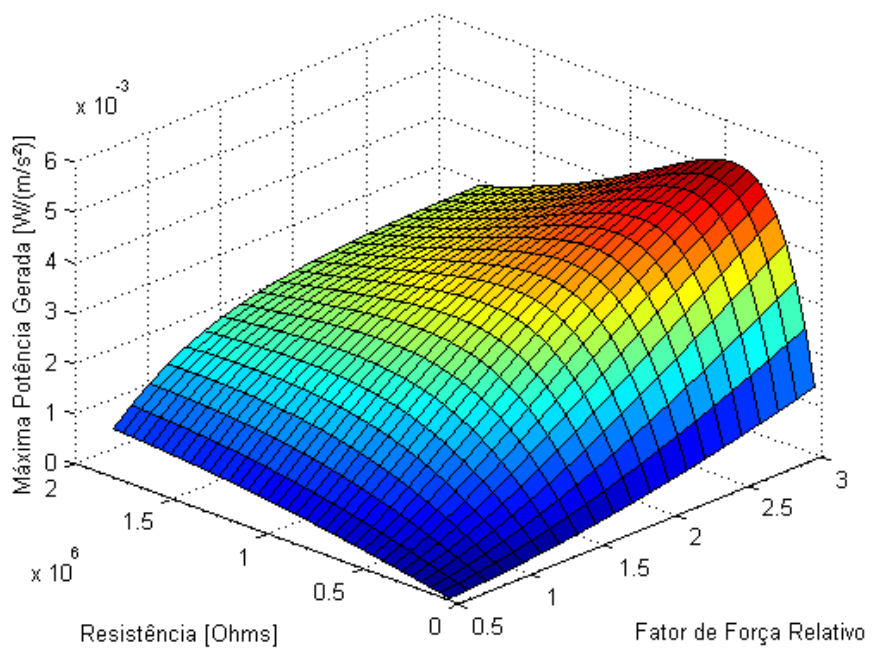

Figura 50 - Máxima potência gerada pelo inserto piezelétrico do terceiro oscilador do modelo de 3GDL do Caso 3, para diferentes resistências e fatores de força relativos.

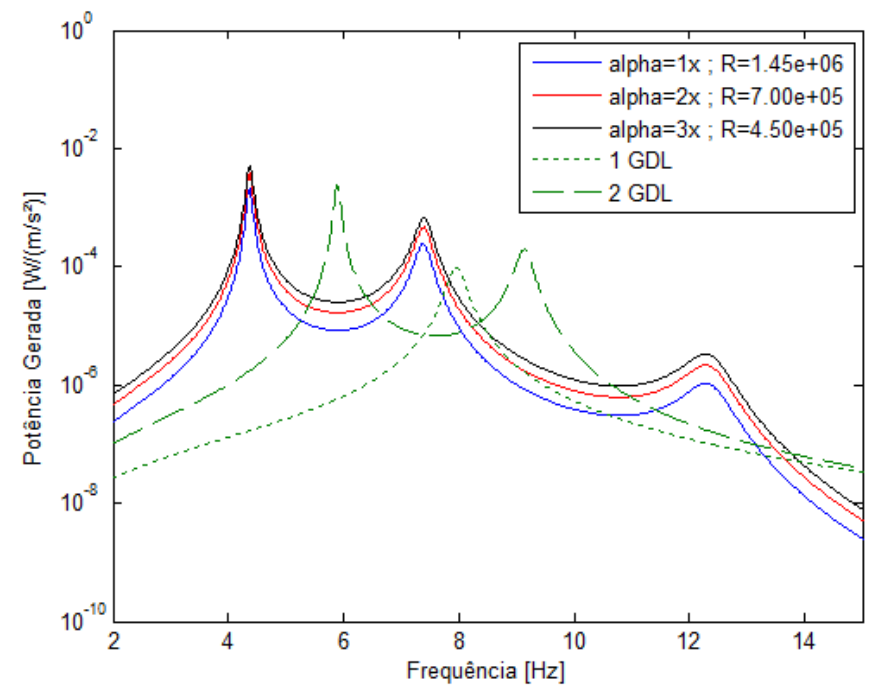

Figura 51 - FRFs de potência gerada pelo inseto do terceiro oscilador no modelo de 3GDL do Caso 3, para fatores de força relativos de 1, 2 e 3 nas resistência que maximizam o resultado, e FRFs do modelo de 1GDL equivalente, e 2GDL do exemplo de Xiao et al. (2015).

No Caso 3 pode-se afirmar que a configuração adotada não faz uso de artifícios que comprometem a viabilidade construtiva do gerador tendo como referência o exemplo de dois GDL. Isso porque não foram utilizadas relações de massa de ordens de grandeza superiores ou inferiores às do modelo de referência, nem relações discrepantes de rigidez. Em relação ao amortecimento, estes chagaram a ser proporcionalmente maiores do que os utilizados na segunda massa oscilante do gerador de referência, o que tende minimizar as amplitudes na ressonância para o modelo proposto. Tais condições trazem robustez aos resultados obtidos 
por não fundamentá-los em soluções impraticáveis, e por isso, não replicáveis a um gerador real, evidenciando o potencial dos múltiplos graus de liberdade para maximização das respostas bem como maximização da faixa de frequência útil do gerador.

Por fim, na tabela 16 estão resumidos os principais resultados obtidos para as configurações avaliadas usando o modelo de parâmetros concentrados, nos quais ficam evidentes os ganhos e compromissos discutidos ao longo do capítulo.

Tabela 16 - Resumo dos resultados dos modelos de 2 e 3 GDL estudados, nas configurações de referência e otimizada.

\begin{tabular}{|c|c|c|c|c|c|c|}
\hline \multirow[b]{2}{*}{ Gerador } & \multicolumn{2}{|c|}{ Potência Total Gerada } & \multicolumn{2}{|c|}{$\begin{array}{c}\text { Banda de Frequência } \\
{[\mathrm{Hz}]}\end{array}$} & \multicolumn{2}{|c|}{ Densidade energética } \\
\hline & $\begin{array}{c}\text { Máxima } \\
{[\mathrm{mW}]}\end{array}$ & $\begin{array}{c}\text { Mínima } \\
\text { (entre } \\
\text { ressonâncias) } \\
{[\mu \mathrm{W}]}\end{array}$ & $\begin{array}{c}\text { Amplitude } \\
\text { de } \\
6,8 \mu \mathrm{W}\end{array}$ & $\begin{array}{c}\text { Amplitude } \\
\text { de } \\
16,8 \mu \mathrm{W}\end{array}$ & $\begin{array}{c}\text { Massa } \\
\text { total } \\
{[\mathrm{mW} / \mathrm{kg}]}\end{array}$ & $\begin{array}{l}\text { Massa de } \\
\text { Piezo } \\
{\left[\mathbf{m W} / \mathbf{m}_{\mathbf{p}}\right]}\end{array}$ \\
\hline $\begin{array}{c}3 \text { GDL } \\
\text { Solução de Referência } \\
\text { Caso } 1\end{array}$ & 3,17 & 47,27 & 3,90 & 3,28 & 65,95 & 1,06 \\
\hline $\begin{array}{c}3 \text { GDL } \\
\text { Solução de Referência } \\
\text { Caso } 2\end{array}$ & 1,63 & 8,49 & 5,65 & 2,77 & 33,96 & 0,54 \\
\hline $\begin{array}{c}3 \text { GDL } \\
\text { Solução de Referência } \\
\text { Caso } 3\end{array}$ & 2,32 & 8,96 & 4,62 & 2,54 & 48,24 & 0,77 \\
\hline $\begin{array}{c}3 \text { GDL } \\
\text { Solução Proposta } \\
\text { Caso } 1\end{array}$ & 5,14 & 91,74 & 4,31 & 3,61 & 107,00 & 2,57 \\
\hline $\begin{array}{c}3 \text { GDL } \\
\text { Solução Proposta } \\
\text { Caso } 2\end{array}$ & 2,01 & 14,19 & 5,42 & 3,47 & 41,96 & 1,01 \\
\hline $\begin{array}{c}3 \text { GDL } \\
\text { Solução Proposta } \\
\text { Caso } 3\end{array}$ & 3,74 & 16,80 & 4,93 & 4,32 & 78,00 & 1,87 \\
\hline $\begin{array}{c}2 \text { GDL } \\
\text { Solução de Referência }\end{array}$ & 2,44 & 6,78 & 4,75 & 2,29 & 50,83 & 1,22 \\
\hline $\begin{array}{c}2 \text { GDL } \\
\text { Solução Proposta }\end{array}$ & 4,06 & 13,21 & 5,04 & 3,34 & 84,52 & 2,03 \\
\hline
\end{tabular}




\subsection{Simulações Numéricas - Modelo de Parâmetros Distribuídos - Viga "L"}

O modelo de parâmetros distribuídos da viga "L" foi estudado nas três configurações apresentadas na figura 9 (capítulo 2), sendo que para cada configuração foi avaliada a potência total gerada em função do comprimento e posicionamento dos insertos piezelétricos, resistência do circuito elétrico associado e posicionamento da segunda massa ao longo da segunda viga. As demais características do gerador foram mantidas constantes ao longo de todo o estudo, e são dadas pela tabela 17. Assim como realizado para os modelos de parâmetros concentrados, as análises foram orientadas no sentido de se maximizar a potência gerada e minimizar a quantidade de material piezelétrico, buscando-se não alterar a massa da estrutura para permitir a comparação dos resultados. As respostas foram avaliadas sempre para uma excitação constante em todo o espectro de frequências de amplitude $1 \mathrm{~m} / \mathrm{s}^{2}$, ou seja, em que a resposta é exatamente a função resposta em frequência do dispositivo.

Tabela 17 - Parâmetros do modelo da viga " $L$ " estudado ao longo do capítulo.

\begin{tabular}{ccc}
\hline \multicolumn{3}{c}{ Parâmetros das Simulações Numéricas - Viga " $\mathbf{~ " ~}$} \\
\hline Parâmetro & Valor & Unidade \\
\hline$L_{1}$ & 187 & $\mathrm{~mm}$ \\
$L_{2}+L_{3}$ & 220 & $\mathrm{~mm}$ \\
$M_{1}$ & 71 & $\mathrm{~g}$ \\
$M_{2}$ & 38 & $\mathrm{~g}$ \\
$\rho_{s}$ & 7870 & $\mathrm{~kg} / \mathrm{m} 3$ \\
$\rho_{p}$ & 7800 & $\mathrm{~kg} / \mathrm{m} 3$ \\
$h_{s l}$ & 3 & $\mathrm{~mm}$ \\
$h_{s 2}$ & 1,5 & $\mathrm{~mm}$ \\
$h_{p}$ & $5 \times 10-2$ & $\mathrm{~mm}$ \\
$b_{s}=b_{p}$ & 25 & $\mathrm{~mm}$ \\
$d_{31}$ & $-1,90 \mathrm{E}-10$ & $\mathrm{C} / \mathrm{N}$ \\
$\varepsilon_{33}^{S}$ & $1,33 \mathrm{E}-08$ & $\mathrm{~F} / \mathrm{m}$ \\
$Y_{s}$ & 207 & $\mathrm{GPa}$ \\
$Y_{p}$ & 60,6 & $\mathrm{GPa}$ \\
\hline
\end{tabular}




\subsubsection{Configuração 1}

A primeira configuração avaliada, dada pela figura 9a, corresponde ao modelo proposto por Erturk et al. (2009) mas com recobrimento apenas parcial da estrutura nas três regiões definidas. Os resultados obtidos para essa montagem foram utilizados como referência para verificação dos ganhos e perdas relativos às demais configurações avaliadas.

\subsubsection{1. - Posição da Massa 2}

A influência do posicionamento da massa 2 nas funções de resposta em frequência de tensão e potência total gerada foi avaliada usando um comprimento fixo, igual a 38,1 mm para todos os insertos piezelétricos, partindo de $x_{k}=0$, e resistência constante igual a $50 \mathrm{k} \Omega$. Observando-se os resultados de tensão e potência gerada na resistência elétrica, dispostos nas figuras 52 a 55, nota-se variações principalmente na frequência natural do primeiro modo de vibrar, as quais o afastamento de $\mathrm{M}_{2}$ em relação à viga 1 causa sua diminuição, decorrente da evidente redução de rigidez do sistema formado pela massa 2 e viga 2. Observa-se ainda que para o cancelamento no primeiro modo, há variações de amplitudes mais significativas na primeira frequência natural do que na segunda, ao contrário da configuração com cancelamento no segundo modo, em que a resposta na segunda frequência varia significativamente.

Os resultados de potência gerada nos insertos, dispostos nas figuras 56 a 58, indicam uma progressiva e acentuada diminuição da contribuição do elemento piezelétrico do segmento $\mathfrak{R}_{3}$ à medida que se desloca a massa 2 para a extremidade, enquanto para os demais segmentos notam-se apenas pequenas variações de amplitude.

Repetindo-se as análises para diferentes resistências (\#Figuras 59 e 60), foi possível verificar que a maximização da potência gerada para esta configuração ocorre com a massa $\mathrm{M}_{2}$ posicionada próxima a região central da viga 2, em $96,8 \mathrm{~mm}$ para o primeiro modo e 118,8 mm para o segundo, com cancelamentos nos modos opostos. Fica evidente ainda a existência de uma resistência que maximiza a potência gerada, em que tanto seu aumento quanto sua diminuição ocasiona redução das amplitudes de resposta, conforme já visto nos modelos de parâmetros concentrados. Apesar disso, observa-se que há pouca variação nos valores ótimos de resistência ao longo das diferentes posições de $\mathrm{M}_{2}$ testadas. 


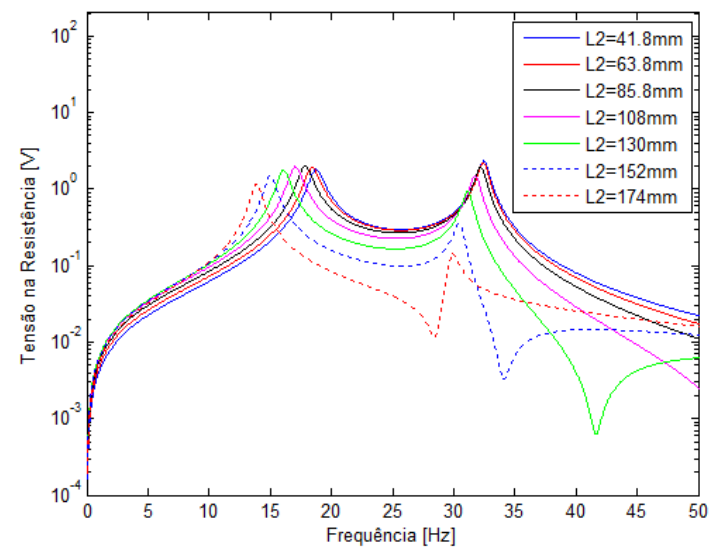

Figura 52 - Tensão gerada na resistência elétrica de $50 \mathrm{k} \Omega$ do circuito associado ao gerador, com cancelamento no segundo modo de vibrar para diferentes posições de $\mathbf{M}_{2}$.

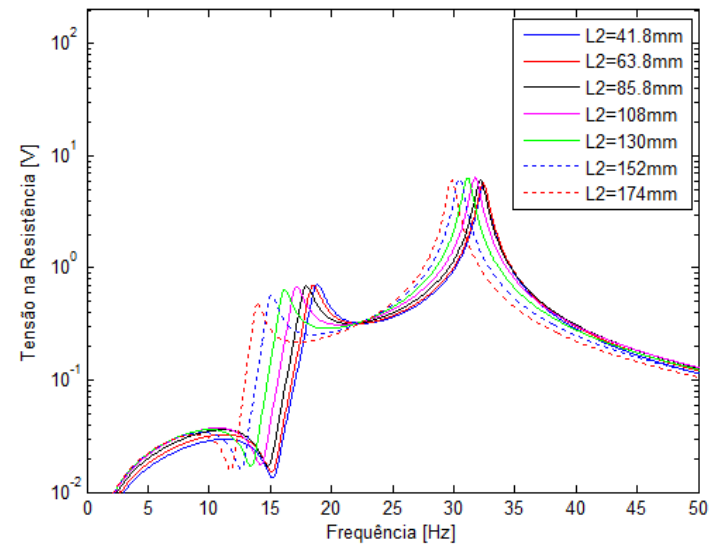

Figura 53 - Tensão gerada na resistência elétrica de $50 \mathrm{k} \Omega$ do circuito associado ao gerador, com cancelamento no primeiro modo de vibrar para diferentes posições de $\mathbf{M}_{2}$.

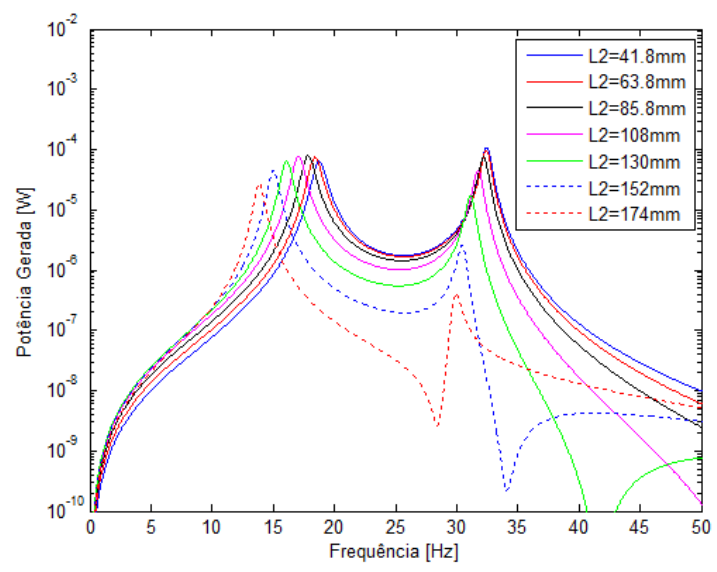

Figura 54 - Potência gerada na resistência elétrica de $50 \mathrm{k} \Omega$ do circuito associado ao gerador, com cancelamento no segundo modo de vibrar para diferentes posições de $\mathbf{M}_{2}$. 


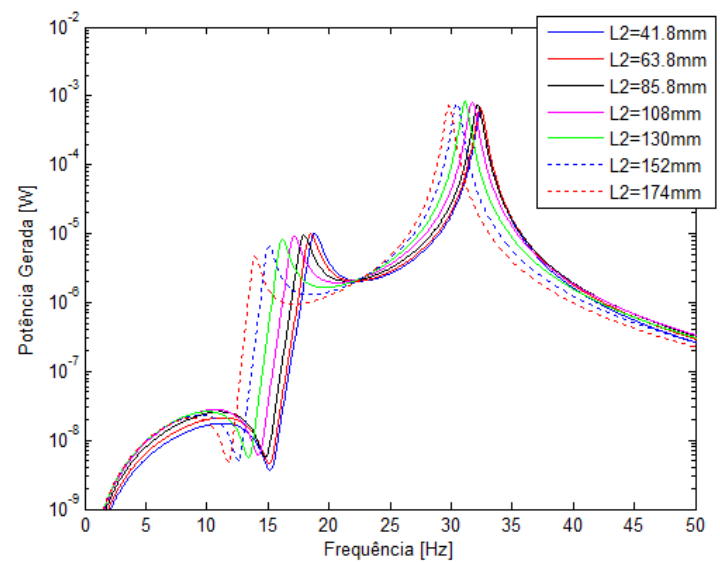

Figura 55 - Potência gerada na resistência elétrica de $50 \mathrm{k} \Omega$ do circuito associado ao gerador, com cancelamento no primeiro modo de vibrar para diferentes posições de $\mathrm{M}_{2}$.

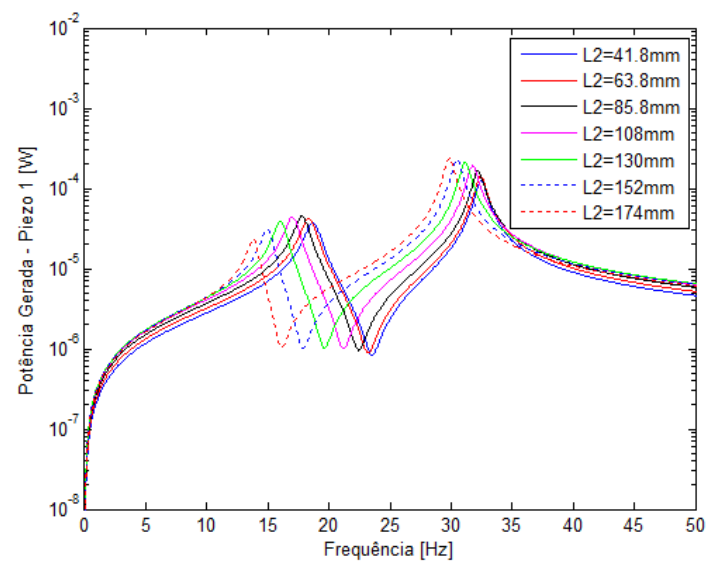

Figura 56 - Potência gerada no inserto piezelétrico de $\Re_{1}$ usando uma resistência de $50 \mathrm{k} \Omega$ para diferentes posições de $\mathrm{M}_{2}$.

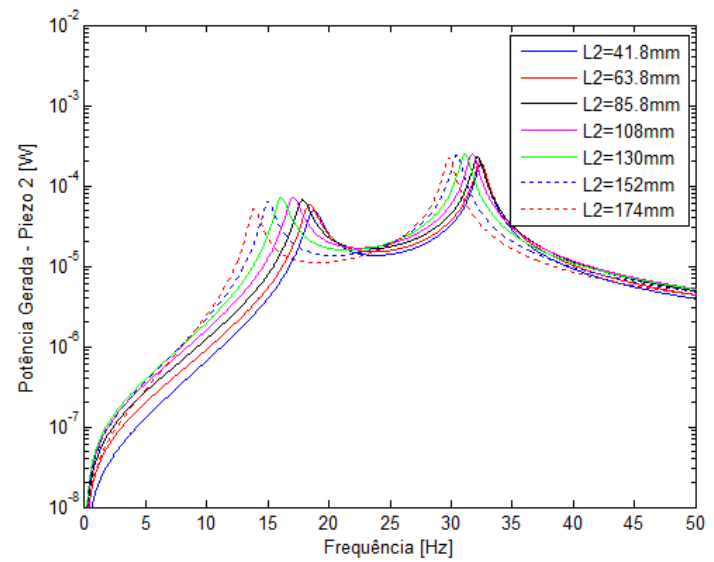

Figura 57 - Potência gerada no inserto piezelétrico de $\mathfrak{R}_{2}$ usando uma resistência de $50 \mathrm{k} \Omega$ para diferentes posições de $\mathbf{M}_{2}$. 


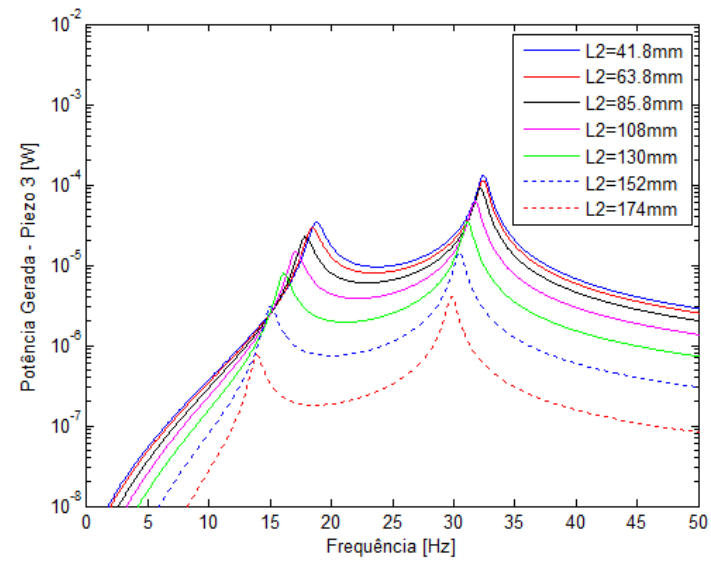

Figura 58 - Potência gerada no inserto piezelétrico de $\Re_{3}$ usando uma resistência de $50 \mathrm{k} \Omega$ para diferentes posições de $\mathrm{M}_{2}$.
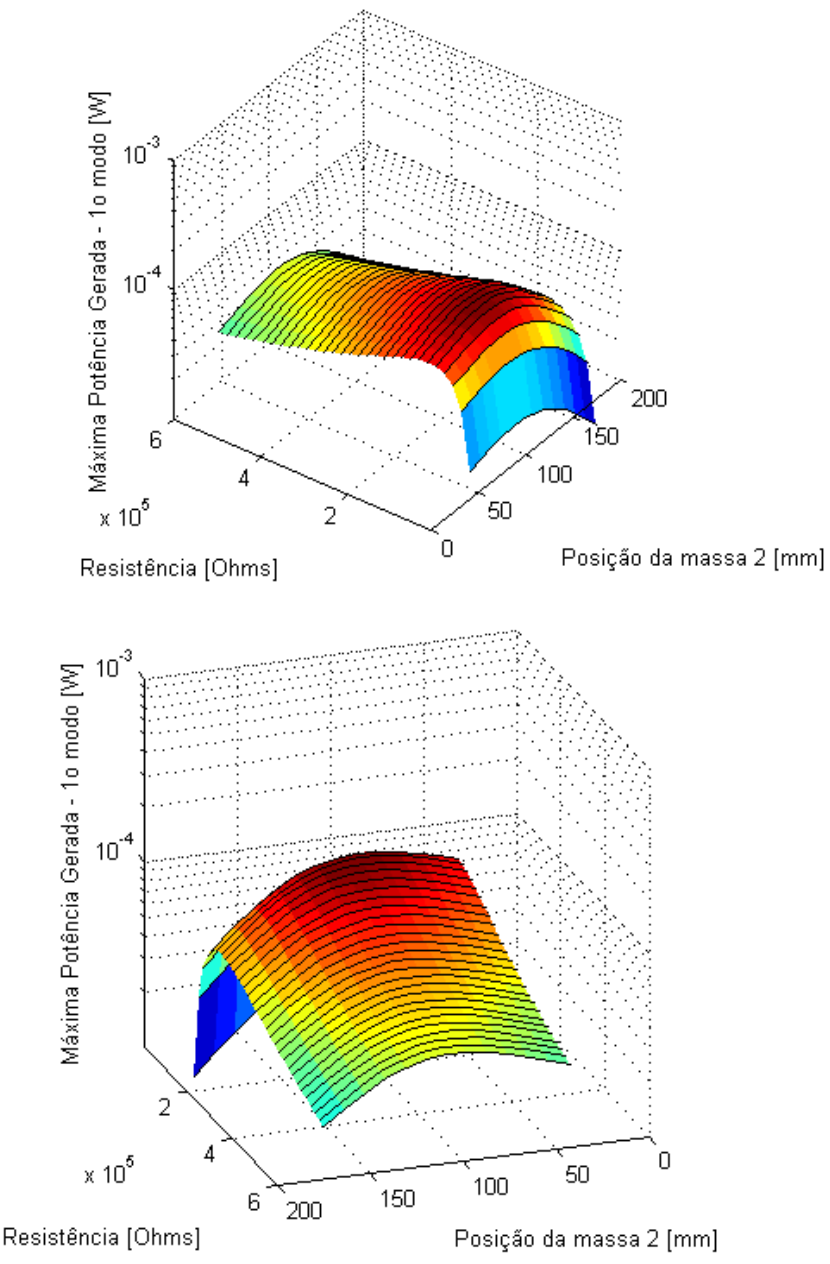

Figura 59 - Máxima potência gerada na resistência para o primeiro modo de vibrar, para diferentes resistências e posições de $M_{2}$, com cancelamento no segundo modo. 

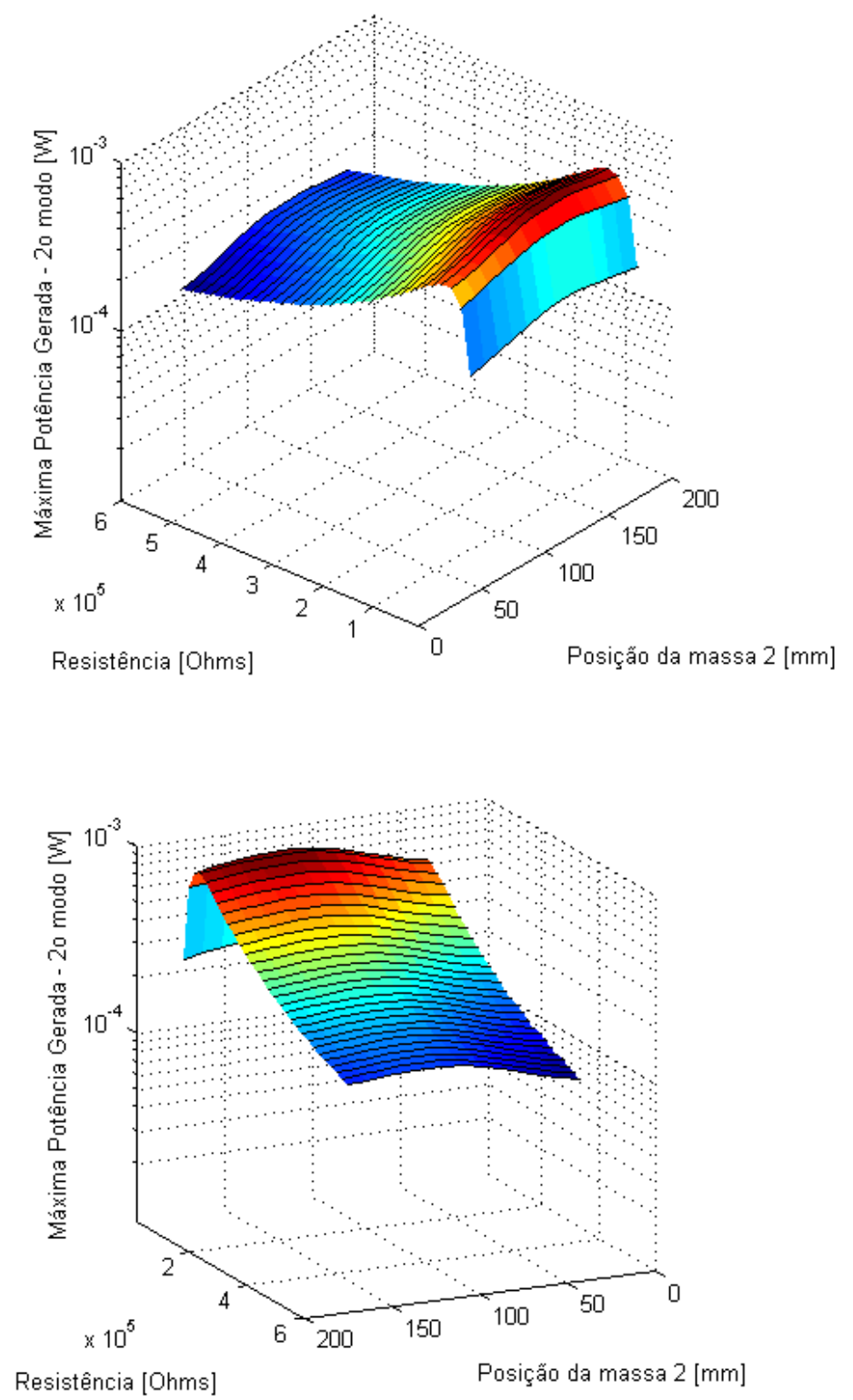

Figura 60 - Máxima potência gerada na resistência para o segundo modo de vibrar, para diferentes resistências e posições de $\mathrm{M} 2$, com cancelamento no primeiro modo. 


\subsubsection{2.- Comprimento do Inserto Piezelétrico.}

Fixando-se a posição da massa 2 no centro da viga $2\left(L_{2}=107,8 \mathrm{~mm}\right)$, variou-se o comprimento de um dos elementos piezelétricos mantendo-se os demais constantes, com $38,1 \mathrm{~mm}$, conforme os parâmetros do estudo anterior, repetindo o procedimento tanto para o inserto de $\mathfrak{R}_{1}$ como de $\mathfrak{R}_{2}$, permitindo entender a natureza da resposta em cada viga.

Primeiramente, usando uma resistência constante igual a $50 \mathrm{k} \Omega$, nota-se que, apesar da introdução de cada vez mais material piezelétrico, a potência total gerada no modo oposto ao cancelamento altera-se muito pouco a partir de um determinado comprimento para ambos os insertos testados, conforme as figuras 61 a 64 . No caso do inserto de $\mathfrak{R}_{1}$, observa-se ainda que o aumento de seu comprimento causa um acentuado aumento das amplitudes de respostas no modo em que ocorre o cancelamento, principalmente quando este configura-se no segundo.

Ao se avaliar a máxima potência gerada para diferentes resistências (\#Figuras 65 a 68) verifica-se que, exceto para o inserto de $\mathfrak{R}_{1}$ no primeiro modo, o aumento do comprimento do inserto aumenta a máxima energia gerada até um determinado limite, a partir do qual esta passa a diminuir. Observa-se ainda, principalmente no caso dos comprimentos menores, nos quais as variações têm maior impacto na potência gerada, que a resposta para cada recobrimento é maximizada por uma resistência diferente (\#Figuras 69 a 72). Já no caso dos comprimentos maiores, em que há pouco reflexo na máxima potência gerada, praticamente não nota-se variação da resistência ótima.

Nesta configuração, com a massa $\mathrm{M}_{2}$ em $107,8 \mathrm{~mm}$, a máxima potência gerada encontrada variando-se o inserto da primeira viga no primeiro e segundo modo de vibrar foi de $121,1 \mu \mathrm{W}$ com $60 \%$ de recobrimento, e $870,8 \mu \mathrm{W}$ com $30 \%$ de recobrimento respectivamente, sempre com cancelamento no modo oposto. No caso do inserto de $\mathfrak{R}_{2}$, as potências obtidas foram 105,5 $\mu \mathrm{W}$ e $868,5 \mu \mathrm{W}$, com recobrimentos de 50 e $60 \%$ para a primeira e segunda frequência natural respectivamente, novamente com cancelamentos no modo oposto.

Nos gráficos de FRF é possível observar ainda que no o aumento da área recoberta em $\mathfrak{R}_{1}$ contribui mais significativamente para o aumento da potência gerada no modo em que ocorre o cancelamento, enquanto o recobrimento da região $\mathfrak{R}_{2}$ apresenta impactos semelhantes nas respostas de ambas as frequências naturais.

Ao se variar a posição da massa 2 para os vários comprimentos dos insertos (\#Figuras 73 a 76) nota-se que em cada configuração há uma porcentagem de recobrimento 
que maximiza a energia gerada. No caso de $\mathfrak{R}_{1}$ a máxima potência gerada na primeira frequência natural, de $122,9 \mu \mathrm{W}$, é obtida para massa $\mathrm{M}_{2}$ em $96,8 \mathrm{~mm}$ com $60 \%$ de recobrimento, enquanto para a segunda frequência, a máxima potência gerada, de $882,3 \mu \mathrm{W}$, ocorre com $\mathrm{M}_{2}$ em 118,8 mm e recobrimento de $30 \%$.

No caso da região $\mathfrak{R}_{2}$, a máxima potência gerada no primeiro modo, de $108,2 \mu \mathrm{W}$, é obtida com $\mathrm{M}_{2}$ em $96,8 \mathrm{~mm}$, enquanto para o segundo modo o melhor resultado, $882,1 \mu \mathrm{W}$, é obtido com $\mathrm{M}_{2}$ em 118,8mm, com recobrimentos de 60 e $50 \%$ respectivamente.

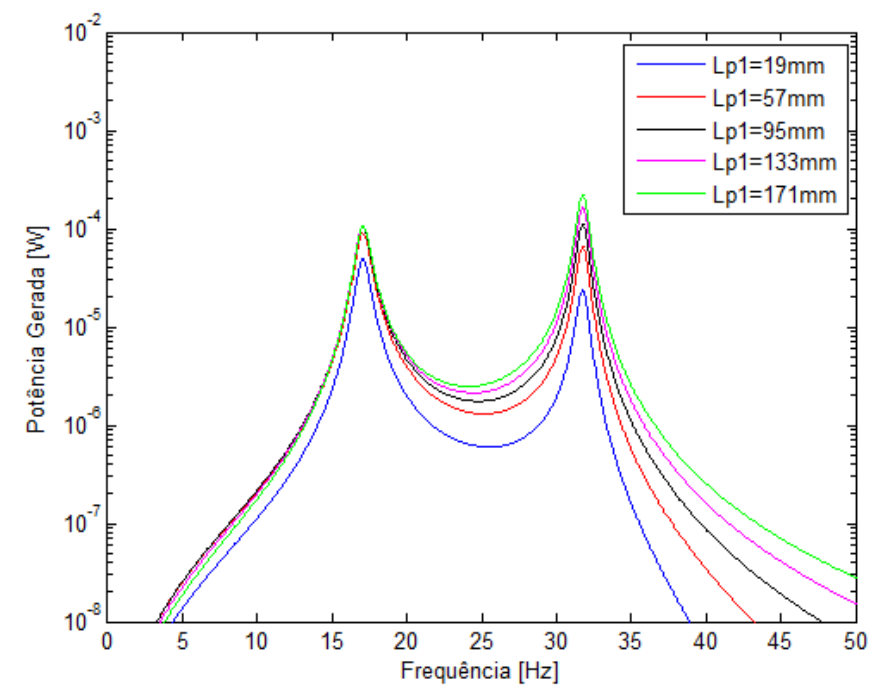

Figura 61 - Potência gerada na resistência de $50 \mathrm{k} \Omega$ para diferentes comprimentos do inserto de $\Re_{1}$, com $\mathrm{M}_{2}$ posicionada em $L_{2}=107,8 \mathrm{~mm}$, e cancelamento no segundo modo.

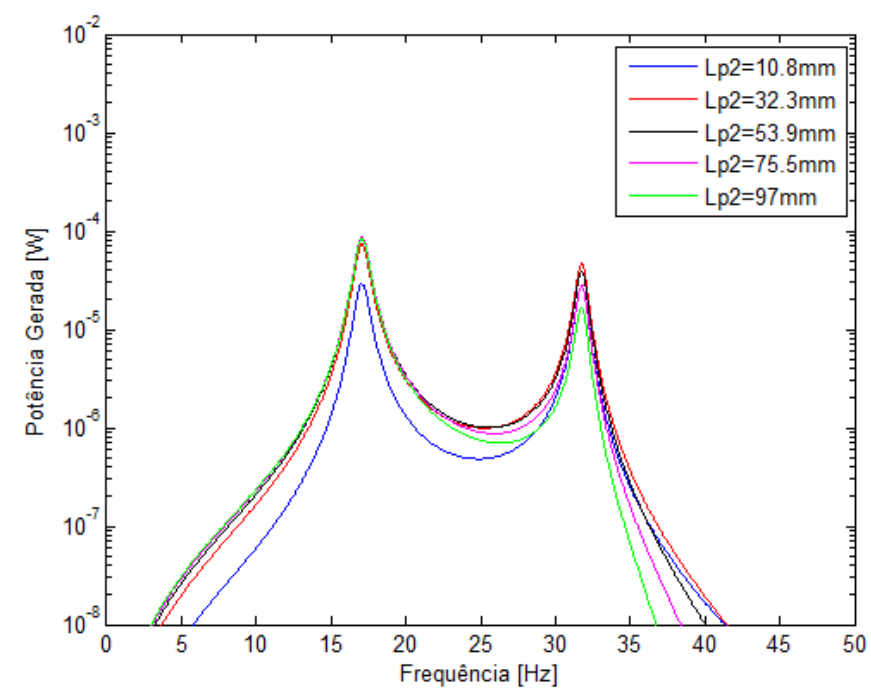

Figura 62 - Potência gerada na resistência de $50 \mathrm{k} \Omega$ para diferentes comprimentos do inserto de $\mathfrak{R 2}$, com $M_{2}$ posicionada em $L_{2}=107,8 \mathrm{~mm}$, e cancelamento no segundo modo. 


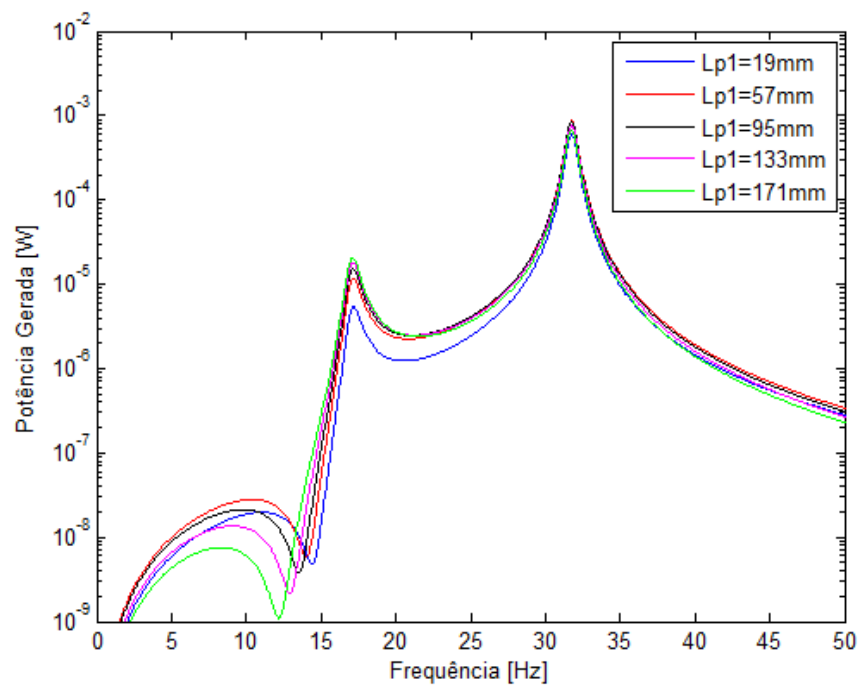

Figura 63 - Potência gerada na resistência de $50 \mathrm{k} \Omega$ para diferentes comprimentos do inserto de $\Re_{1}$ com $M_{2}$ posicionada em $L_{2}=107,8 \mathrm{~mm}$, e cancelamento no primeiro modo.

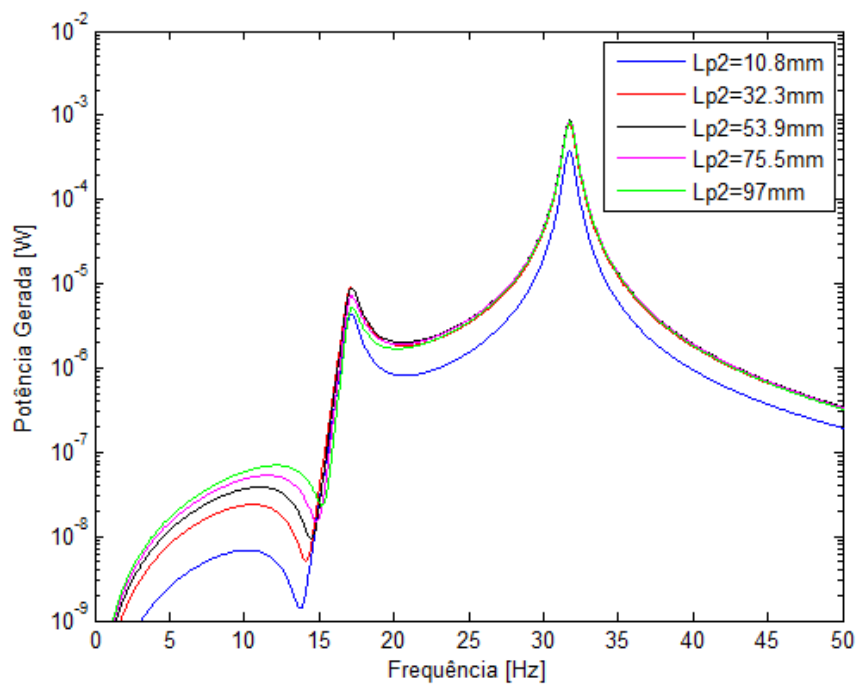

Figura 64 - Potência gerada na resistência de $50 \mathrm{k} \Omega$ para diferentes comprimentos do inserto de $\Re_{2}$, com $\mathrm{M}_{2}$ posicionada em $L_{2}=107,8 \mathrm{~mm}$, e cancelamento no primeiro modo. 


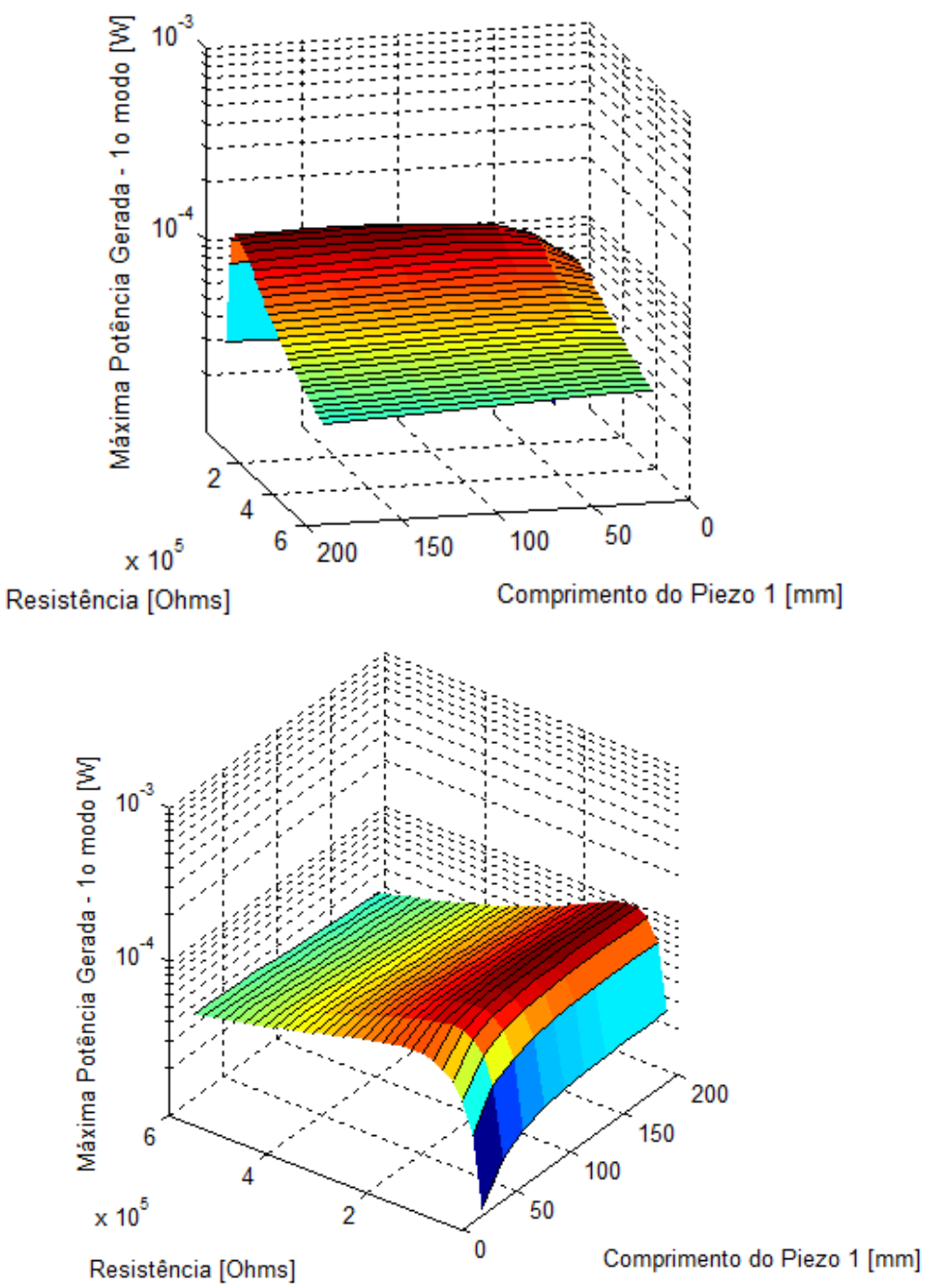

Figura 65 - Máxima potência gerada na resistência para o primeiro modo de vibrar, com $M_{2} \mathrm{em} \mathrm{108mm} \mathrm{e}$ cancelamento no segundo modo, para diferentes resistências e comprimentos do inserto de $\mathfrak{R}_{1}$. 


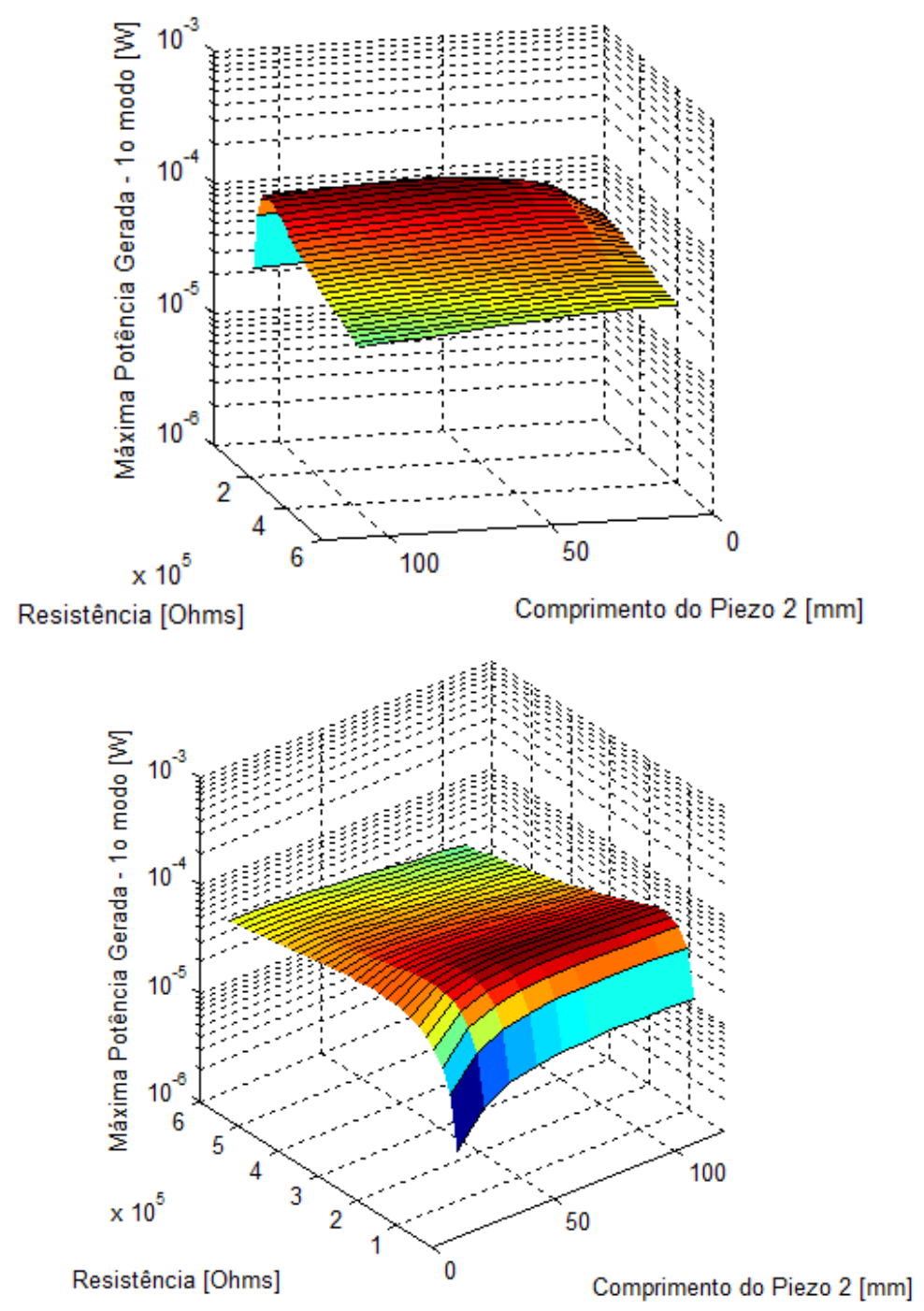

Figura 66 - Máxima potência gerada na resistência para o primeiro modo de vibrar, com $M_{2}$ em 107,8 mm e cancelamento no segundo modo, para diferentes resistências e comprimentos do inserto de $\mathfrak{R}_{2 \text {. }}$ 


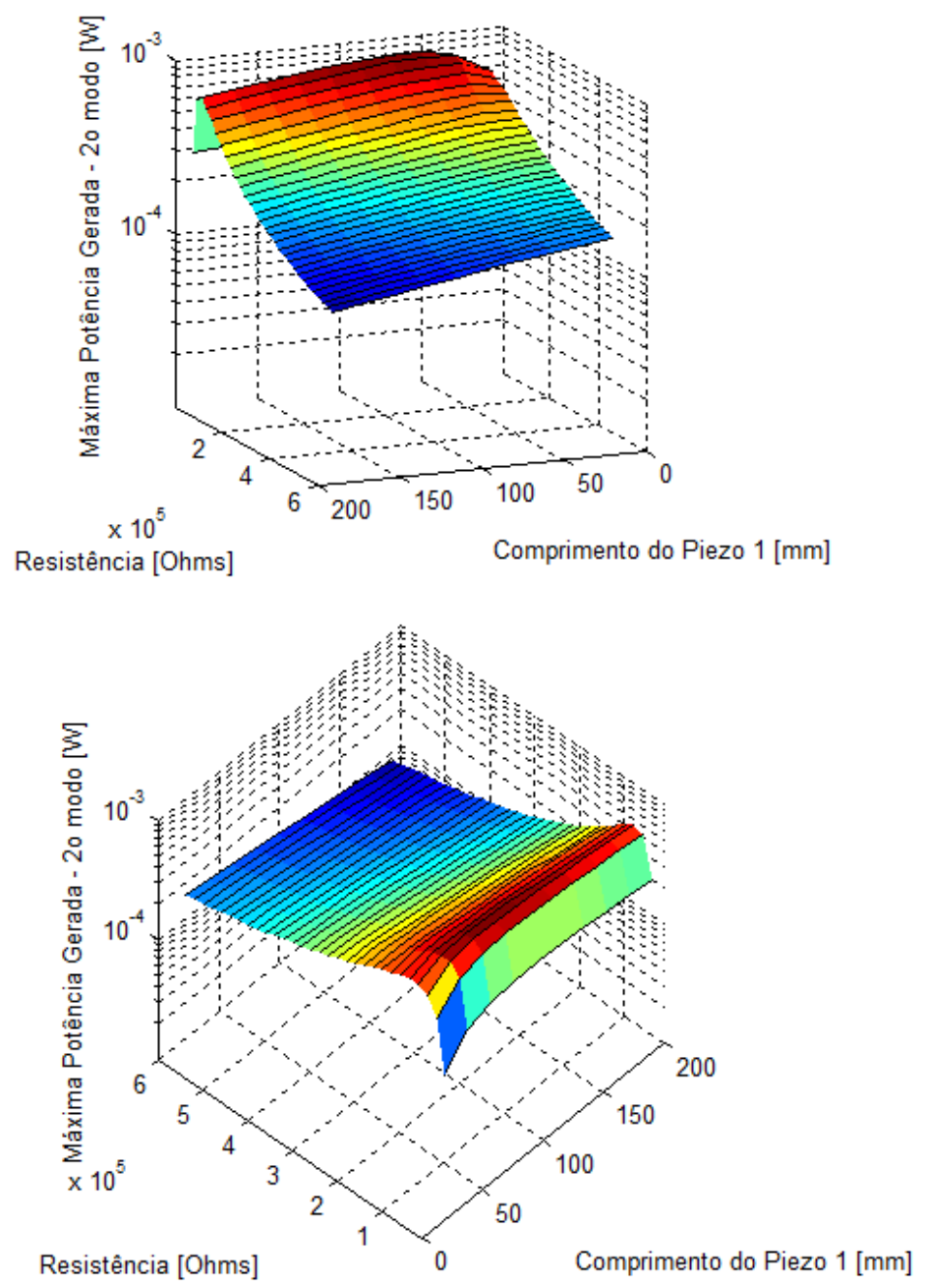

Figura 67 - Máxima potência gerada na resistência para o segundo modo de vibrar, com $M_{2}$ em 107,8mm e cancelamento no primeiro modo, para diferentes resistências e comprimentos do inserto de $\mathfrak{R}_{1}$ 

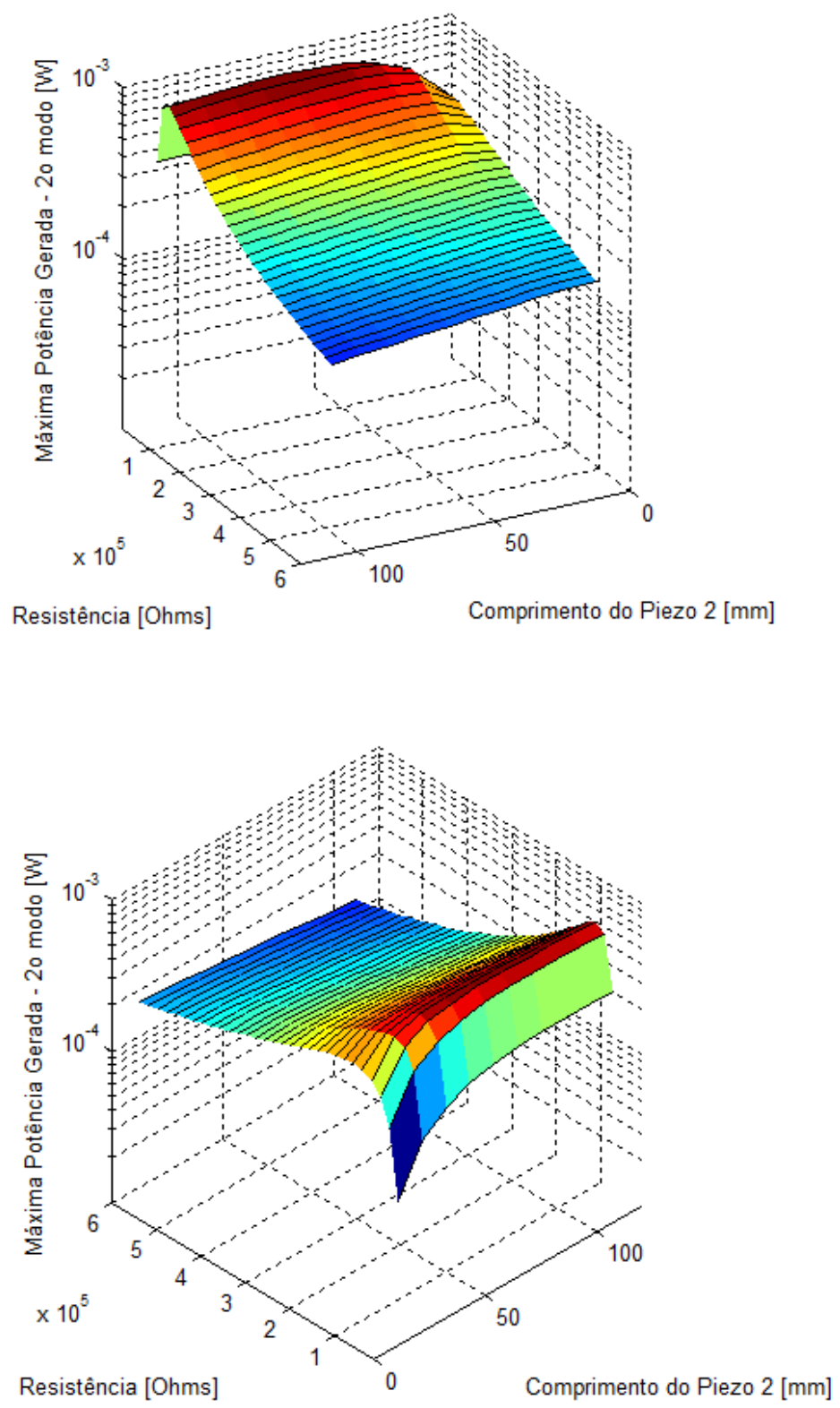

Figura 68 - Máxima potência gerada na resistência para o segundo modo de vibrar, com $M_{2}$ em 107,8mm e cancelamento no primeiro modo, para diferentes resistências e comprimentos do inserto de $\mathfrak{R}_{2}$. 


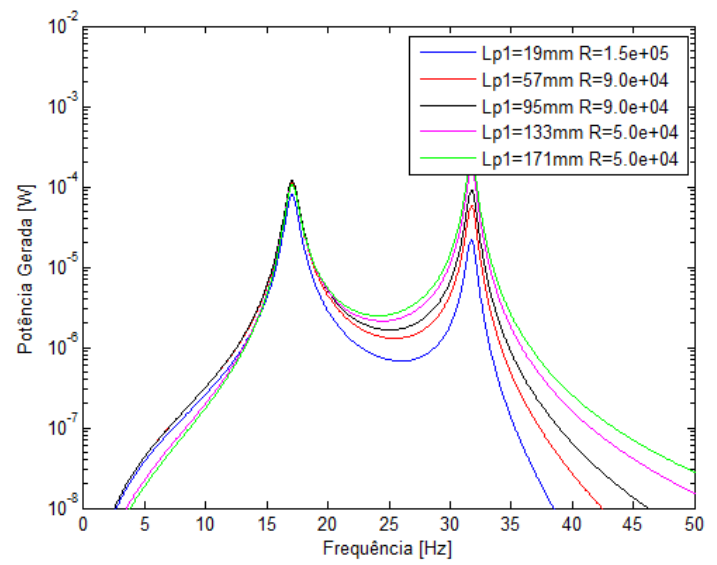

Figura 69 - FRF de potência gerada na resistência, com $M_{2}$ em 107,8mm e cancelamento no segundo modo, para diferentes comprimentos do inserto de $\mathfrak{R}_{1}$ às resistências que otimizam a resposta do gerador.

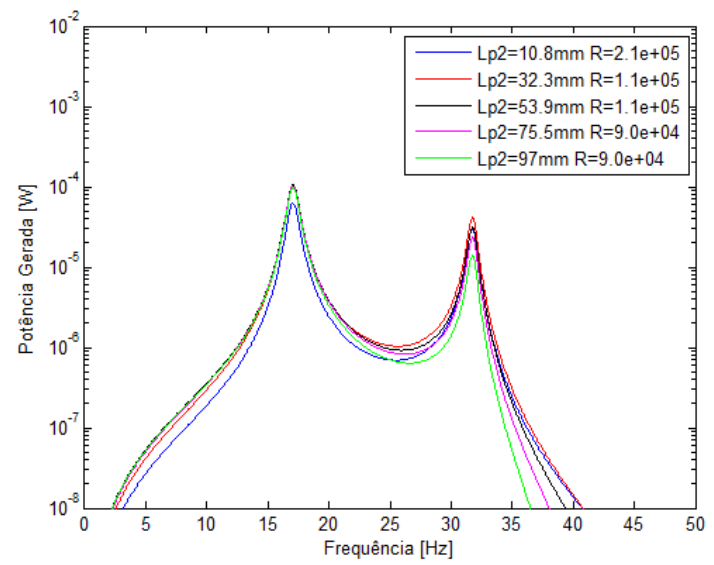

Figura 70 - FRF de potência gerada na resistência, com $M_{2}$ em 107,8mm e cancelamento no segundo modo, para diferentes comprimentos do inserto de $\mathfrak{R}_{2}$ às resistências que otimizam a resposta do gerador.

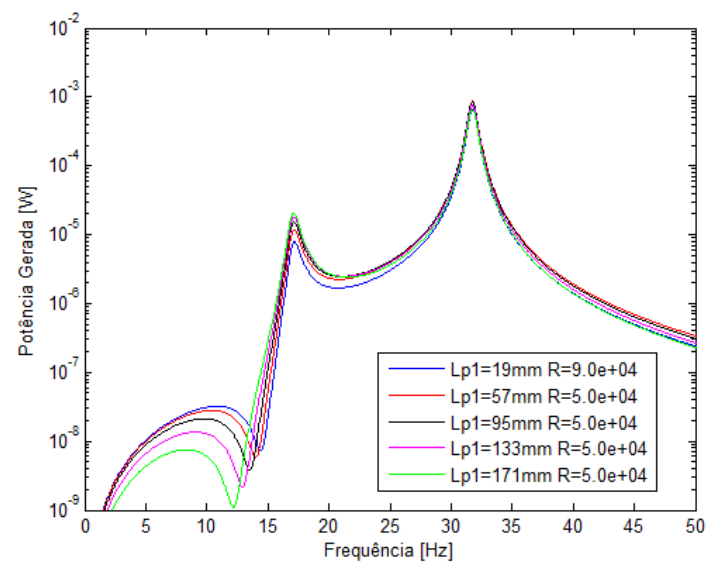

Figura 71 - FRF de potência gerada na resistência, com $M_{2}$ em $107,8 m m$ e cancelamento no primeiro modo, para diferentes comprimentos do inserto de $\mathfrak{R}_{1}$ às resistências que otimizam a resposta do gerador. 


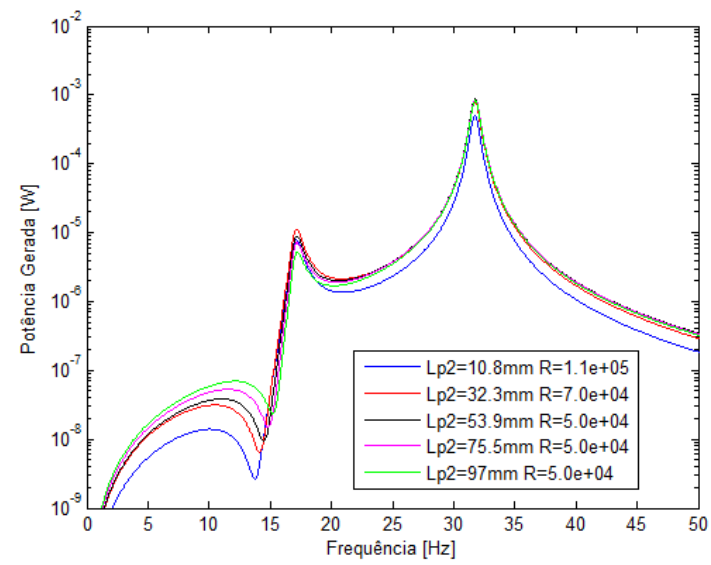

Figura 72 - FRF de potência gerada na resistência, com $M_{2}$ em $107,8 \mathrm{~mm}$ e cancelamento no primeiro modo, para diferentes comprimentos do inserto de $\mathfrak{R}_{2}$ às resistências que otimizam a resposta do gerador.

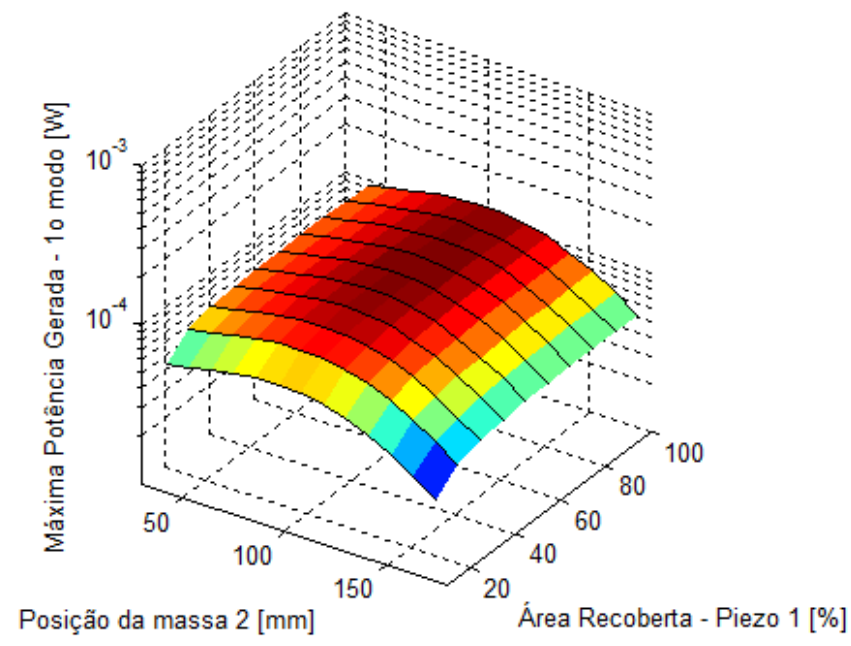

Figura 73 - Máxima potência gerada no primeiro modo de vibrar, à resistência de maior eficiência e cancelamento no segundo modo, para diferentes posições de $M_{2}$ e comprimentos do inserto de $\mathfrak{R}_{1}$

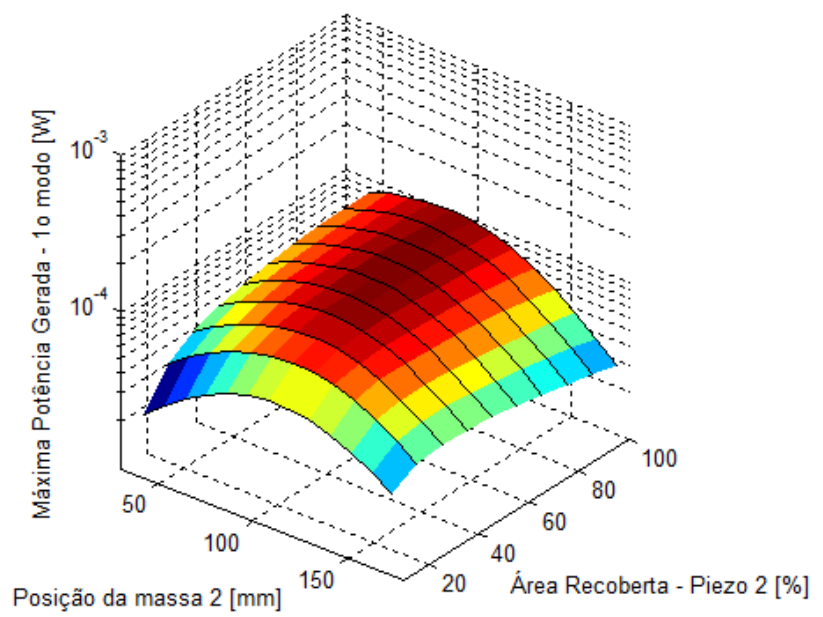

Figura 74 - Máxima potência gerada no primeiro modo de vibrar, à resistência de maior eficiência e cancelamento no segundo modo, para diferentes posições de $M_{2}$ e comprimentos do inserto de $\Re_{2}$. 


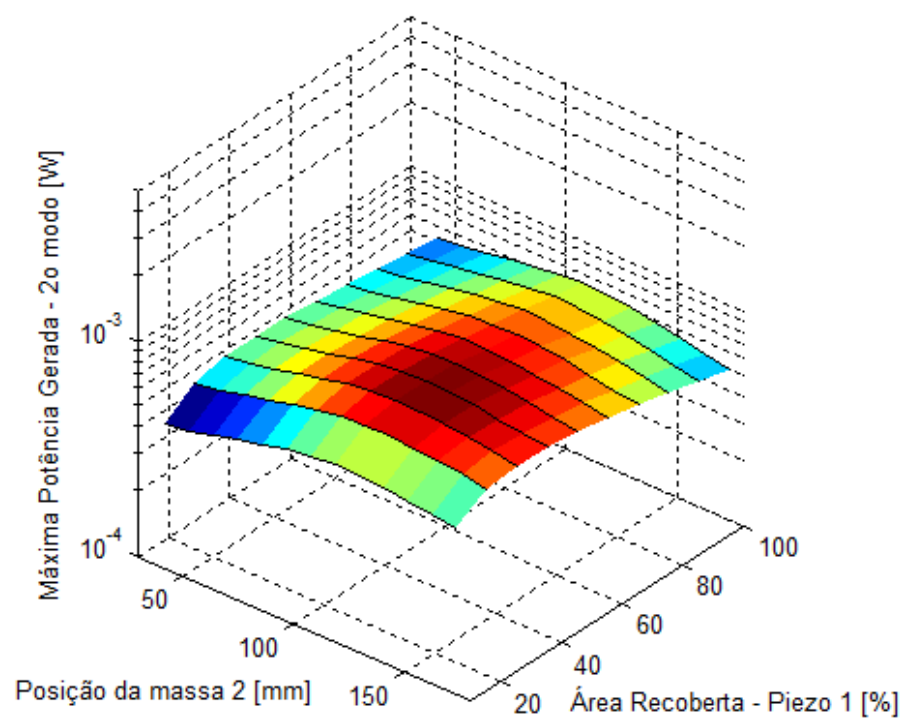

Figura 75 - Máxima potência gerada no segundo modo de vibrar, à resistência de maior eficiência e cancelamento no primeiro modo, para diferentes posições de $M_{2}$ e comprimentos do inserto de $\Re_{1}$

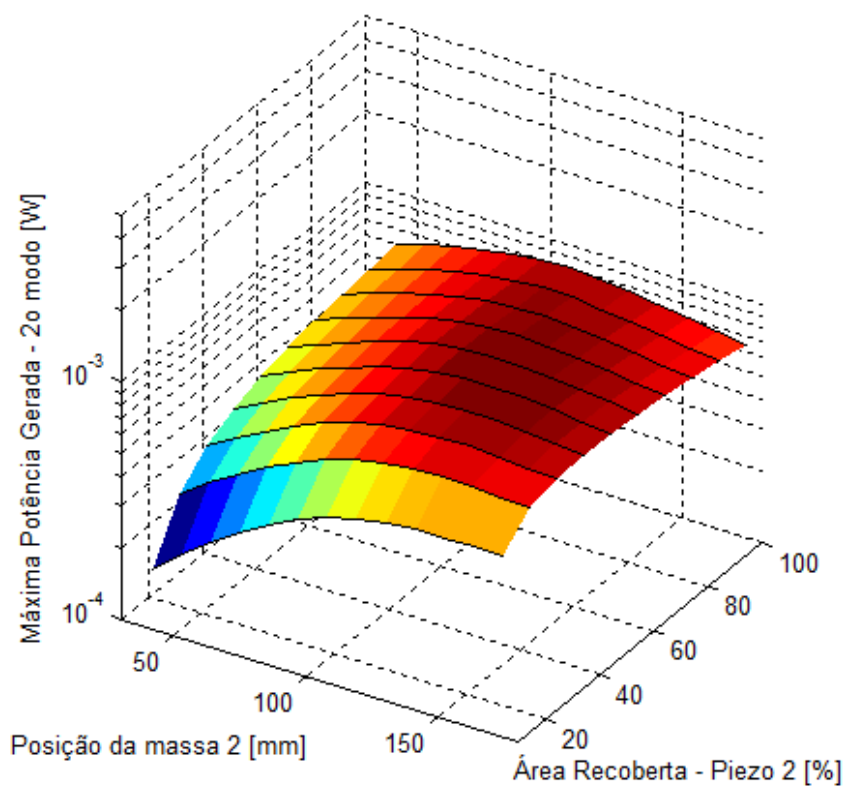

Figura 76 - Máxima potência gerada no segundo modo de vibrar, à resistência de maior eficiência e cancelamento no primeiro modo, para diferentes posições de $M_{2}$ e comprimentos do inserto de $\Re_{2}$ 


\subsubsection{Posição do Inserto Piezelétrico.}

Nesse estudo os comprimentos dos insertos foram mantidos constantes iguais a $38,1 \mathrm{~mm}$, variando-se apenas seu posicionamento ao longo da estrutura. Novamente realizouse o estudo para o primeiro e segundo inserto, primeiramente fixando-se a posição da massa $\mathrm{M}_{2}$ em $107,8 \mathrm{~mm}$, e usando uma resistência constante igual a $50 \mathrm{k} \Omega$.

Nos gráficos das figuras 77 a 80 é possível observar que para o inserto de $\mathfrak{R}_{2}$ as máximas potências geradas em ambas as frequências naturais e cancelamentos ocorrem em $L_{2}=0$, decaindo à medida que o inserto se afasta do início da viga. Já no caso de $\mathfrak{R}_{1}$, nota-se comportamentos distintos entre as duas frequências naturais observadas, com diminuição da potência gerada em uma, e aumento em outra, cujo aumento ocorre sempre no mesmo modo em que inicialmente foi configurado o cancelamento.

Verificando-se a máxima potência gerada no modo oposto ao do cancelamento para diferentes resistências (\#Figuras 81 a 84), nota-se que a resposta do gerador é sempre maximizada em $L o 2=0 \mathrm{~mm}$ tanto para o inserto de $\mathfrak{R}_{1}$, como o de $\mathfrak{R}_{2}$. Nota-se ainda que em todas as posições testadas a maximização da energia gerada ocorre sempre para a mesma resistência.

Ao se verificar os efeitos da variação da posição do inserto piezelétrico para diferentes posições de $M_{2}$ (\#Figuras 85 a 88), observa-se a maximização da potência gerada em $L_{2}=96,8 \mathrm{~mm}$ para o primeiro modo, e $L_{2}=118,8 \mathrm{~mm}$ para o segundo, sempre com $L o_{k}=0$ em ambos os segmentos avaliados.

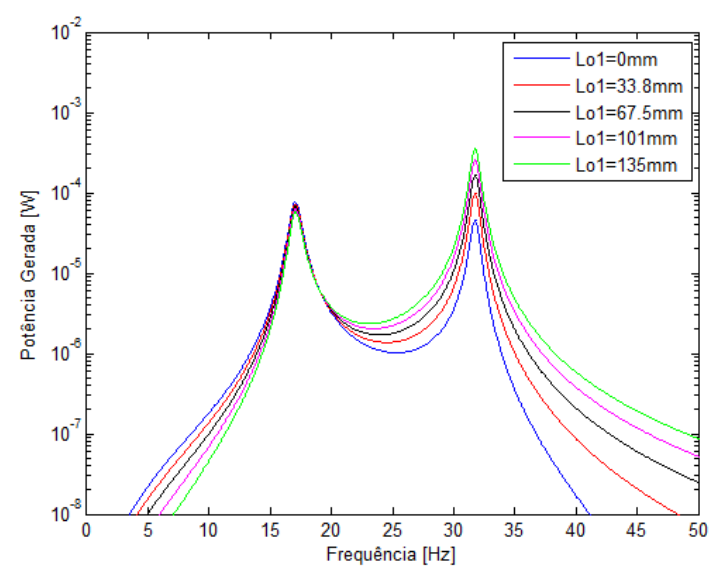

Figura 77 - FRF de potência gerada na resistência elétrica, para diferentes posições do inserto de $\Re_{1}$, com $\mathrm{M}_{2} \mathrm{em} 107,8 \mathrm{~mm}$, resistência de $50 \mathrm{k} \Omega$, e cancelamento no segundo modo. 


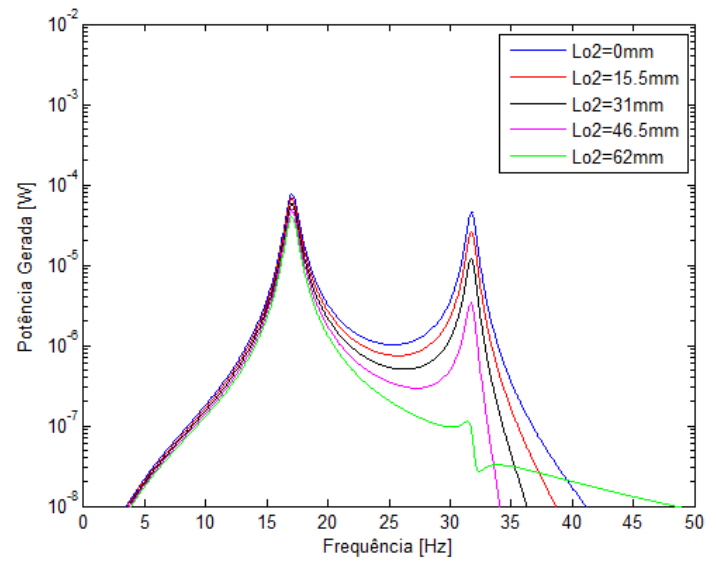

Figura 78 - FRF de potência gerada na resistência elétrica, para diferentes posições do inserto de $\Re_{2}$, com $M_{2}$ em 107,8mm, resistência de $50 \mathrm{k} \Omega$, e cancelamento no segundo modo.

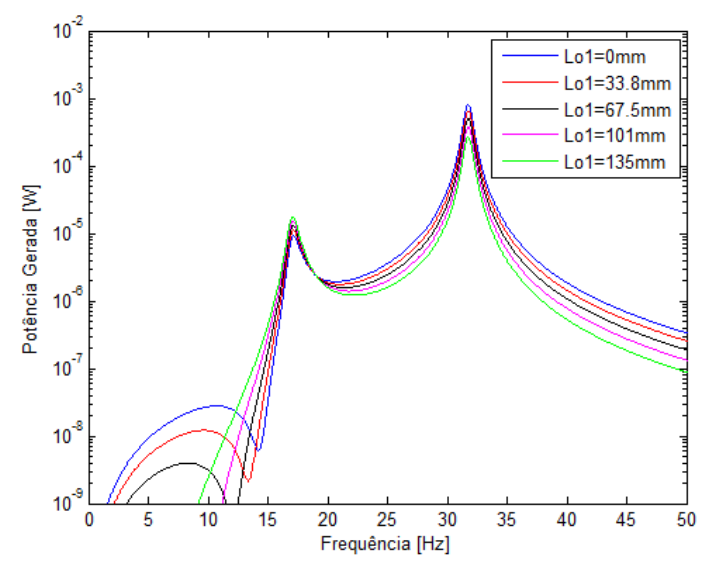

Figura 79 - FRF de potência gerada na resistência elétrica, para diferentes posições do inserto de $\Re_{1}$, com $\mathrm{M}_{2} \mathrm{em} 107,8 \mathrm{~mm}$, resistência de $50 \mathrm{k} \Omega$, e cancelamento no primeiro modo.

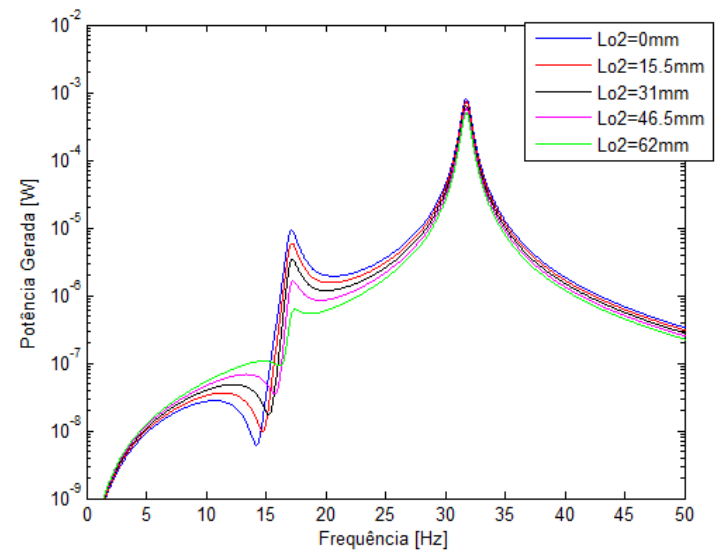

Figura 80 - FRF de potência gerada na resistência elétrica, para diferentes posições do inserto de $\Re_{2}$, com $M_{2}$ em $107,8 \mathrm{~mm}$, resistência de $50 \mathrm{k} \Omega$, e cancelamento no primeiro modo. 


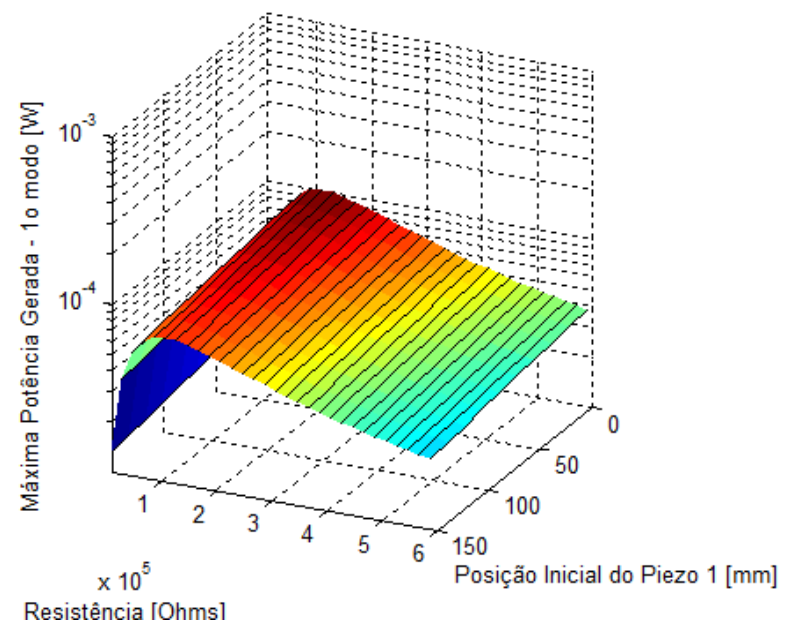

Figura 81 - Máxima potência gerada no primeiro modo de vibrar, para diferentes resistências e posições do inserto de $\Re_{1}$, com cancelamento no segundo modo e $M_{2}$ em $107,8 \mathrm{~mm}$.

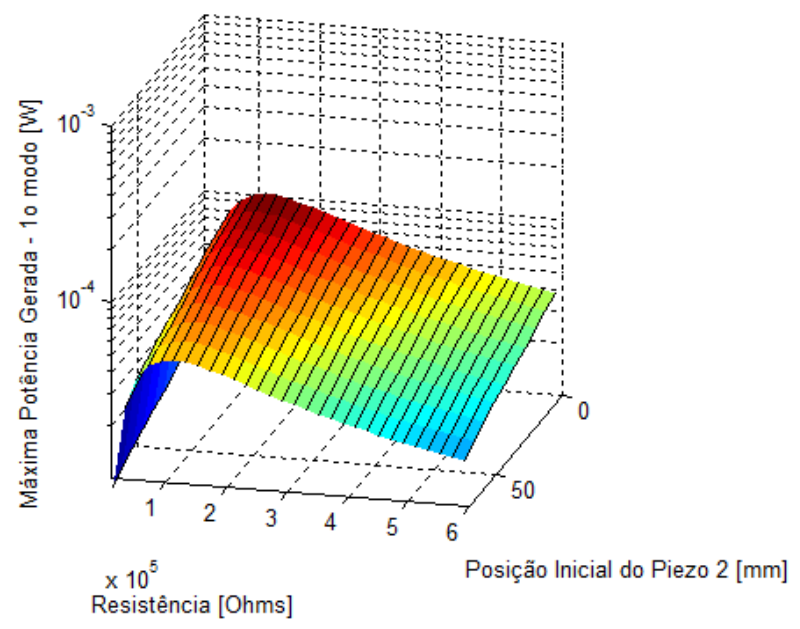

Figura 82 - Máxima potência gerada no primeiro modo de vibrar, para diferentes resistências e posições do inserto de $\Re_{2}$, com cancelamento no segundo modo e $M_{2}$ em $107,8 \mathrm{~mm}$.

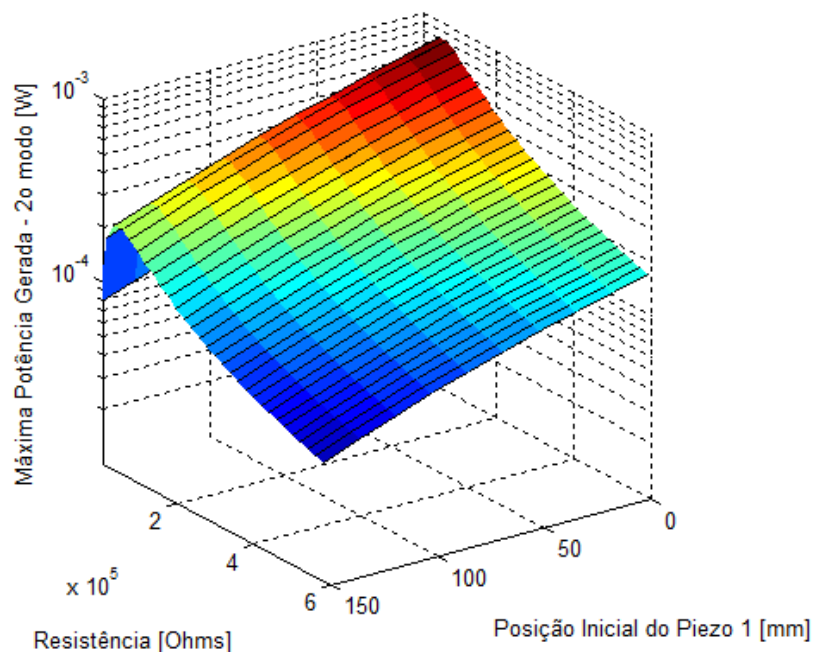

Figura 83 - Máxima potência gerada no segundo modo de vibrar, para diferentes resistências e posições do inserto de $\Re_{1}$, com cancelamento no primeiro modo e $M_{2}$ em $107,8 \mathrm{~mm}$. 


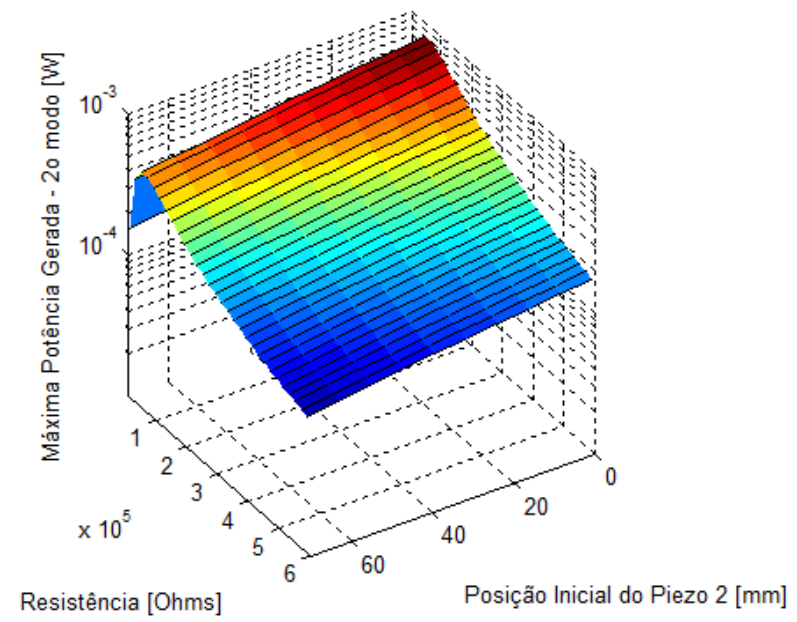

Figura 84 - Máxima potência gerada no segundo modo de vibrar, para diferentes resistências e posições do inserto de $\Re_{2}$, com cancelamento no primeiro modo e $M_{2}$ em $107,8 \mathrm{~mm}$.

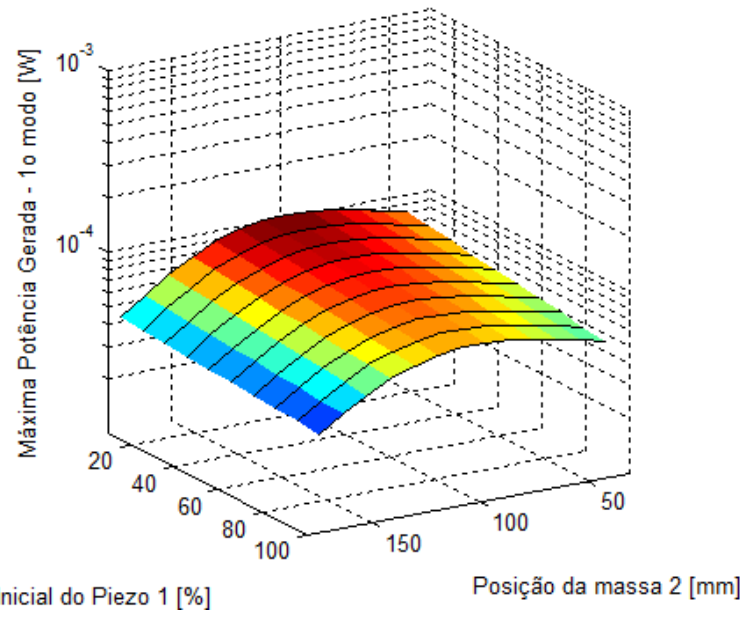

Figura 85 - Máxima potência gerada no primeiro modo de vibrar, para diferentes posições de $M_{2}$ e do inserto de $\Re_{1} \operatorname{com} \mathrm{Lo}_{1}$ na forma porcentagem de $\mathrm{L}_{1}$, com cancelamento no segundo modo à resistência de maior resposta.

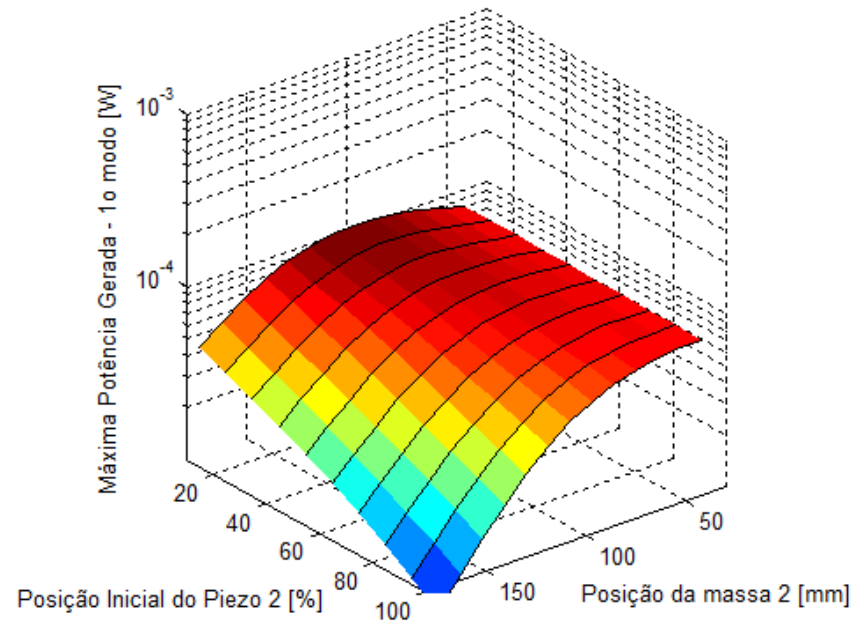

Figura 86 - Máxima potência gerada no primeiro modo de vibrar, para diferentes posições de $M_{2}$ e do inserto de $\Re_{2}$, com $L_{2}$ na forma porcentagem de $L_{2}$, com cancelamento no segundo modo à resistência de maior resposta. 


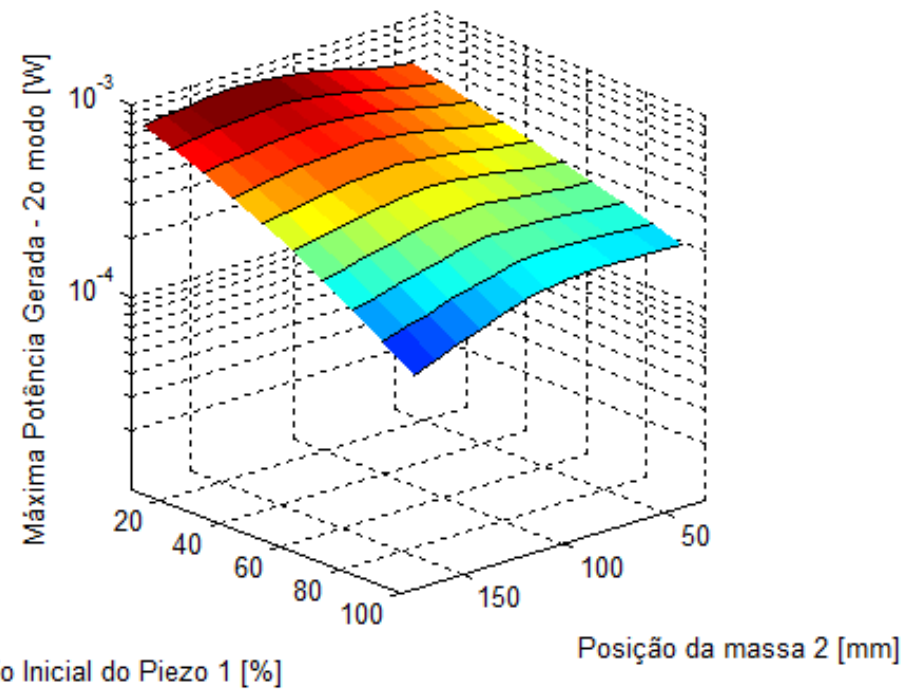

Figura 87 - Máxima potência gerada no segundo modo de vibrar, para diferentes posições de $M_{2}$ e do inserto de $\Re_{1}$, com $L o_{1}$ na forma porcentagem de $L_{1}$, com cancelamento no primeiro modo à resistência de maior resposta.

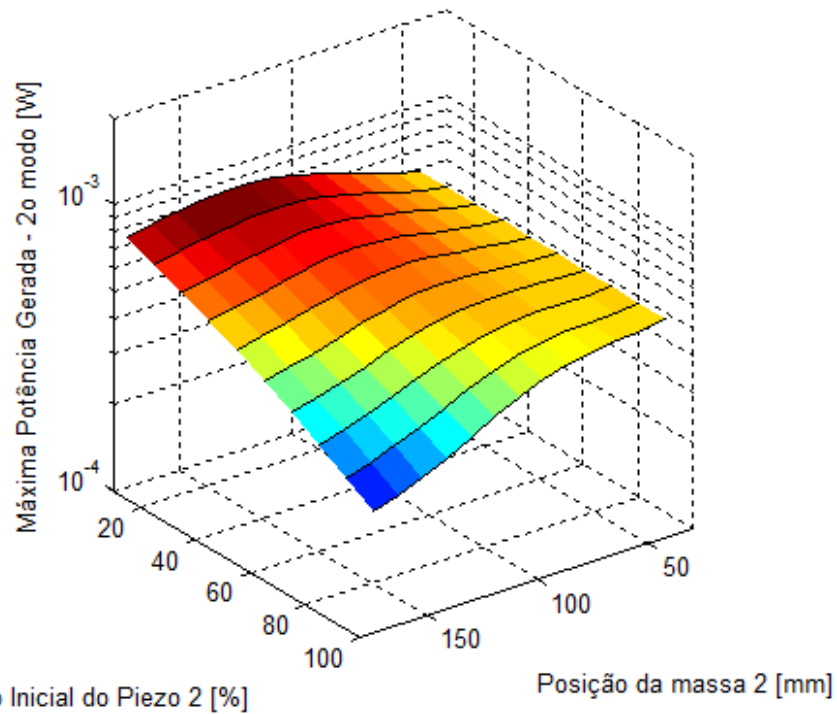

Figura 88 - Máxima potência gerada no segundo modo de vibrar, para diferentes posições de $M_{2}$ e do inserto de $\Re_{2}$, com $\mathrm{Lo}_{2}$ na forma porcentagem de $\mathrm{L}_{2}$, com cancelamento no primeiro modo à resistência de maior resposta. 


\subsubsection{Eficiência dos Insertos Piezelétricos}

Confrontando-se a potência gerada no inserto piezelétrico, calculada através da equação 102, é possível identificar a contribuição de cada elemento para a potência total gerada na resistência. Nas figuras 89 a 91 estão dispostos os módulos de $P_{m}(m=1,2$ e 3) para as configurações com $\mathrm{M}_{2}$ em $L_{2}=41,8 \mathrm{~mm}, L_{2}=107,8 \mathrm{~mm}$ e $L_{2}=173,8 \mathrm{~mm}$, usando insertos de comprimentos iguais $(38,1 \mathrm{~mm})$ sempre posicionados no início de cada região.

Nos resultados obtidos observa-se que o segundo inserto apresenta maiores amplitudes de potência gerada para todas as posições de $\mathbf{M}_{2}$, seguido do primeiro inserto, com resultados sensivelmente inferiores, mas com uma pronunciada e indesejada anti-ressonância entre elas. Já para o terceiro inserto, os resultados são significativamente dependentes da posição de $\mathrm{M}_{2}$, nos quais os melhores resultados do inserto ocorrem com a minimização de $\mathrm{L}_{2}$, chegando inclusive a superar o da primeira viga. No entanto, para as configurações com melhores resultados para o gerador, com maiores valores de $\mathrm{L}_{2}$, nota-se que a contribuição do terceiro inserto é significativamente inferior, principalmente em relação ao segundo inserto.

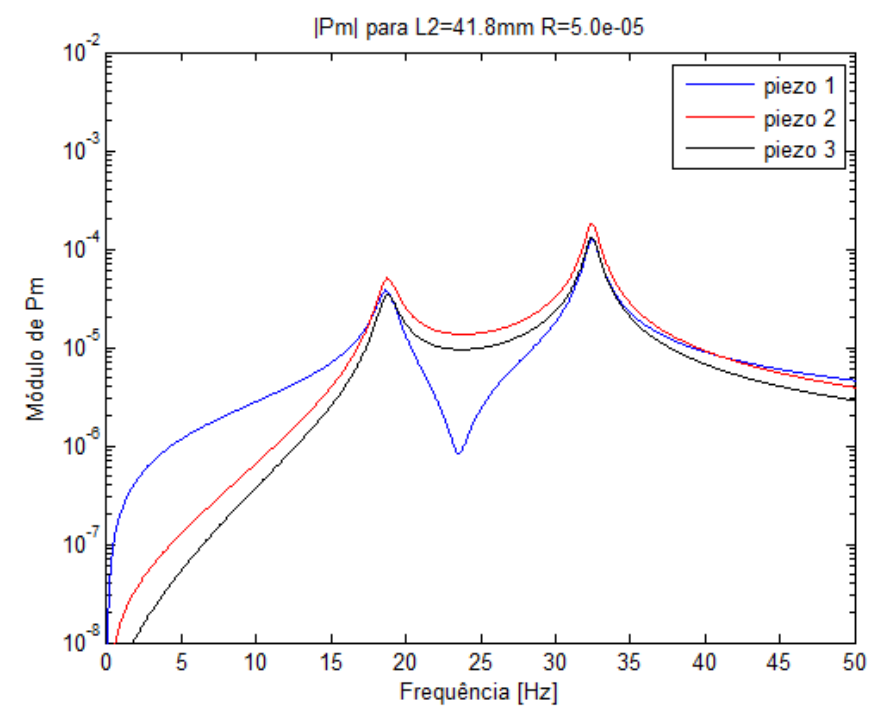

Figura 89 - FRF de potência gerada nos insertos das três regiões do gerador, com $M_{2}$ em $L_{2}=41,8 \mathrm{~mm}$, $L o_{k}=0$, e resistência de $110 \mathrm{k} \Omega$. 


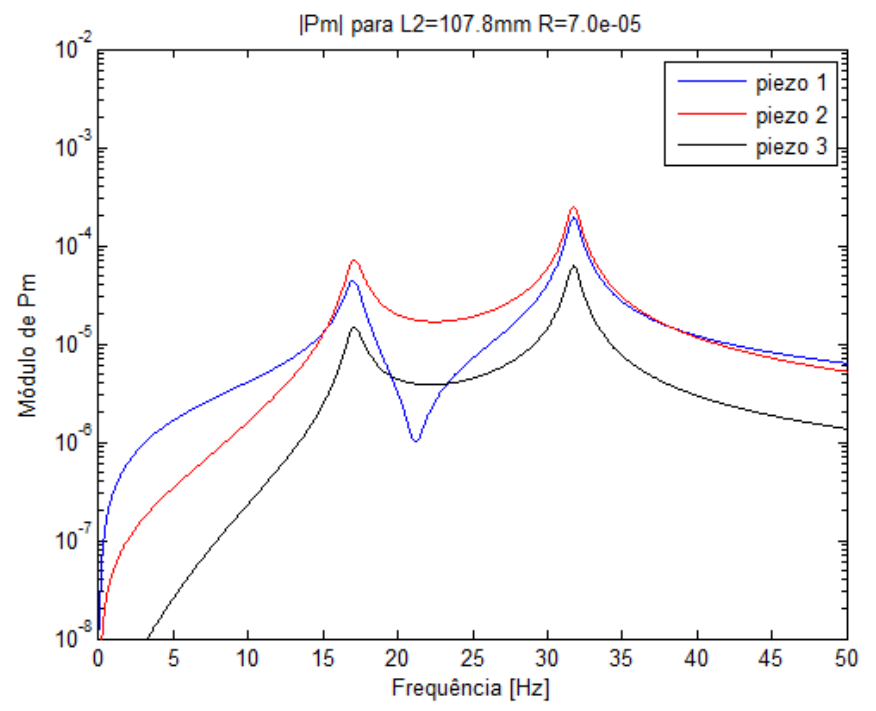

Figura 90 - FRF de potência gerada nos insertos das três regiões do gerador, com $M_{2}$ em $L_{2}=107,8 \mathrm{~mm}$, $\mathrm{Lo}_{\mathrm{k}}=0$, e resistência de $110 \mathrm{k} \Omega$.

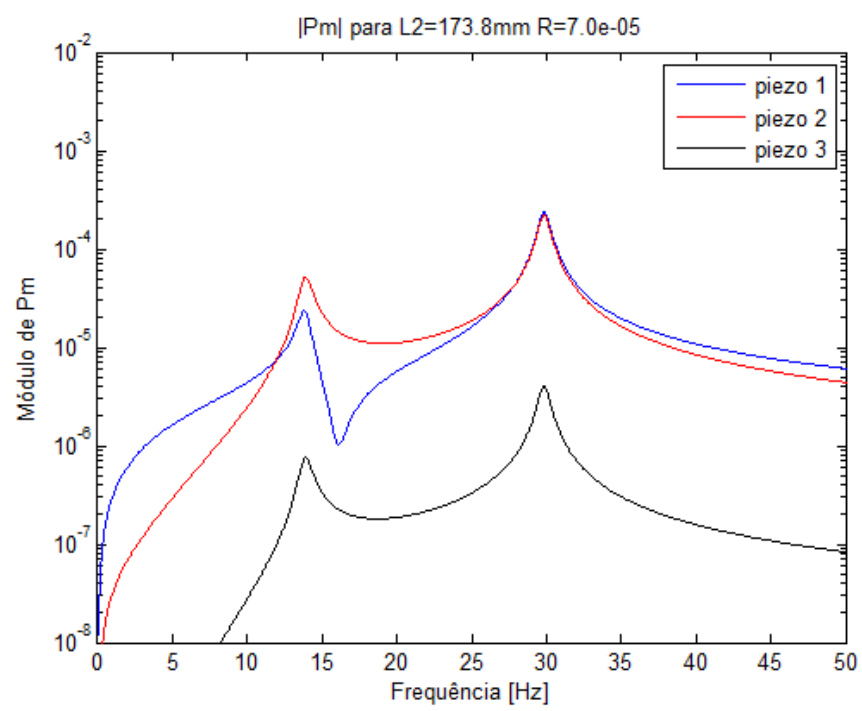

Figura 91 - FRF de potência gerada nos insertos das três regiões do gerador, com $M_{2}$ em $L_{2}=173,8 \mathrm{~mm}$, $\mathrm{Lo}_{\mathrm{k}}=0$, e resistência de $130 \mathrm{k} \Omega$. 


\subsubsection{Resumo dos Resultados - Configuração 1}

A máximas potências geradas para a configuração 1 com $\mathrm{M}_{2}$ em $L_{2}=41,8 \mathrm{~mm}$, $L_{2}=107,8 \mathrm{~mm}$ e $L_{2}=173,8 \mathrm{~mm}$ para os cancelamentos nos modos 1 e 2 estão dispostas nas tabelas 18 e 19,sempre com recobrimento parcial das vigas usando insertos de $38,1 \mathrm{~mm}$ na posição de maior eficiência $\left(L o_{k}=0\right)$. Foram incluídos ainda os resultados $\operatorname{com} \mathrm{M}_{2}$ na posição de maior resposta tanto para o recobrimento parcial, como para o recobrimento total dos segmentos $\mathfrak{R}_{1}, \mathfrak{R}_{2}$ e $\mathfrak{R}_{3}$, correspondente à solução proposta por Erturk et al. (2009). Esses resultados foram usados como referências de potência gerada e densidade energética em termos de massa total e massa de material piezelétrico, permitindo a verificação dos ganhos obtidos para as demais configurações avaliadas ao longo do trabalho.

Tabela 18 - Resultados de potência máxima no $1^{\circ}$ modo para o gerador na configuração 1 com cancelamento no $2^{\circ}$ modo.

\begin{tabular}{|c|c|c|c|c|}
\hline \multicolumn{5}{|c|}{ Configuração 1 - Potência Máxima - Cancelamento no $2^{\circ} \operatorname{modo}$} \\
\hline \multirow[b]{2}{*}{$\begin{array}{c}L_{2} \\
{[\mathbf{m m}]}\end{array}$} & \multirow[b]{2}{*}{$\begin{array}{c}R_{l} \\
{[\Omega]}\end{array}$} & \multirow[b]{2}{*}{$\begin{array}{c}\text { Máxima } \\
\text { Potência } \\
\text { Gerada } \\
{[\mu W]}\end{array}$} & \multicolumn{2}{|c|}{ Densidade Energética } \\
\hline & & & $\begin{array}{c}\text { Por Massa do } \\
\text { Gerador } \\
{[\mu W / k g]}\end{array}$ & $\begin{array}{c}\text { Por Massa de } \\
\text { Material } \\
\text { Piezelétrico } \\
{[\mu \mathrm{W} / \mathrm{g}]}\end{array}$ \\
\hline 41,8 & $1,1 \times 10^{5}$ & 81,72 & 63,32 & 74,29 \\
\hline 96,8 & $1,1 \times 10^{5}$ & 105,1 & 81,43 & 95,55 \\
\hline 107,8 & $1,1 \times 10^{5}$ & 103,1 & 79,89 & 93,73 \\
\hline 173,8 & $1,3 \times 10^{5}$ & 42,4 & 32,85 & 38,55 \\
\hline $96,8 *$ & $3,0 \times 10^{4}$ & 174,3 & 135,1 & 43,58 \\
\hline
\end{tabular}

* Gerador com recobrimento total dos três segmentos

Tabela 19 - Resultados de potência máxima no $2^{\circ}$ modo para o gerador na configuração 1 com cancelamento no $1^{\circ} \operatorname{modo}$.

\begin{tabular}{ccccc}
\hline \multicolumn{4}{c}{ Configuração 1 - Potência Máxima - Cancelamento no 10 modo } \\
\hline $\begin{array}{c}\boldsymbol{L}_{\mathbf{2}} \\
{[\mathbf{m m}]}\end{array}$ & $\begin{array}{c}\boldsymbol{R}_{\boldsymbol{l}} \\
{[\mathbf{\Omega}]}\end{array}$ & $\begin{array}{c}\text { Máxima } \\
\text { Potência } \\
\text { Gerada } \\
{[\boldsymbol{\mu W}]}\end{array}$ & $\begin{array}{c}\text { Densidade Energética } \\
\text { Por Massa do } \\
\text { Gerador } \\
{[\boldsymbol{\mu W} / \mathbf{k g}]}\end{array}$ & $\begin{array}{c}\text { Por Massa de } \\
\text { Material } \\
\text { Piezelétrico } \\
{[\boldsymbol{\mu W} / \mathbf{g}]}\end{array}$ \\
\hline 41,8 & $5,0 \times 10^{4}$ & 587,6 & 455,29 & 534,2 \\
107,8 & $7,0 \times 10^{4}$ & 817,5 & 633,43 & 743,2 \\
118,8 & $7,0 \times 10^{4}$ & 831,7 & 644,43 & 756,1 \\
173,8 & $7,0 \times 10^{4}$ & 746,4 & 578,34 & 678,6 \\
$96,8 *$ & $1,5 \times 10^{4}$ & 874,6 & 677,67 & 218,7 \\
\hline
\end{tabular}

* Gerador com recobrimento total dos três segmentos 


\subsubsection{Configuração 2}

Seguindo o mesmo procedimento utilizado nos estudos com modelos de parâmetros concentrados, na configuração 2 buscou-se a eliminação do material piezelétrico subutilizado, bem como a potencialização dos que apresentaram resultados superiores na configuração de referência (configuração 1). Desse modo, foi retirado o inserto piezelétrico do segmento $\mathfrak{R}_{3}$, e acrescentado um inserto na região $\mathfrak{R}_{2}$, configurando uma montagem bimorph para esta última, conforme ilustrado na figura $9 \mathrm{~b}$,

Para avaliar o gerador nesta configuração seguiu-se o mesmo roteiro da anterior, com estudos de sensibilidade quanto à posição de $\mathrm{M}_{2}$, comprimento e posição dos insertos.

\subsubsection{1.- Posição da Massa 2}

Seguindo o mesmo padrão da configuração de referência, adotou-se para todos os insertos piezelétricos um comprimento fixo, igual a $38,1 \mathrm{~mm}$, partindo de $x_{k}=0$, inicialmente com resistência constante igual a $50 \mathrm{k} \Omega$ (\#Figuras 92 a 98).

Ao analisar os resultados obtidos verifica-se um comportamento bastante similar ao da configuração de referência, contemplando variações de amplitude, mas bem menos evidentes do que as variações nas frequências naturais.

Já nos resultados de potência no inserto $\left(P_{m}\right)$ para cada inserto piezelétrico, ao contrário da configuração 1, fica evidente que para esta configuração não há mais um prejuízo da potência gerada devido ao posicionamento da massa 2, já que os piezos 2 e 3 estão posicionados no segmento $\mathfrak{R}_{2}$.

Avaliando-se a máxima potência gerada em função também da resistência elétrica (\#Figuras 99 e 100), percebe-se que esta é maximizada para $L_{2}=118,8 \mathrm{~mm}$ e $R_{l}=110 \mathrm{k} \mathrm{k} \Omega$, no caso da primeira frequência de ressonância (cancelamento para o segundo modo) e $L_{2}=140,8 \mathrm{~mm}$ e $R_{l}=70 \mathrm{k} \Omega$ para a segunda frequência (cancelamento para o primeiro modo), ambas mais próximas da extremidade da segunda viga que na configuração original. Mesmo com a massa na posição central, a qual favorece a configuração de referência, observa-se que a máxima potência gerada ainda é bastante superior, sendo $211,7 \mu \mathrm{W}$ contra $103,1 \mu \mathrm{W}$ no caso da primeira frequência de ressonância, para as configurações 2 e 1 respectivamente, e $1,510 \mathrm{~mW}$ contra $817,5 \mu \mathrm{W}$ para a segunda frequência de ressonância. 


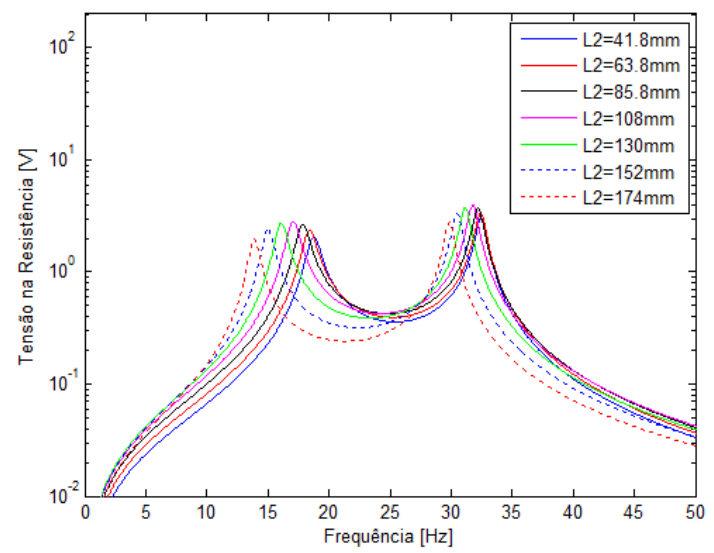

Figura 92 - Tensão gerada na resistência para a Configuração 2, com cancelamento no segundo modo de vibrar para diferentes posições de $M_{2}$, usando uma resistência de $50 \mathrm{k} \Omega$.

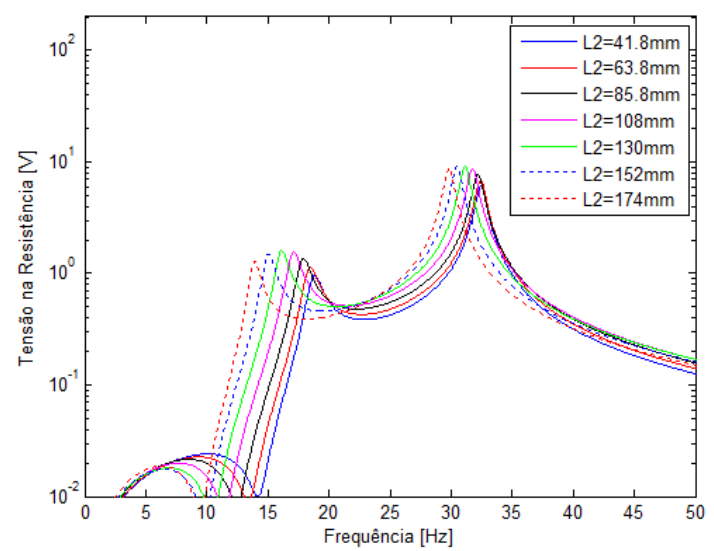

Figura 93 - Tensão gerada na resistência para a Configuração 2, com cancelamento no primeiro modo de vibrar para diferentes posições de $M_{2}$, usando uma resistência de $50 \mathrm{k} \Omega$.

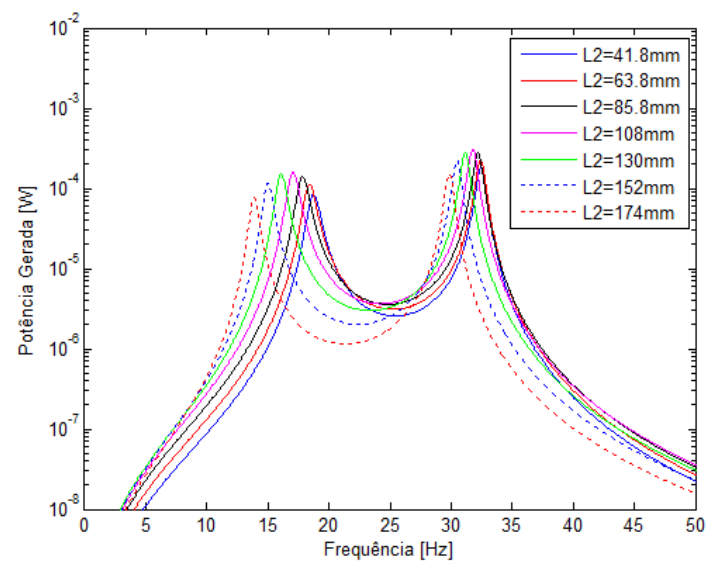

Figura 94 - Potência gerada na resistência para a Configuração 2, com cancelamento no segundo modo de vibrar para diferentes posições de $M_{2}$, usando uma resistência de $50 \mathrm{k} \Omega$. 


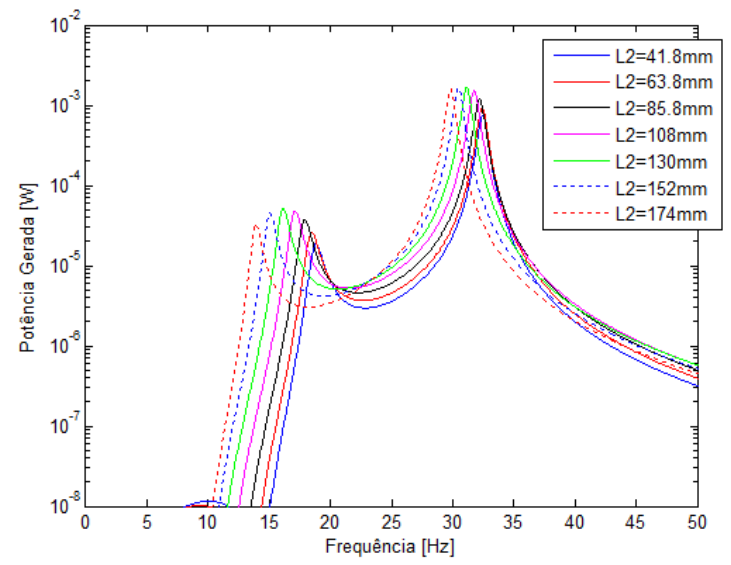

Figura 95 - Potência gerada na resistência para a Configuração 2, com cancelamento no primeiro modo de vibrar para diferentes posições de $M_{2}$, usando uma resistência de $50 \mathrm{k} \Omega$.

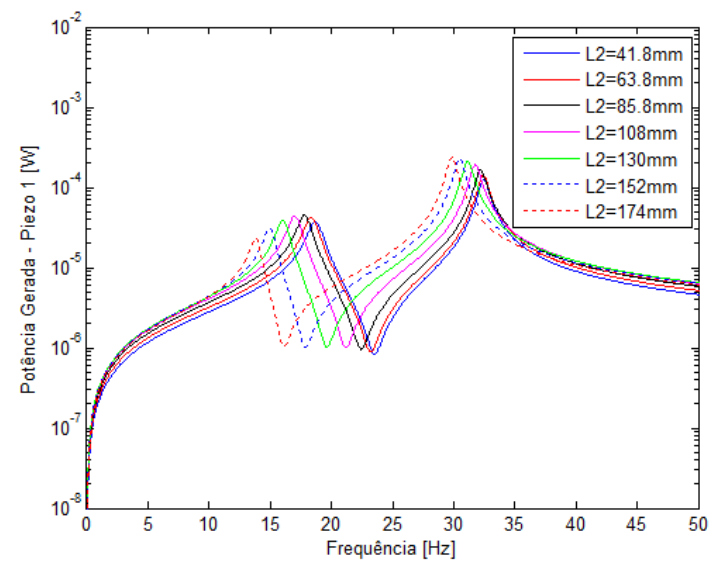

Figura 96 - Potência gerada no inserto de $\Re_{1}$ para a Configuração 2 , em diferentes posições de $M_{2}$, usando uma resistência de $50 \mathrm{k} \Omega$.

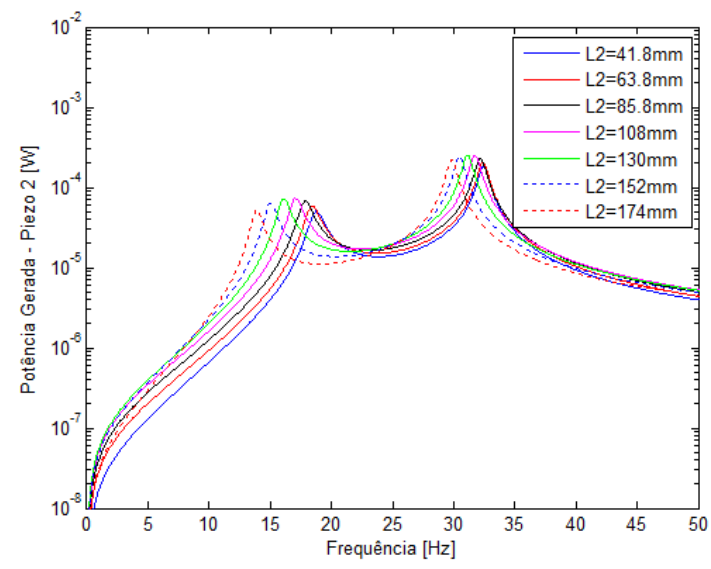

Figura 97 - Potência gerada no primeiro inserto de $\Re_{2}$ para a Configuração 2, em diferentes posições de $M_{2}$, usando uma resistência de $50 \mathrm{k} \Omega$. 


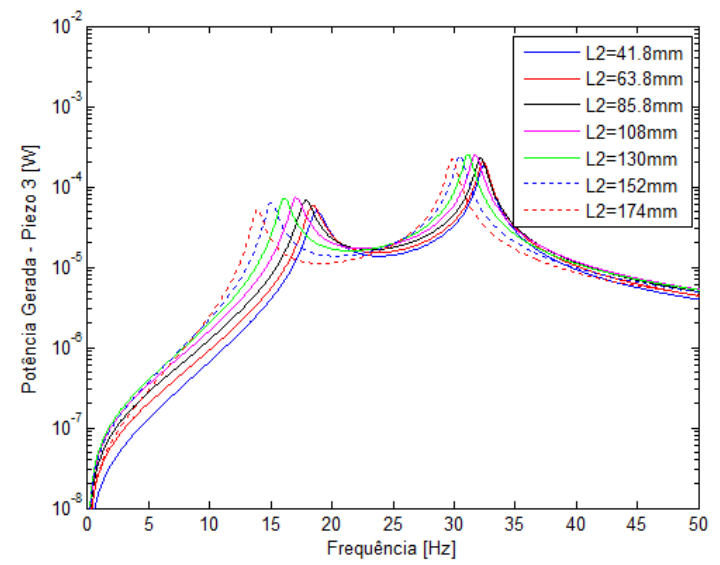

Figura 98 - Potência gerada no segundo inserto de $\Re_{2}$ para a Configuração 2 , em diferentes posições de $M_{2}$, usando uma resistência de $50 \mathrm{k} \Omega$.
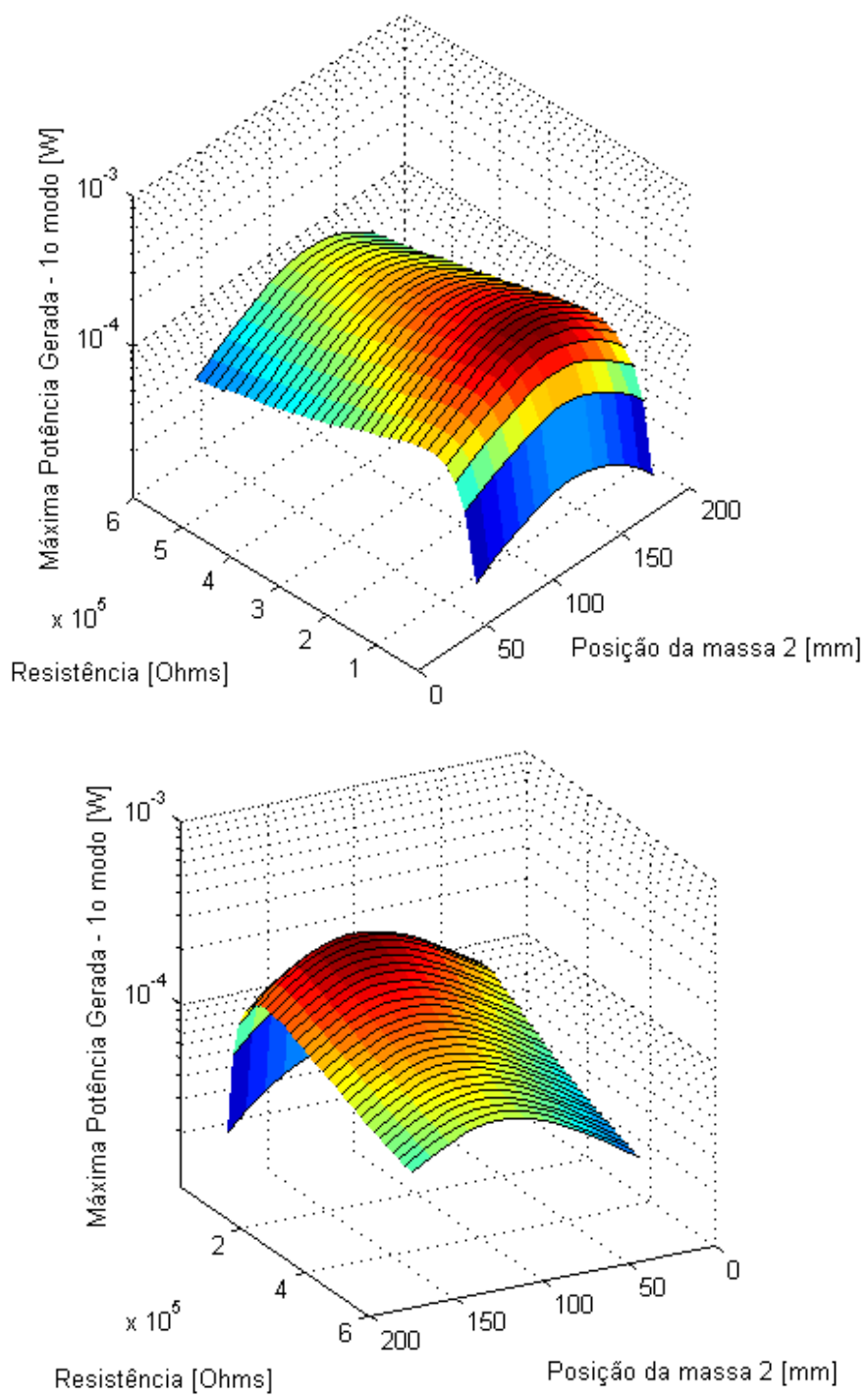

Figura 99 - Máxima potência gerada na resistência para o primeiro modo de vibrar da Configuração 2, para diferentes resistências e posições de $M_{2}$, com cancelamento no segundo modo. 

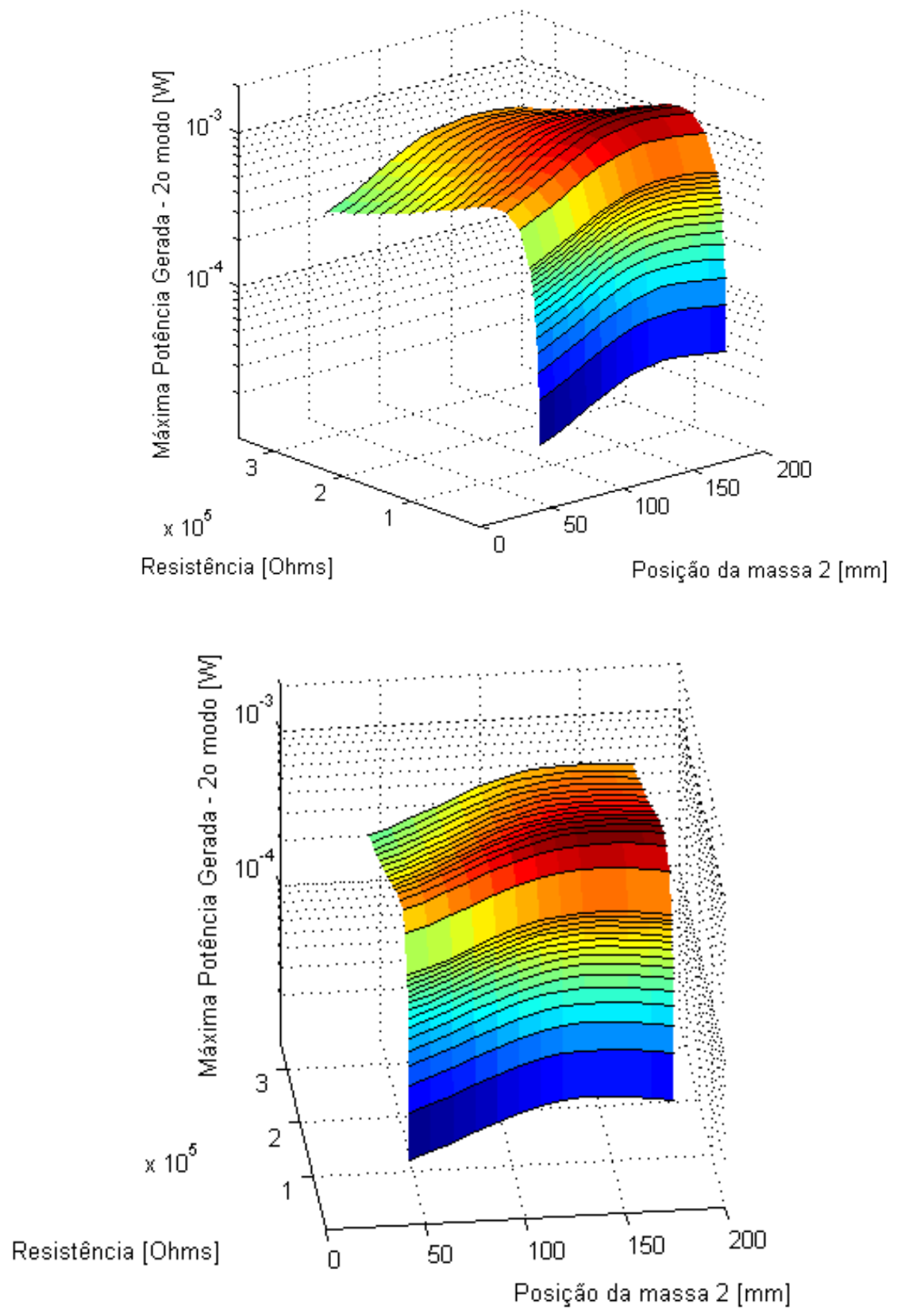

Figura 100 - Máxima potência gerada na resistência para o segundo modo de vibrar da Configuração 2, para diferentes resistências e posições de $\mathbf{M}_{2}$, com cancelamento no primeiro modo. 


\subsubsection{2.- Comprimento do Inserto Piezelétrico.}

Para facilitar a comparação entre as configurações, assumiu-se para $\mathrm{M}_{2}$ a mesma posição dos estudos realizados na configuração de referência, com $L_{2}=107,8 \mathrm{~mm}$, variando-se o comprimento dos elementos piezelétricos de $\mathfrak{R}_{2}$, e mantendo o de $\mathfrak{R}_{1}$ constante, igual a $38,1 \mathrm{~mm}$. No entanto, para a configuração 2 o estudo não foi replicado para o inserto de $\mathfrak{R}_{1}$, já que a montagem desse segmento é exatamente a mesma da configuração anterior.

Primeiramente usando uma resistência constante igual a $50 \mathrm{k} \Omega$, nota-se que, assim como na configuração original, a introdução de material piezelétrico aumenta a potência gerada, mas com incrementos cada vez menores (\#Figuras 101 e 102). Estendendo a análise para várias resistências (\#Figuras 103 e 104) observa-se que a maximização da potência gerada ocorre para um comprimento de inserto de aproximadamente $75 \mathrm{~mm}$ e $86 \mathrm{~mm}$ para o primeiro e segundo modo respectivamente, apresentando um máximo de $243,4 \mu \mathrm{W}$ com uma resistência de $70 \mathrm{k} \Omega$ no primeiro, e $1,798 \mathrm{~mW}$ com $30 \mathrm{k} \Omega$ no segundo, com cancelamento nos modos opostos. Após o comprimento de máxima potência gerada nota-se um comportamento sensivelmente mais uniforme que o encontrado na configuração de referência.

Como há um maior acoplamento eletromecânico, nota-se nos gráficos das figuras 105 e 106 que para cada comprimento a potência gerada é maximizada para resistências menores que na configuração original. No entanto, cabe destacar que nos estudos da primeira configuração foi alterado apenas o comprimento de um inserto por vez, enquanto para a configuração 2, devido à montagem bimorph, foram variados os comprimentos de dois insertos ao mesmo tempo. Por isso é importante lembrar que neste caso, para uma mesma variação de comprimento a quantidade de material piezelétrico inserida foi duas vezes maior.

Fazendo-se a variação do comprimento dos insertos de $\mathfrak{R}_{2}$ para várias posições de $\mathrm{M}_{2}$ (\#Figuras 107 e 108), observa-se que a maximização da potência gerada ocorre valores de $\mathrm{L}_{2}$ maiores que na montagem original, nas quais a máxima potência gerada na primeira frequência natural com cancelamento no segundo modo ocorre para $L_{2}=118,8 \mathrm{~mm}$, com $60 \%$ da área recoberta, enquanto para a segunda frequência e cancelamento no primeiro modo, o melhor resultado ocorre em $. L_{2}=151,8$ com $70 \%$ de recobrimento. 


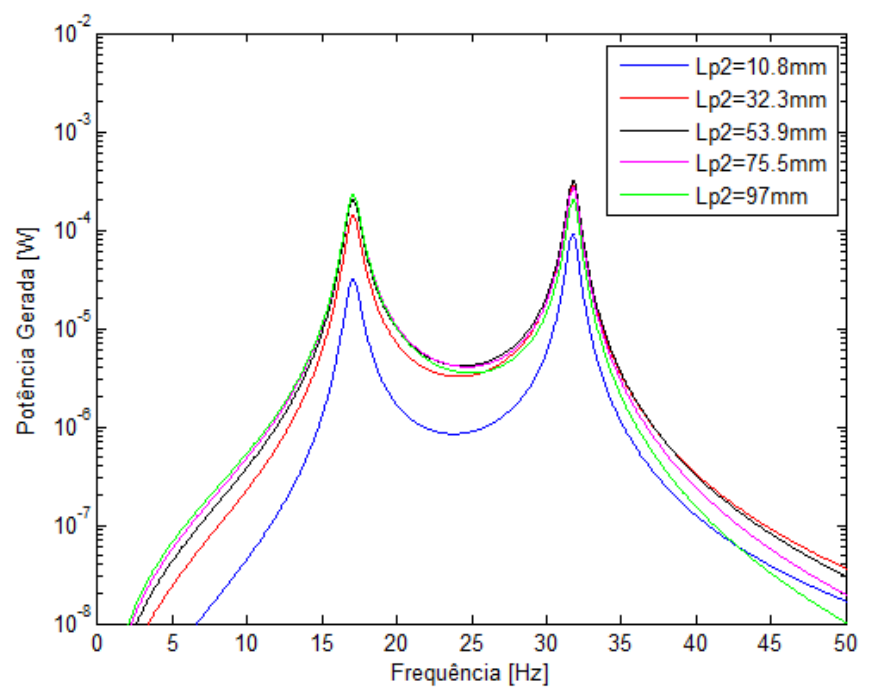

Figura 101 - FRF de potência gerada na resistência para a configuração 2, com $M_{2} \mathrm{em} \mathrm{107,8mm} \mathrm{e}$ cancelamento no segundo modo, para diferentes comprimentos do insertos de $\Re_{2}$ e resistência de $50 \mathrm{k} \Omega$.

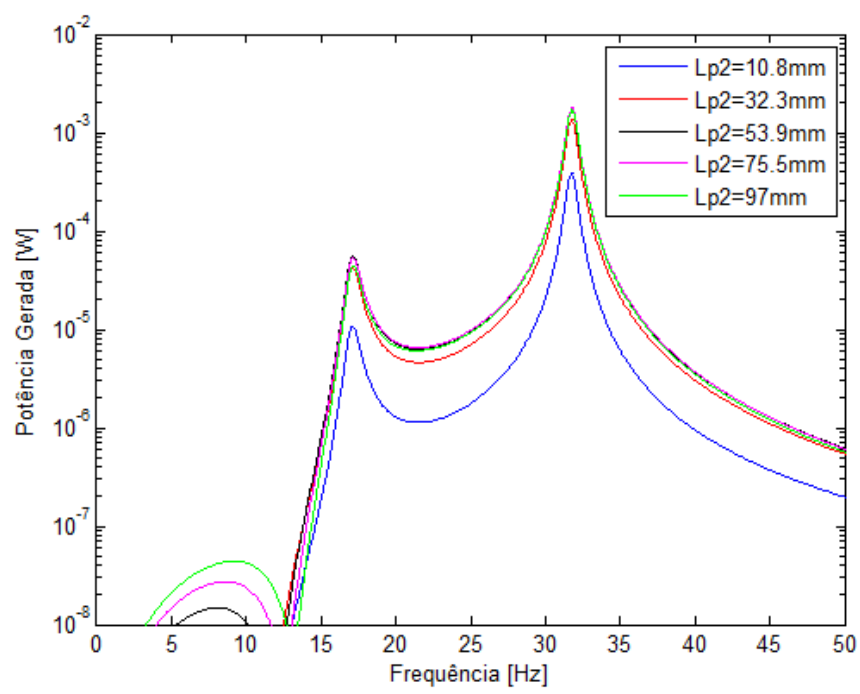

Figura 102 - FRF de potência gerada na resistência para a configuração 2, com $M_{2} \mathrm{em}$ 107,8mm e cancelamento no primeiro modo, para diferentes comprimentos do insertos de $\mathfrak{R}_{2} \mathrm{e}$ resistência de $50 \mathrm{k} \Omega$. 

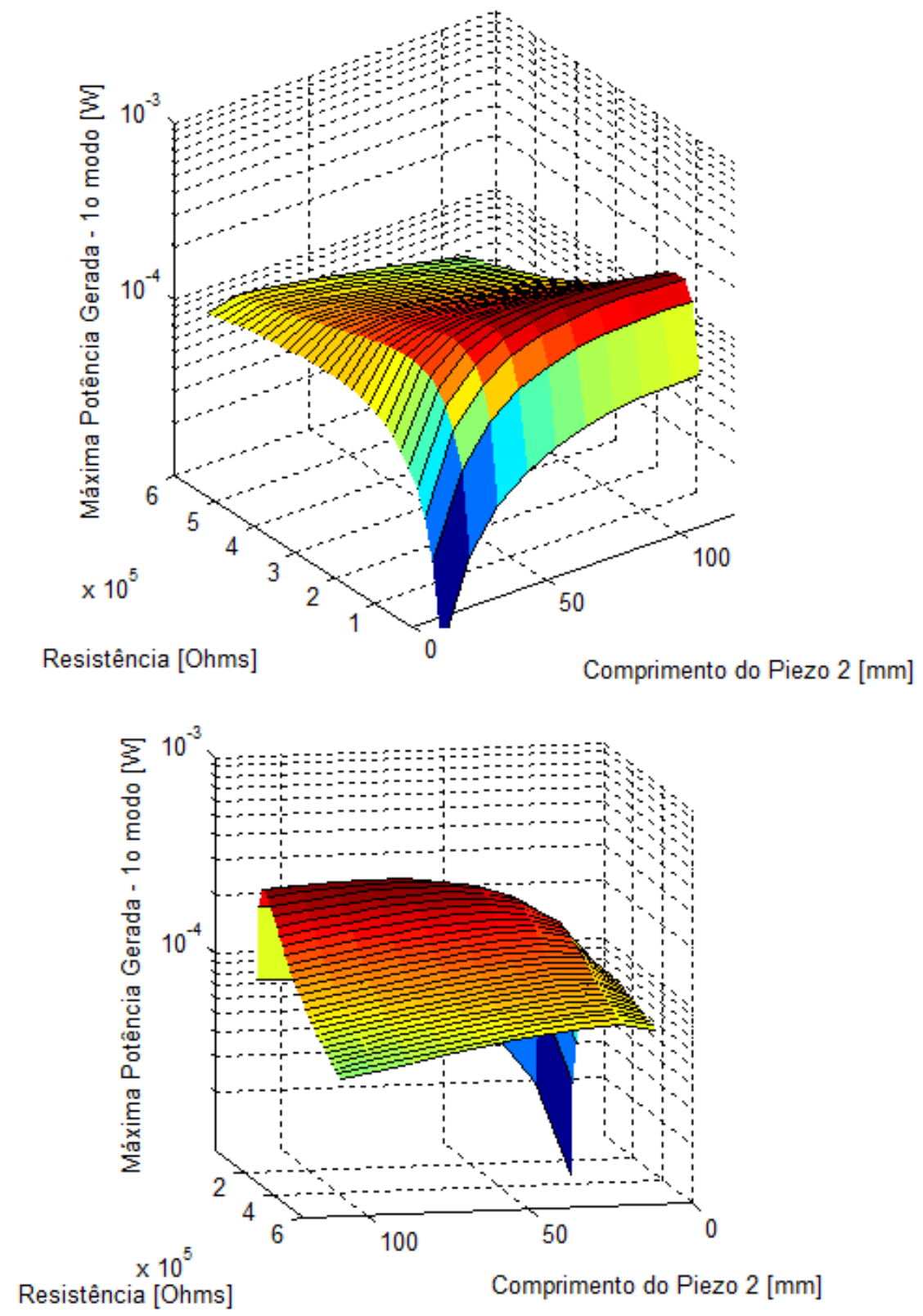

Figura 103 - Máxima potência gerada na resistência para a configuração 2 no primeiro modo de vibrar, com $\mathrm{M}_{2}$ em 107,8mm e cancelamento no segundo modo, para diferentes resistências e comprimentos do inserto de $\Re_{2}$ 

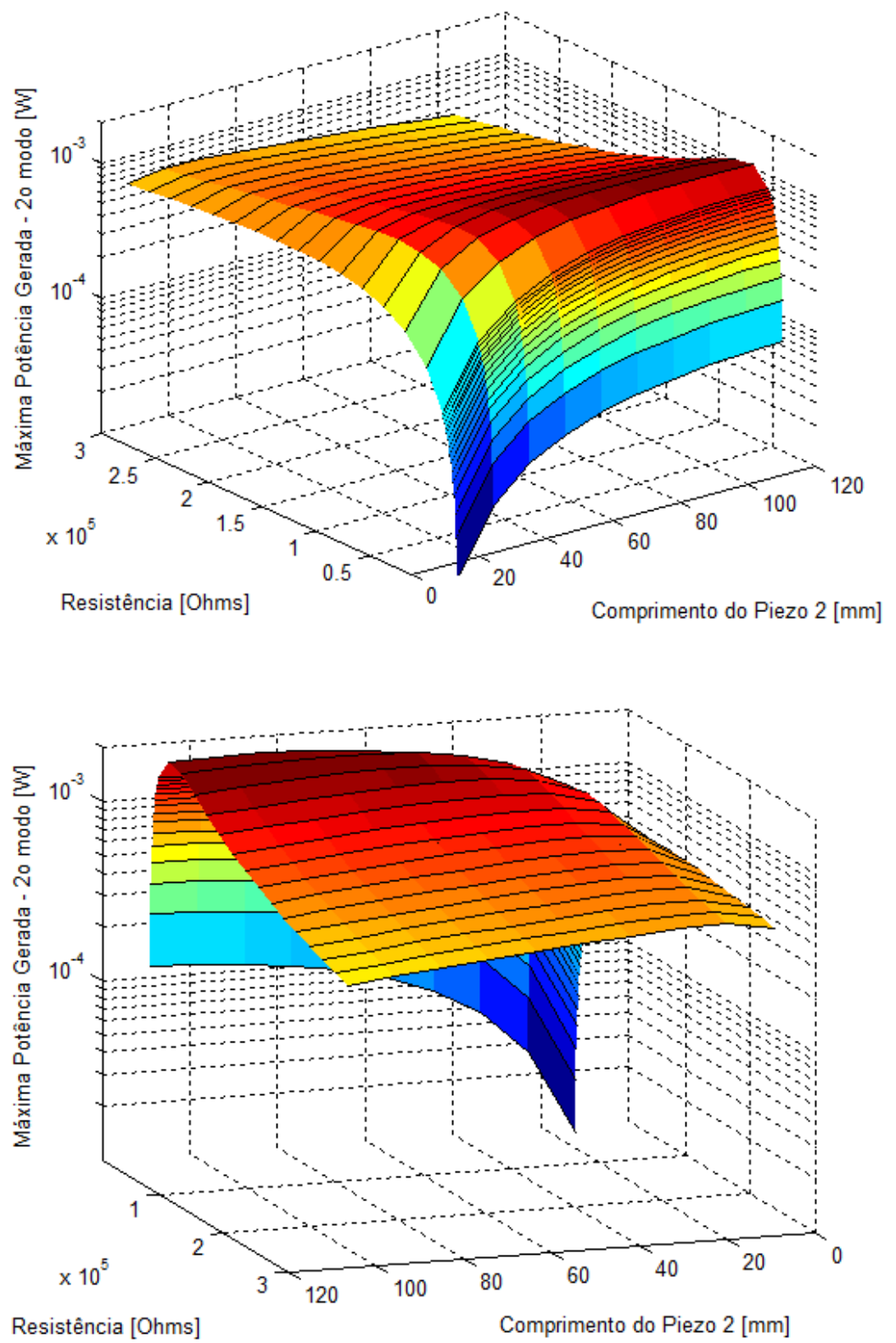

Figura 104 - Máxima potência gerada na resistência para a configuração 2 no segundo modo de vibrar, com $\mathrm{M}_{2}$ em 107,8mm e cancelamento no primeiro modo, para diferentes resistências e comprimentos do inserto de $\Re_{2}$. 


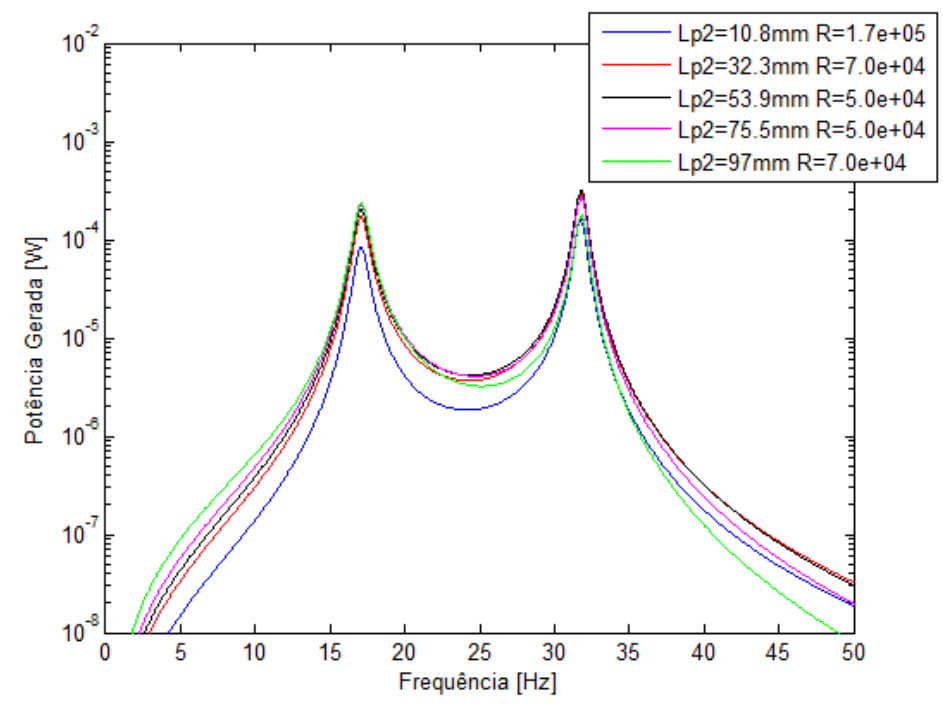

Figura 105 - FRF de potência gerada na resistência para a configuração 2 , com $M_{2}$ em $107,8 \mathrm{~mm}$ e cancelamento no segundo modo, para diferentes comprimentos do insertos de $\mathfrak{R}_{2}$ às resistências que otimizam a resposta do gerador.

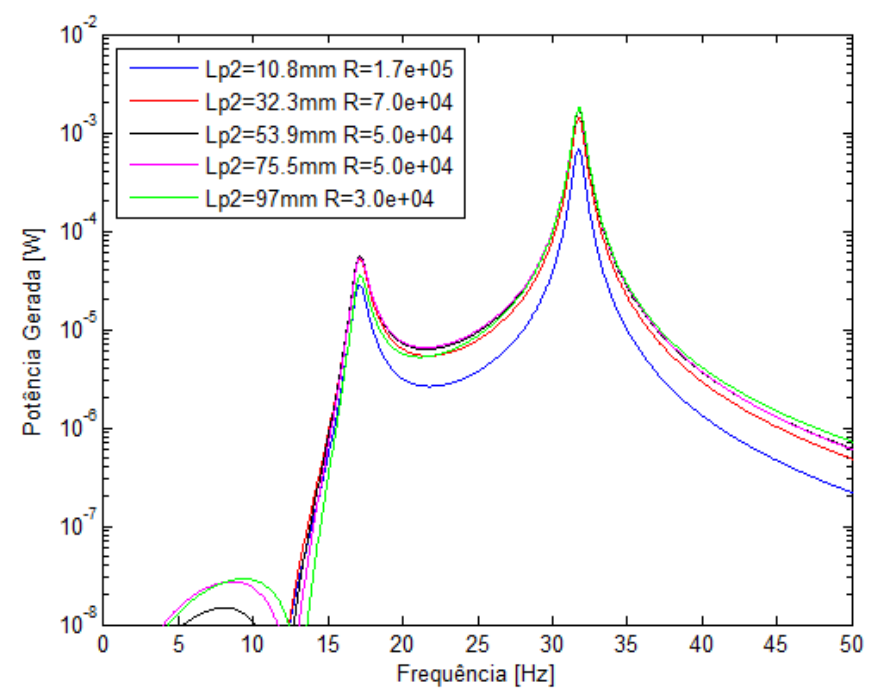

Figura 106 - FRF de potência gerada na resistência para a configuração 2, com $M_{2}$ em $107,8 \mathrm{~mm}$ e cancelamento no primeiro modo, para diferentes comprimentos do insertos de $\mathfrak{R}_{2}$ às resistências que otimizam a resposta do gerador. 


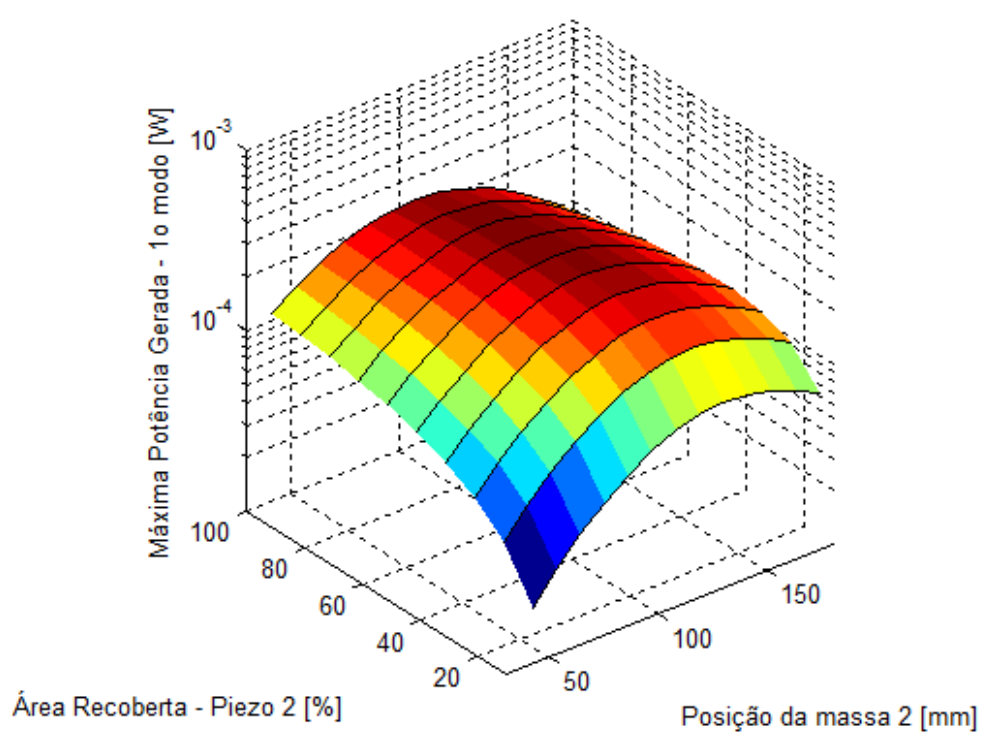

Figura 107 - Máxima potência gerada para a configuração 2 no primeiro modo de vibrar, à resistência de maior eficiência e cancelamento no segundo modo, para diferentes posições de $M_{2}$ e comprimentos dos insertos de $\Re_{2}$.

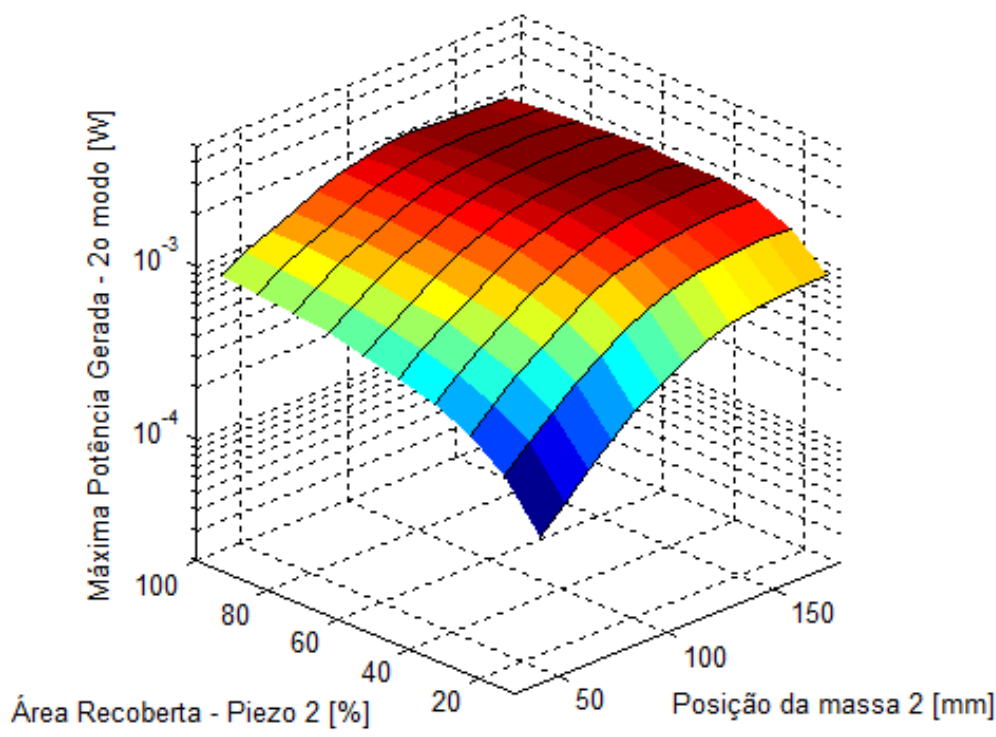

Figura 108 - Máxima potência gerada para a configuração 2 no segundo modo de vibrar, à resistência de maior eficiência e cancelamento no primeiro modo, para diferentes posições de $M_{2}$ e comprimentos dos insertos de $\mathfrak{R}_{2}$. 


\subsubsection{Posição do Inserto Piezelétrico.}

Para a configuração 2, a influência do posicionamento dos insertos foi avaliada para a montagem bimorph do segmento $\mathfrak{R}_{2}$ mantendo-se novamente seus comprimentos sempre constantes, iguais a $38,1 \mathrm{~mm}$.

Inicialmente fixando-se a posição da massa $\mathrm{M}_{2}$ em $L_{2}=107,8 \mathrm{~mm}$, com uma resistência constante igual a $50 \mathrm{k} \Omega$ observa-se nos resultados, dispostos nas figuras 109 e 110, que a maior potência gerada ocorre para $L o_{2}=0$, assim como na configuração 1 .

Estendendo-se a verificação para várias resistências (\#Figuras 111 e 112) nota-se que a potência gerada é maximizada para a mesma resistência em todas as posições, confirmandose a maior eficiência em $\mathrm{Lo}_{2}=0$. Verifica-se ainda que a ausência de material piezelétrico em $\mathfrak{R}_{3}$ torna o resultado mais sensível à eficiência dos insertos de $\mathfrak{R}_{2}$, onde se observa um decaimento mais intenso na potência gerada à medida que se aumenta $\mathrm{Lo}_{2}$.

Estendendo-se a verificação agora para diferentes posições de $\mathrm{M}_{2}$ (\#Figuras 113 e 114), fica evidente novamente a maior eficiência dos insertos quando posicionados no início do segmento, com resultados otimizados para $L_{2}=118,8 \mathrm{~mm}$ no caso da primeira frequência natural, e $L_{2}=140,8 \mathrm{~mm}$ no caso da segunda.

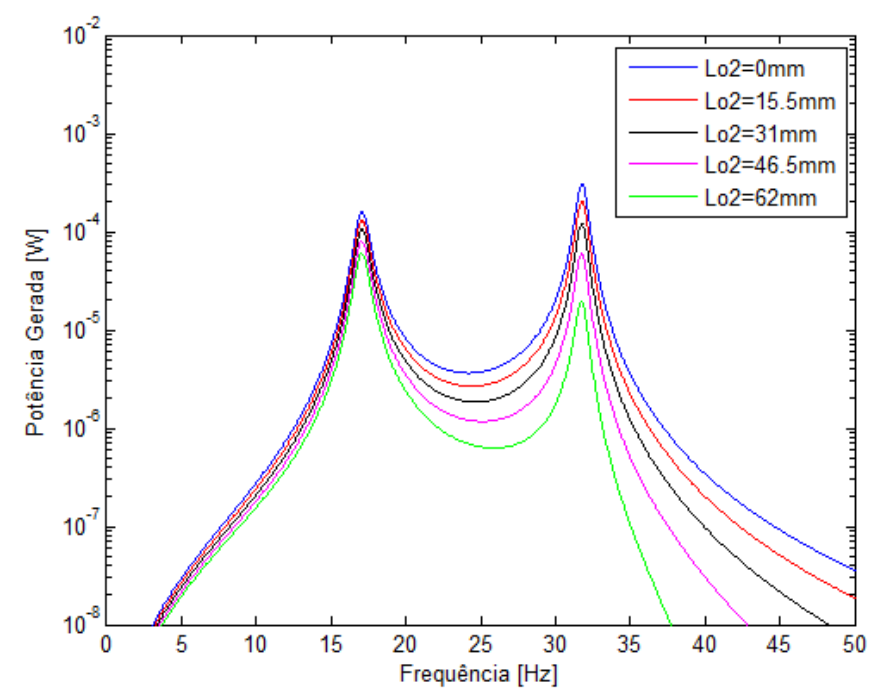

Figura 109 - FRF de potência gerada na resistência elétrica para a configuração 2, para diferentes posições dos insertos de $\mathfrak{R}_{2}$, com $M_{2}$ em $107,8 \mathrm{~mm}$, resistência de $50 \mathrm{k} \Omega$, e cancelamento no segundo modo. 


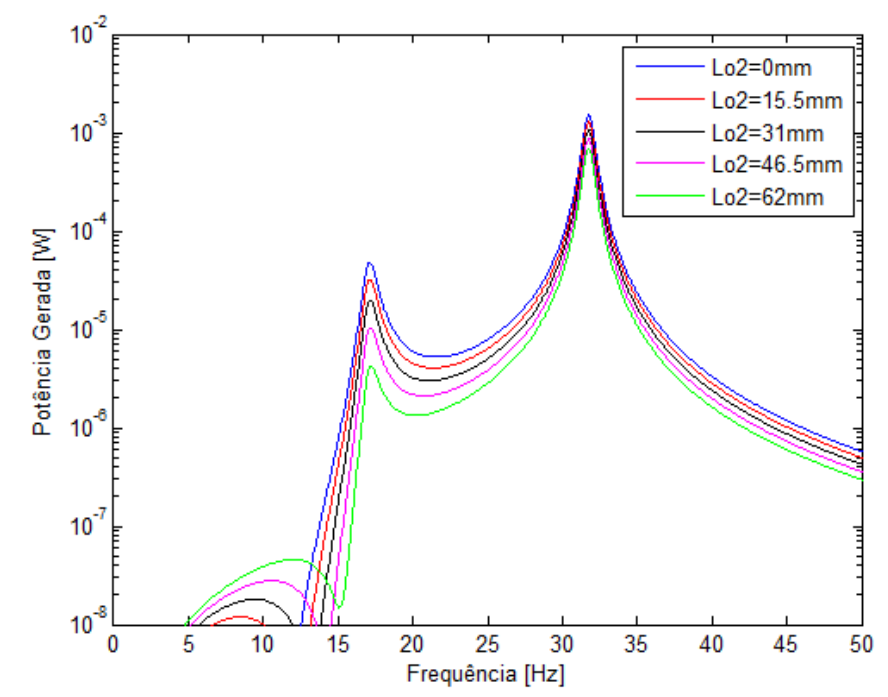

Figura 110 - FRF de potência gerada na resistência elétrica para a configuração 2, para diferentes posições dos insertos de $\Re_{2}, \operatorname{com} M_{2}$ em $107,8 \mathrm{~mm}$, resistência de $50 \mathrm{k} \Omega$, e cancelamento no primeiro modo.

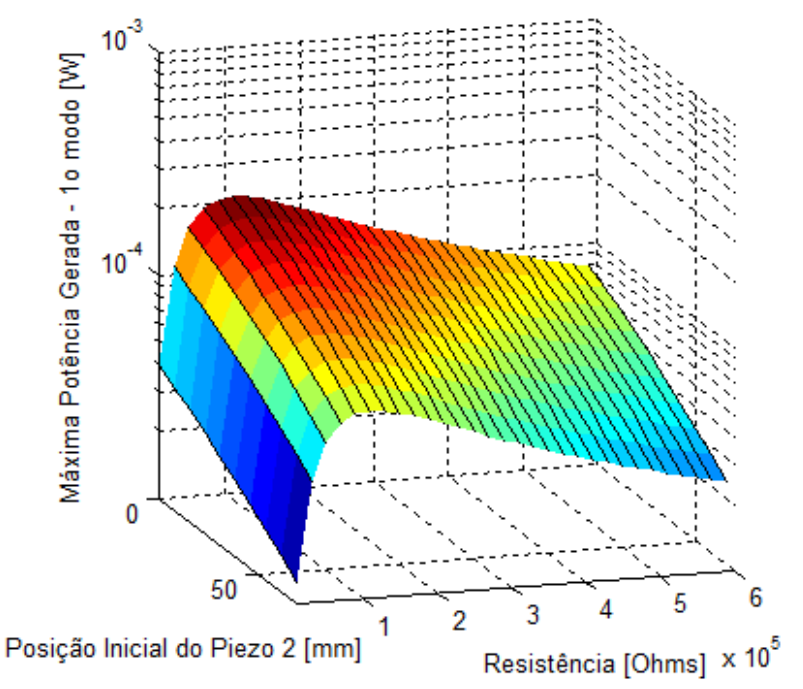

Figura 111 - Máxima potência gerada no primeiro modo de vibrar da configuração 2 para diferentes resistências e posições dos insertos de $\Re_{2}$, com cancelamento no segundo modo e $M_{2}$ em 107,8mm. 


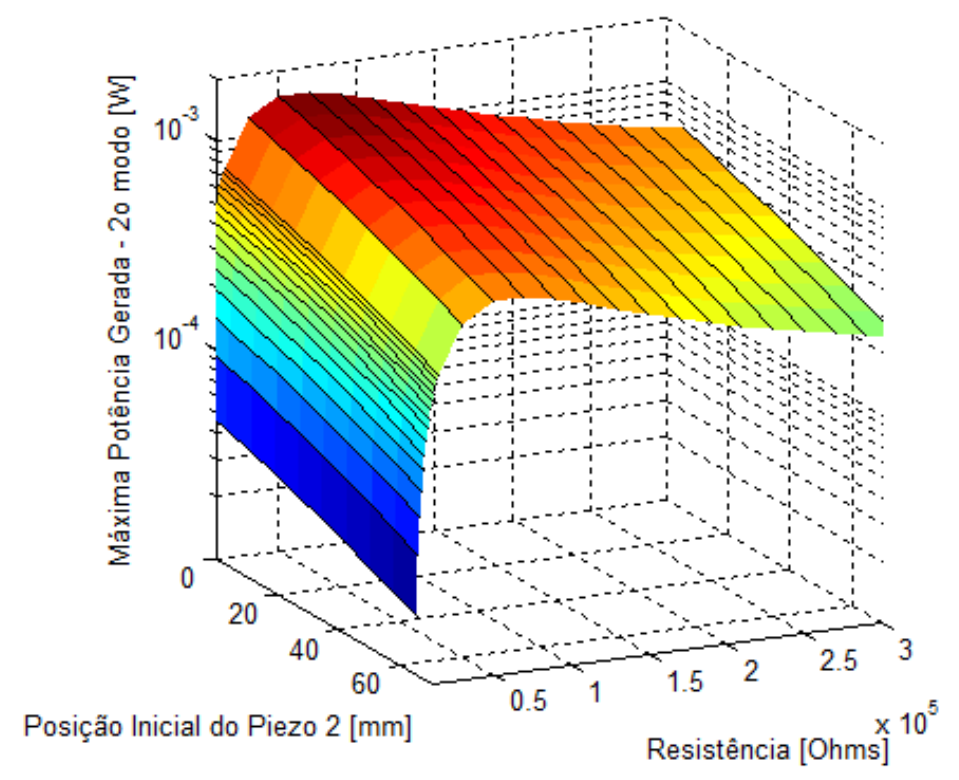

Figura 112 - Máxima potência gerada no segundo modo de vibrar da configuração 2 para diferentes resistências e posições dos insertos de $\Re_{2}$, com cancelamento no primeiro modo e $M_{2}$ em $107,8 \mathrm{~mm}$.

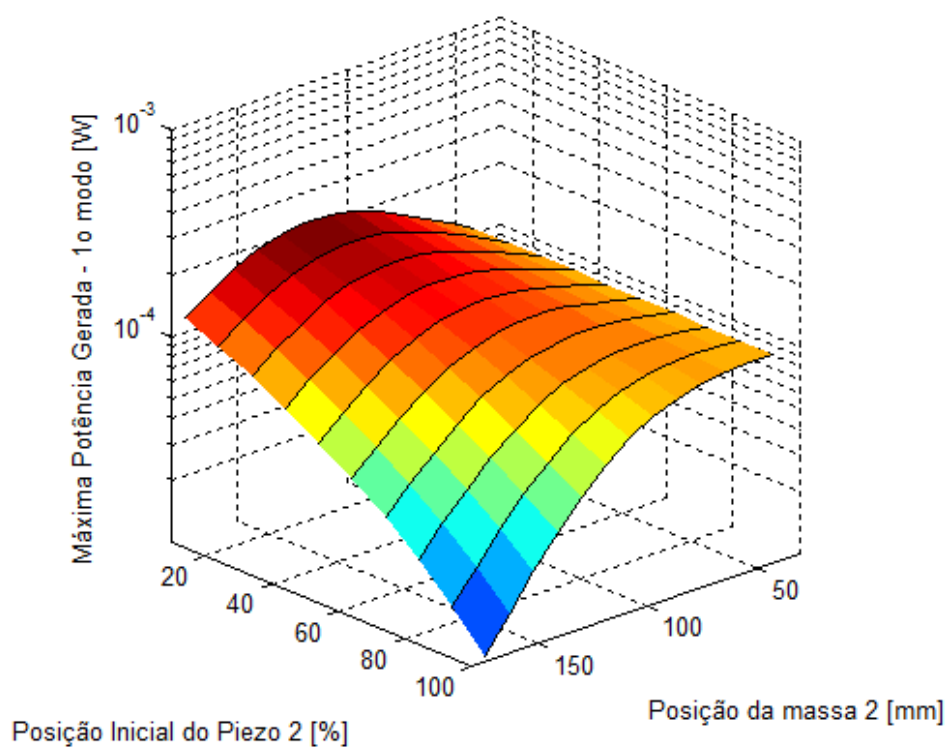

Figura 113 - Máxima potência gerada no primeiro modo de vibrar da configuração 2 para diferentes posições de $M_{2}$ e dos insertos de $\mathfrak{R}_{2}$, com cancelamento no segundo modo à resistência de máxima resposta. 


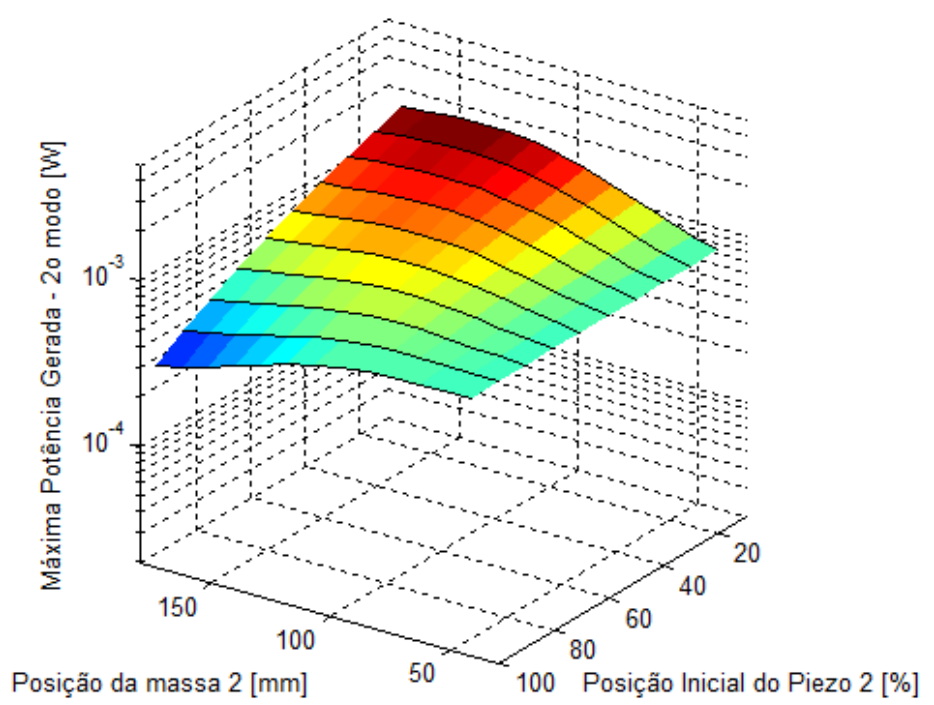

Figura 114 - Máxima potência gerada no segundo modo de vibrar da configuração 2 para diferentes posições de $M_{2}$ e dos insertos de $\mathfrak{R}_{2}$, com cancelamento no primeiro modo à resistência de máxima resposta.

\subsubsection{Eficiência dos Insertos Piezelétricos}

Fazendo o confronto dos resultados de potência para cada inserto notam-se variações de amplitude e frequência natural, mas sem a severa redução da eficiência para diferentes posições da massa, como se verificava no terceiro inserto da primeira configuração (\#Figuras 115 a 117). Como esperado, os insertos que configuram a montagem bimorph apresentam resultados idênticos, ambos superiores aos do inserto de $\mathfrak{R}_{1}$, assim como verificado para o inserto de $\mathfrak{R}_{2}$ na configuração 1 .

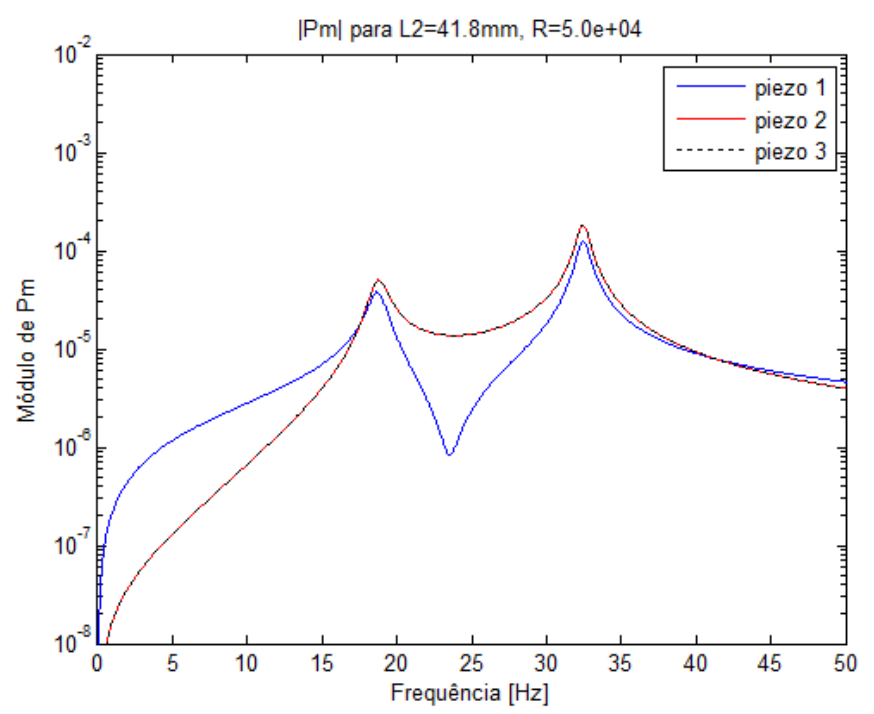

Figura 115 - FRF de potência gerada nos insertos da configuração 2, sendo o primeiro em $\Re_{1}$ e os demais em $\Re_{2}$, com $M_{2}$ em $L_{2}=41,8 \mathrm{~mm}, L_{k}=0$, e resistência de $50 \mathrm{k} \Omega$. 


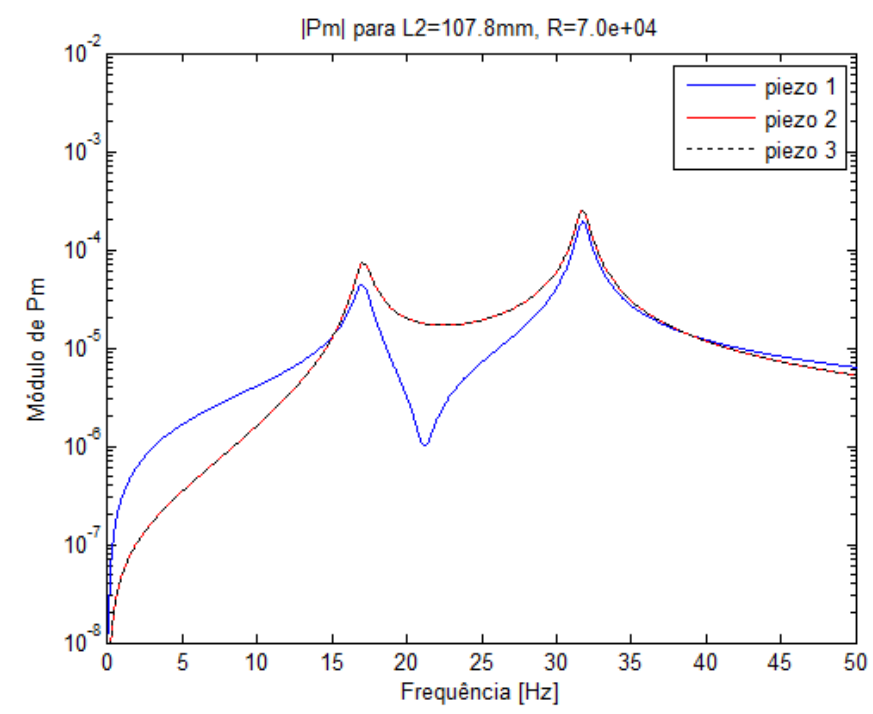

Figura 116 - FRF de potência gerada nos insertos da configuração 2 , sendo o primeiro em $\Re_{1}$ e os demais em $\Re_{2}, \operatorname{com} M_{2}$ em $L_{2}=107,8 \mathrm{~mm}, L_{k}=0$, e resistência de $70 \mathrm{k} \Omega$.

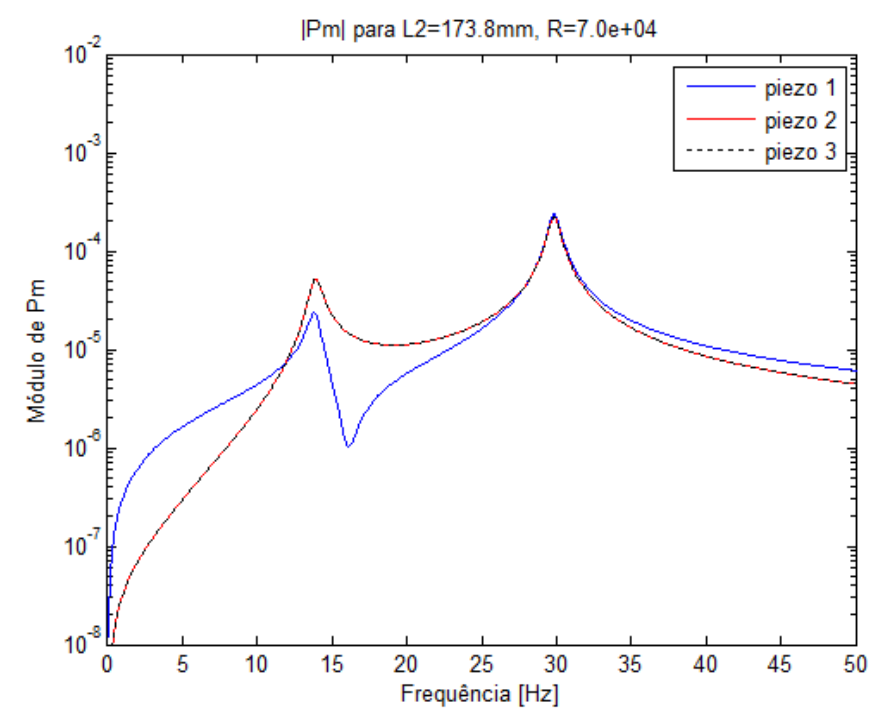

Figura 117 - FRF de potência gerada nos insertos da configuração 2 , sendo o primeiro em $\Re_{1}$ e os demais em $\Re_{2}$, com $M_{2} e m L_{2}=173,8 \mathrm{~mm}, L o_{k}=0$, e resistência de $70 \mathrm{k} \Omega$. 


\subsubsection{Resumo dos Resultados - Configuração 2}

Nas tabelas 20 e 21 estão dispostos os resultados obtidos para o gerador utilizando insertos de $38,1 \mathrm{~mm}$ de comprimento, posicionados no início de cada segmento e $\mathrm{M}_{2}$ nas mesmas posições $L_{2}=41,8 \mathrm{~mm}, L_{2}=107,8 \mathrm{~mm}$ e $L_{2}=173,8 \mathrm{~mm}$ verificadas na configuração original, além das configurações de maior eficiência, tanto para o comprimento constante dos insertos, como para o recobrimento (em $\mathfrak{R}_{2}$ ) com melhores resultados de potência gerada..

Tabela 20 - Resultados de potência máxima no $1^{\circ}$ modo para o gerador na configuração 2 com cancelamento no $2^{\circ} \operatorname{modo}$.

\begin{tabular}{|c|c|c|c|c|}
\hline \multicolumn{5}{|c|}{ Configuração 2 - Potência Máxima - Cancelamento no $2^{\circ}$ modo } \\
\hline \multirow[b]{2}{*}{$\begin{array}{c}L_{2} \\
{[\mathrm{~mm}]}\end{array}$} & \multirow[b]{2}{*}{$\begin{array}{c}\boldsymbol{R}_{\boldsymbol{l}} \\
{[\mathbf{\Omega}]}\end{array}$} & \multirow{2}{*}{$\begin{array}{c}\text { Máxima } \\
\text { Potência } \\
\text { Gerada } \\
{[\mu W]}\end{array}$} & \multicolumn{2}{|c|}{ Densidade Energética } \\
\hline & & & $\begin{array}{c}\text { Por Massa do } \\
\text { Gerador } \\
{[\mu \mathrm{W} / \mathrm{kg}]}\end{array}$ & $\begin{array}{c}\text { Por Massa de } \\
\text { Material } \\
\text { Piezelétrico } \\
{[\mu \mathrm{W} / \mathrm{g}]}\end{array}$ \\
\hline 41,8 & $1,1 \times 10^{4}$ & 105,8 & 81,98 & 96,18 \\
\hline 107,8 & $1,1 \times 10^{4}$ & 211,7 & 164,0 & 192,5 \\
\hline 118,8 & $1,1 \times 10^{4}$ & 214,7 & 166,36 & 195,2 \\
\hline $118,8^{*}$ & $7,0 \times 10^{4}$ & 246,0 & 190,61 & 125,04 \\
\hline 173,8 & $1,3 \times 10^{4}$ & 117,8 & 91,28 & 107,09 \\
\hline
\end{tabular}

* Recobrimento de $70 \%$ da superfície de $\mathfrak{R}_{2}$

Tabela 21 - Resultados de potência máxima no $2^{\circ}$ modo para o gerador na configuração 2 com cancelamento no $1^{\circ}$ modo.

\begin{tabular}{ccccc}
\hline \multicolumn{4}{c}{ Configuração 2 - Potência Máxima - Cancelamento no 1 $\mathbf{1}^{\mathbf{0}}$ modo } \\
\hline $\begin{array}{c}\boldsymbol{L}_{\mathbf{2}} \\
{[\mathbf{m m}]}\end{array}$ & $\begin{array}{c}\boldsymbol{R}_{\boldsymbol{l}} \\
{[\mathbf{\Omega}]}\end{array}$ & $\begin{array}{c}\text { Máxima } \\
\text { Potência } \\
\text { Gerada } \\
{[\boldsymbol{\mu W}]}\end{array}$ & $\begin{array}{c}\text { Por Massa do } \\
\text { Gerador } \\
{[\boldsymbol{\mu W} / \mathbf{k g}]}\end{array}$ & $\begin{array}{c}\text { Por Massa de } \\
\text { Material } \\
\text { Piezelétrico } \\
{[\boldsymbol{\mu W} / \mathbf{g}]}\end{array}$ \\
\hline 41,8 & $5,0 \times 10^{4}$ & 733,2 & 568,1 & 666,6 \\
107,8 & $7,0 \times 10^{4}$ & 1510 & 1170 & 1372,7 \\
140,8 & $7,0 \times 10^{4}$ & 1703 & 1320 & 1548,2 \\
$151,8 * *$ & $3,0 \times 10^{4}$ & 2087 & 1617 & 865,3 \\
173,8 & $7,0 \times 10^{4}$ & 1595 & 1236 & 1450 \\
\hline$* *$ Recobrimento de $70 \%$ da superfície de $\Re_{2}$ & &
\end{tabular}




\subsubsection{Configuração 3}

Observando os resultados apresentados para as configurações anteriores, nota-se que para uma mesma quantidade de material piezelétrico a potência gerada pelo inserto do segmento $\mathfrak{R}_{1}$ é sensivelmente menor do que a dos insertos de $\mathfrak{R}_{2}$, e que em sua resposta há a presença de uma acentuada anti-ressonância, fazendo com que entre as duas primeiras frequências naturais haja uma região de baixa eficiência. Além disso, as deformações apresentadas pelas vigas nos dois primeiros modos de vibrar são conflitantes já que as superfícies em tração e compressão na primeira e segunda viga alternam-se de maneira que sempre haverá cancelamento do potencial gerado quando insertos em $\mathfrak{R}_{1}$ e $\mathfrak{R}_{2}$ forem ligados em série a um mesmo circuito elétrico.

Na configuração 3, tendo em vista estes aspectos, foi eliminado o inserto piezelétrico do segmento $\mathfrak{R}_{1}$, mantendo apenas a montagem bimorph de $\mathfrak{R}_{2}$, a qual se mostrou mais eficiente. Para esta nova configuração foram repetidos os estudos de sensibilidade quanto à posição de $\mathrm{M}_{2}$, comprimentos e posições dos insertos, agora presentes apenas em $\mathfrak{R}_{2}$.

\subsubsection{1.- Posição da Massa 2}

$\mathrm{O}$ estudo de sensibilidade à posição de $\mathrm{M}_{2}$ na configuração 3 foi iniciado seguindo o mesmo padrão das configurações anteriores, adotando um comprimento constante de $38,1 \mathrm{~mm}$ para os insertos, com $L o 2=0$.

Avaliando-se os resultados inicialmente com uma resistência constante de $50 \mathrm{k} \Omega$, verifica-se novamente que posicionamento de $\mathrm{M}_{2}$ apresenta grande influência nas frequências naturais, mas pouco reflexo nas amplitudes de resposta (\#Figuras 118 e 119). Ao se comparar a máxima potência gerada para diferentes resistências elétricas (\#Figuras 120 e 121), na primeira frequência verifica-se a maximização da resposta com $L_{2}=118,8 \mathrm{~mm}$ e $R_{l}=70 \mathrm{k} \Omega$, gerando $195,8 \mu \mathrm{W}$, enquanto para o segundo modo essa maximização ocorre em $L_{2}=129,8$ $m m$ e $R_{l}=50 \mathrm{k} \Omega$, com $1,199 \mathrm{~mW}$ gerados. Com a massa na posição central as potências geradas são $189,1 \mu \mathrm{W} \operatorname{com} R_{l}=70 \mathrm{k} k \Omega$ e $1,134 \mathrm{~mW} \operatorname{com} R_{l}=50 \mathrm{k} \Omega$, para a primeira e segunda frequência natural respectivamente. 


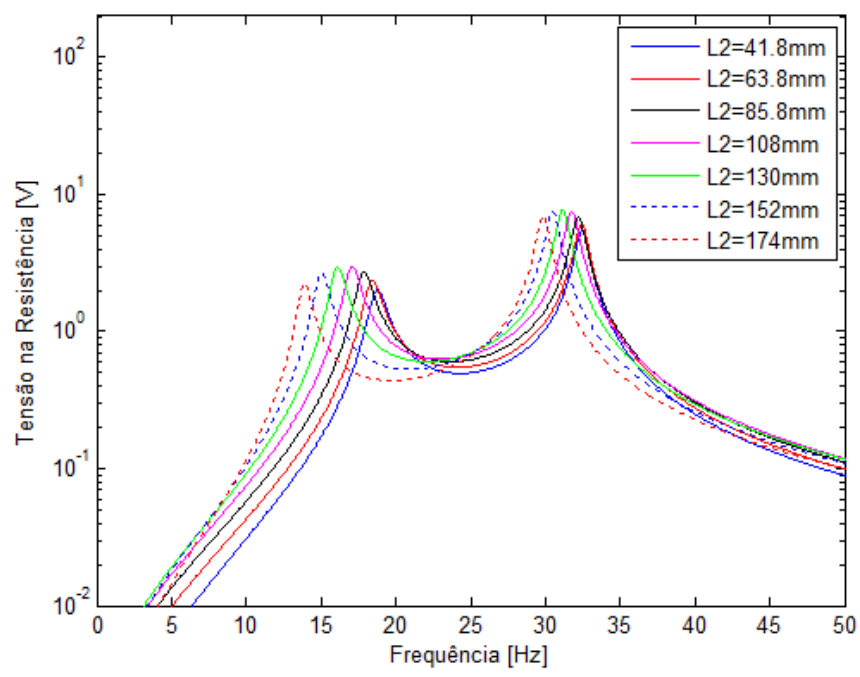

Figura 118 - FRF de tensão gerada na resistência para a Configuração 3, em diferentes posições de $M_{2}$, usando uma resistência de $50 \mathrm{k} \Omega$.

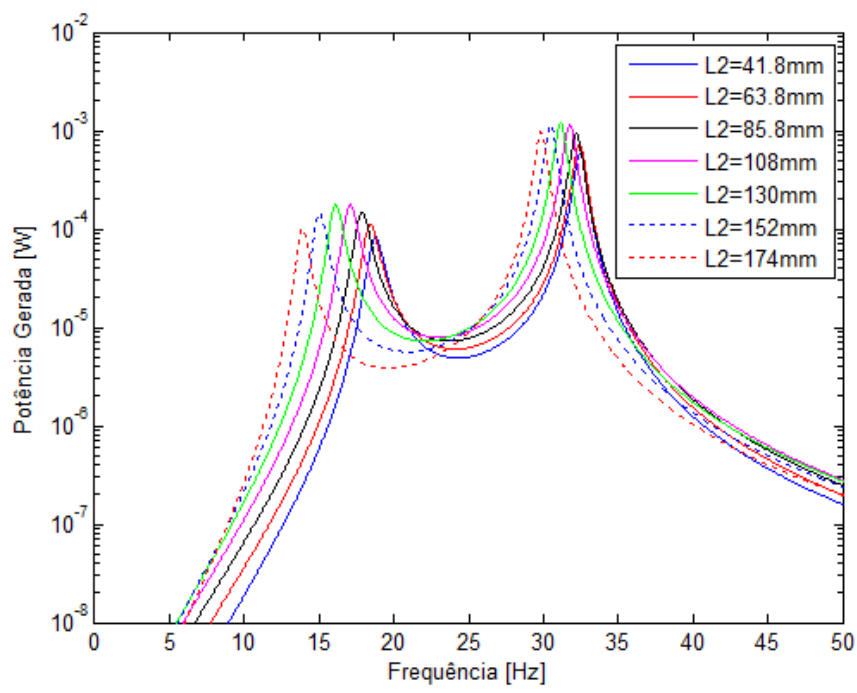

Figura 119 - FRF de potência gerada na resistência para a Configuração 3, em diferentes posições de $M_{2}$, usando uma resistência de $50 \mathrm{k} \Omega$. 


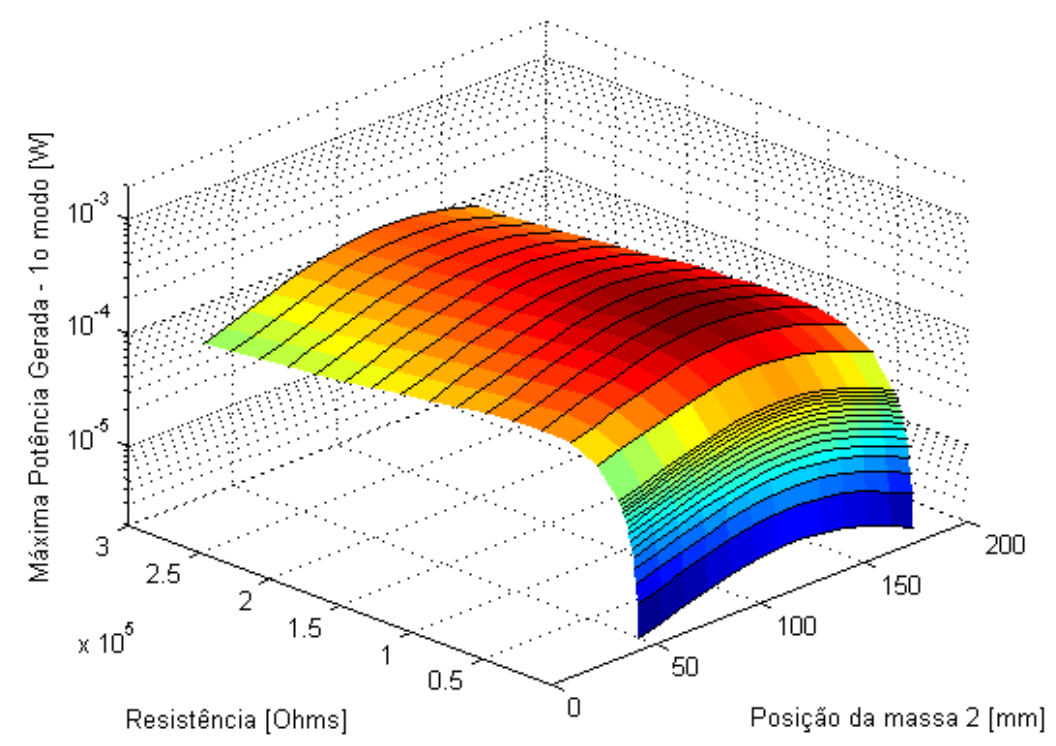

Figura 120 - Máxima potência gerada na resistência para o primeiro modo da configuração 3, para diferentes valores de resistência e posições de $M_{2}$

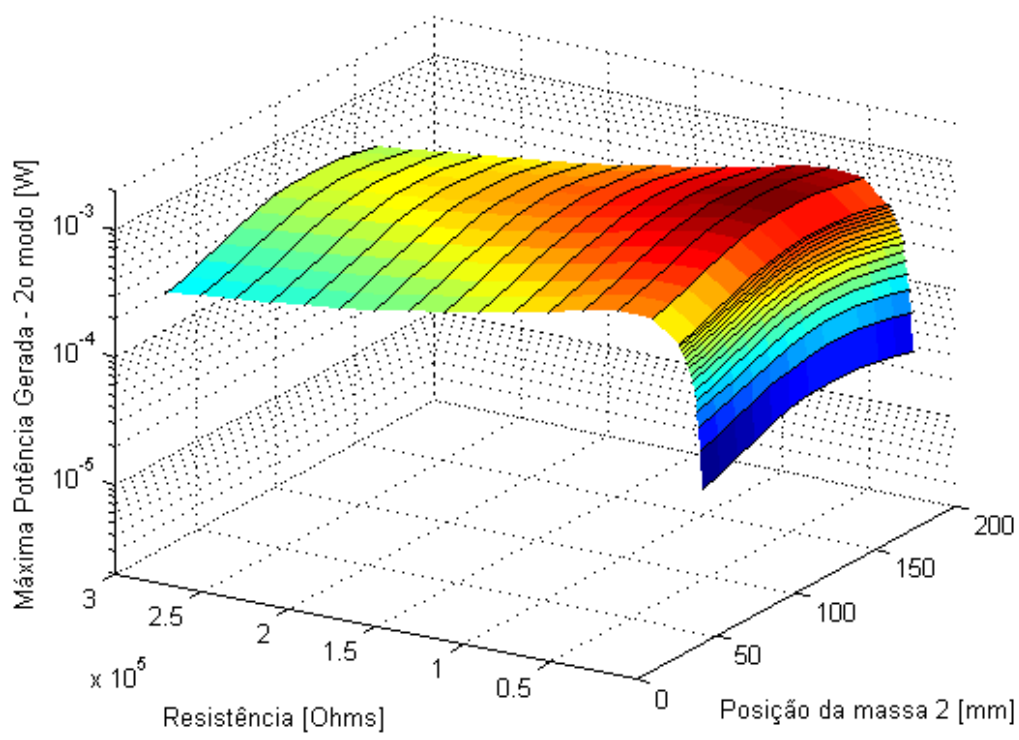

Figura 121 - Máxima potência gerada na resistência para o segundo modo da configuração 3, para diferentes valores de resistência e posições de $M_{2}$ 


\subsubsection{2.- Comprimento do Inserto Piezelétrico.}

Assim como na configuração anterior, as análises de sensibilidade quanto ao comprimento dos insertos foi realizada variando-se o comprimento de ambos os elementos da montagem bimorph em $\mathfrak{R}_{2}$ ao mesmo tempo.

Primeiramente com $\mathrm{M}_{2}$ em $L_{2}=107,8 \mathrm{~mm}$, e uma resistência constante de $50 \mathrm{k} \Omega$, observa-se novamente o aumento da potência gerada, mas não na mesma proporção do aumento da quantidade de material piezelétrico(\#Figura 122). Estendendo a análise para diferentes resistências elétricas verifica-se que a máxima potência gerada em ambas as frequências naturais ocorre para um comprimento de $97 \mathrm{~mm}$, chegando a $271,3 \mu \mathrm{W}$ na primeira frequência natural, com $R_{l}=30 \mathrm{k} \Omega$, e $1,724 \mathrm{~mW}$ na segunda, com $R_{l}=15 \mathrm{k} \Omega$ (\#Figuras 123 a 126).

Repetindo a avaliação dos vários comprimentos de inserto para outras posições de $\mathrm{M}_{2}$ (\#Figuras 127 e 128) é possível observar que a maximização da potência gerada para a primeira e segunda frequência natural ocorre para $\mathrm{L}_{2}=129,8 \mathrm{~mm}$. A máxima potência encontrada para o primeiro modo foi de $285,9 \mu \mathrm{W}$, enquanto para o segundo, encontrou-se $1,858 \mathrm{~mW}$, ambos com $80 \%$ de recobrimento.

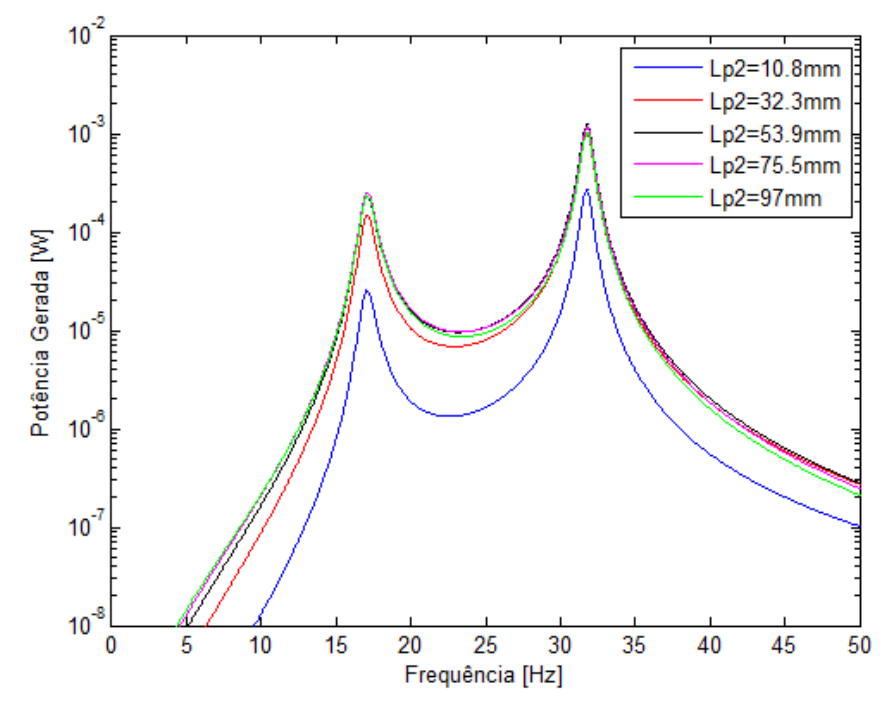

Figura 122 - FRF de potência gerada na resistência para a configuração 3 , com $M_{2}$ em 107,8mm, diferentes comprimentos dos insertos de $\mathfrak{R}_{2}$ e resistência de $50 \mathrm{k} \Omega$. 


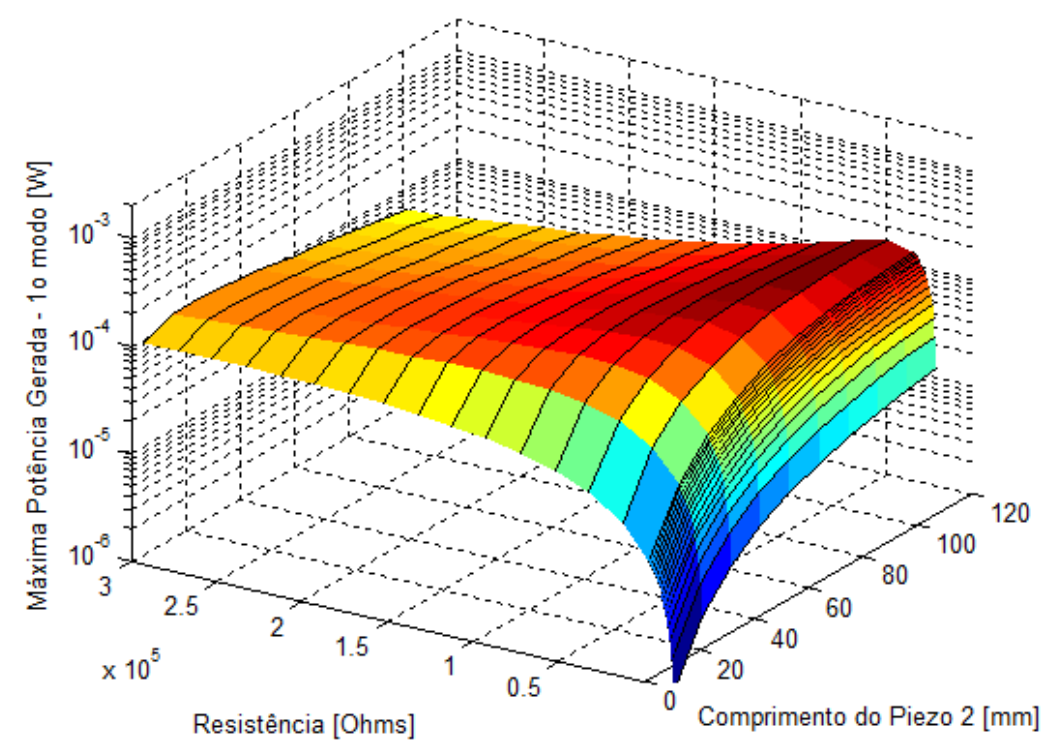

Figura 123 - Máxima potência gerada na resistência para a configuração 3 no primeiro modo de vibrar, com $M_{2}$ em 107,8mm, para diferentes resistências e comprimentos dos insertos de $\Re_{2}$.

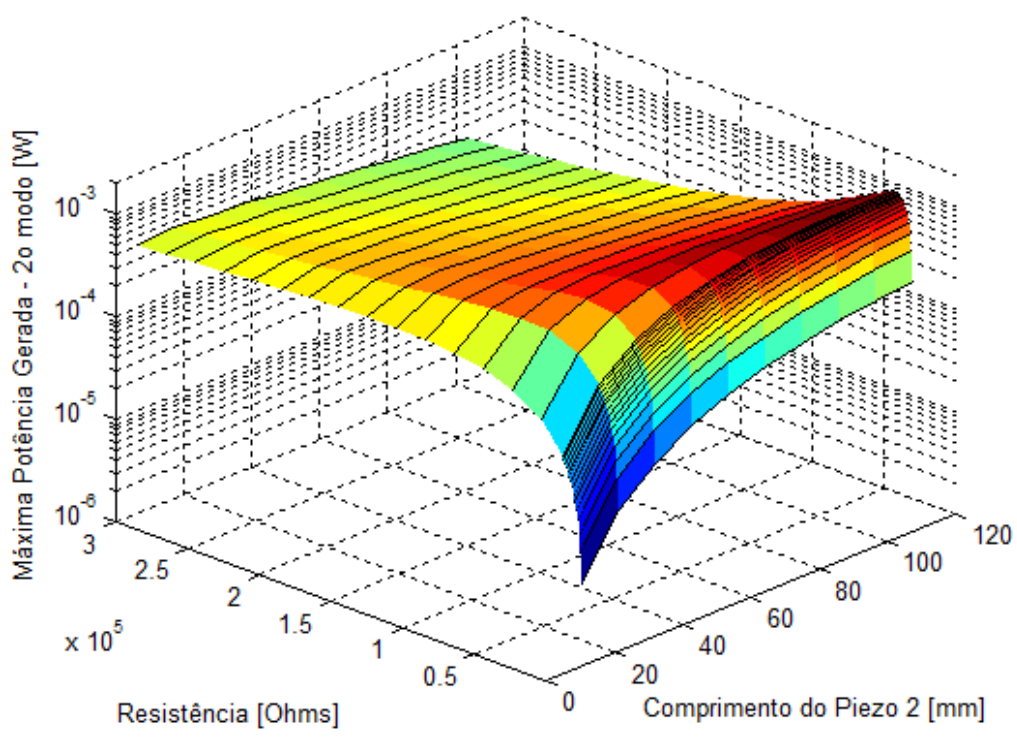

Figura 124 - Máxima potência gerada na resistência para a configuração 3 no segundo modo de vibrar, com $M_{2}$ em 107,8mm, para diferentes resistências e comprimentos dos insertos de $\Re_{2}$. 


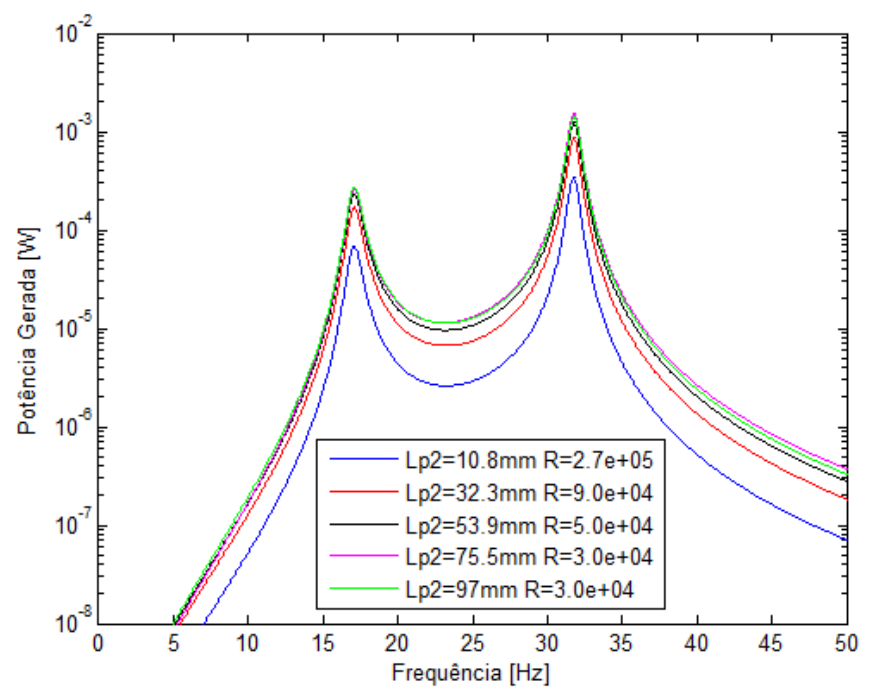

Figura 125 - FRF de potência gerada na resistência para a configuração 3, com $M_{2} \mathrm{em} \mathrm{107,8mm}$, para diferentes comprimentos dos insertos de $\mathfrak{R}_{2}$ à resistência que maximiza a resposta no primeiro modo de vibrar.

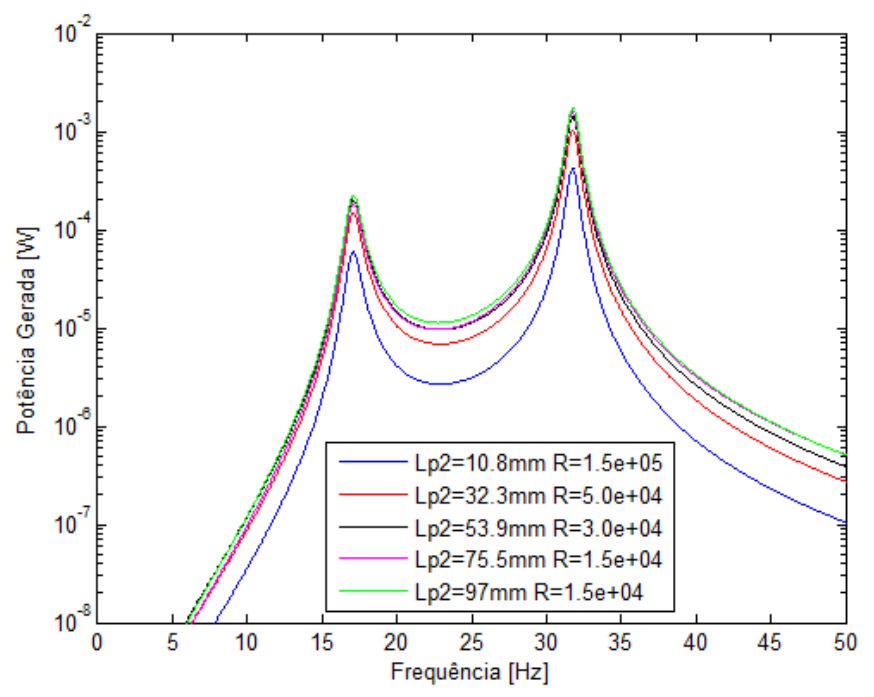

Figura 126 - FRF de potência gerada na resistência para a configuração 3, com $M_{2} \mathrm{em} \mathrm{107,8mm}$, para diferentes comprimentos dos insertos de $\mathfrak{R}_{2}$ à resistência que maximiza a resposta no segundo modo de vibrar. 


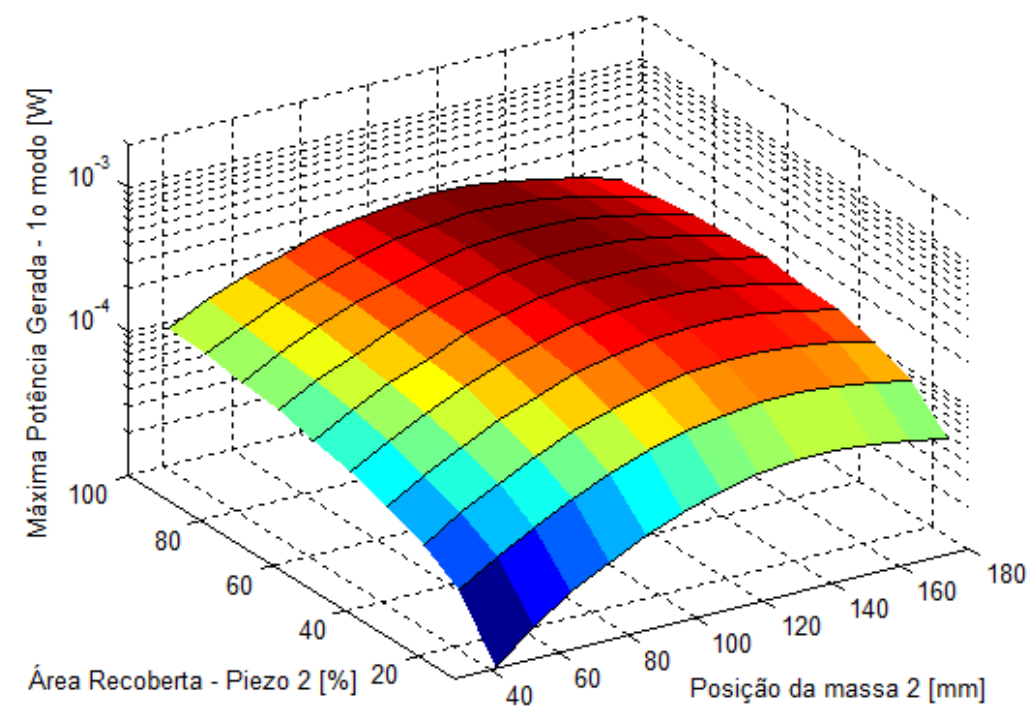

Figura 127 - Máxima potência gerada para a configuração3 no primeiro modo de vibrar, à resistência de maior eficiência, para diferentes posições de $M_{2}$ e comprimentos dos insertos de $\Re_{2}$.

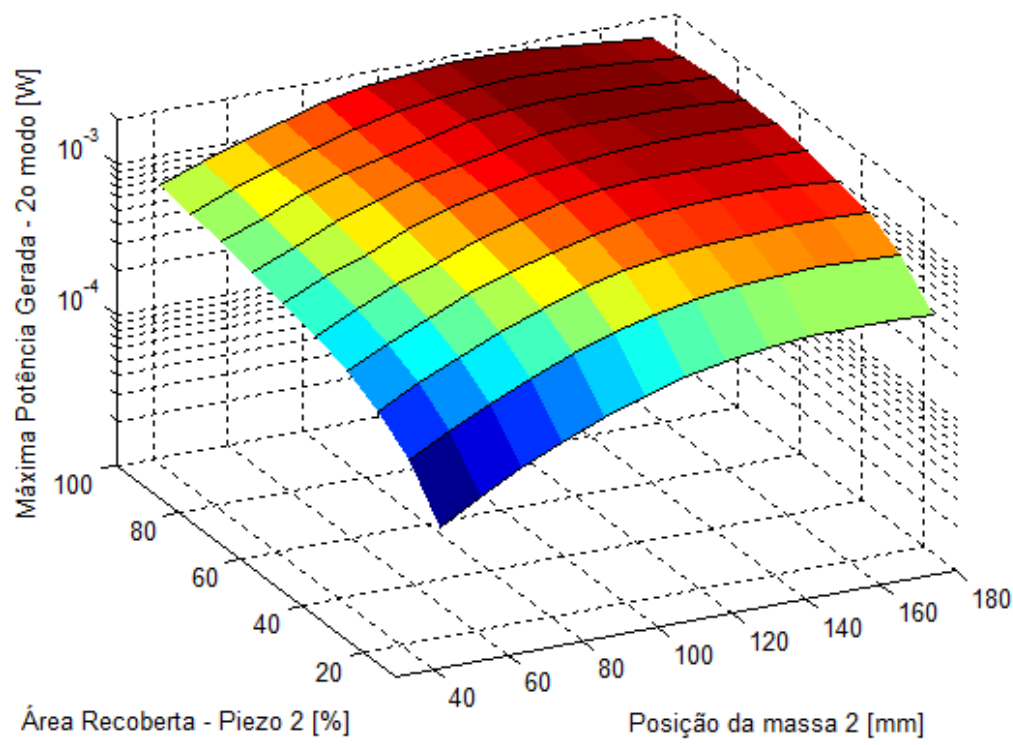

Figura 128 - Máxima potência gerada para a configuração3 no segundo modo de vibrar, à resistência de maior eficiência, para diferentes posições de $M_{2}$ e comprimentos dos insertos de $\Re_{2}$. 


\subsubsection{Posição do Inserto Piezelétrico.}

O estudo de sensibilidade à posição dos insertos foi realizado deslocando sempre ambos os insertos da montagem bimorph de $\mathfrak{R}_{2}$, como na configuração 2 , assumindo para estes um comprimento fixo de $38,1 \mathrm{~mm}$.

Mais uma vez iniciou-se o estudo com $\mathrm{M}_{2}$ em $107,8 \mathrm{~mm}$ e $\mathrm{R}_{\mathrm{l}}=50 \mathrm{k} \Omega$, verificando-se melhores resultados para $\mathrm{Lo}_{2}=0$, como nas configurações anteriores(\#Figura 129). Ao se estender a avaliação a outras resistências encontra-se o mesmo resultado (\#Figuras 130 e 131).

O mesmo ocorre no caso da máxima potência gerada para várias posições de $\mathrm{M}_{2}$, em que a maximização da resposta sempre ocorre em $L_{2}=0$, e no caso do primeiro modo para $L_{2}=118,8 \mathrm{~mm}$ e para o segundo $L_{2}=129,8 \mathrm{~mm}$, com potências máximas de $195,8 \mu \mathrm{W}$ e 1,199 $\mathrm{mW}$ respectivamente (\#Figuras 132 e 133).

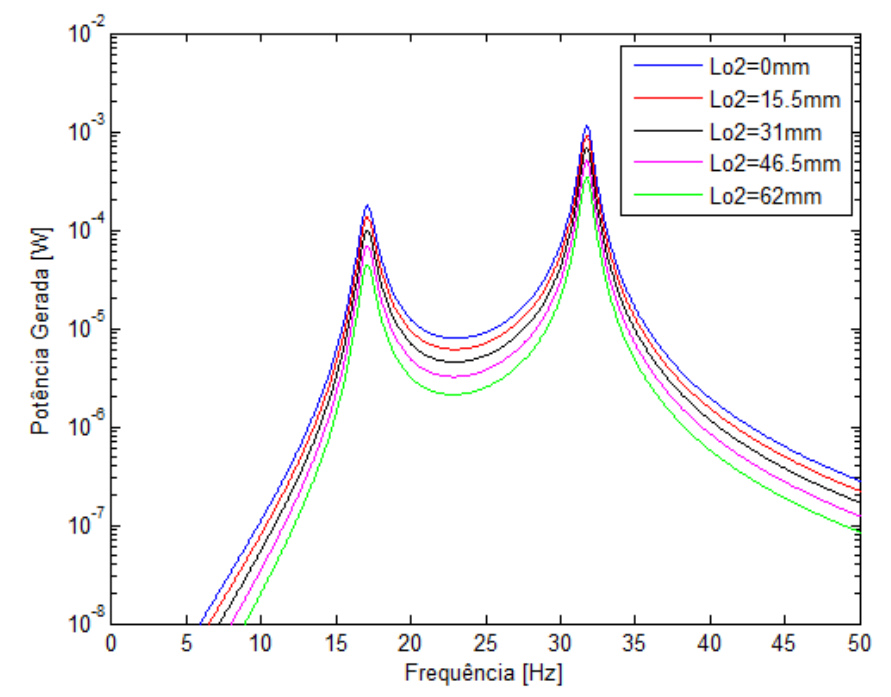

Figura 129 - FRF de tensão gerada na resistência para a configuração 3, em diferentes posições dos insertos de $\Re_{2}$, para $L_{2}=107,8 \mathrm{~mm}$ e usando uma resistência de $50 \mathrm{k} \Omega$. 


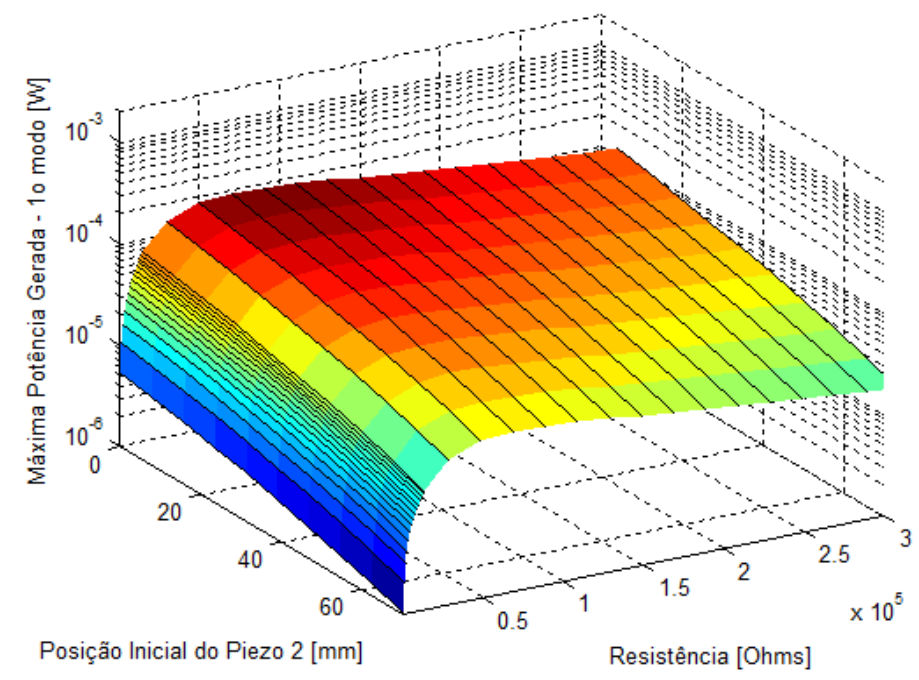

Figura 130 - Máxima potência gerada no primeiro modo de vibrar da configuração 3 para diferentes resistências e posições dos insertos de $\Re_{2}$, com $M_{2}$ em $107,8 \mathrm{~mm}$.

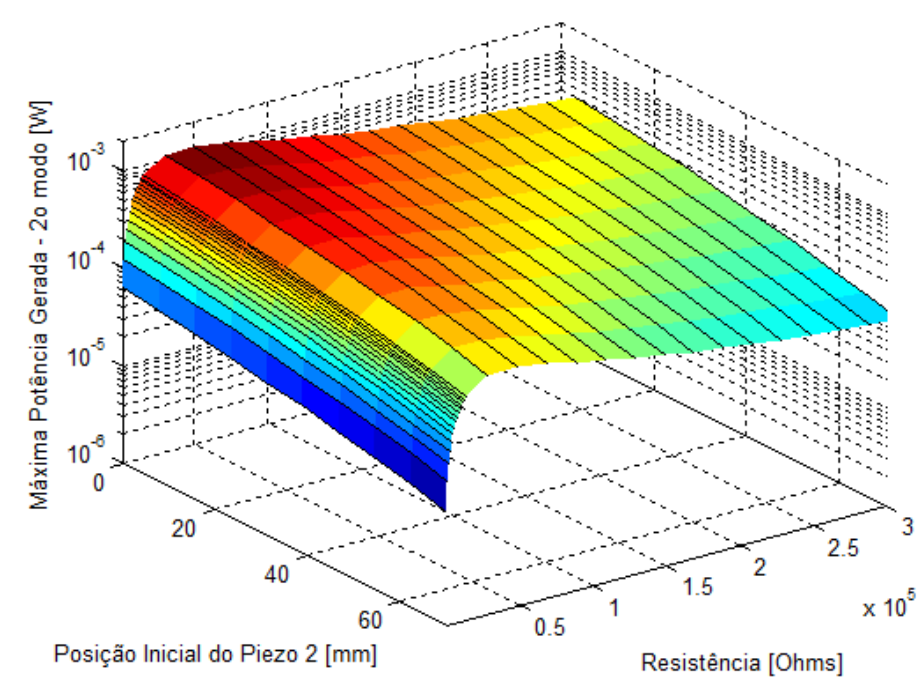

Figura 131 - Máxima potência gerada no segundo modo de vibrar da configuração 3 para diferentes resistências e posições dos insertos de $\Re_{2}$, com $M_{2}$ em $107,8 \mathrm{~mm}$. 


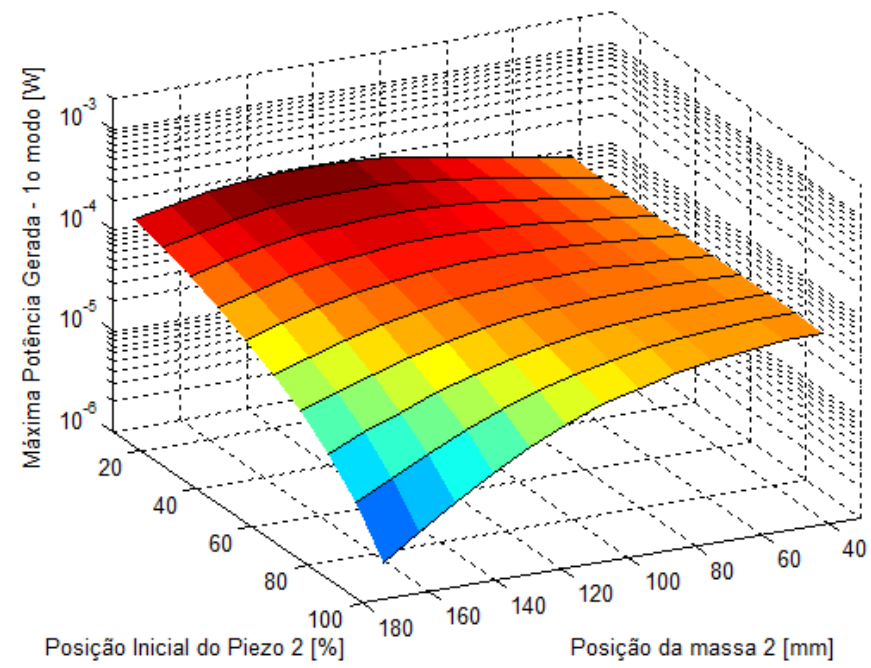

Figura 132 - Máxima potência gerada no primeiro modo de vibrar da configuração 3 para diferentes posições de $\mathrm{M}_{2}$ e dos insertos de $\mathfrak{R}_{2}$, à resistência de máxima resposta.

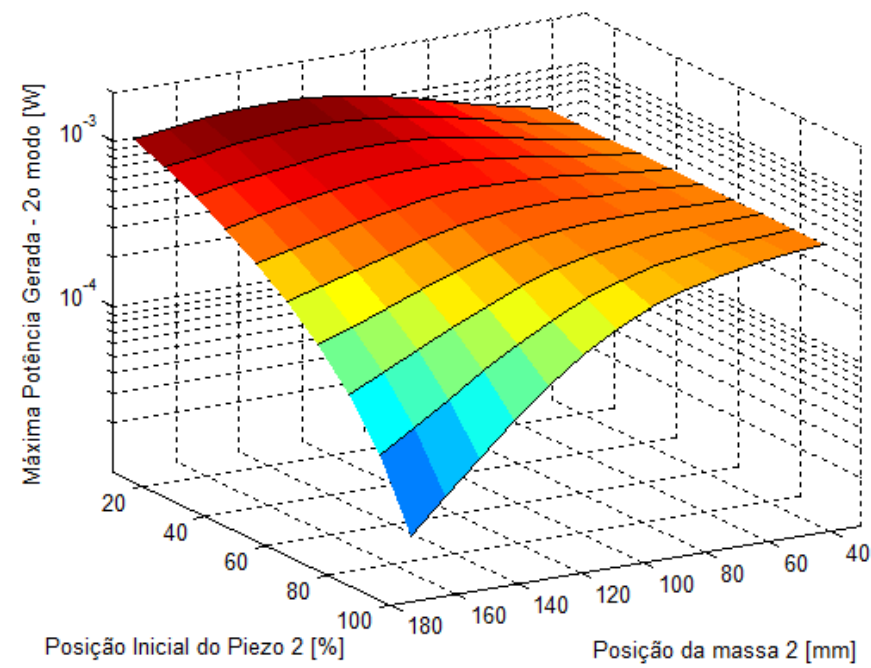

Figura 133 - Máxima potência gerada no segundo modo de vibrar da configuração 3 para diferentes posições de $M_{2}$ e dos insertos de $\Re_{2}$, à resistência de máxima resposta.

\subsubsection{Eficiência dos Insertos Piezelétricos}

No caso da configuração 3 não há a necessidade de se confrontar a eficiência dos insertos, uma vez que ambos apresentam exatamente a mesma resposta, já que estão posicionados na mesma secção da estrutura., conforme já visto na configuração 2 . 


\subsubsection{Resumo dos Resultados - Configuração 3}

Os resultados para o gerador na configuração 3, com insertos de 38,1mm nas posições $L_{2}=41,8 \mathrm{~mm}, L_{2}=107,8 \mathrm{~mm}$ e $L_{2}=173,8 \mathrm{~mm}$ estão dispostos nas tabelas 22 e 23 . Adicionalmente foram listados os resultados das montagens que apresentaram os melhores resultados de potência gerada usando um recobrimento maior.

Para as montagens de maior recobrimento, apesar da maior densidade energética por massa do gerador, há significativa redução na densidade energética por massa de material piezelétrico, consequente do decaimento da eficiência à medida que a região recoberta se distancia do início do segmento $\mathfrak{R}_{2}$. Apesar disso, todos os resultados se mostram bastante superiores aos encontrados na configuração original.

Tabela 22 - Resultados de potência máxima no $1^{\circ}$ modo de vibrar para o gerador na configuração 3.

\begin{tabular}{ccccc}
\hline \multicolumn{4}{c}{ Configuração 3 - Respostas na $\mathbf{1}^{\text {a }}$ Frequência Natural } \\
\hline $\begin{array}{c}\boldsymbol{L}_{\mathbf{2}} \\
{[\mathbf{m m}]}\end{array}$ & $\begin{array}{c}\boldsymbol{R}_{\boldsymbol{l}} \\
{[\mathbf{\Omega}]}\end{array}$ & $\begin{array}{c}\text { Máxima } \\
\text { Potência } \\
\text { Gerada } \\
{[\boldsymbol{\mu W}]}\end{array}$ & $\begin{array}{c}\text { Por Massa do } \\
\text { Gerador } \\
{[\boldsymbol{\mu W} / \mathbf{k g}]}\end{array}$ & $\begin{array}{c}\text { Por Massa de } \\
\text { Material } \\
\text { Piezelétrico } \\
{[\boldsymbol{\mu W} / \mathbf{g}]}\end{array}$ \\
\hline 41,8 & $7,0 \times 10^{4}$ & 85,29 & 66,1 & 116,3 \\
107,8 & $7,0 \times 10^{4}$ & 189,1 & 146,5 & 257,9 \\
118,8 & $7,0 \times 10^{4}$ & 195,8 & 151,7 & 267,0 \\
$129,8 *$ & $3,0 \times 10^{4}$ & 285,9 & 221,5 & 143,1 \\
173,8 & $9,0 \times 10^{4}$ & 119,2 & 92,4 & 162,6 \\
\hline
\end{tabular}

* Recobrimento de $80 \%$ da superfície de $\mathfrak{R}_{2}$

Tabela 23 - Resultados de potência máxima no $2^{\circ}$ modo de vibrar para o gerador na configuração 3.

\begin{tabular}{ccccc}
\hline \multicolumn{4}{c}{ Configuração 3 - Respostas na $\mathbf{2}^{\text {a }}$ Frequência Natural } \\
\hline $\begin{array}{c}\boldsymbol{L}_{2} \\
{[\mathbf{m m}]}\end{array}$ & $\boldsymbol{R}_{\boldsymbol{l}}$ & $\begin{array}{c}\text { Máxima } \\
\text { Potência } \\
\text { Gerada } \\
{[\boldsymbol{\Omega W}]}\end{array}$ & $\begin{array}{c}\text { Por Massa do } \\
\text { Gerador } \\
{[\boldsymbol{\mu W} / \mathbf{k g}]}\end{array}$ & $\begin{array}{c}\text { Pensidade Energética } \\
\text { Paterial } \\
\text { Piezelétrico } \\
{[\boldsymbol{\mu W} / \mathbf{g}]}\end{array}$ \\
\hline 41,8 & $3,0 \times 10^{4}$ & 584,3 & 452,7 & 797,8 \\
107,8 & $5,0 \times 10^{4}$ & 1134 & 878,7 & 1546 \\
129,8 & $5,0 \times 10^{4}$ & 1199 & 929,0 & 1635 \\
$129,8 *$ & $1,5 \times 10^{4}$ & 1858 & 1439,6 & 929,6 \\
173,8 & $5,0 \times 10^{4}$ & 990,4 & 767,4 & 1351 \\
\hline
\end{tabular}

* Recobrimento de $80 \%$ da superfície de $\mathfrak{R}_{2}$ 


\subsection{Discussão dos Resultados}

\subsubsection{Parâmetros Concentrados}

Avaliando-se os modelos de dois graus de liberdade estudados nos trabalhos de Tang e Yang (2012) e Xiao et al. (2015) verificou-se uma grande divergência na potência gerada pelos elementos piezelétricos de cada oscilador, com o segundo inserto apresentando amplitudes de resposta cerca de 10 vezes maiores que as do primeiro. Como ambos os insertos possuem a mesma quantidade de material piezelétrico, entende-se que aquele com menores amplitudes de resposta está sendo subutilizado, caracterizando uma ineficiência do sistema, a qual foi o ponto de partida da otimização do gerador.

Através da simples eliminação do inserto ineficiente foi possível aumentar significativamente a densidade energética em função da massa de material piezelétrico, com pouco impacto na densidade energética por massa do gerador. Adiante, ao se aumentar a quantidade de material piezelétrico no segundo inserto, caracterizando a realocação do material removido anteriormente, foram obtidas amplitudes de potência gerada bastante superiores às da configuração original, com melhores resultados de densidades energéticas nos dois ambitos.

No caso do modelo com 3 graus de liberdade, ao se utilizar de parâmetros de massa, rigidez e coeficientes de acoplamento eletromecânico compatíveis com os do modelo de 2 GDL, buscou-se evidenciar estratégias para maximização da potência gerada bem como aumento da largura da faixa de frequência útil do gerador.

Nos estudos de sensibilidade apresentados nota-se que o escalonamento dos osciladores de modo a dispor uma menor rigidez ligada à base resulta na potencialização da amplitude da resposta na primeira frequência natural, mas com significativo estreitamento na largura da faixa de frequência útil do gerador. Já o contrário, dispondo uma menor rigidez na extremidade, resulta em amplitudes de resposta mais uniformes entre as frequências naturais, favorecendo o aumento da largura das faixas de frequência úteis para o gerador.

Nestes estudos observa-se ainda que apenas o último oscilador não apresenta regiões de anti-ressonância entre as frequências naturais, bastante prejudiciais quando se trabalha com excitações de larga banda de frequência. 
Ao final do estudo foram apresentadas configurações de geradores que convenientemente favorecem tanto a otimização da resposta do geradorar, como a disposição do material piezelétrico em um único oscilador. Basicamente estas configurações usam do escalonamento das massas e rigidezes de modo crescente, com maior rigidez na base, e menor na extremidade, de modo a favorecer a maximização das amplitudes do terceiro oscilador, produzir respostas de amplitudes semelhantes para as várias frequências naturais, e assim, maximizar a faixa de frequência útil do gerador. Os resultados obtidos, comparados com os do gerador de dois graus de liberdade proposto por Tang e Yang (2012) e Xiao et al. (2015) evidenciam o potencial do uso dos múltiplos graus de liberdade para tanto para maximização da energia gerada, como para aumento da faixa de frequência útil do dispositivo, sem deixar de lado o foco no aumento da eficiência do gerador, verificando-se uma potência máxima 1,5 vezes maior, com mínima potência entre as duas primeiras ressonâncias 2,6 vezes maior sem aumento de massa do dispositivo nem de material piezelétrico.

\subsubsection{Parâmetros Distribuídos}

Utilizando a solução construtiva do tipo viga "L" foram replicados os conceitos desenvolvidos nos modelos de parâmetros concentrados buscando a maximização da energia gerada com minimização da quantidade de material piezelétrico.

Partindo de uma configuração similar à proposta por Erturk et al. (2009), de mesma topologia, mas com as superfícies do substrato apenas parcialmente recobertas por material piezelétrico, foi possível verificar os efeitos da resistência do circuito elétrico, posição da massa 2, área recoberta pelo material piezelétrico e posição desse recobrimento parcial nos resultados de potência gerada.

Ao se avaliar a contribuição de cada inserto para a potência total gerada, assim como observado no modelo de parâmetros concentrados, notou-se que mesmo com tamanho e propriedades piezelétricas idênticas estes apresentavam amplitudes muito diferentes de resposta. Foi possível verificar ainda que o posicionamento do inserto dentro do segmento afetou significativamente sua contribuição para a potência gerada.

No caso da configuração adotada para o circuito elétrico, em que vários insertos são ligados em série, verificou-se ainda a presença do fenômeno de cancelamento dos potenciais gerados, conforme visto nas configurações 1 e 2 , com comprometimento significativo da potência total gerada. 
Analisando-se as equações (76) e (80) que definem $\chi_{k r}$ e $\psi_{k r}$, utilizados no cálculo da tensão no inserto, é possível notar em ambos os casos a dependência da variável em relação à variação da derivada dos autovetores de cada modo de vibrar.

$$
\begin{gathered}
\chi_{k r}=\left.\vartheta_{k} \frac{d \phi_{k r}\left(x_{k}\right)}{d x_{k}}\right|_{L_{o_{k}}} ^{L_{0_{k}}+L_{p_{k}}} \\
\psi_{k r}=-\left.\left(d_{31}\right)_{k}\left(Y_{p}\right)_{k}\left(h_{p c}\right)_{k} b_{k} \frac{d \phi_{k r}\left(x_{k}\right)}{d x_{k}}\right|_{L_{0_{k}}} ^{L_{0_{k}}+L_{p_{k}}} \\
\sum_{k=1}^{p} Q_{m k} V_{a_{k}}=P_{m} \quad m=1,2, \ldots, p . \\
Q_{m k}=\frac{1}{R_{l}}+j \omega\left(C_{p}\right)_{m} \delta_{m k}+\sum_{r=1}^{\infty} \frac{j \omega \psi_{m r} \chi_{k r}}{\omega_{r}^{2}-\omega^{2}+j 2 \zeta_{r} \omega_{r} \omega} \\
P_{m}=\sum_{r=1}^{\infty} \frac{j \omega \psi_{m r} \lambda_{r} A_{B}}{\omega_{r}^{2}-\omega^{2}+j 2 \zeta_{r} \omega_{r} \omega}
\end{gathered}
$$

Ao se analisar essas derivadas normalizadas para as diferentes posições da massa 2 no gerador estudado, dispostas nos gráficos da figura 135, é possível notar as regiões em que essas variações são mais acentuadas, com maior potencial de geração de energia, as quais explicam os resultados obtidos. Observa-se ainda que há casos em que a partir de um determinado comprimento o módulo da derivada diminui fazendo com que essa diferença regrida, bastante evidente no caso do segmento $\mathfrak{R}_{1}$ para o segundo modo, explicando a diminuição da potencia gerada mesmo com o aumento da área recoberta. Mais evidentes ao se observar a derivada segunda dos autovetores (\#Figura 136), na qual o cruzamento com o eixo das coordenadas indica a inflexão da derivada primeira, tal circunstância indica a ocorrência de cancelamento do potencial gerado dentro do próprio inserto, já que parte do material ligado a um mesmo eletrodo está sob tração, e parte em compressão. A diminuição da potência gerada com aumento da área recoberta é o caso também das regiões em que a derivada tende a um valor constante, fazendo com que o aumento da quantidade de material piezelétrico aumente capacitância do inserto sem contribuir com potenciais significativos de geração.

No caso do cancelamento entre insertos, fica evidente ao se observar os autovetores (\#Figura 134) dos segmentos $\mathfrak{R}_{1}$ e $\mathfrak{R}_{2}$, que as deformações do primeiro e segundo modo são concorrentes, ou seja, ao se ajustar a ligação do circuito elétrico para que os potenciais 
gerados no primeiro modo se somem, ocorrerá o cancelamento no segundo, e vice-versa. Em outras palavras, quando há tração em uma determinada superfície da viga 1 , na superfície da viga 2 haverá tração para um modo, e compressão para o outro. Tal fato impede que haja pleno aproveitamento do potencial gerado em toda a faixa de operação, já que em uma das frequências naturais haverá anulação de parte do potencial gerado, atribuindo uma severa ineficiência ao gerador.

a)

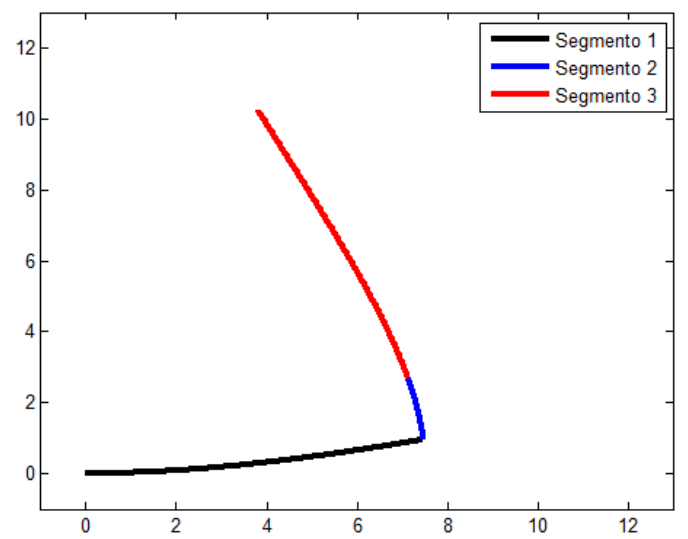

c)

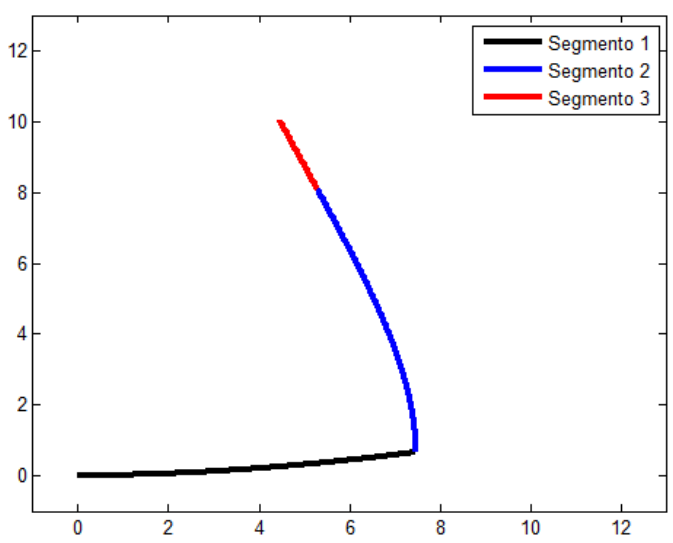

b)

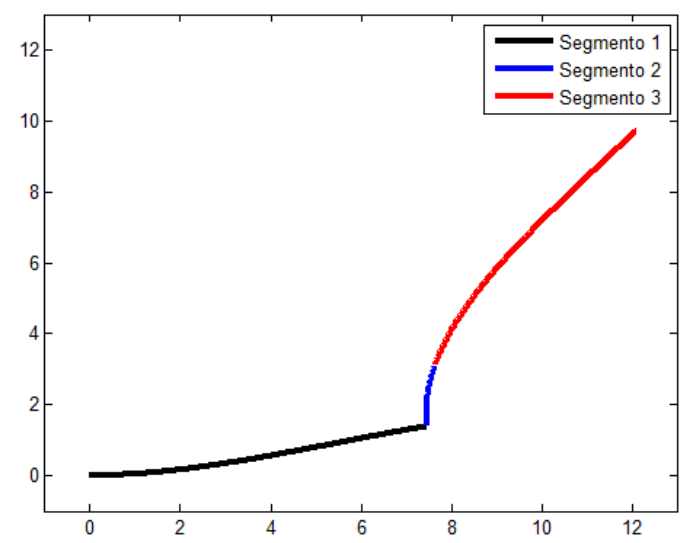

d)

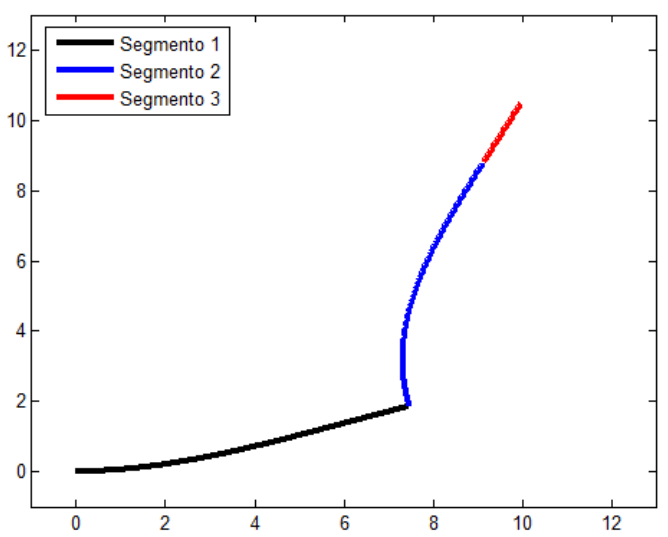

Figura 134 - Modos de vibrar do gerador viga " $L$ ", sendo: a) primeiro modo de vibrar, com $L_{2}=41,8 \mathrm{~mm}$; b) segundo modo de vibrar, com $L_{2}=41,8 \mathrm{~mm}$; c) primeiro modo de vibrar com $L_{2}=173,8 \mathrm{~mm}$; d) segundo modo de vibrar com $L_{2}=173,8 \mathrm{~mm}$. 
Para contornar tal adversidade é possível adotar circuitos elétricos mais elaborados, nos quais a cada inserto pode ser associado a um retificador de corrente diferente. No entanto, é evidente que tais abordagens trazem custos mais elevados, e por isso devem ser avaliadas com cautela. Outra solução, conforme a otimização realizada, está em buscar configurações que favoreçam a maximização das deformações em uma região bem comportada da estrutura, em que se possa utilizar insertos apenas onde não há solicitações concorrentes dentro da faixa de frequências de trabalho desejada.

a)

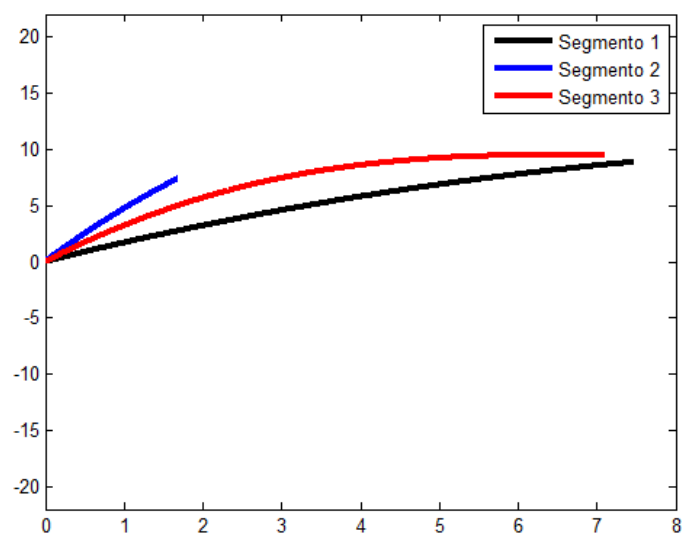

c)

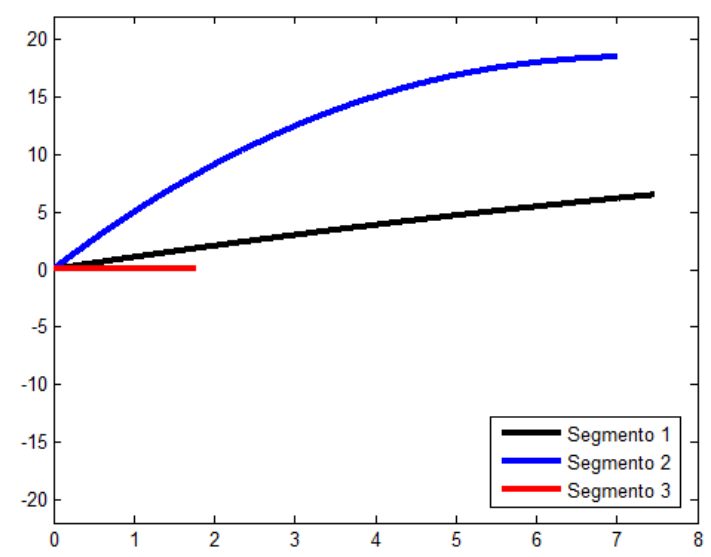

b)

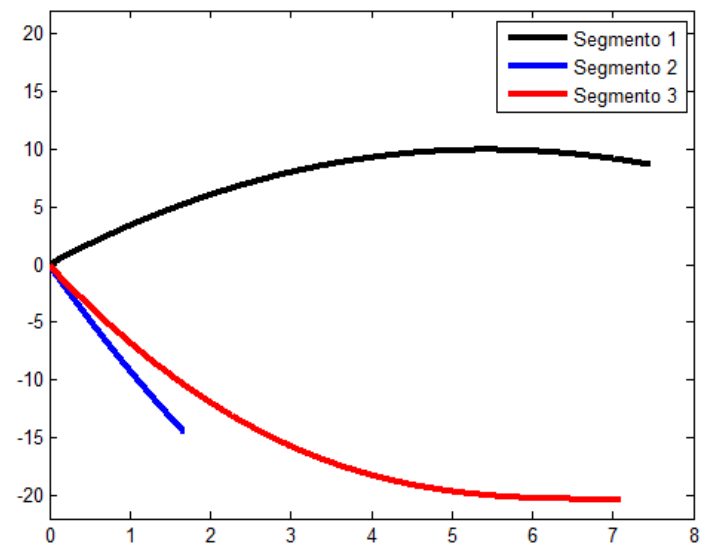

d)

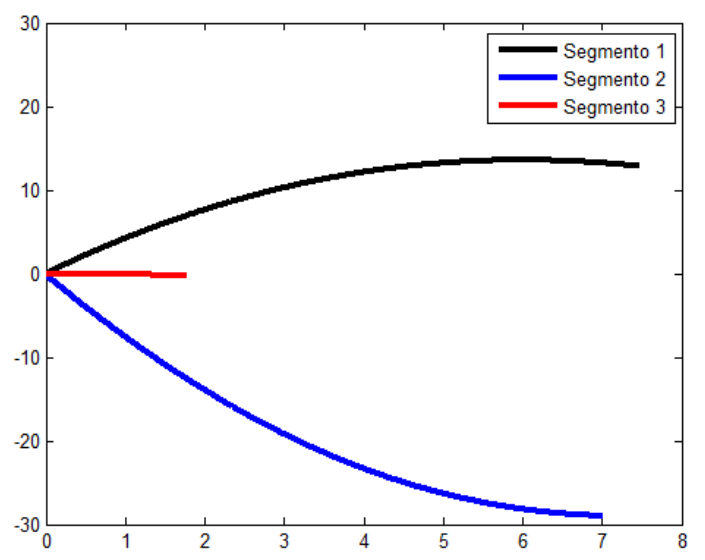

Figura 135 - Derivada dos autovetores do gerador viga " $L$ " normalizados para $x_{k}=0$, sendo: a) primeiro modo, com $L_{2}=41,8 \mathrm{~mm}$; b) segundo modo, com $L_{2}=41,8 \mathrm{~mm}$; c) primeiro modo, com $L_{2}=173,8 \mathrm{~mm}$; d) segundo modo, com $\mathrm{L}_{2}=173,8 \mathrm{~mm}$.

Conhecendo as características da resposta do gerador, foi realizada sua otimização em duas etapas, primeiramente eliminando-se o inserto de menor potência gerada, neste caso 
o inserto de $\mathfrak{R}_{3}$, reinserindo-o na região que apresentou melhores resultados, no caso em $\mathfrak{R}_{2}$, configurando uma montagem bimorph para esta última.

Os resultados obtidos para tal configuração mostraram conformidade com aqueles dos modelos de parâmetros concentrados, apresentando significativo aumento da potência gerada e, como não houve aumento da quantidade de material piezelétrico, nem de massa do gerador, melhores resultados de densidade energética.

a)

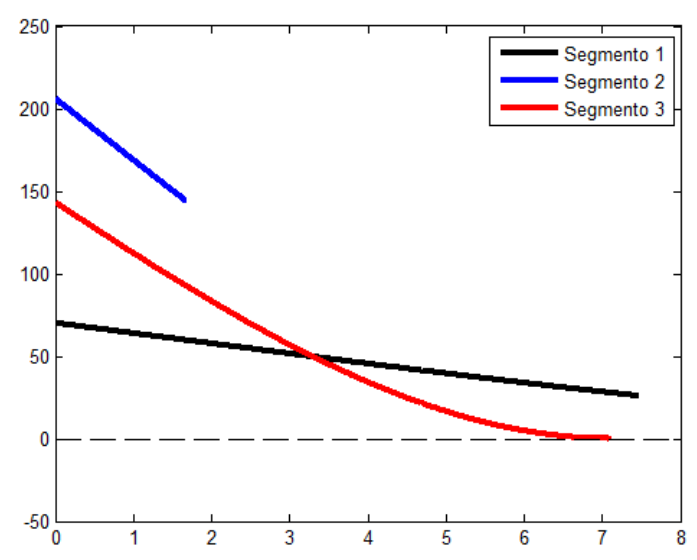

c)

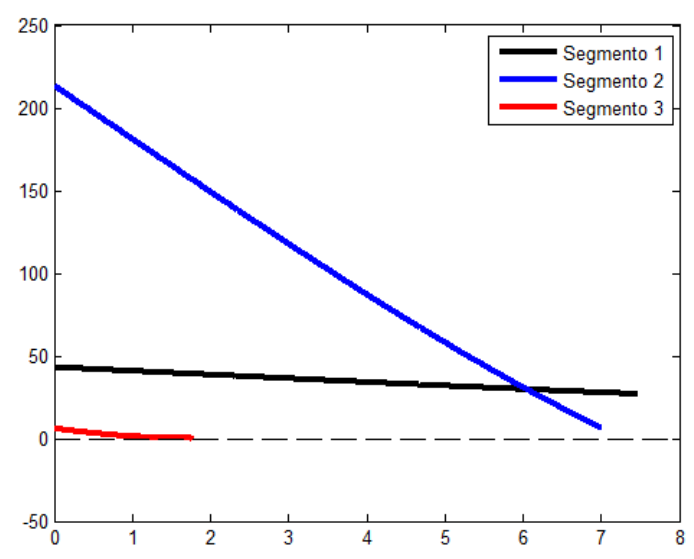

b)

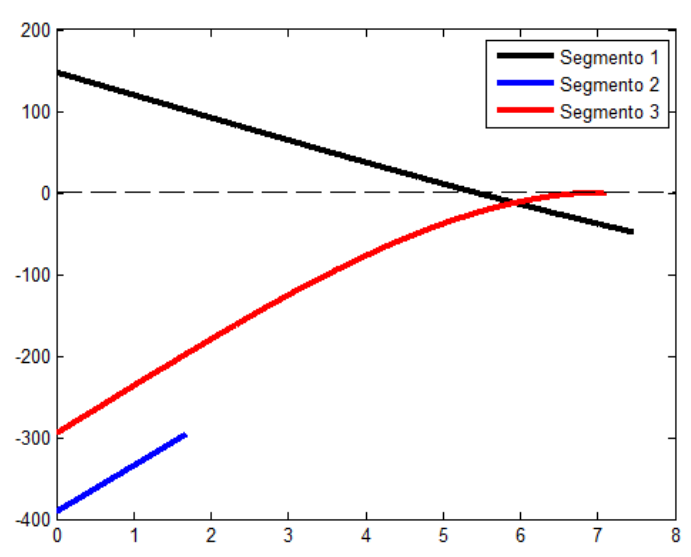

d)

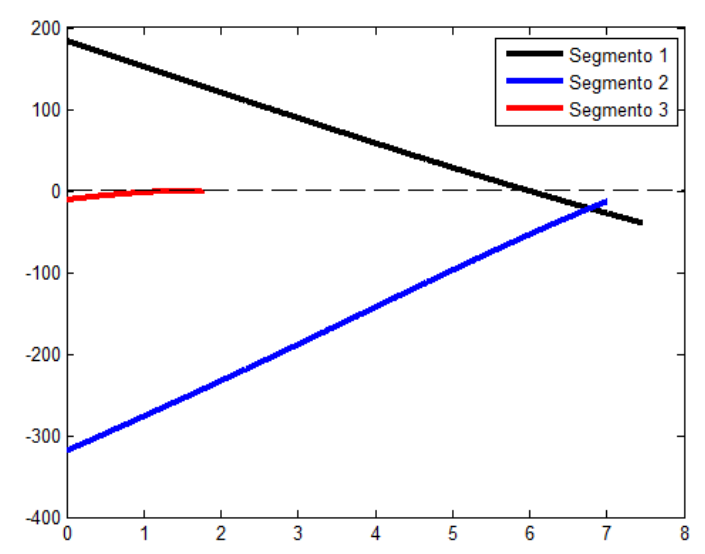

Figura 136 - Derivada segunda dos autovetores do gerador viga " $L$ ", sendo: a) primeiro modo, com $L_{2}=41,8 \mathrm{~mm}$; b) segundo modo, com $L_{2}=41,8 \mathrm{~mm}$; c) primeiro modo, com $L_{2}=173,8 \mathrm{~mm}$; d) segundo modo, $\operatorname{com} L_{2}=173,8 m m$.

$\mathrm{Na}$ etapa seguinte buscou-se a minimização das ineficiências do sistema, obtida através da eliminação do inserto piezelétrico do segmento $\mathfrak{R}_{1}$, que apesar de apresentar potencial de geração considerável, anulava parte da energia gerada pelos insertos de $\mathfrak{R}_{2}$ devido ao fenômeno de cancelamento. Novamente, os resultados obtidos foram bastante 
promissores, em que mesmo com a diminuição da quantidade de material piezelétrico foi possível aumentar a potência gerada em pelo menos uma das frequências naturais, enquanto a outra apresentou apenas pequenas reduções na amplitude da resposta, já que os insertos com maior contribuição foram mantidos. Evidentemente tal resultado refletiu num significativo aumento da densidade energética em função da massa de material piezelétrico.

Por fim, comparando-se os resultados das configurações com as vigas completamente recobertas, proposta por Erturk, com a última configuração proposta utilizando o recobrimento que apresentou melhores resultados de potência gerada (\#Figuras 137 e 138), foi possível verificar um significativo aumento na máxima potência gerada, chegando a 2,1 vezes, mesmo com redução de quase $50 \%$ na quantidade material piezelétrico utilizado, impactando num grande aumento da densidade energética tanto em função da massa do gerador (2,1vezes) como em função da massa de material piezelétrico (4,25 vezes).

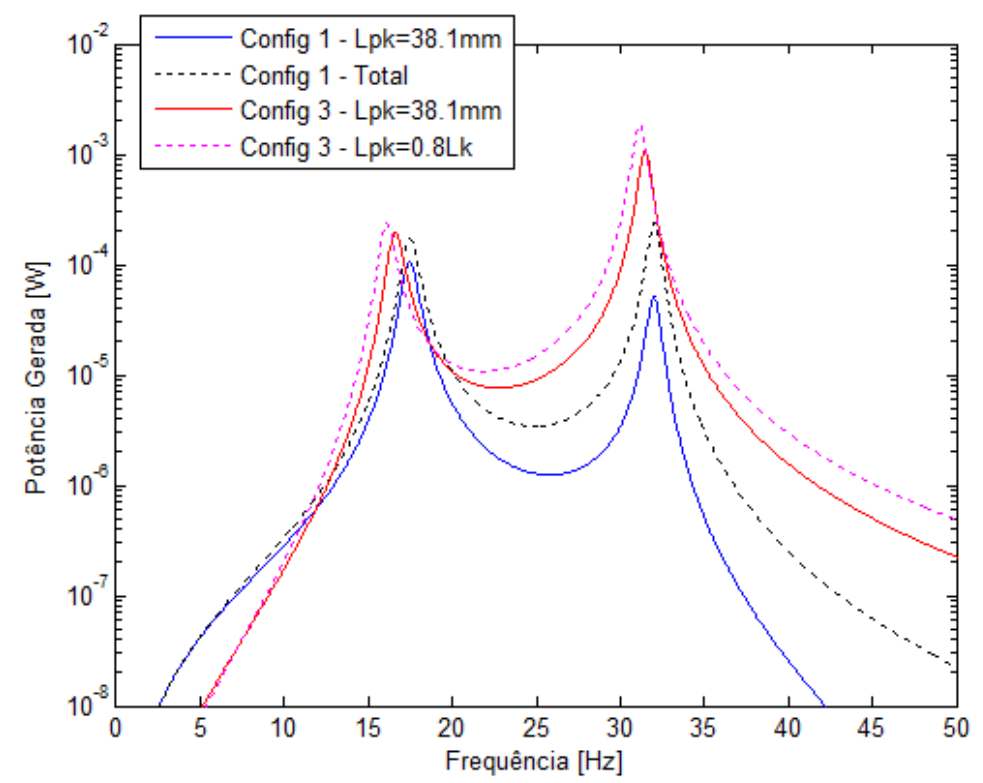

Figura 137 - Potência gerada na resistência elétrica para as configurações 1 com insertos de 38,1 mm (azul) e com recobrimento total (preto), ambos com cancelamento no segundo modo, e configurações 3 com insertos de $38,1 \mathrm{~mm}$ (vermelho) e recobrimento de $80 \%$ de $\mathfrak{R}_{2}$ (magenta) otimizados para o primeiro modo. 


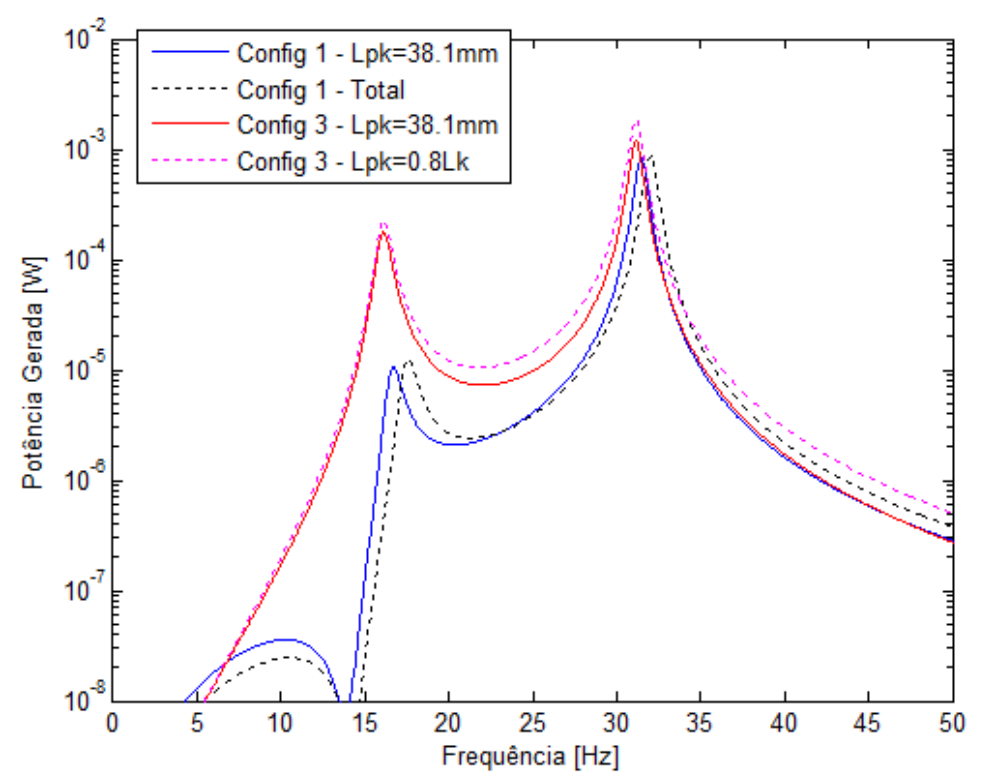

Figura 138 - Potência gerada na resistência elétrica para as configurações 1 com insertos de 38,1mm (azul) e com recobrimento total (preto), ambos com cancelamento no primeiro modo, e configurações 3 com insertos de $38,1 \mathrm{~mm}$ (vermelho) e recobrimento de $80 \%$ de $\mathfrak{R}_{2}$ (magenta) otimizados para o segundo modo. 


\section{Ensaios Experimentais}

Com o intuito de se validar os modelos matemáticos utilizados para conduzir a otimização do gerador tipo viga-L, foram realizados ensaios em laboratório utilizando um protótipo do dispositivo, permitindo a verificação dos resultados de tensão e potência gerada para as três configurações discutidas ao longo do capítulo 3.

Primeiramente são apresentados os equipamentos e procedimentos utilizados na realização dos ensaios e medições, seguidos dos resultados obtidos para as diferentes configurações avaliadas. Posteriormente estes resultados são comparados àqueles obtidos nas simulações numéricas, com uma breve discussão ao final, onde são pontuadas as divergências e semelhanças encontradas, concluindo a validação do modelo matemático.

\subsection{Materiais e Métodos}

O protótipo do gerador do tipo viga-L foi construído utilizando uma estrutura em aço SAE1070, com blocos em alumínio para representação das massas $M_{1}$ e $M_{2}$, e vinculação da viga 2 na viga 1 . Foram utilizados quatro insertos piezelétricos MIDE QP16N, sendo um posicionado no inicio da viga 1 , e os demais na viga dois, com dois insertos no inicio de $\mathfrak{R}_{2}$, configurando uma montagem bimorph, e um no início de $\mathfrak{R}_{3}$, para $\mathrm{M}_{2}$ posicionada no centro da segunda viga. Os insertos foram ligados em série conforme cada configuração estudada, utilizando uma década resistiva para representação da resistência elétrica.

As solicitações foram aplicadas através de um excitador eletrodinâmico modelo Brüel \& Kjaer 4810, com medição das respostas de tensão nos polos da década resistiva, e aceleração na fixação do gerador, aquisitadas com o auxílio de um analisador espectral DP Quattro. Foram realizadas também medições de transmissibilidade nas massas $M_{1}$ e $M_{2}$ para verificação da resposta mecânica do conjunto.

Para cada configuração foram testados três valores de resistência elétrica, $100 \mathrm{k} \Omega$, $500 \mathrm{k} \Omega$ e $1 \mathrm{M} \Omega$, e nas configurações 1 e 2 , verificadas montagens com cancelamento no primeiro e segundo modo de vibrar.

Em todas as medições foram utilizadas excitações aleatórias, com duração de 3,2s e frequências até $500 \mathrm{~Hz}$. A aquisição dos dados foi realizada a $1,28 \mathrm{kHz}$, e para o cálculo do 
espectro das respostas foi utilizado um janelamento Hanning, com 50 a 90 repetições para o cálculo da média.

Tabela 24 - Parâmetros do protótipo da viga-L e do modelo ajustado pela FRF de transmissibilidade medida em $M_{1}$ e $M_{2}$.

\begin{tabular}{cccc}
\hline \multicolumn{4}{c}{ Parâmetros - Protótipo da Viga "L" } \\
\hline Parâmetro & Protótipo & Modelo Ajustado & Unidade \\
\hline$L_{1}$ & 192 & 192 & $\mathrm{~mm}$ \\
$L_{2}+L_{3}$ & 182 & 182 & $\mathrm{~mm}$ \\
$M_{1}$ & 71 & $\mathbf{8 5}$ & $\mathrm{g}$ \\
$M_{2}$ & 38 & 38 & $\mathrm{~g}$ \\
$\rho_{s}$ & 7870 & 7870 & $\mathrm{~kg} / \mathrm{m}^{3}$ \\
$\rho_{p}$ & 7800 & 7800 & $\mathrm{~kg} / \mathrm{m}^{3}$ \\
$h_{s 1}$ & 2,65 & $\mathbf{2 , 5}$ & $\mathrm{mm}$ \\
$h_{s 2}$ & 1,59 & $\mathbf{1 , 6 5}$ & $\mathrm{mm}$ \\
$h_{p}$ & $3 \times 10^{-2}$ & $3 \times 10^{-2}$ & $\mathrm{~mm}$ \\
$b_{s}$ & 25 & 25 & $\mathrm{~mm}$ \\
$b_{p}$ & 20,6 & 20,6 & $\mathrm{~mm}$ \\
$Y_{s}$ & 207 & 207 & $\mathrm{GPa}$ \\
$Y_{p}$ & 60,6 & 60,6 & $\mathrm{GPa}$ \\
$L o_{1}$ & 20 & 20 & $\mathrm{~mm}$ \\
$L o_{2}$ & 15 & 15 & $\mathrm{~mm}$ \\
$L o_{3}$ & 10 & 10 & $\mathrm{~mm}$ \\
$L p_{1} ; L p_{2} ; L p_{3}$ & 46 & 46 & $\mathrm{~mm}$ \\
$\zeta_{1}$ & 0,030 & 0,030 & - \\
$\zeta_{2}$ & 0,015 & $\mathbf{0 , 0 2}$ & - \\
\hline
\end{tabular}

Tabela 25 - Propriedades dos insertos piezelétricos utilizadas nos modelos com parâmetros uniformes, e ajustados de acordo com os dados medidos, em que $\Re_{2 \mathrm{a}}$ e $\Re_{2 \mathrm{~b}}$ correspondem aos insertos que configuram a montagem bimorph de $\Re_{2}$, sendo $\Re_{2 \mathrm{a}} \mathrm{o}$ inserto utilizado também na configuração 1.

\begin{tabular}{ccccc}
\hline \multicolumn{5}{c}{ Propriedades dos Insertos Piezelétricos } \\
\hline Parâmetro & Segmento & Parâmetros Uniformes & Parâmetros Ajustados & Unidade \\
\hline \multirow{3}{*}{$\mathrm{d}_{31}$} & $\Re_{1}$ & & $-140,7 \times 10^{-12}$ & \\
& $\Re_{2 \mathrm{a}}$ & $-140,7 \times 10^{-12}$ & $-31,67 \times 10^{-12}$ & $\mathrm{C} / \mathrm{N}$ \\
& $\Re_{2 \mathrm{~b}}$ & & $-34,2 \times 10^{-12}$ & \\
& $\Re_{3}$ & & $-135,7 \times 10^{-12}$ & \\
\hline
\end{tabular}


Tabela 26 - Capacitâncias medidas nos insertos e valores de permissividade dielétrica utilizados no modelo ajustado.

\begin{tabular}{cccc}
\hline & Segmento & $\begin{array}{c}\text { Parâmetro ajustado } \\
{[\mathbf{F} / \mathbf{m}]}\end{array}$ & $\begin{array}{c}\text { Capacitância Medida } \\
{[\mathbf{n F}]}\end{array}$ \\
\cline { 2 - 4 } & $\Re_{1}$ & $3,49 \times 10^{-9}$ & 110 \\
$\varepsilon_{33}^{S}$ & $\mathfrak{R}_{2 \mathrm{a}}$ & $2,95 \times 10^{-9}$ & 95 \\
& $\mathfrak{R}_{2 \mathrm{~b}}$ & $2,95 \times 10^{-9}$ & 90 \\
& $\mathfrak{R}_{3}$ & $2,95 \times 10^{-9}$ & 93 \\
\hline
\end{tabular}

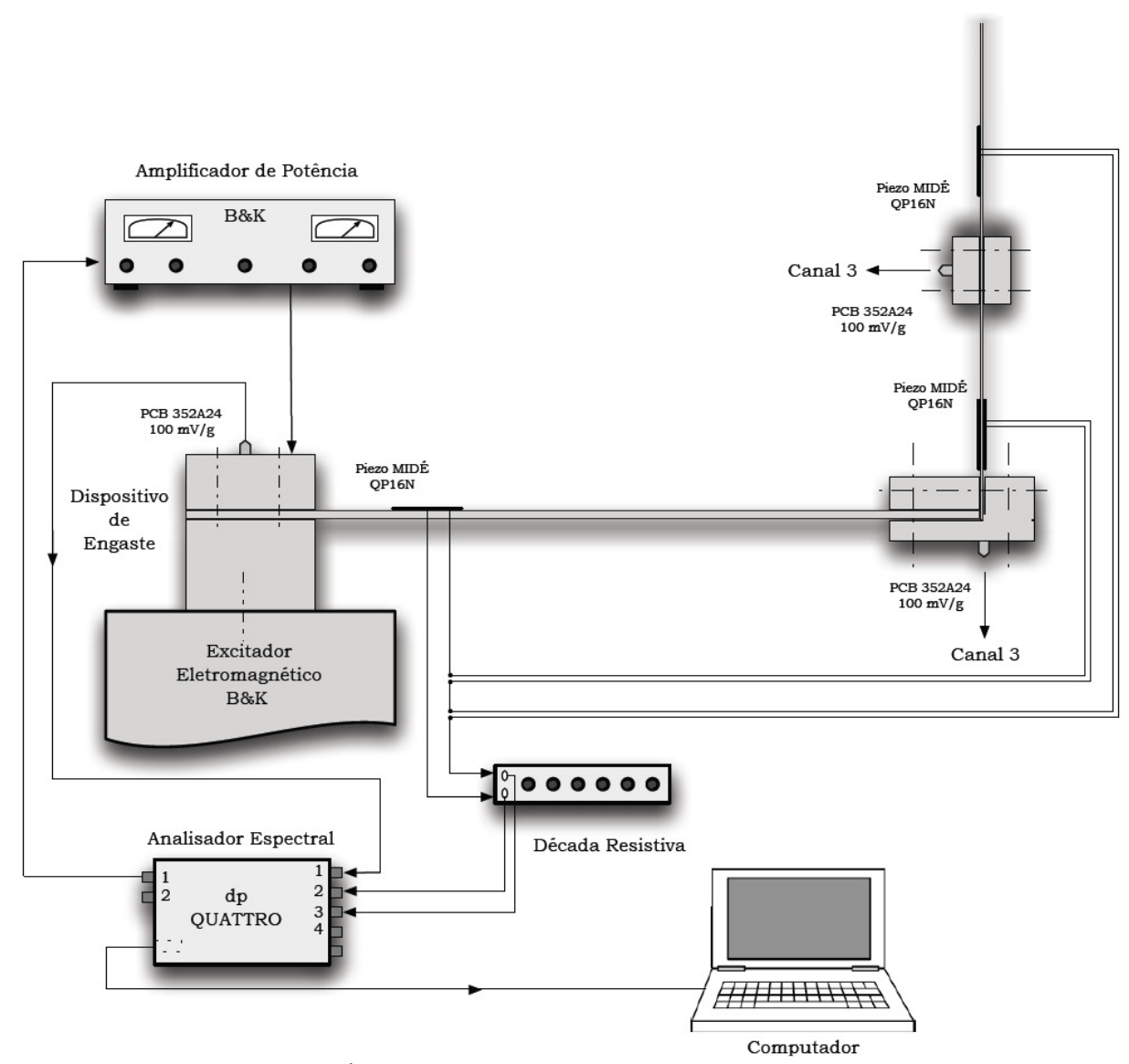

Figura 139 - Esquemático do arranjo utilizado para os ensaios experimentais.
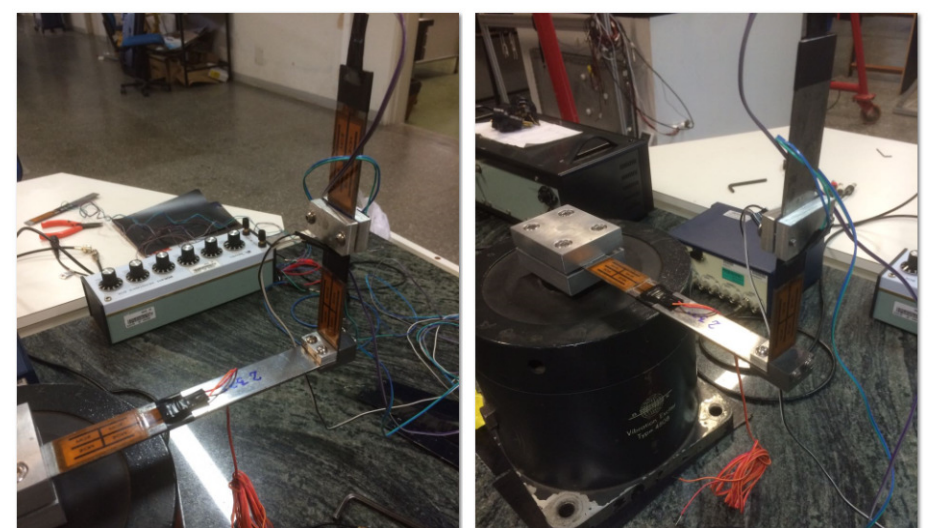

Figura 140 - Montagem do protótipo do gerador piezelétrico para realização dos ensaios experimentais. 


\subsection{Resultados Experimentais}

Confrontando-se os resultados obtidos para diferentes resistências elétricas de uma mesma configuração (\#Figura 141) é possível observar que a sensibilidade da resposta obtida experimentalmente é essencialmente a mesma daquela encontrada nos modelos matemáticos, em que o aumento da resistência associada ao circuito induz o aumento das tensões geradas, mas com incrementos cada vez menores. No caso da potência, observa-se também a existência de um ponto de máxima eficiência, verificada diretamente nos resultados das configurações cujas respostas obtidas com as resistências de $100 \mathrm{k} \Omega$ e $1 \mathrm{M} \Omega$ se mostraram inferiores aos da configuração $\operatorname{com} 500 \mathrm{k} \Omega$, e indiretamente nos casos em que a máxima potência ocorre usando a resistência de $100 \mathrm{k} \Omega$, cujo aumento de tensão devido ao aumento da resistência não reflete num aumento de potência gerada.

No caso das FRFs das configurações 1 e 2 nota-se perfis diferentes daqueles encontrados nos modelos matemáticos. No caso do cancelamento no primeiro modo, são observadas diferentes proporções entre os picos de resposta nas ressonâncias, além de um evidente deslocamento da região de antirressonância. Já com o cancelamento no segundo modo, nota-se uma diminuição bem mais acentuada das amplitudes de resposta nos arredores deste.

Ao se confrontar as respostas das três configurações (\#Figura 142), observa-se que a configuração 2 apresenta amplitudes de resposta superiores aos da configuração 1, conforme previsto nas simulações numéricas. No entanto, ao se comparar os resultados medidos para a configuração 3, verifica-se uma redução na máxima energia gerada, contradizendo os resultados esperados. 
a)
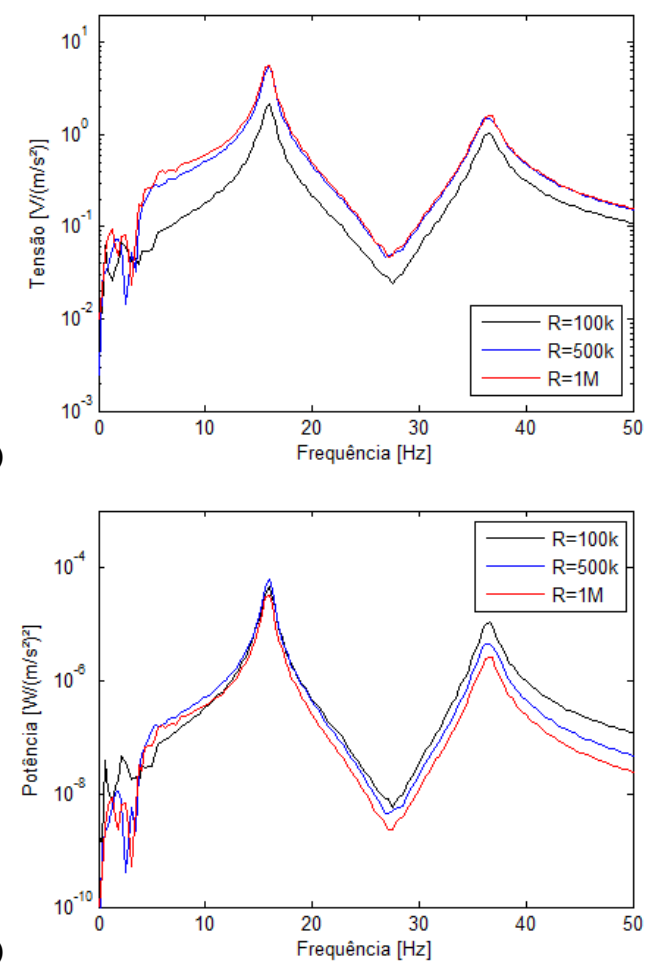

c)

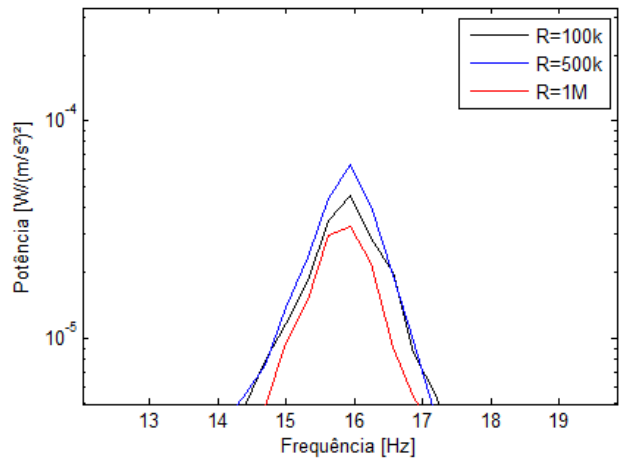

b)

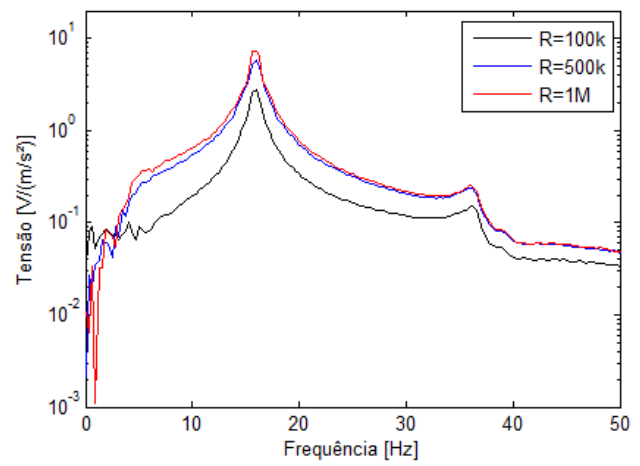

d)

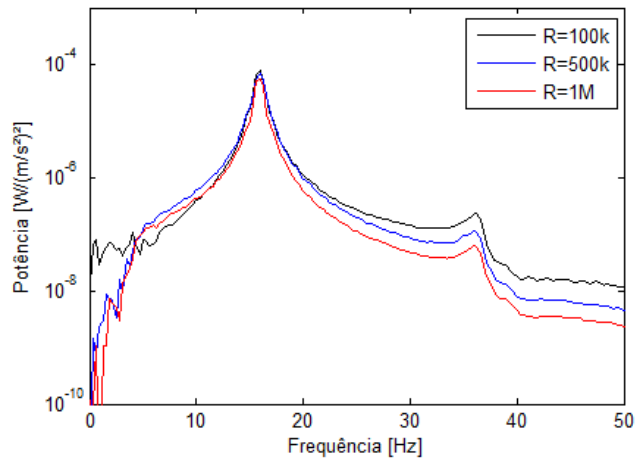

f)

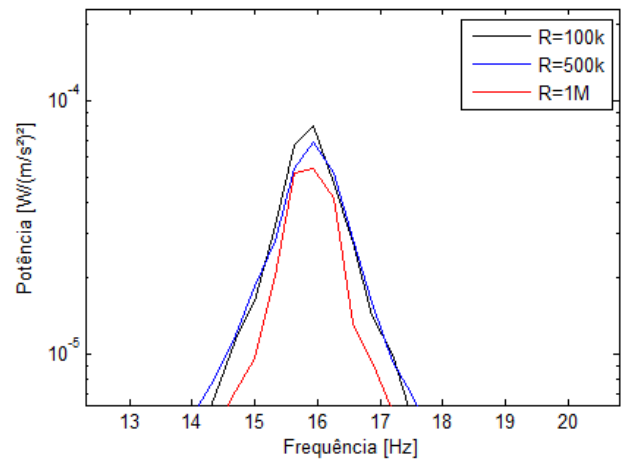

Figura 141 -FRFs de tensão e potência geradas medidas para o gerador na configuração 1 usando diferentes resistências, sendo (a) e (b) as tensões geradas, (c) e (d) as potências geradas, e (e) e (f) o pico de potência gerada no primeiro modo, com cancelamentos no primeiro e segundo modo respectivamente.
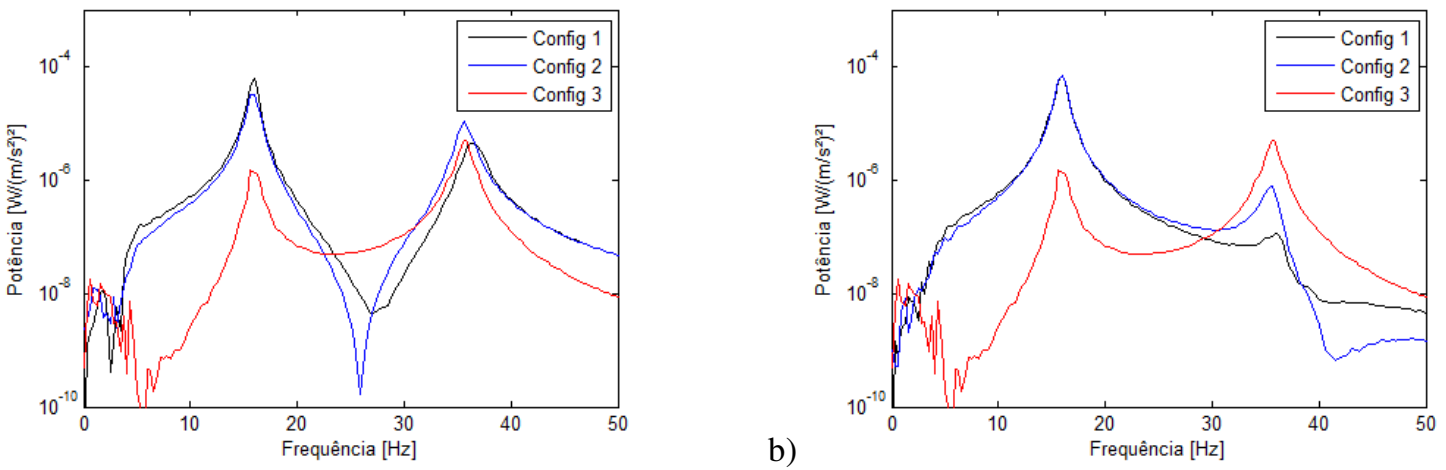

Figura 142 -FRFs de potência gerada medidas para as configurações 1, 2 e 3 do gerador tipo viga $L$, com resistência de $500 \mathrm{k} \Omega$ e cancelamentos (a) no primeiro e (b) segundo modo. 


\subsection{Verificação do Modelo Matemático}

Primeiramente, comparando-se as respostas mecânicas medidas e simuladas foi possível ajustar os parâmetros da estrutura do gerador utilizados no modelo matemático da viga-L, dispostos na tabela 24 , obtendo-se grande conformidade das respostas simuladas com aquelas medidas, verificando a validade da solução teórica adotada para o calculo dos autovetores e frequências naturais, bem como para a resposta mecânica forçada (\#Figura 143).

A partir deste modelo, com resposta mecânica ajustada, foram adequados os parâmetros dos insertos piezelétricos conforme o datasheet do fabricante para obtenção das respostas de tensão e potência geradas, $\operatorname{com} \varepsilon_{33}^{\mathrm{S}}$ ajustado de acordo com as capacitâncias medidas em cada inserto.

Confrontando-se os resultados simulados e experimentais fica bastante evidente a divergência entre os perfis das FRFs conforme comentado anteriormente. Apesar de as frequências naturais serem coincidentes, há diferenças bastante acentuadas nas amplitudes dos modos em que ocorrem os cancelamentos para as configurações 1 e 2 . No caso da configuração 3, apesar de o perfil das FRFs serem muito semelhantes, foram observadas para os dados medidos amplitudes reduzidas ao longo de toda a faixa de frequência avaliada.

Tendo em vista essas divergências, utilizou-se os resultados da configuração 3 para ajustar a resposta dos insertos do início da segunda viga variando-se apenas a propriedade $\mathrm{d}_{31}$ como forma de representar o acoplamento eletromecânico reduzido observado. Uma correlação muito boa foi encontrada assumindo-se um valor aproximadamente 4,5 vezes menor para P2 e P3, conforme evidenciado na figura 148c.

Adotando esse valor ajustado para as demais configurações do gerador, foram obtidas respostas bastante coerentes, com fiel representação das amplitudes e perfis das FRFs, além das variações relativas às diferentes resistências elétricas e cancelamentos (\#Figuras 144 a 148).

Para todos os resultados definiu-se o erro relativo $\operatorname{Er}(\omega)$ entre os dados simulados e medidos conforme a equação (109), em que $Z_{\text {sim }}$ e $Z_{\text {med }}$ correspondem às amplitudes das FRFs simuladas e medidas.

$$
\operatorname{Er}(\omega)=\frac{Z_{\text {med }}(\omega)-Z_{\text {sim }}(\omega)}{Z_{\text {med }}(\omega)}
$$



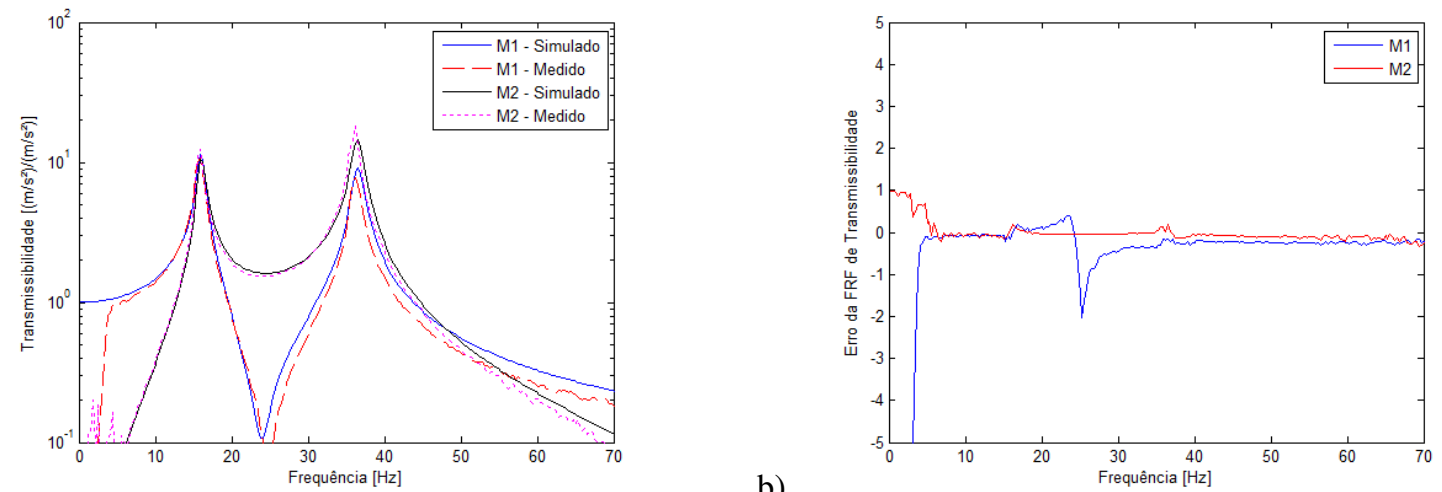

a)

Figura 143 - Resultados simulados e medidos em M1 e M2, sendo (a) a transmissibilidade na direção transversal para M1 e M2, e (b) o erro relativo entre os resultados simulados e medidos.

a)

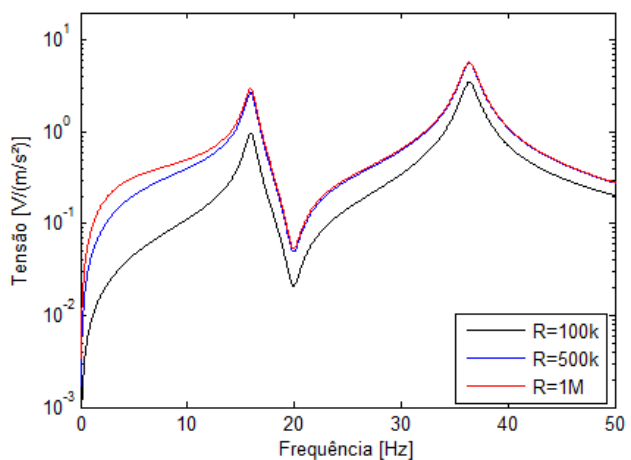

c)

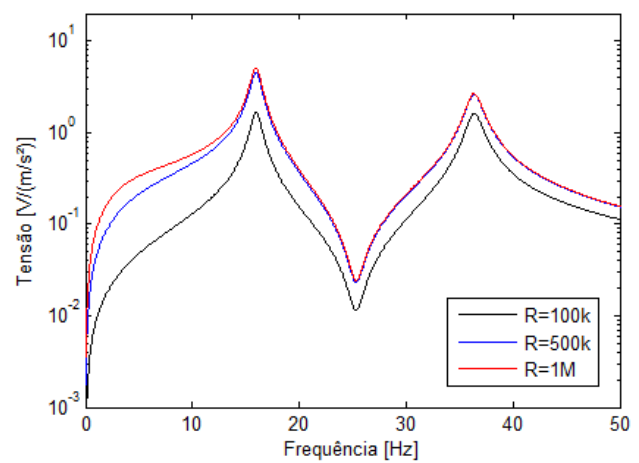

e)

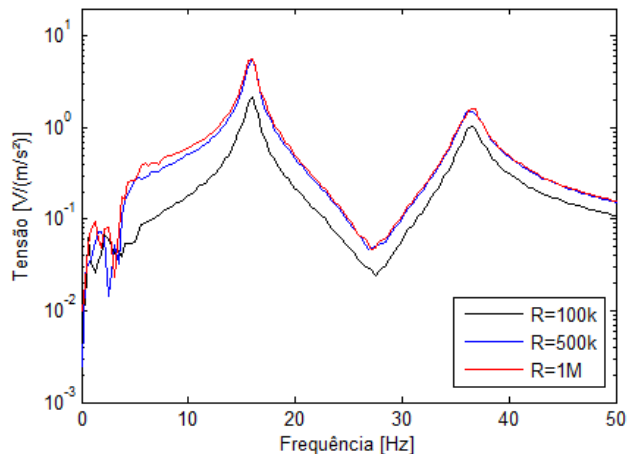

b)

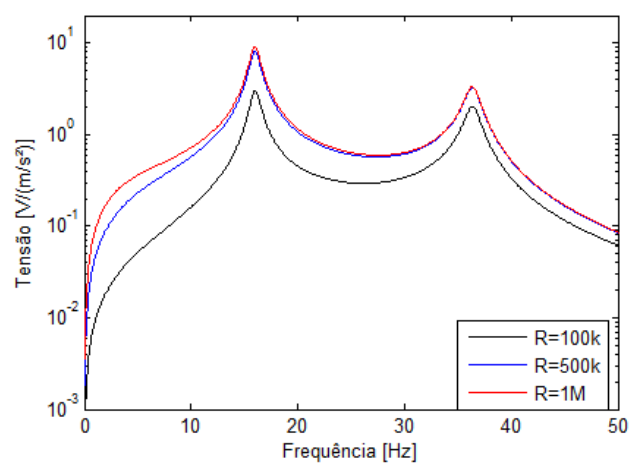

d)
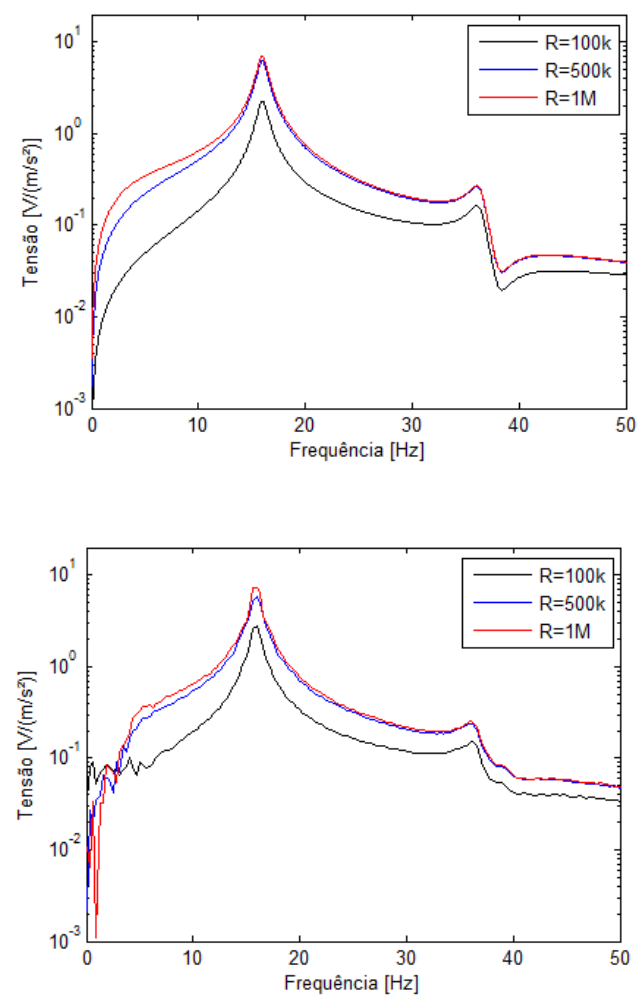

Figura 144 - FRF de tensão na resistência para a Configuração 1, sendo: (a) e (b) as respostas simuladas para insertos com propriedades iguais, (c) e (d) as respostas simuladas para insertos com propriedades ajustadas, (e) e (f) resultados medidos, com cancelamentos no primeiro e segundo modo respectivamente. 
a)

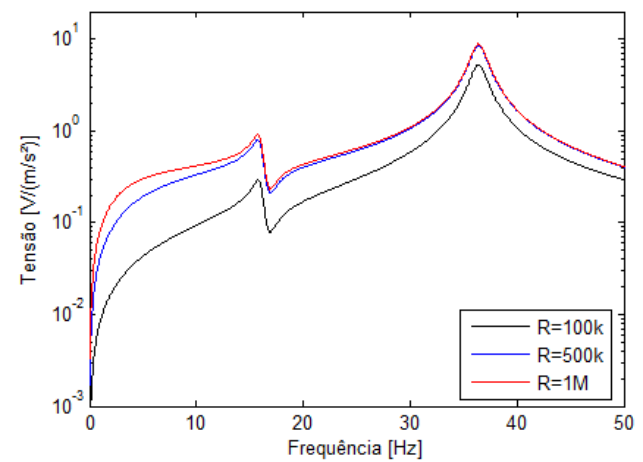

c)

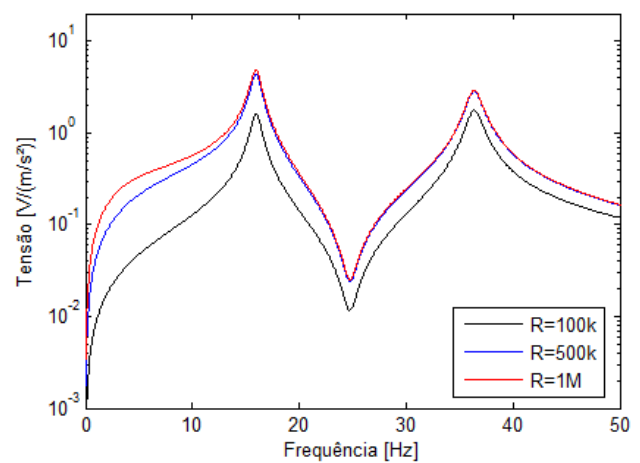

e)

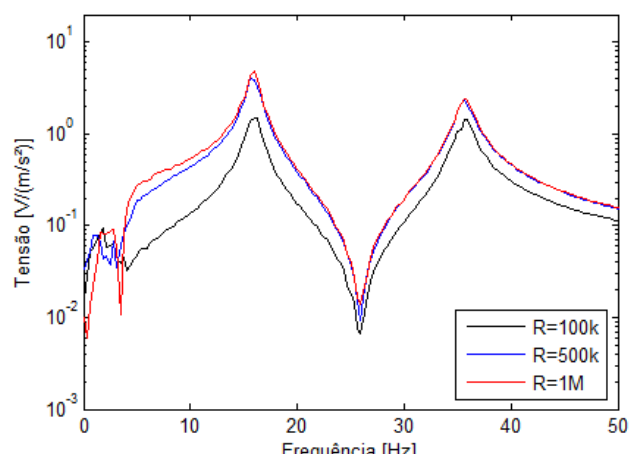

b)

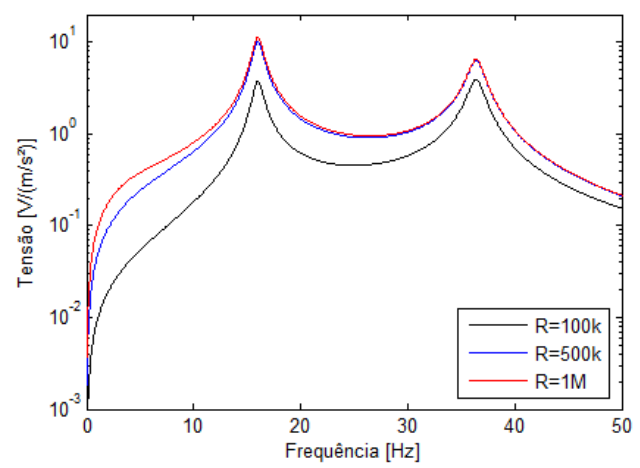

d)
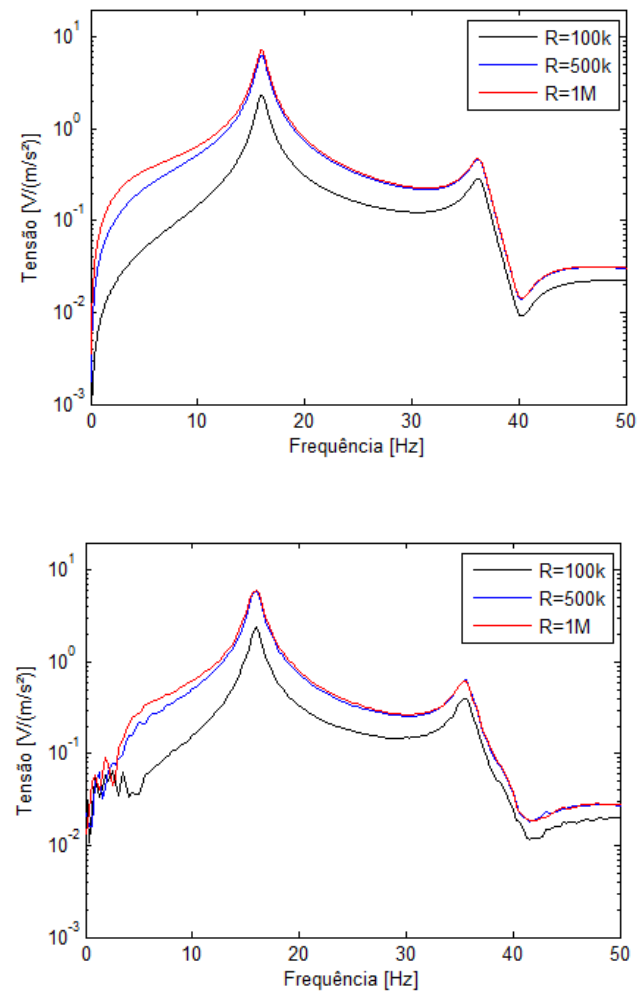

Figura 145 - FRF de tensão na resistência para a Configuração 2, sendo: (a) e (b) as respostas simuladas para insertos com propriedades iguais, (c) e (d) as respostas simuladas para insertos com propriedades ajustadas, (e) e (f) resultados medidos, com cancelamentos no primeiro e segundo modo respectivamente 
a)
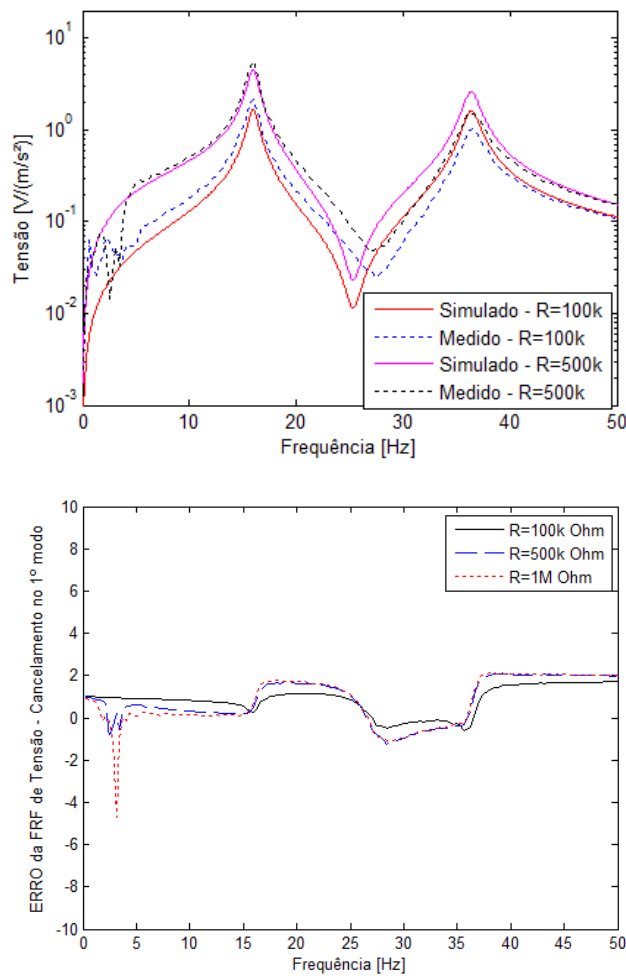

Figura 146 - Resultados simulados e medidos para a configuração 1, sendo (a) e (b) as FRFs de tensão na resistência, e (c) e (d) os erros relativos entre os resultados simulados e medidos, com cancelamento no primeiro e segundo modo respectivamente.

a)
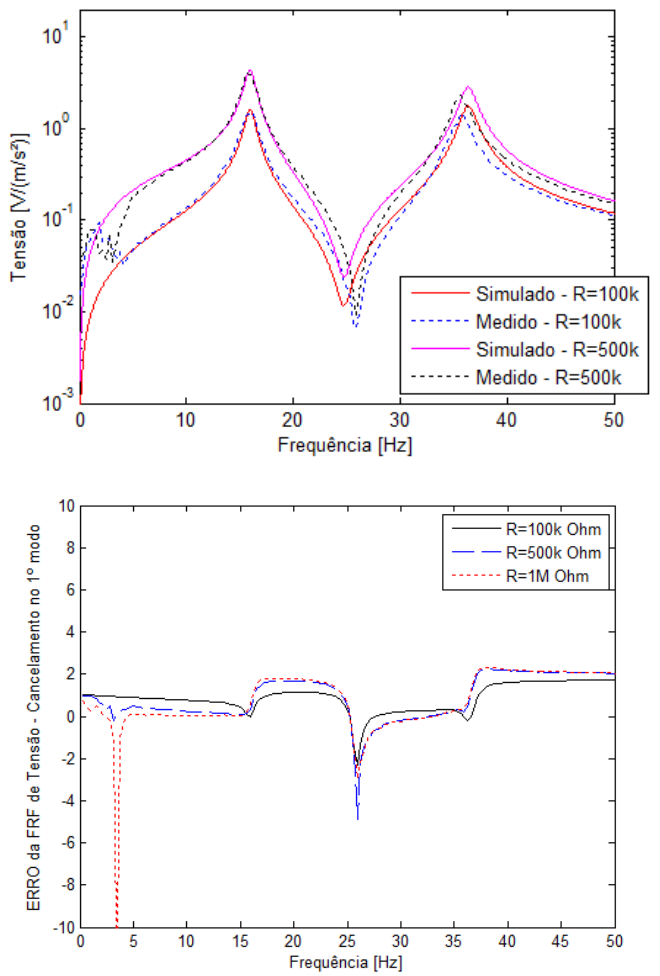

c)

Figura 147 - Resultados simulados e medidos para a configuração 2, sendo (a) e (b) as FRFs de tensão na resistência, e (c) e (d) os erros relativos entre os resultados simulados e medidos, com cancelamento no primeiro e segundo modo respectivamente. b)
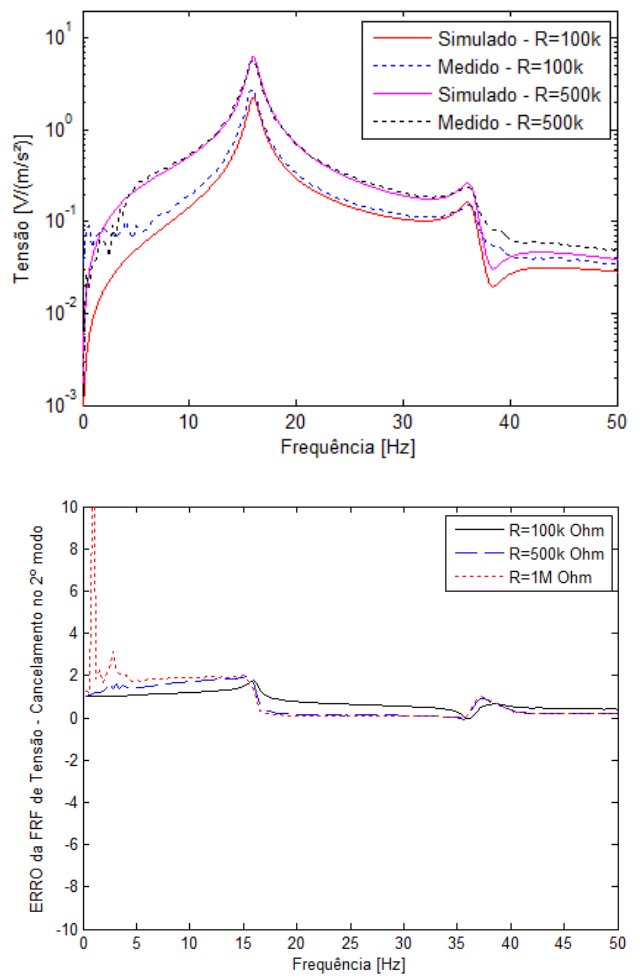

b)
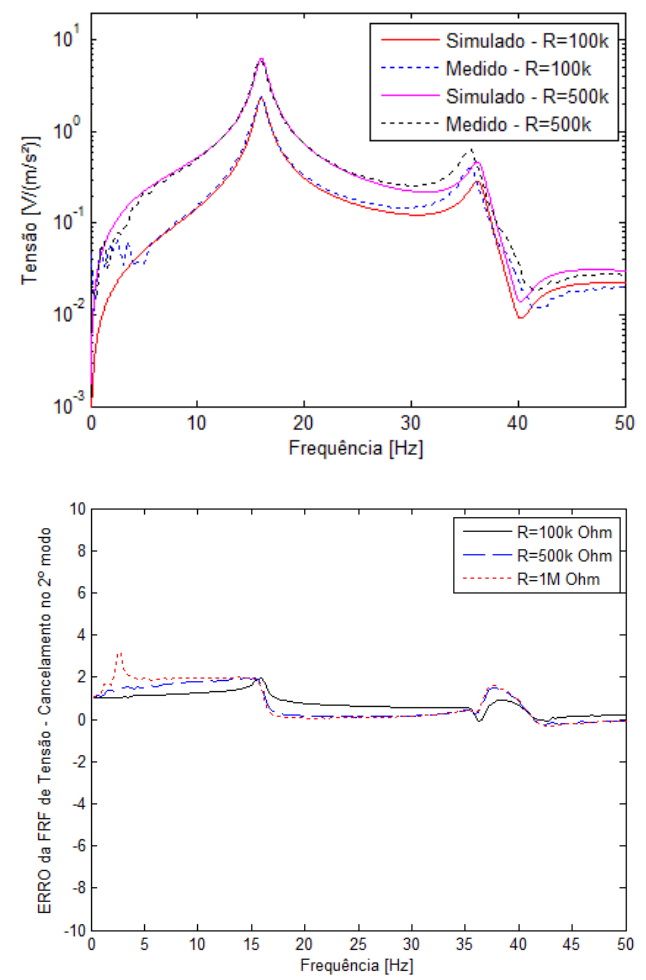

d)

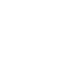




\subsection{Discussão}

Confrontando-se os resultados experimentais e simulados foram observadas significativas divergências quando adotados parâmetros iguais para todos os insertos piezelétricos, enquanto ao se corrigir as propriedades dos insertos do início da segunda viga, os modelos das três configurações passaram a apresentar ótima correlação com os dados medidos.

Apesar destas divergências, nota-se que em todos os resultados ficaram muito bem representados os fenômenos de cancelamento entre os insertos, bem como a sensibilidade das respostas de tensão e potência ao valor de resistência elétrica associada.

Diante de tal contexto, é importante ressaltar que o caráter artesanal da fabricação d o protótipo do gerador, especialmente do processo de colagem dos insertos piezelétricos, pode ter sido o principal responsável pelas divergências encontradas nos resultados. A escala de utilização do adesivo não favorece a repetibilidade do processo de colagem, uma vez que a proporção dos reagentes que o compõe fica bastante suscetível à precisão do equipamento disponível para sua manipulação. Como as vigas foram confeccionadas em etapas distintas, não se pode garantir que a composição do adesivo seja as mesmas em todos os casos, e desse modo, as propriedades mecânicas e até mesmo uniformidade da camada de adesivo são questionáveis, cuja rigidez local pode interferir diretamente nas deformações às quais os insertos são efetivamente submetidos, refletindo num acoplamento eletromecânico aparentemente reduzido.

Por fim, como foram confrontados diferentes casos, contemplando cancelamentos em modos alternados, além de três diferentes resistências para três configurações distintas do gerador, pode-se dizer que um modelo matemático não representativo exigiria diferentes parâmetros de ajuste para cada caso. Para o modelo teórico desenvolvido neste trabalho, utilizando-se de um único setup de parâmetros, em que foi assumido um acoplamento eletromecânico reduzido para os insertos da segunda viga, foi possível representar satisfatoriamente todos os fenômenos medidos, e por isso entende-se que este modelo pode ser considerado representativo, e dito verificado pelos experimentos conduzidos. 
a)
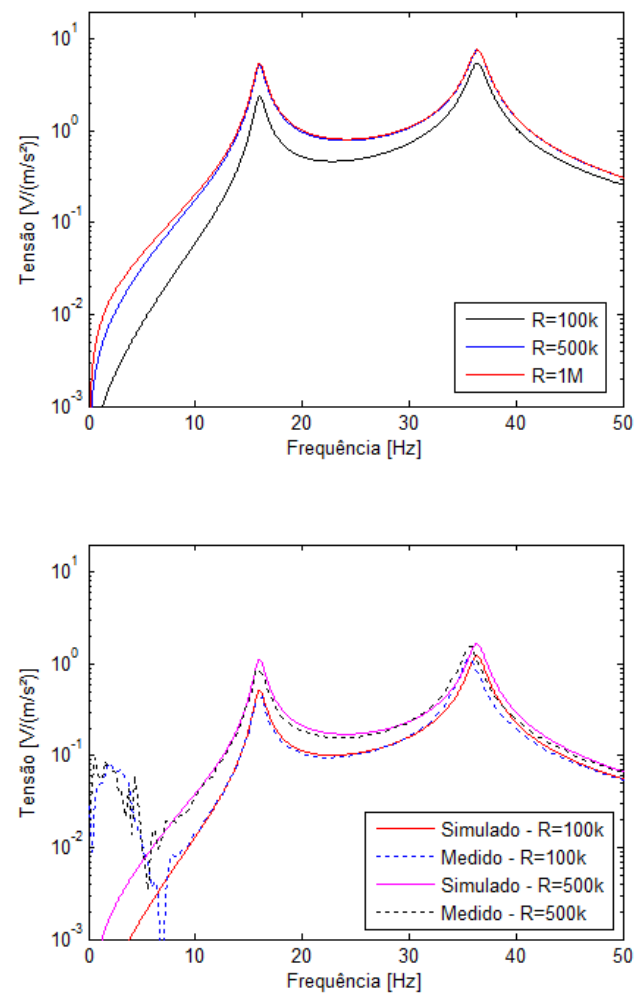

c)

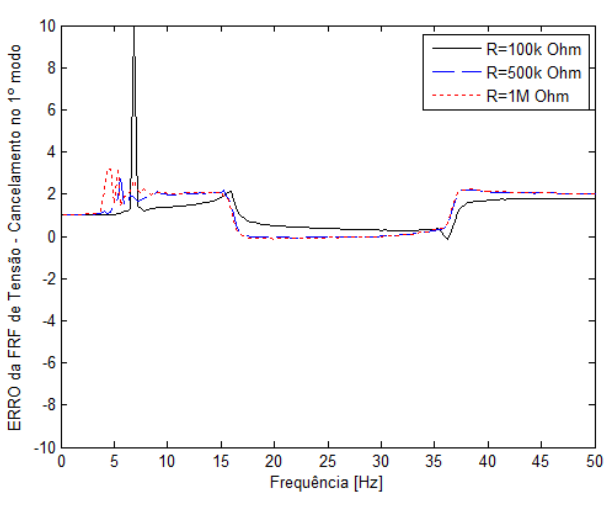

e) b)

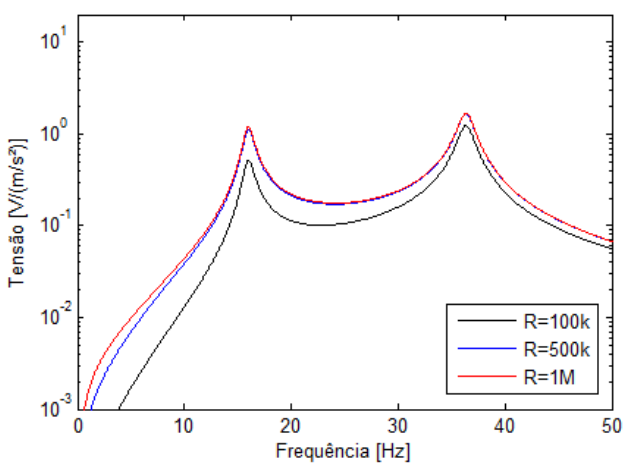

d)

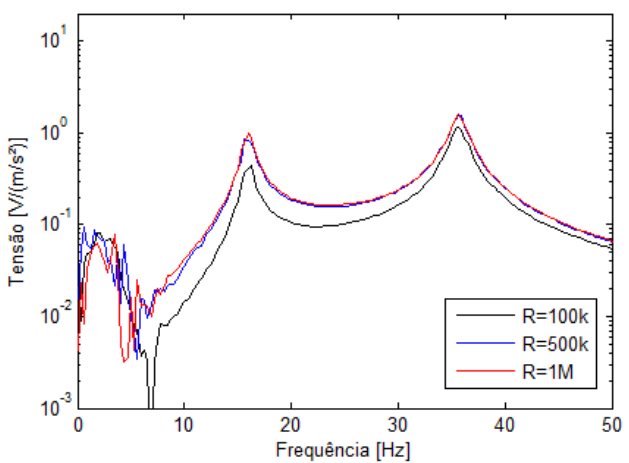

Figura 148 -FRF de tensão na resistência para a Configuração 3, sendo: (a) as respostas simuladas para insertos com propriedades iguais, (b) as respostas simuladas para insertos com propriedades ajustadas, (c) os resultados medidos, (d) os resultados medidos e simulados confrontados, e (e) o erro relativo entre os resultados simulados e medidos. 


\section{Conclusão e Trabalhos Futuros}

\subsection{Conclusão}

Ao longo deste trabalho foram estudadas várias configurações de energy harvesters com foco no uso dos múltiplos graus de liberdade tanto para maximização da energia gerada, como para a ampliação da faixa de frequência útil do gerador. Foi discutida ainda a maximização da densidade energética do gerador em função da quantidade de material piezelétrico, fundamental na viabilização comercial dos geradores por estar diretamente relacionada ao custo dos dispositivos. Através de modelos computacionais, organizados em duas etapas distintas, foram ressaltados aspectos relevantes para o projeto de geradores piezelétricos, conforme sumarizados a seguir.

Primeiramente através de modelos simplificados, de parâmetros concentrados, foi possível verificar a aplicabilidade dos múltiplos graus de liberdade para otimização do gerador de duas maneiras distintas. Uma delas através da diminuição da primeira frequência natural do dispositivo, resultante da utilização de elementos de rigidez reduzida nos primeiros osciladores, com acentuado aumento da máxima potência gerada por estes, mas significativo estreitamento da faixa de frequência útil. Já em outra abordagem, o escalonamento da rigidez dos osciladores de forma decrescente da base para a extremidade possibilitou a aproximação das frequências naturais do sistema e maximização da resposta do último oscilador. Neste caso, apesar de não apresentar amplitudes de resposta tão superiores, o nivelamento da resposta nas diferentes frequências naturais permitiu o aumento da faixa de frequência útil do gerador, condição favorável no caso de excitações de natureza aleatória e larga banda de frequências.

Ainda através dos modelos de parâmetros concentrados, ficou evidente que o posicionamento do inserto piezelétrico pode não ser interessante em todos os osciladores, já que, dependendo de como são configurados, podem apresentar amplitudes de resposta muito discrepantes. Nestes casos, a alocação indiscriminada dos insertos pode resultar na subutilização de seu potencial, como demonstrado para o modelo de 2 GDL analisado, com significativa penalização da eficiência do dispositivo.

Além disso, a presença de anti-ressonâncias acentuadas nas respostas de todos os osciladores exceto o último evidencia neste uma condição mais favorável ao gerador nos arredores das ressonâncias. Nas altas frequências notou-se que o último oscilador apresenta 
resultados inferiores aos demais, mas sem grandes prejuízos ao dispositivo nos casos avaliados, já que nestas faixas de frequência mesmo os osciladores com melhores resultados apresentaram respostas muito aquém daquelas obtidas nas proximidades das ressonâncias, tendo pouca relevância nos resultados de potência gerada.

Sendo assim, dos modelos de parâmetros concentrados pode-se concluir que uma estratégia conveniente para a maximização da eficiência dos energy harvesters está aproveitar a natureza favorável da resposta do último oscilador, adotando para os elementos elásticos um escalonamento decrescente de modo a maximizá-la, facilitando a alocação do material piezelétrico de maneira concentrada no mesmo.

Na segunda etapa do estudo, fazendo uso de modelos de parâmetros concentrados baseados na viga de Euler-Bernoulli, foi avaliada uma estrutura construtiva com múltiplos graus de liberdade, a viga "L", através da qual se buscou a confirmação das premissas levantadas nos modelos de parâmetros concentrados.

Foi adotado para o gerador o escalonamento decrescente de rigidez das vigas, conforme os direcionamentos do modelo de parâmetros concentrados, cujos resultados obtidos indicaram conformidade com os conceitos estudados anteriormente. O perfil da resposta da segunda viga, correspondente ao último oscilador desta estrutura construtiva, reforçou a ausência das anti-ressonâncias entre as frequências naturais, diferentemente da primeira viga, além de maiores amplitudes de resposta, conforme esperado.

Ao contrário dos estudos com parâmetros concentrados, em que cada oscilador possuía um circuito elétrico independente, o uso de um circuito elétrico comum a todos os insertos no modelo de parâmetros concentrados trouxe uma série de novos aspectos ao estudo. Pode-se dizer que o fenômeno de cancelamento do potencial gerado, seja entre insertos, seja entre regiões do mesmo inserto, é um dos mais importantes. A existência desse fenômeno torna crítico ao projeto do gerador o completo conhecimento dos mode shapes da estrutura, tanto para utilizar adequadamente as regiões sujeitas a maiores deformações, e por isso de maior potencial de geração, como para evitar regiões contendo inflexões, responsáveis pelos cancelamentos no próprio inserto, além de configurações com deformações concorrentes entre os modos de vibrar, causadora dos cancelamentos entre insertos.

Comparando-se os resultados obtidos para o gerador otimizado, com uma adequada alocação do material piezelétrico, e minimização das ineficiências devido à subutilização de insertos e fenômenos de cancelamento, com os de um gerador com recobrimento total das superfícies ficou evidente que o aumento indiscriminado da quantidade de material 
piezelétrico pode não contribuir para o aumento da potência gerada, mas sim diminuí-la dependendo das circunstâncias. Com uma potência máxima 2,1 vezes maior utilizando apenas $50 \%$ do material piezelétrico para o caso citado, pode-se dizer que as premissas levantadas para a otimização do gerador puderam ser confirmadas.

Por fim, ao se reproduzir com os modelos matemáticos os resultados obtidos em ensaios experimentais usando um protótipo do gerador do tipo viga "L", foi possível comprovar a validade do conteúdo teórico desenvolvido ao longo do trabalho.

\subsection{Trabalhos Futuros}

Para dar continuidade ao estudo do uso de múltiplos graus de liberdade para aumentar a eficiência dos piezoelectric energy harvesters sugere-se o desenvolvimento de estruturas construtivas com mais que dois modos de vibrar representativos na faixa de frequência útil, através das quais seria possível confirmar a tendência notada entre os modelos de 2 e 3 GDL desenvolvidos utilizando modelos de parâmetros concentrados.

Sugere-se ainda o estudo da influência de diferentes estruturas construtivas com mesmo número de modos representativos no desempenho do gerador, já que se verificou neste trabalho que não somente a quantidade de graus de liberdade é relevante, mas os perfis dos modos de vibrar da estrutura também são mandatórios, podendo favorecer ou prejudicar significativamente o desempenho do gerador.

Por fim, pode-se dizer que há ainda oportunidades de pesquisa nos circuitos elétricos associados aos geradores, nos quais cabem estudos da relação custo-benefício do aumento de complexidade destes circuitos para aumentar a potência gerada, como pela eliminação dos efeitos de cancelamento, por exemplo. 


\section{Referências Bibliográficas}

ANTON, S. R.; INMAN, D. J. Vibration energy harvesting for unmanned aerial vehicles - art. no. 692824. Conference on Active and Passive Smart Structures and Integrated Systems, 2008, San Diego, CA. Spie-Int Soc Optical Engineering, Mar 10-13. p.92824-92824.

ANTON, S., SODANO, H., 2007. A Review of Power Harvesting Using Piezoelectric Materials (2003-2006), Smart Materials and Structures, Vol. 16, pp. 1-21.

BAKER J., ROUNDY S. WRIGHT P. Alternative Geometries for Increasing Power Densityin Vibration Energy Scavenging for Wireless Sensor Networks. $3^{\text {rd }}$ International Energy Conversion Engineering Conference 15 - 18 August 2005, San Francisco, California

BEEBY, S. P.; TUDOR, M. J.; WHITE, N. M. Energy harvesting vibration sources for microsystems applications. Measurement Science \& Technology, v. 17, n. 12, p. R175-R195, Dec 2006.

CALIO, R. et al. Piezoelectric Energy Harvesting Solutions. Sensors, v. 14, n. 3, p. 47554790, Mar 2014.

CAO, D. X.; ZHANG, W.; YAO, M. H. Analytical and experimental studies on nonlinear characteristics of an L-shape beam structure. Acta Mechanica Sinica, v. 26, n. 6, p. 967-976, Dec 2010.

COTTONE, F. et al. Piezoelectric buckled beams for random vibration energy harvesting. Smart Materials and Structures, v. 21, n. 3, p. 11, Mar 2012

DAQAQ, M. F. et al. On the Role of Nonlinearities in Vibratory Energy Harvesting: A Critical Review and Discussion. Applied Mechanics Reviews, v. 66, n. 4, p. 23, Jul 2014.

DUTOIT, N. E.; WARDLE, B. L.; KIM, S. G. Design considerations for MEMS-scale piezoelectric mechanical vibration energy harvesters. Integrated Ferroelectrics, v. 71, p. 121- 
160, 2005. ISSN 1058-4587. Disponível em: \&lt; \&lt;Go to ISI\&gt;://WOS:000231149200013 \&gt;.

ERTURK, A.; HOFFMANN, J.; INMAN, D. J. A piezomagnetoelastic structure for broadband vibration energy harvesting. Applied Physics Letters, v. 94, n. 25, p. 3, Jun 2009.

ERTURK, A.; INMAN, D. J. A distributed parameter electromechanical model for cantilevered piezoelectric energy harvesters. Journal of Vibration and Acoustics-Transactions of the Asme, v. 130, n. 4, p. 15, Aug 2008a.

Issues in mathematical modeling of piezoelectric energy harvesters. Smart Materials \& Structures, v. 17, n. 6, p. 14, Dec 2008b.

On Mechanical Modeling of Cantilevered Piezoelectric Vibration Energy Harvesters. Journal of Intelligent Material Systems and Structures, v. 19, n. 11, p. 1311-1325, Nov 2008c.

An experimentally validated bimorph cantilever model for piezoelectric energy harvesting from base excitations. Smart Materials \& Structures, v. 18, n. 2, Feb 2009. ISSN 0964-1726

ERTURK, A.; RENNO, J. M.; INMAN, D. J. Modeling of Piezoelectric Energy Harvesting from an L-shaped Beam-mass Structure with an Application to UAVs. Journal of Intelligent Material Systems and Structures, v. 20, n. 5, p. 529-544, Mar 2009.

FERRARI, M. et al. Improved energy harvesting from wideband vibrations by nonlinear piezoelectric converters. Sensors and Actuators A: Physical, v. 162, n. 2, p. 425-431, 8// 2010 .

GOLDSCHMIDTBOEING, F.; WOIAS, P. Characterization of different beam shapes for piezoelectric energy harvesting. Journal of Micromechanics and Microengineering, v. 18, $\mathrm{n}$. 10, p. 7, Oct 2008. 
IBRAHIM, S. W.; ALI, W. G. A review on frequency tuning methods for piezoelectric energy harvesting systems. Journal of Renewable and Sustainable Energy, v. 4, n. 6, p. 29, Nov 2012.

JEON, Y. B. et al. MEMS power generator with transverse mode thin film PZT. Sensors and Actuators a-Physical, v. 122, n. 1, p. 16-22, Jul 2005. ISSN 0924-4247. Disponível em: \&lt; \&lt;Go to ISI\&gt;://WOS:000231170900003 \&gt;

KIM, H. S.; KIM, J. H.; KIM, J. A Review of Piezoelectric Energy Harvesting Based on Vibration. International Journal of Precision Engineering and Manufacturing, v. 12, n. 6, p. 1129-1141, Dec 2011.

KIM, I. H. et al. Broadband energy-harvesting using a two degree-of-freedom vibrating body. Applied Physics Letters, v. 98, n. 21, p. 3, May 2011.

KLUGER, J. M.; SAPSIS, T. P.; SLOCUM, A. H. Robust energy harvesting from walking vibrations by means of nonlinear cantilever beams. Journal of Sound and Vibration, v. 341, n. 0, p. 174-194, 4/14/ 2015.

LEO, D. Engineering Analysis of Smart Materials Systems, John Wiley \& Sons, NY, 2007.

LI, H. D.; TIAN, C.; DENG, Z. D. Energy harvesting from low frequency applications using piezoelectric materials. Applied Physics Reviews, v. 1, n. 4, p. 20, Dec 2014.

LIN, J. T.; ALPHENAAR, B. Enhancement of Energy Harvested from a Random Vibration Source by Magnetic Coupling of a Piezoelectric Cantilever. Journal of Intelligent Material Systems and Structures, v. 21, n. 13, p. 1337-1341, Sep 2010.

LU F, LEE H AND LIM S. Modeling and analysis of micro piezoelectric power generators for micro-electromechanical-systems applications Smart Material and Structures. v.13, p. 5763, 2004.

MANN, B. P.; OWENS, B. A. Investigations of a nonlinear energy harvester with a bistable potential well. Journal of Sound and Vibration, v. 329, n. 9, p. 1215-1226, Apr 2010. 
RAO, S.S. Vibration of Continuous Systems, Wiley, New York, 2007.

ROUNDY, S.; WRIGHT, P. K.; RABAEY, J. A study of low level vibrations as a power source for wireless sensor nodes. Computer Communications, v. 26, n. 11, p. 1131-1144, 7/1/ 2003.

ROUNDY, S.; ZHANG, Y. Toward self-tuning adaptive vibration based micro-generators. Conference on Smart Structures, Devices, and Systems II, 2004, Sydney, AUSTRALIA. SpieInt Soc Optical Engineering, Dec 13-15. p.373-384.

SADEQI, S.; ARZANPOUR, S.; HAJIKOLAEI, K. H. Broadening the Frequency Bandwidth of a Tire-Embedded Piezoelectric-Based Energy Harvesting System Using Coupled Linear Resonating Structure. Mechatronics, IEEE/ASME Transactions on, v. PP, n. 99, p. 1-10, 2014.

SODANO, H. A. et al. Use of piezoelectric energy harvesting devices for charging batteries. Smart Structures and Materials 2003 Conference, 2003, San Diego, Ca. Spie-Int Soc Optical Engineering, Mar 02-06. p.101-108.

STANTON, S. C.; MCGEHEE, C. C.; MANN, B. P. Reversible hysteresis for broadband magnetopiezelastic energy harvesting. Applied Physics Letters, v. 95, n. 17, p. 3, Oct 2009.

Nonlinear dynamics for broadband energy harvesting: Investigation of a bistable piezoelectric inertial generator. Physica D-Nonlinear Phenomena, v. 239, n. 10, p. 640-653, May 2010.

STARNER T, PARADISO J. Human generated power for mobile electronics. Low Power Electronics Design, C. Piguet, ed., CRC Press, 2004, vol. 45, p. 1-35.).

STEPHEN, N. G. On energy harvesting from ambient vibration. Journal of Sound and Vibration, v. 293, n. 1-2, p. 409-425, May 2006. 
TANG, L. H.; YANG, Y. W. A multiple-degree-of-freedom piezoelectric energy harvesting model. Journal of Intelligent Material Systems and Structures, v. 23, n. 14, p. 1631-1647, Sep 2012. ISSN 1045-389X. Disponível em: \&lt; \&lt;Go to ISI\&gt;://WOS:000308046000007 \&gt;

TANG, L. H.; YANG, Y. W.; WU, H. Modeling and Experiment of a Multiple-DOF Piezoelectric Energy Harvester. Conference on Active and Passive Smart Structures and Integrated Systems, 2012, San Diego, CA. Spie-Int Soc Optical Engineering, Mar 12-15.

TOPRAK, A.; TIGLI, O. Piezoelectric energy harvesting: State-of-the-art and challenges. Applied Physics Reviews, v. 1, n. 3, p. 14, Sep 2014.

UMEDA, M.; NAKAMURA, K.; UEHA, S. Analysis of the transformation of mechanical impact energy to electric energy using piezoelectric vibrator. Japanese Journal of Applied Physics Part 1-Regular Papers Short Notes \& Review Papers, v. 35, n. 5B, p. 3267-3273, May 1996.

WANG, H. Y. et al. A 2DOF hybrid energy harvester based on combined piezoelectric and electromagnetic conversion mechanisms. Journal of Zhejiang University-Science A, v. 15, n. 9, p. 711-722, Sep 2014.

WILLIAMS, C. B.; YATES, R. B. Analysis of a micro-electric generator for microsystems. Sensors and Actuators a-Physical, v. 52, n. 1-3, p. 8-11, Mar-Apr 1996

WU, H. et al. A novel two-degrees-of-freedom piezoelectric energy harvester. Journal of Intelligent Material Systems and Structures, v. 24, n. 3, p. 357-368, Feb 2013.

Development of a broadband nonlinear two-degree-of-freedom piezoelectric energy harvester. Journal of Intelligent Material Systems and Structures, v. 25, n. 14, p. 1875-1889, Sep 2014.

XIAO, H.; WANG, X.; JOHN, S. A multi-degree of freedom piezoelectric vibration energy harvester with piezoelectric elements inserted between two nearby oscillators. Mechanical 
Systems and Signal Processing, v. 68-69, p. 138-154, Feb 2016. ISSN 0888-3270. Disponível em: \&lt; \&lt;Go to ISI\&gt;:/WOS:000362916800009 \&gt;

ZUO, L.; TANG, X. D. Large-scale vibration energy harvesting. Journal of Intelligent Material Systems and Structures, v. 24, n. 11, p. 1405-1430, Jul 2013.

ZUO, L.; ZHANG, P. S. Energy Harvesting, Ride Comfort, and Road Handling of Regenerative Vehicle Suspensions. Journal of Vibration and Acoustics-Transactions of the Asme, v. 135, n. 1, p. 8, Feb 2013. 